10

$0 \bullet \bullet \bullet \bullet$

10
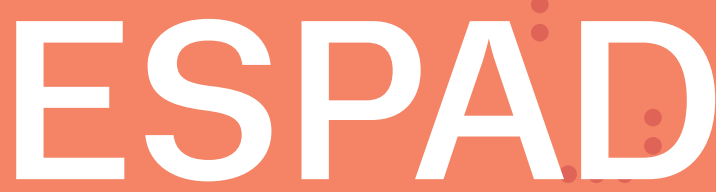

$\cap 0$
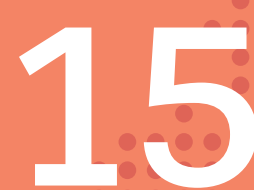

0000
100.

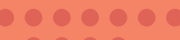

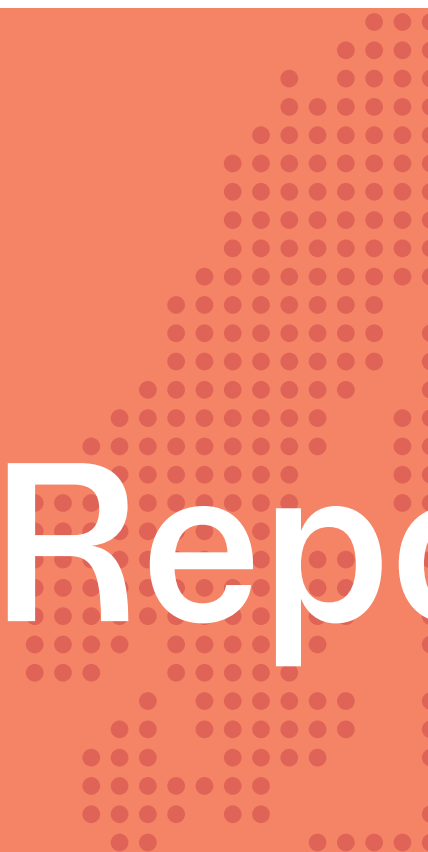

100000

000000

$\bullet \bullet \bullet \bullet \bullet \bullet$

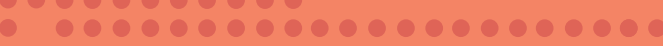

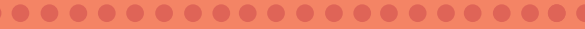

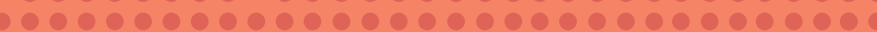

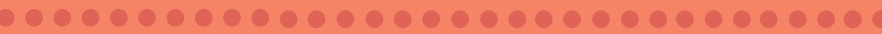
०

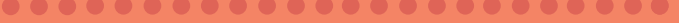

0 100

$\bullet \bullet \bullet \bullet \bullet \bullet \bullet \bullet \bullet \bullet \bullet \bullet \bullet \bullet \bullet \bullet \bullet$

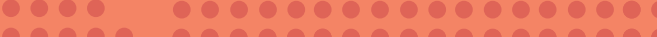
10.0

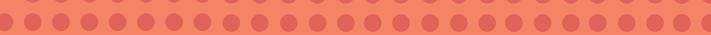

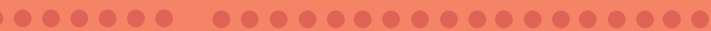

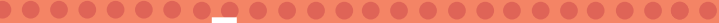

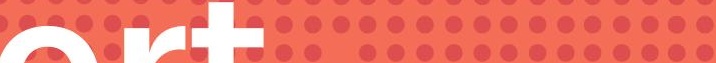
$\mathrm{S}_{0}$ ○००. З००० 100000

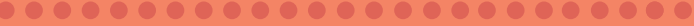

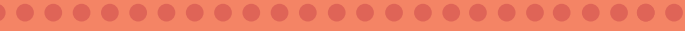
๑ $\bullet \bullet \bullet \bullet \bullet \bullet \bullet \bullet \bullet \bullet \bullet \bullet \bullet \bullet \bullet \bullet \bullet \bullet \bullet \bullet \bullet$

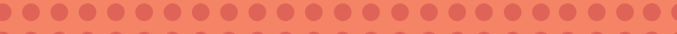
-

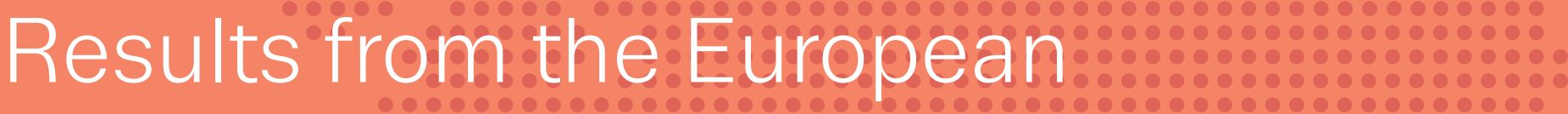

School Survey Projection

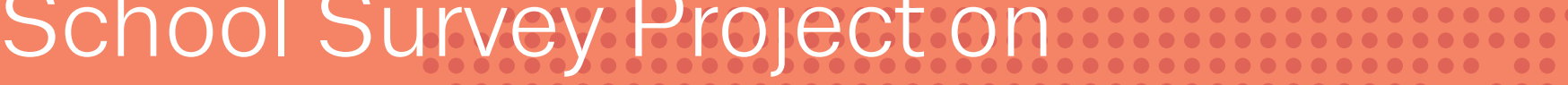
Alcohol and:Other:Drugs::: :: : : : : : :

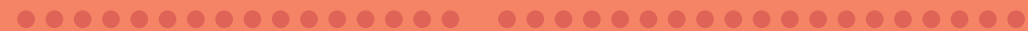

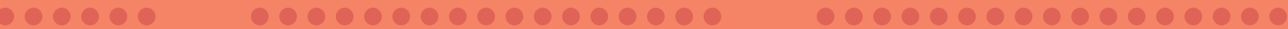

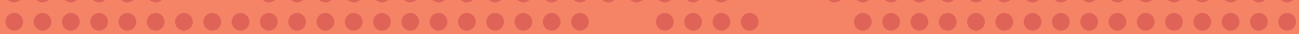

웅

-

10 -

\section{The ESPAD Group}

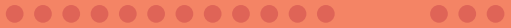

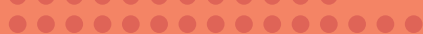

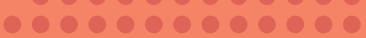

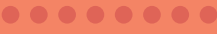

$$
\begin{aligned}
& 0
\end{aligned}
$$

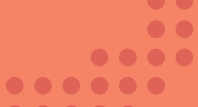

100

-

10

\section{-}

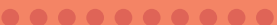
- 000 100 100

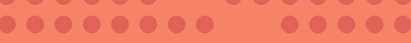
10 10 0

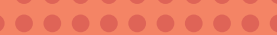

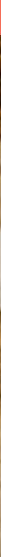





\section{ESPAD Report 2015}

\section{Results from the European School Survey Project on Alcohol and Other Drugs}

\section{ESPAD Group}

Ludwig Kraus, Ulf Guttormsson, Håkan Leifman, Sharon Arpa, Sabrina Molinaro, Karin Monshouwer, Marcis Trapencieris, Julian Vicente, Ársæll Már Arnarsson, Olga Balakireva, Elin K. Bye, Anina Chileva, Mihai Ciocanu, Luke Clancy, Ladislav Csémy, Tatijana Djurisic, Zsuzsanna Elekes, Fernanda Feijão, Silvia Florescu, Iva Pejnović Franelić, Esther Kocsis, Anna Kokkevi, Patrick Lambrecht, Tanja Urdih Lazar, Alojz Nociar, Silvana Oncheva, Kirsimarja Raitasalo, Liudmila Rupšienè, Janusz Sierosławski, Mette Vinther Skriver, Stanislas Spilka, Julian Strizek, Lela Sturua, Ervin Toçi, Kyriacos Veresies, Sigrid Vorobjov, Pál Weihe, André Noor, João Matias, Nicki-Nils Seitz, Daniela Piontek, Johan Svensson, Anna Englund and Björn Hibell

\section{Coordinating Committee}

Ludwig Kraus, Håkan Leifman and Julian Vicente

\section{Steering Committee}

Sharon Arpa, Ludwig Kraus, Håkan Leifman, Sabrina Molinaro, Karin Monshouwer, Marcis Trapencieris and Julian Vicente 
This publication of the European Monitoring Centre for Drugs and Drug Addiction (EMCDDA) and the European School Survey Project on Alcohol and Other Drugs (ESPAD) is protected by copyright. The EMCDDA and ESPAD accept no responsibility or liability for any consequences arising from the use of the data contained in this document. The contents of this publication do not necessarily reflect the official opinions of the partners of the EMCDDA and ESPAD, any European Union Member State or any institution, agency or other body of the European Union.

Europe Direct is a service to help you find answers to your questions about the European Union.

\section{Freephone number ( $\left.{ }^{*}\right): 0080067891011$}

$\left(^{\star}\right)$ The information given is free, as are most calls (though some operators, phone boxes or hotels may charge you).

More information on the European Union is available on the internet (http://europa.eu).

Luxembourg: Publications Office of the European Union, 2016

\begin{tabular}{|c|c|c|}
\hline Print & ISBN 978-92-9168-918-7 & doi: 10.2810/022073 \\
\hline PDF & ISBN 978-92-9168-919-4 & doi: $10.2810 / 86718$ \\
\hline EPUB & ISBN 978-92-9168-917-0 & doi: $10.2810 / 849983$ \\
\hline HTML & ISBN 978-92-9168-920-0 & doi: $10.2810 / 063862$ \\
\hline
\end{tabular}

(C) European Monitoring Centre on Drugs and Drug Addiction, 2016

(C) European School Survey Project on Alcohol and Other Drugs, 2016

Reproduction is authorised provided the source is acknowledged. Credits for photos: iStock.

\section{Printed in Luxembourg}

Printed on elemental chlorine-free bleached paper (ECF)

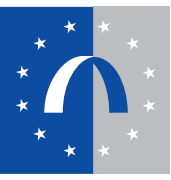




\section{Contents}

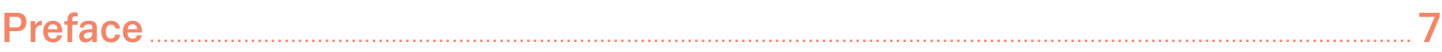

List of authors

Summary

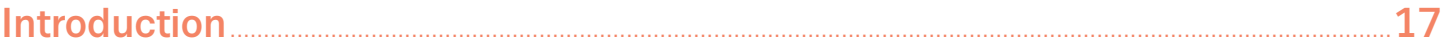

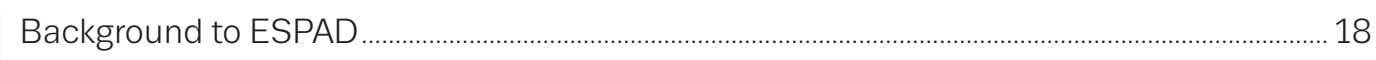

ESPAD Report 2015 .......................................................................................................................................... 20

Methodology _...

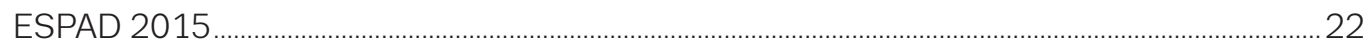

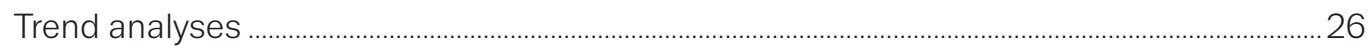

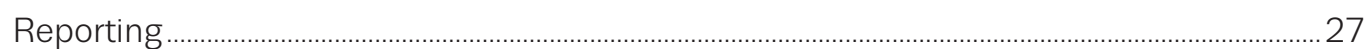

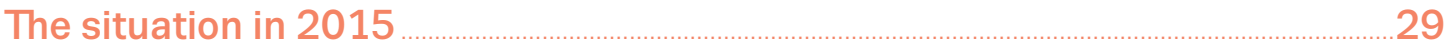

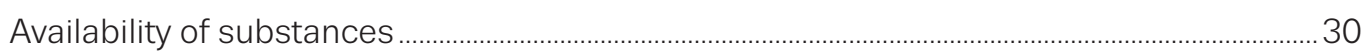

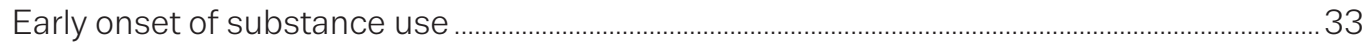

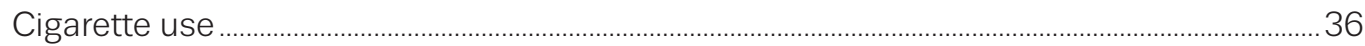

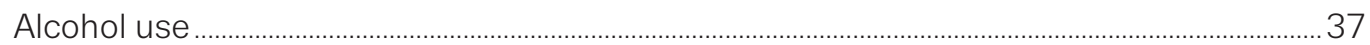

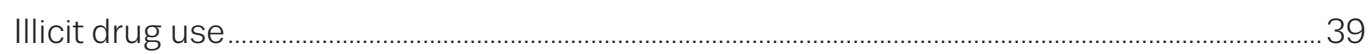

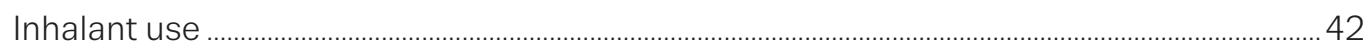

New psychoactive substance use ..................................................................................................... 43

Conditional probabilities of substance use ......................................................................... 44

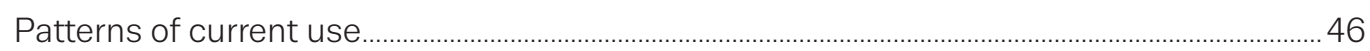

Internet use, gaming and gambling ........................................................................................ 64

Trends 1995-2015

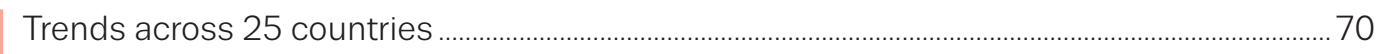

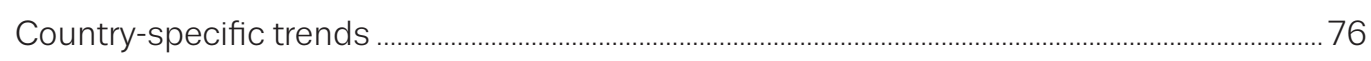

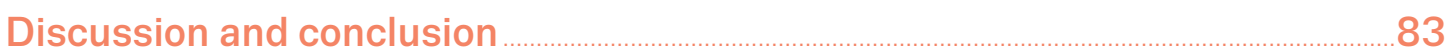

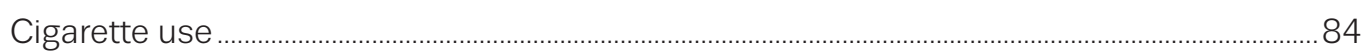

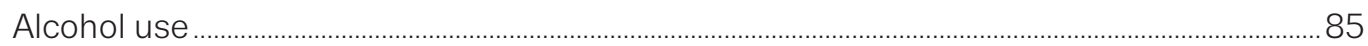

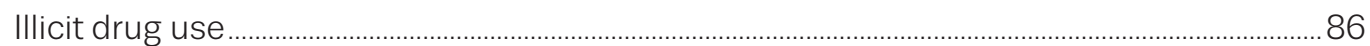

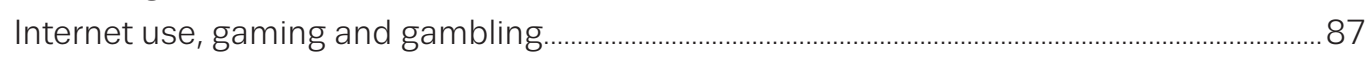

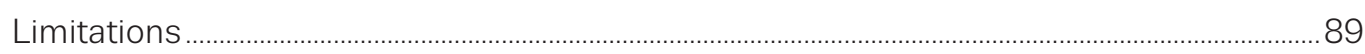

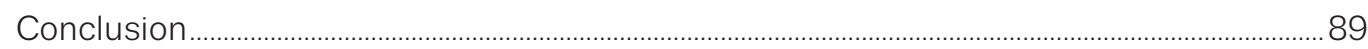

Acknowledgements .

References 


\section{Tables}

Table 1. Overview of countries participating in ESPAD. 1995-2015

Table 2. Sampling characteristics of ESPAD 2015

Table 3a. Perceived availability of substances: prevalence of students responding substance 'fairly easy' or 'very easy' to obtain (percentage)

Table 3b. Perceived availability of substances: prevalence of students responding substance 'fairly easy' or 'very easy' to obtain (percentage)

Table 4a. Early onset of substance use: prevalence of students experiencing substance use (cigarettes, daily smoking, alcohol, intoxication) at the age of 13 or younger (percentage)

Table 4b. Early onset of substance use: prevalence of students experiencing substance use (cannabis, ecstasy, amphetamine/methamphetamine, cocaine/crack) at the age of 13 or younger (percentage)

Table 5. $\quad$ Cigarette use: prevalence of lifetime and 30-day use (percentage) 36

Table 6. Alcohol use: prevalence of lifetime use, 30-day use and intoxication (percentage) 38

Table 7a. Illicit drug use: lifetime prevalence of the use of any drug, cannabis, ecstasy, amphetamine and methamphetamine (percentage)

Table 7b. Illicit drug use: lifetime prevalence of the use of cocaine, crack, LSD or other hallucinogens, heroin and GHB (percentage)

Table 8. Inhalants and new psychoactive substances (NPS): prevalence of lifetime use (percentage)

Table 9. Pharmaceuticals: lifetime prevalence of the use of painkillers to get high, tranquillisers or sedatives without prescription and anabolic steroids (percentage)

Table 10. Prevalence of lifetime use of substance B conditional on the lifetime use of substance A (percentage) and number of users of substance $A(n)$

Table 11a. Average number of days on the internet (mean number of days) and prevalence of internet activities on 4 or more days in the last 7 days (percentage)

Table 11b. Prevalence of internet activities on 4 or more days in the last 7 days by gender (percentage)

Table 12. Gambling for money: prevalence in the last 12 months (percentage)

Table 13. Overview of ESPAD surveys conducted between 1995 and 2015 by country: sample size and participation rate

Table 14. ESPAD average for selected indicators based on 25 countries: 1995-2015

Figure 1a. Daily cigarette use: prevalence in the last 30 days (percentage) 46

Figure 1b. Daily cigarette use: prevalence in the last 30 days by gender (percentage)

Figure 2a. Frequency of alcohol intake in the last 30 days (mean number of occasions among users)

Figure $2 \mathrm{~b}$. Frequency of alcohol intake in the last 30 days by gender (mean number of occasions among users)

Figure 3a. Average alcohol intake on the last drinking day in centilitres of ethanol among users

Figure 3b. Average alcohol intake on the last drinking day in centilitres of ethanol among users by gender

Figure 4a. Preferences of alcoholic beverages on the last drinking day; proportion of alcohol volume in centilitres of ethanol for each beverage on total consumption 
Figure 4b. Preferences of alcoholic beverages on the last drinking day by gender; proportion of alcohol volume in centilitres of ethanol for each beverage on total consumption

Figure 5a. Prevalence of five or more drinks at least once in the last 30 days; one drink contains approximately 2 centilitres of ethanol (percentage)

Figure 5b. Prevalence of five or more drinks at least once in the last 30 days by gender; one drink contains approximately 2 centilitres of ethanol (percentage)

Figure 6a. Prevalence of cannabis use in the last 30 days (percentage)

Figure 6b. Prevalence of cannabis use in the last 30 days by gender (percentage)

Figure 7a. Frequency of cannabis use in the last 12 months (mean number of occasions among users)

Figure 7b. Frequency of cannabis use in the last 12 months by gender (mean number of occasions among users)

Figure 8a. Prevalence of inhalant use in the last 30 days (percentage)

Figure $8 \mathrm{~b} . \quad$ Prevalence of inhalant use in the last 30 days by gender (percentage)

Figure 9a. Prevalence of new psychoactive substance use in the last 12 months (percentage)

Figure 9b. Prevalence of new psychoactive substance use in the last 12 months by gender (percentage)

Figure 10. Countries included in the 25-country average (marked in blue)

Figure 11. Perceived availability of cannabis by gender; students responding cannabis 'fairly easy' or 'very easy' to obtain: 25-country trend 1995-2015 (percentage)

Figure 12. Daily cigarette use at the age of 13 or younger by gender: 25-country trend 1995-2015 (percentage)

Figure 13. Cannabis use at the age of 13 or younger by gender: 25-country trend 1995-2015 (percentage)

Figure 14. Lifetime use of cigarettes by gender: 25-country trend 1995-2015 (percentage)

Figure 15. Cigarette use in the last 30 days by gender: 25-country trend 1995-2015 (percentage) 74

Figure 16. Daily cigarette use by gender: 25-country trend 1995-2015 (percentage) 74

Figure 17. Lifetime alcohol use by gender: 25-country trend 1995-2015 (percentage) 74

Figure 18. Alcohol use in the last 30 days by gender: 25-country trend 1995-2015 (percentage)

Figure 19. Heavy episodic drinking (five or more drinks on one occasion) during the last 30 days by gender: 25-country trend 1995-2015 (percentage)

Figure 20. Lifetime use of illicit drugs by gender: 25-country trend 1995-2015 (percentage) 74

Figure 21. Lifetime use of cannabis by gender: 25-country trend 1995-2015 (percentage) 75

Figure 22. Cannabis use in the last 30 days by gender: 25-country trend 1995-2015 (percentage) 75

Figure 23. Lifetime use of illicit drugs other than cannabis by gender: 25-country trend 1995-2015 (percentage)

Figure 24. Lifetime use of inhalants by gender: 25-country trend 1995-2015 (percentage)

Figure 25. Lifetime use of tranquillisers or sedatives without a doctor's prescription by gender: 25-country trend 1995-2015 (percentage)

Figure 26. Lifetime use of cigarettes by country: 1995-2015 (percentage)

Figure 27. Lifetime alcohol use of alcohol by country: 1995-2015 (percentage) 78

Figure 28. Lifetime use of cannabis by country: 1995-2015 (percentage) 79

Figure 29. Lifetime use of inhalants by country: 1995-2015 (percentage) 80

Figure 30. Lifetime use of tranquillisers or sedatives without a doctor's prescription by country: 1995-2015 (percentage) 


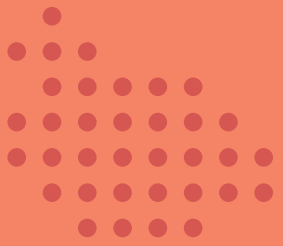
$\bullet$

\section{$\bullet \bullet \bullet$ \\ $\bullet \bullet \bullet \bullet \bullet \bullet \bullet$}

$\circ \bullet$

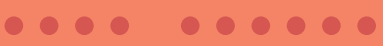

$\bullet \bullet \bullet \bullet \bullet \bullet \bullet$ -

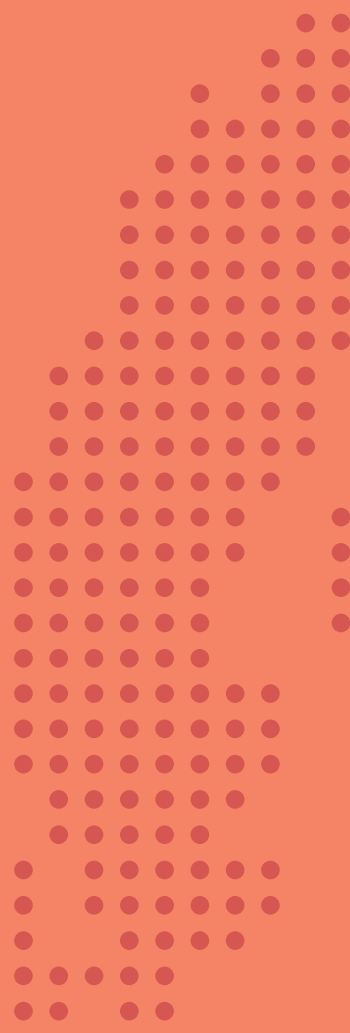

-

$\bullet \bullet \bullet \bullet \bullet \bullet \bullet \bullet$

$\bullet \bullet \bullet \bullet \bullet \bullet \bullet \bullet \bullet \bullet \bullet \bullet$

$\bullet \bullet \bullet \bullet \bullet \bullet \bullet \bullet \bullet \bullet \bullet \bullet \bullet \bullet \bullet \bullet \bullet \bullet \bullet \bullet \bullet \bullet$ $\bullet \bullet \bullet \bullet \bullet \bullet \bullet \bullet \bullet \bullet \bullet \bullet \bullet \bullet \bullet$

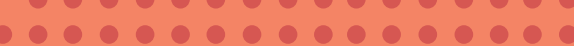

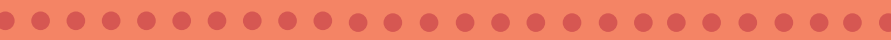
$\bullet \bullet \bullet \bullet \bullet \bullet \bullet \bullet \bullet \bullet \bullet \bullet \bullet \bullet \bullet \bullet \bullet \bullet \bullet \bullet \bullet \bullet \bullet \bullet \bullet$ $\bullet \bullet \bullet \bullet \bullet \bullet \bullet \bullet \bullet \bullet \bullet \bullet \bullet \bullet \bullet \bullet \bullet \bullet \bullet \bullet \bullet \bullet \bullet \bullet \bullet$ $\bullet \bullet \bullet \bullet \bullet \bullet \bullet \bullet \bullet \bullet \bullet \bullet \quad \bullet \bullet \bullet \bullet \bullet \bullet \bullet \bullet \bullet \bullet \bullet$ $\bullet \bullet \bullet \bullet \bullet \bullet \bullet$ $\bullet \bullet \bullet \bullet \bullet \bullet \bullet \bullet \bullet \bullet \bullet \bullet ~ \bullet \bullet \bullet \bullet \bullet \bullet \bullet \bullet \bullet \bullet \bullet \bullet$ -

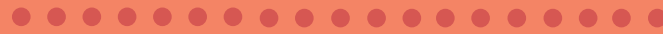

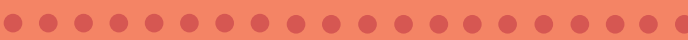
$\bullet \bullet \bullet \bullet \bullet \bullet \bullet \bullet \bullet \bullet \bullet \bullet \bullet \bullet \bullet \bullet \bullet$

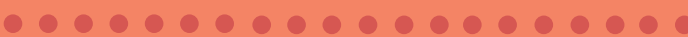
$\bullet \bullet \bullet \bullet \bullet \bullet \bullet \bullet \bullet \bullet \bullet \bullet \bullet \bullet \bullet \bullet$ ○・ $\bullet \bullet \bullet$ - $\bullet \bullet \bullet \bullet \bullet \bullet \bullet$ $\bullet \bullet \bullet \bullet \bullet$

$\bullet \bullet \bullet \bullet \bullet \bullet$ $\bullet \bullet \bullet \bullet \bullet \bullet \bullet \bullet \bullet$ -

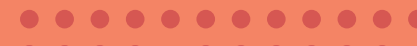
$\bullet \bullet \bullet \bullet \bullet \bullet$ $\bullet \bullet \bullet \bullet \bullet$ ○。०

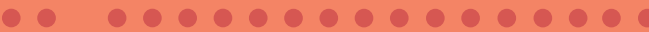

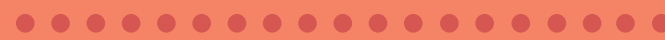
$\bullet \bullet \bullet \bullet \bullet \bullet \bullet \bullet \bullet \bullet \bullet \bullet \bullet \bullet \bullet \bullet \bullet \bullet$ $\bullet \bullet \bullet \bullet \bullet \bullet \bullet \bullet \bullet \bullet \bullet \bullet \bullet \bullet \bullet \bullet \bullet$

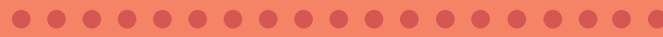
0 $\bullet \bullet \bullet \bullet \bullet \bullet \bullet \bullet \bullet \bullet \bullet \bullet \bullet \bullet \bullet \bullet \bullet \bullet \bullet \bullet \bullet \bullet$ $\bullet \bullet \bullet \bullet \bullet \bullet \bullet \bullet \bullet \bullet \bullet \bullet \bullet \bullet \bullet \bullet \bullet \bullet \bullet \bullet \bullet \bullet \bullet \bullet \bullet \bullet \bullet \bullet \bullet$

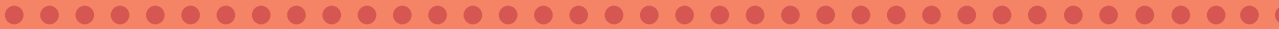
$\bullet \bullet \bullet \bullet \bullet \bullet \quad \bullet \bullet \bullet \bullet \bullet \bullet \bullet \bullet \bullet \bullet \bullet \bullet \bullet \bullet \bullet \bullet \bullet \bullet \bullet \bullet \bullet \bullet \bullet \bullet \bullet \bullet \bullet \bullet \bullet \bullet \bullet$

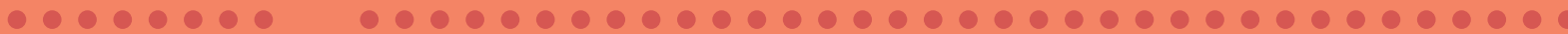

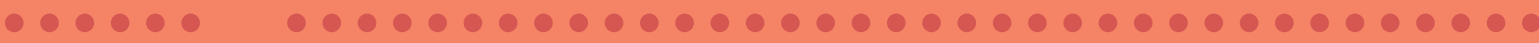

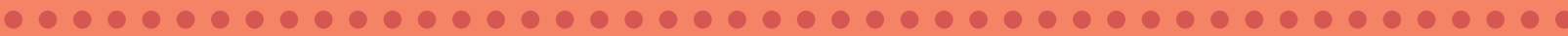

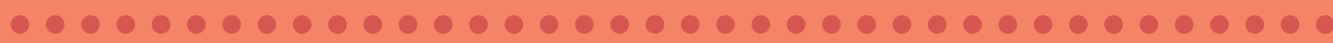

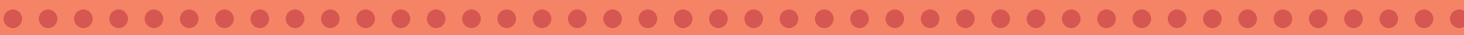

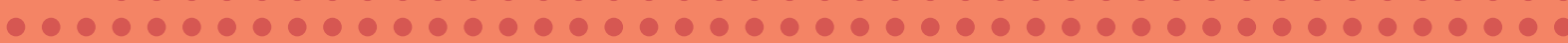

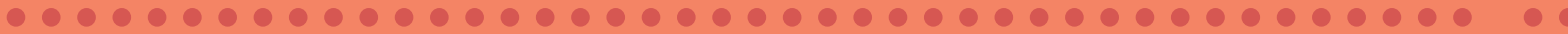
० $\bullet \bullet \bullet \bullet \bullet \bullet \bullet \bullet \bullet \bullet \bullet \bullet \bullet \bullet \bullet \bullet \bullet \bullet \bullet \bullet \bullet \bullet \bullet \bullet \bullet \bullet \bullet \bullet \bullet \bullet \bullet \bullet \bullet \bullet \bullet \bullet \bullet \bullet$

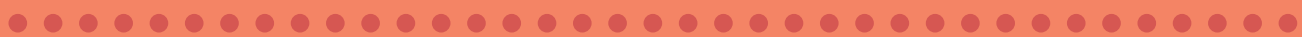

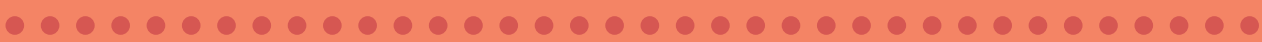
$\bullet \bullet \bullet \bullet \bullet \bullet \bullet \bullet \bullet \bullet \bullet \bullet \bullet \bullet \bullet \bullet \bullet \bullet \bullet \bullet \bullet \bullet \bullet \bullet \bullet \bullet \bullet \bullet \bullet \bullet \bullet \bullet \bullet$ • $\bullet \bullet \bullet \bullet \bullet \bullet \quad \bullet \bullet \bullet \bullet \bullet \bullet \bullet \bullet \bullet \bullet \bullet \bullet \bullet \bullet \bullet \bullet \bullet$

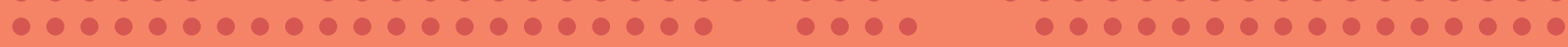
$\bullet \bullet \bullet \bullet \bullet \bullet \bullet \bullet \bullet \bullet \bullet \bullet \bullet \bullet \bullet \bullet \bullet \bullet ~ \bullet \bullet \bullet \bullet$

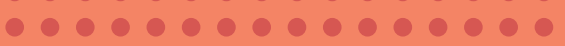
$\bullet \bullet \bullet \bullet \bullet \bullet \bullet \bullet \bullet \bullet \bullet \bullet$ $\bullet \bullet \bullet \bullet \bullet \bullet \bullet \bullet \bullet \bullet \bullet$ $\bullet \bullet \bullet \bullet \bullet \bullet \bullet \bullet \bullet$ $\circ \bullet$ $\bullet \bullet \bullet \bullet \bullet \bullet \bullet \bullet \bullet \bullet \bullet \bullet \bullet \bullet$

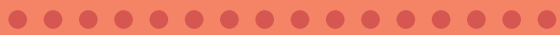

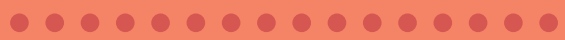

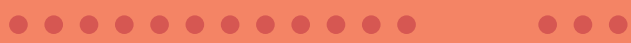

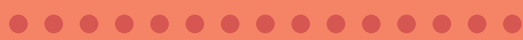
๑・・・・

-

-

-

$\bullet$

-
- 0 ○ $10 \circ 00$ - 00000000 - 0 - 0 10 -

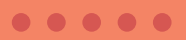
100000000000

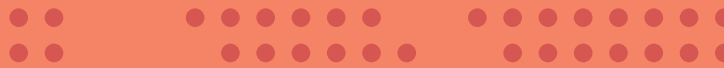
- 10 - 1

- 1000 - 100

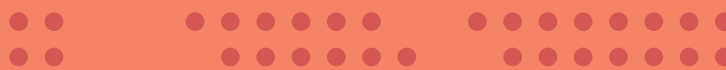

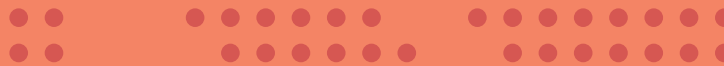
10 (n) 


\section{Preface}

This report presents the results of the sixth data-collection wave of the European School Survey Project on Alcohol and Other Drugs (ESPAD). The report marks the 20th anniversary of ESPAD data collection (1995-2015), which increases considerably the value of the information presented, allowing the identification of long-term trends with a standardised and comparable methodology.

This report is based on the information provided by 96043 students from 35 European countries, 24 of them being Member States of the European Union. About 600000 students have participated in the successive ESPAD data-collection waves, making the project the most extensive, harmonised data collection on substance use in Europe.

The immediate objective of ESPAD is to collect comparable and reliable information in as many European countries as possible, but the final purpose is to provide a solid basis to help formulate policies, in particular those aimed at young people.

The first ESPAD report, based on 1995 data, included information from 26 countries. The number of participating countries increased notably in the following waves of data collection. In the last two waves (2011 and 2015), the number of countries has stabilised at 35-36. A total of 46 countries have participated in at least one of the project's data-collection rounds.

ESPAD has a long history and a promising future. The project was initiated by the Swedish Council for Information on Alcohol and Other Drugs (CAN) following initial work carried out by the Pompidou Group of the Council of Europe. For 20 years CAN coordinated ESPAD with the support of the Swedish government. In recent years the European Monitoring Centre for Drugs and Drug Addiction (EMCDDA) has progressively increased its support to the network, and since 2013 it has been involved in the coordination of ESPAD. These developments have taken place at the instigation of the Swedish government and the EMCDDA Management Board, and in agreement with the ESPAD network. The EMCDDA is pleased now to have assumed responsibility for ensuring the production of this report and its accompanying website.

The results presented here are based on the substantial contribution of leading national experts, their collaborators and the institutions that supported and funded the data collection. The report would not have been possible without the contribution of many schools, teachers, research assistants and, notably, students who volunteered to give their time and information to the ESPAD project so that we can obtain a better understanding of European students' substance use and their attitudes towards it.

\author{
Alexis Goosdeel \\ EMCDDA Director
}

\author{
Ludwig Kraus, Håkan Leifman and \\ Julian Vicente \\ ESPAD Coordination Committee
}




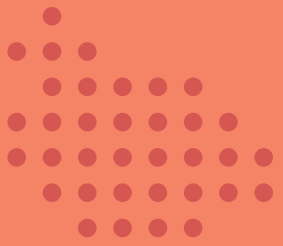
$\bullet$

\section{$\bullet \bullet \bullet$ \\ $\bullet \bullet \bullet \bullet \bullet \bullet \bullet$}

$\circ \bullet$

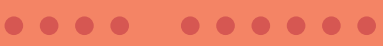

$\bullet \bullet \bullet \bullet \bullet \bullet \bullet$ -

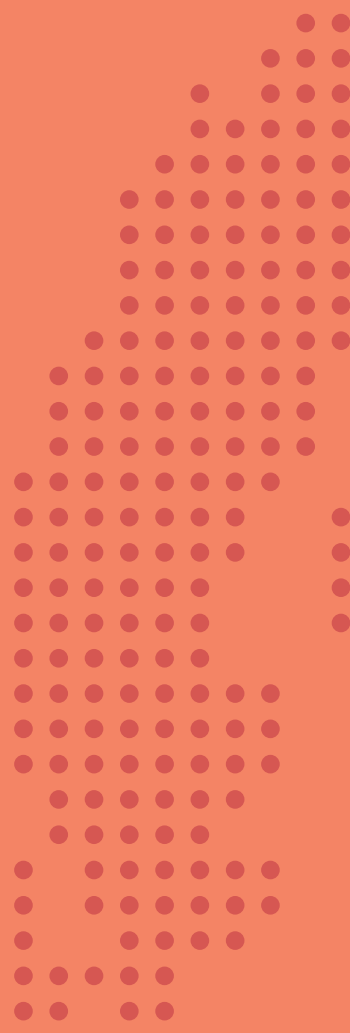

-

$\bullet \bullet \bullet \bullet \bullet \bullet \bullet \bullet$

$\bullet \bullet \bullet \bullet \bullet \bullet \bullet \bullet \bullet \bullet \bullet \bullet$

$\bullet \bullet \bullet \bullet \bullet \bullet \bullet \bullet \bullet \bullet \bullet \bullet \bullet \bullet \bullet \bullet \bullet \bullet \bullet \bullet \bullet \bullet$ $\bullet \bullet \bullet \bullet \bullet \bullet \bullet \bullet \bullet \bullet \bullet \bullet \bullet \bullet \bullet$

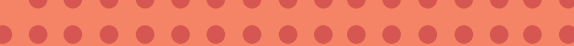

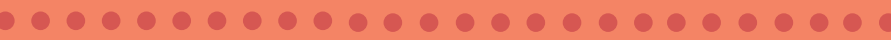
$\bullet \bullet \bullet \bullet \bullet \bullet \bullet \bullet \bullet \bullet \bullet \bullet \bullet \bullet \bullet \bullet \bullet \bullet \bullet \bullet \bullet \bullet \bullet \bullet \bullet$ $\bullet \bullet \bullet \bullet \bullet \bullet \bullet \bullet \bullet \bullet \bullet \bullet \bullet \bullet \bullet \bullet \bullet \bullet \bullet \bullet \bullet \bullet \bullet \bullet \bullet$ $\bullet \bullet \bullet \bullet \bullet \bullet \bullet \bullet \bullet \bullet \bullet \bullet \quad \bullet \bullet \bullet \bullet \bullet \bullet \bullet \bullet \bullet \bullet \bullet$ $\bullet \bullet \bullet \bullet \bullet \bullet \bullet$ $\bullet \bullet \bullet \bullet \bullet \bullet \bullet \bullet \bullet \bullet \bullet \bullet ~ \bullet \bullet \bullet \bullet \bullet \bullet \bullet \bullet \bullet \bullet \bullet \bullet$ -

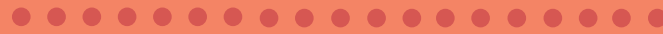

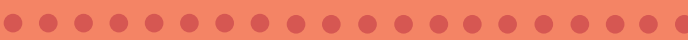
$\bullet \bullet \bullet \bullet \bullet \bullet \bullet \bullet \bullet \bullet \bullet \bullet \bullet \bullet \bullet \bullet \bullet$

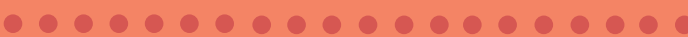
$\bullet \bullet \bullet \bullet \bullet \bullet \bullet \bullet \bullet \bullet \bullet \bullet \bullet \bullet \bullet \bullet$ ○・ $\bullet \bullet \bullet$ - $\bullet \bullet \bullet \bullet \bullet \bullet \bullet$ $\bullet \bullet \bullet \bullet \bullet$

$\bullet \bullet \bullet \bullet \bullet \bullet$ $\bullet \bullet \bullet \bullet \bullet \bullet \bullet \bullet \bullet$ -

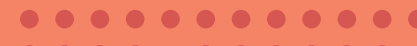
$\bullet \bullet \bullet \bullet \bullet \bullet$ $\bullet \bullet \bullet \bullet \bullet$ ○。०

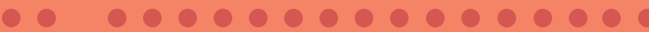

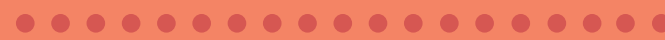
$\bullet \bullet \bullet \bullet \bullet \bullet \bullet \bullet \bullet \bullet \bullet \bullet \bullet \bullet \bullet \bullet \bullet \bullet$ $\bullet \bullet \bullet \bullet \bullet \bullet \bullet \bullet \bullet \bullet \bullet \bullet \bullet \bullet \bullet \bullet \bullet$

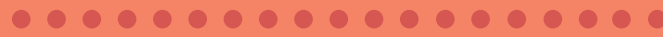
0 $\bullet \bullet \bullet \bullet \bullet \bullet \bullet \bullet \bullet \bullet \bullet \bullet \bullet \bullet \bullet \bullet \bullet \bullet \bullet \bullet \bullet \bullet$ $\bullet \bullet \bullet \bullet \bullet \bullet \bullet \bullet \bullet \bullet \bullet \bullet \bullet \bullet \bullet \bullet \bullet \bullet \bullet \bullet \bullet \bullet \bullet \bullet \bullet \bullet \bullet \bullet \bullet$

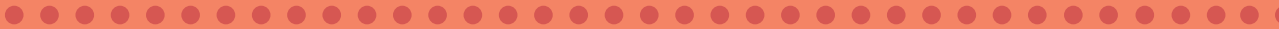
$\bullet \bullet \bullet \bullet \bullet \bullet \quad \bullet \bullet \bullet \bullet \bullet \bullet \bullet \bullet \bullet \bullet \bullet \bullet \bullet \bullet \bullet \bullet \bullet \bullet \bullet \bullet \bullet \bullet \bullet \bullet \bullet \bullet \bullet \bullet \bullet \bullet \bullet$

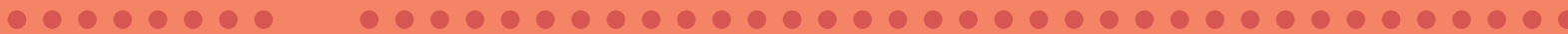

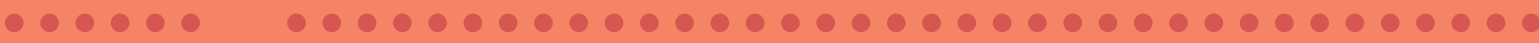

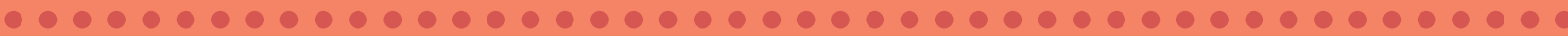

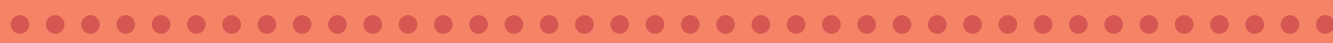

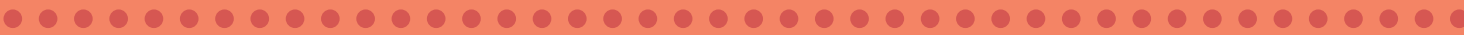

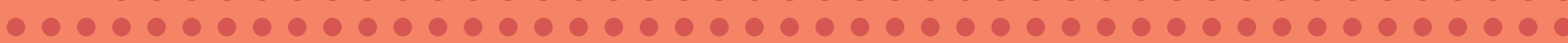

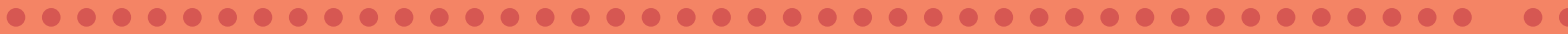
० $\bullet \bullet \bullet \bullet \bullet \bullet \bullet \bullet \bullet \bullet \bullet \bullet \bullet \bullet \bullet \bullet \bullet \bullet \bullet \bullet \bullet \bullet \bullet \bullet \bullet \bullet \bullet \bullet \bullet \bullet \bullet \bullet \bullet \bullet \bullet \bullet \bullet \bullet$

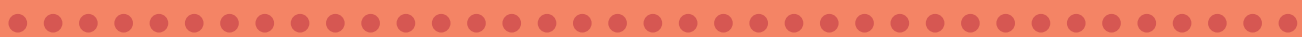

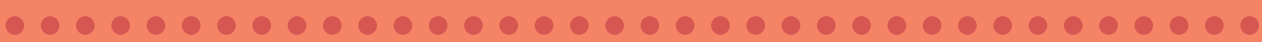
$\bullet \bullet \bullet \bullet \bullet \bullet \bullet \bullet \bullet \bullet \bullet \bullet \bullet \bullet \bullet \bullet \bullet \bullet \bullet \bullet \bullet \bullet \bullet \bullet \bullet \bullet \bullet \bullet \bullet \bullet \bullet \bullet \bullet$ • $\bullet \bullet \bullet \bullet \bullet \bullet \quad \bullet \bullet \bullet \bullet \bullet \bullet \bullet \bullet \bullet \bullet \bullet \bullet \bullet \bullet \bullet \bullet \bullet$

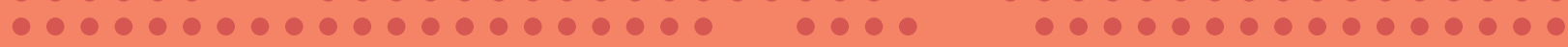
$\bullet \bullet \bullet \bullet \bullet \bullet \bullet \bullet \bullet \bullet \bullet \bullet \bullet \bullet \bullet \bullet \bullet \bullet ~ \bullet \bullet \bullet \bullet$

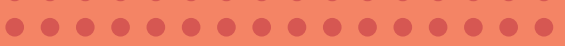
$\bullet \bullet \bullet \bullet \bullet \bullet \bullet \bullet \bullet \bullet \bullet \bullet$ $\bullet \bullet \bullet \bullet \bullet \bullet \bullet \bullet \bullet \bullet \bullet$ $\bullet \bullet \bullet \bullet \bullet \bullet \bullet \bullet \bullet$ $\circ \bullet$ $\bullet \bullet \bullet \bullet \bullet \bullet \bullet \bullet \bullet \bullet \bullet \bullet \bullet \bullet$

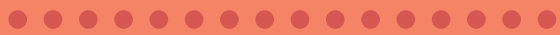

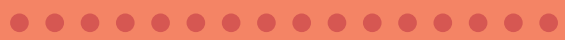

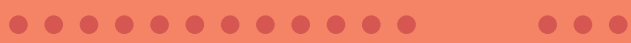

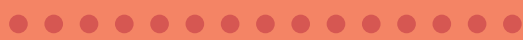
๑・・・・

-

-

-

$\bullet$

-
- 0 ○ $10 \circ 00$ - 00000000 - 0 - 0 10 -

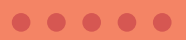
100000000000

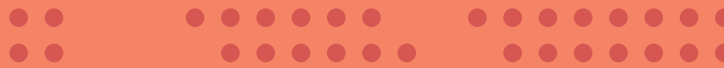
- 10 - 1

- 1000 - 100

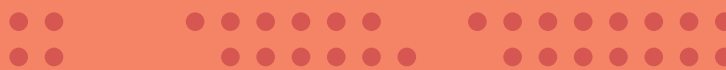

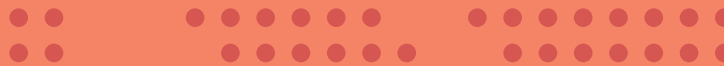
10 (n) 


\section{List of authors}

Ludwig Kraus

Ulf Guttormsson

Håkan Leifman

Sharon Arpa

Sabrina Molinaro

Karin Monshouwer

Marcis Trapencieris

Julian Vicente

Ársæll Már Arnarsson

Olga Balakireva

Elin K. Bye

Anina Chileva

Mihai Ciocanu

Luke Clancy

Ladislav Csémy

Tatijana Djurisic

Zsuzsanna Elekes

Fernanda Feijão

Silvia Florescu

Iva Pejnović Franelić

Esther Kocsis

Anna Kokkevi

Patrick Lambrecht

Tanja Urdih Lazar

Alojz Nociar
IFT Institut für Therapieforschung, Munich, Germany and Centre for Social Research on Alcohol and Drugs (SoRAD), Stockholm University, Stockholm, Sweden

Swedish Council for Information on Alcohol and Other Drugs (CAN), Stockholm, Sweden

Swedish Council for Information on Alcohol and Other Drugs (CAN) Stockholm, Sweden

Foundation for Social Welfare Services, Santa Venera, Malta

National Research Council, Institute of Clinical Physiology, Pisa, Italy

Trimbos Institute, Utrecht, the Netherlands

Institute of Philosophy and Sociology, University of Latvia, Riga, Latvia

European Monitoring Centre for Drugs and Drug Addiction (EMCDDA), Lisbon, Portugal

Centre for Prevention Studies, University of Akureyri, Akureyri, Iceland

Department for Monitoring of the Social and Economic

Transformations, Institute for Economy and Forecasting, NAS, Kiev, Ukraine

Norwegian Institute of Public Health, Oslo, Norway

National Centre for Public Health and Analyses, Sofia, Bulgaria

National Centre for Health Management, Chisinau, Moldova

TobaccoFree Research Institute Ireland, Focas Research Institute, Dublin, Ireland

National Institute of Mental Health, Klecany, Czech Republic Institute of Public Health of Montenegro, Podgorica, Montenegro

Corvinus University of Budapest, Institute of Sociology and Social Policy, Budapest, Hungary

General-Directorate for Intervention on Addictive Behaviours and Dependencies (SICAD), Lisbon, Portugal

National School of Public Health, Management and Professional Development, Bucharest, Romania

Mental Health Promotion and Addiction Prevention Department with Counselling Centre, Health Promotion Division, Reference Centre of the Ministry of Health for Health Promotion, Croatian Institute of Public Health, Zagreb, Croatia

Amt für Soziale Dienste, Schaan, Liechtenstein

Epidemiology and Psychosocial Research Unit, University Mental Health Research Institute (UMHRI), Athens, Greece

Department of Clinical and Lifespan Psychology (KLEP), Free University of Brussels (VUB), Brussels, Belgium

University Medical Centre Ljubljana, Clinical Institute of Occupational, Traffic and Sports Medicine, Ljubljana, Slovenia

St. Elizabeth University of Health and Social Work, Bratislava, Slovakia 
Silvana Oncheva

Kirsimarja Raitasalo

Liudmila Rupšienè

Janusz Sierosławski

Mette Vinther Skriver

Stanislas Spilka

Julian Strizek

Lela Sturua

Ervin Toçi

Kyriacos Veresies

Sigrid Vorobjov

Pál Weihe

André Noor

João Matias

Nicki-Nils Seitz

Daniela Piontek

Johan Svensson

Anna Englund

Björn Hibell
Institute for Public Health, Skopje, former Yugoslav Republic of Macedonia

National Institute for Health and Welfare (THL), Helsinki, Finland Klaipeda University, Klaipèda, Lithuania

Institute of Psychiatry and Neurology Department of Studies on Alcoholism and Drug Dependencies, Warsaw, Poland

Department of Public Health, Aarhus University, Aarhus, Denmark

French Monitoring Centre for Drugs and Drug Addiction (OFDT), Paris, France

Gesundheit Österreich GmbH (GÖG), Vienna, Austria

Non-communicable Diseases Department, National Centre for Disease Control and Public Health, Tiblisi, Georgia

Institute of Public Health, Tirana, Albania

Centre for Education about Drugs and Treatment of Drug-Addicted Persons (Kenthea), Nicosia, Cyprus

National Institute for Health Development, Tallinn, Estonia

Department of Occupational Medicine and Public Health, Tórshavn, Faroes

European Monitoring Centre for Drugs and Drug Addiction (EMCDDA), Lisbon, Portugal

European Monitoring Centre for Drugs and Drug Addiction (EMCDDA), Lisbon, Portugal

IFT Institut für Therapieforschung, Munich, Germany

IFT Institut für Therapieforschung, Munich, Germany

Swedish Council for Information on Alcohol and Other Drugs (CAN), Stockholm, Sweden

Swedish Council for Information on Alcohol and Other Drugs (CAN), Stockholm, Sweden

Former ESPAD Coordinator 


\section{Summary}
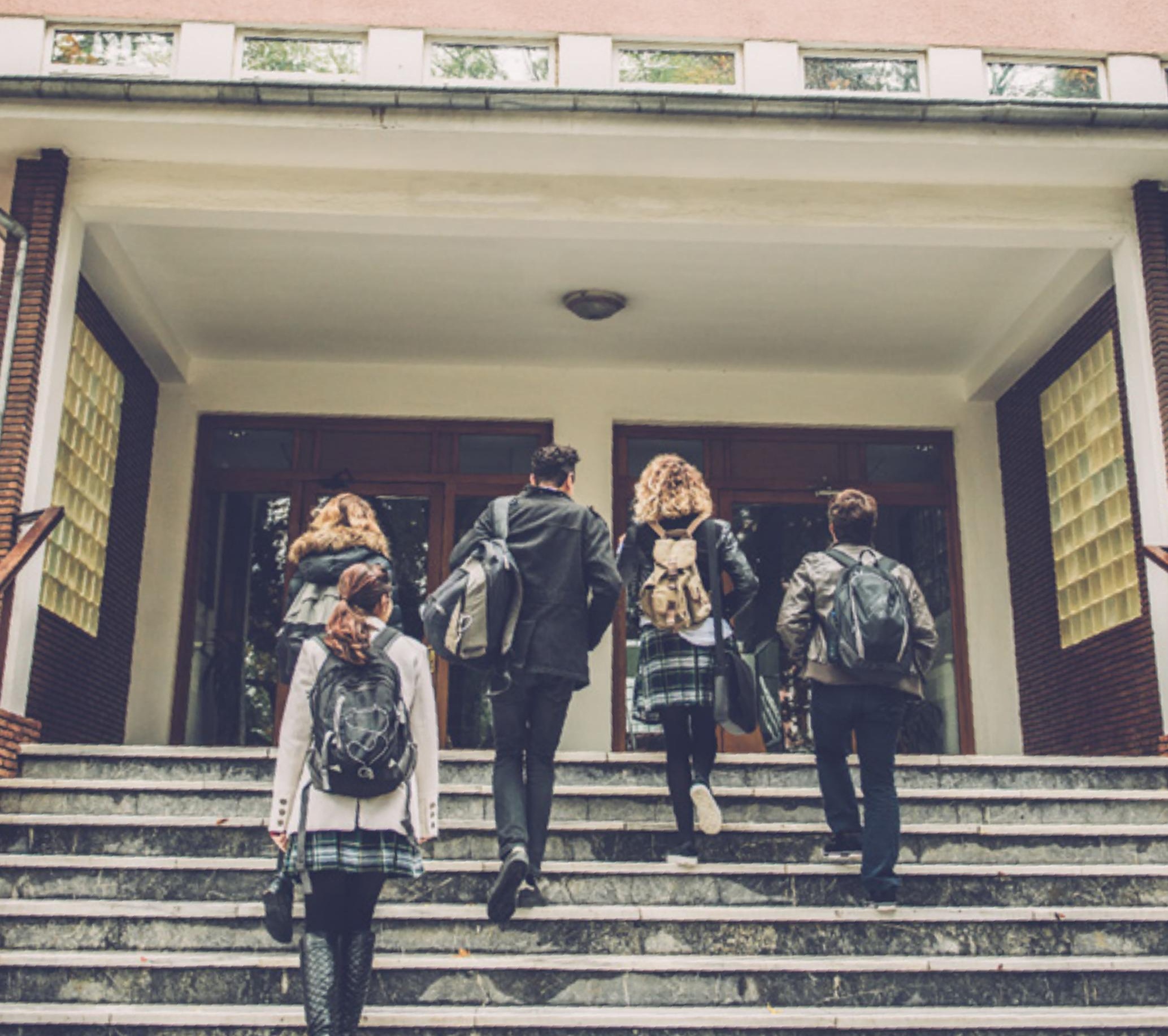

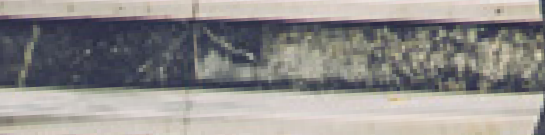

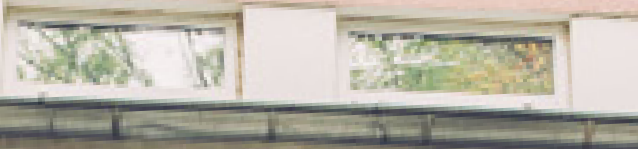




\section{Summary}

The main purpose of the European School Survey Project on Alcohol and Other Drugs (ESPAD) is to collect comparable data on substance use among 15- to 16-year-old students in order to monitor trends within as well as between countries. Between 1995 and 2015, six surveys were conducted in 48 European countries. The present report differs from the earlier ESPAD reports in that it presents selected key results of the 2015 ESPAD survey rather than the full range of results and tables. The full set of data on which the current report is based, including all the usual tables in the familiar ESPAD format, is available online (http://www.espad.org). All of the tables can be downloaded in Excel format and used for further analysis.

The present report provides information on the perceived availability of substances, early onset of substance use and prevalence estimates of substance use (cigarettes, alcohol, illicit drugs, inhalants, new psychoactive substances and pharmaceuticals). The descriptive information includes indicators of intensive substance use and prevalence estimates of internet use, gaming and gambling by country and gender. Secondly, overall ESPAD trends between 1995 and 2015 are presented. For selected indicators, ESPAD trends are shown based on data from 25 countries that participated in at least four (including the 2015 data collection) of the six surveys. Finally, for some indicators, country-specific trends are shown.

In the 2015 ESPAD data collection, 96043 students took part from 35 countries: Albania, Austria, Belgium (Flanders), Bulgaria, Croatia, Cyprus, the Czech Republic, Denmark, Estonia, the Faroes, Finland, the former Yugoslav Republic of Macedonia, France, Georgia, Greece, Hungary, Iceland, Ireland, Italy, Latvia, Liechtenstein, Lithuania, Malta, Moldova, Monaco, Montenegro, the Netherlands, Norway, Poland, Portugal, Romania, Slovakia, Slovenia, Sweden and Ukraine. For comparative reasons, the tables of the 2015 ESPAD results contain, in addition to country-specific estimates, an average across all participating countries as well as prevalence estimates for two non-ESPAD countries: Spain and the United States. The instruments used in the Spanish and US surveys overlap to a large degree with the ESPAD questionnaire, and the methodology used in all three surveys allows for rough comparisons across the countries.

\section{Methodology}

The ESPAD target population is defined as regular students who turn 16 in the calendar year of the survey and are present in the classroom on the day of the survey. Students who were enrolled in regular, vocational, general or academic studies were included, excluding those who were enrolled in either special schools or special classes for students with learning disorders or severe physical disabilities. In each participating country, a cluster sampling design was used to sample the target population, except in the Faroes, Iceland, Liechtenstein, Malta, Monaco and Montenegro, where all 1999-born target students were included. Data were collected by self-administered questionnaires. All countries used a paper-and-pencil questionnaire except for Austria, Latvia, Liechtenstein and the Netherlands, where students answered a web-based questionnaire. The students answered the questionnaires anonymously in the classroom. All samples were nationally representative, apart from Belgium (Flanders), Cyprus (government-controlled areas) and Moldova (Transnistria region not included). Sample sizes varied from 316 students in Liechtenstein to 11822 in Poland.

\section{Cigarette use}

On average, over $60 \%$ of the students in the participating countries replied that they would find it fairly or very easy (hereafter referred to as easy) to get hold of cigarettes if they wanted to. Students in the Czech Republic were most likely to find it easy (80\%), followed closely by Austria (79\%), Liechtenstein (77\%) and Denmark (76\%). Low figures of perceived availability were found in Moldova (22\%) and in three other countries in the eastern part of Europe: the former Yugoslav Republic of Macedonia (38 \%), Romania (37\%) and Ukraine (39\%). Gender differences were negligible at the aggregate level (62\% for boys versus $60 \%$ for girls).

More than one in five ESPAD students (23 \%) had smoked cigarettes at the age of 13 or younger. The proportions vary considerably across countries, from $46 \%$ in Estonia and $45 \%$ in Lithuania to 9-13\% in the former Yugoslav Republic of Macedonia, Iceland, Malta and Norway. Both on average and in most individual countries, more boys than girls have smoked cigarettes at the age of 13 or younger. On average, $4 \%$ of the students began smoking cigarettes on a daily basis at the age of 13 or younger. The rates were highest in Estonia and Slovakia (8 \% each) and lowest in Norway (1\%).

In general, the results on cigarette smoking among European students can be interpreted as showing positive developments. Today, the majority of adolescents have never smoked (54\%) and less than one quarter (21\%) of the sample can be considered current smokers, i.e. having 
smoked in the last 30 days. The average lifetime prevalence of cigarette smoking was about the same among boys (47\%) and girls (44\%). More than $10 \%$ of the students reported that they had smoked every day in the last 30 days. Comparatively high percentages of daily smoking were found in Bulgaria, Croatia, Italy, Liechtenstein and Romania (20\% or more). Lower rates were observed in Albania, Iceland, Moldova and Norway (5 \% and less).

The trend data indicate an overall decrease in lifetime, last30-day and daily cigarette use. Moreover, gender differences have narrowed over time. In 1995, boys showed higher rates than girls with regard to all indicators. In 2015, these differences were no longer apparent or became smaller. However, gender convergence is more marked in prevalence of use, whereas problematic patterns of use (daily smoking, early onset) are still more prevalent among boys.

\section{Alcohol use}

Alcoholic beverages were perceived to be easily available in most countries. More than three in four students (78 \%) stated that alcoholic beverages would be easy to obtain if they wanted to. In the Czech Republic, Denmark and Greece, more than $90 \%$ of the students reported easy access. The lowest proportions were found in Moldova (52 \%), the former Yugoslav Republic of Macedonia (53 \%) and Romania (60\%). In most countries, perceptions of availability among boys and girls were rather similar.

Nearly half of the students (47\%) reported alcohol use at the age of 13 or younger. The highest proportions were found in Georgia (72\%), the Czech Republic (68 \%) and Cyprus (66\%). The countries with the lowest rates were Iceland (14\%) and Norway (19\%). Boys were more likely than girls to have used alcohol at an early age. One in twelve students had experienced intoxication at the age of 13 or younger. The proportion of students reporting intoxication at an early age varied quite substantially across countries: Georgia (22\%) and Estonia (15\%) were at the high end of the scale, and Iceland (2\%) and Belgium (Flanders) (3\%) were at the low end. Higher rates were more likely to be found in the eastern part of Europe.

In all ESPAD countries except Iceland (35 \%), $50 \%$ or more of the students have drunk alcohol at least once during their lifetime. The ESPAD average was $80 \%$ (range: 35-96 \%). The highest rates of lifetime alcohol prevalence (93\% or more) were found in the Czech Republic, Greece and Hungary. In addition to Iceland, countries with relatively low rates (60\% or less) were Albania, the former Yugoslav Republic of Macedonia and Norway. A total of $13 \%$ of the students reported having been intoxicated during the last 30 days. Denmark scored highest, with almost one third of the students (32\%). Countries with levels of $10 \%$ or less were Albania, Estonia, the Faroes, the former Yugoslav Republic of Macedonia, Georgia, Greece, Iceland, Moldova, Montenegro, Norway, Portugal, Sweden and Ukraine. On average, slightly more boys (13\%) than girls (12\%) reported that they had been intoxicated during the last 30 days.

Students who reported alcohol use in the last 30 days drank alcohol on an average of 5.4 occasions. Students from Cyprus and Liechtenstein consumed alcohol on 8.2 and 9.1 occasions, respectively, and students from Estonia, Finland, Iceland, Lithuania, Moldova, Norway and Sweden drank alcohol on four or fewer occasions on average. In most countries, boys who drank did so more frequently than girls, with a difference of up to three occasions or more in the last 30 days in Bulgaria and the former Yugoslav Republic of Macedonia. Every third student (35\%) reported heavy episodic drinking in the past month. This drinking pattern was found more often in Austria, Cyprus and Denmark, where it was reported by about every second student. The lowest figures were found in Norway (19\%) and Iceland ( $8 \%$ ). The difference between boys and girls was about 5 percentage points on average, with generally higher percentages for boys. Students drank an average of 4.7 centilitres of ethanol on the last drinking day. Drinking volume was highest in Denmark (9.3 centilitres), Estonia (6.2 centilitres), Sweden (6.1 centilitres), Finland and Ireland ( 6.0 centilitres each), and lowest in Moldova (2.1 centilitres) and Romania (2.8 centilitres). Boys reported higher volumes than girls, with significant differences in most countries. On average, beer (35\%) and spirits (34\%) were the preferred alcoholic beverages. In Albania (68 \%), Belgium (Flanders) (58\%), the former Yugoslav Republic of Macedonia (54\%), Romania (52 \%) and Poland (52 \%), more than half of the students preferred beer. Spirits were preferred in Malta (60\%), Portugal (53\%), Slovakia (53\%), France (48\%) and Monaco (48\%). A preference for wine was found in Ukraine (44\%), Moldova (41\%) and Georgia (39\%), and for alcopops in Liechtenstein (36 \%). In Denmark, Estonia, the Faroes, Ireland, Norway and Sweden, cider accounted for approximately one quarter or more of total alcohol consumption. In these countries, cider was the second preferred alcoholic beverage next to beer or spirits.

Despite the continued high rates of alcohol use, in particular of heavy alcohol use, temporal trends over the past two decades indicate a positive development, with an overall decrease in lifetime and last-30-day use of alcohol between 1995 and 2015 from 89 \% to $81 \%$ and from 56 \% to $47 \%$, respectively. Most interestingly, both lifetime and last-30day prevalence decreased markedly after a peak in 2003. Unfortunately, changes in heavy episodic drinking were less pronounced and only observed among boys, with overall rates declining from $36 \%$ to $35 \%$ over the past 20 years. 


\section{Illicit drug use}

About three in ten students (30\%) rated cannabis to be easily available. In the Czech Republic (50 \%), more students than in any other ESPAD country reported easy access. High proportions were also found in Slovenia (45\%), as well as in Bulgaria and Liechtenstein (44\% each). The countries with the lowest perceived availability of cannabis were Moldova (5\%) and Ukraine (11\%). Boys were more likely than girls to consider cannabis to be easily available (32\% versus $29 \%$ )

The perceived availability of other illicit drugs was relatively low: ecstasy (12\%), cocaine (11\%), amphetamine (9\%), methamphetamine (7\%) and crack (8\%). In Bulgaria (e.g. amphetamine $23 \%$, methamphetamine $17 \%$ ), illicit drugs were perceived as more easily available than elsewhere in Europe. The perceived availability of ecstasy was highest in Bulgaria, the Czech Republic and Ireland (20\% or more), whereas for cocaine it was highest in Bulgaria, Ireland, Liechtenstein and Poland (17-19\%). Countries with the lowest perceived availability of nearly all illicit drugs were the Faroes, Finland, Georgia, Moldova and Ukraine.

On average, $3 \%$ of the students reported that they had first used cannabis at the age of 13 or younger. The highest proportions were found in Monaco (8\%), France and Liechtenstein (6 \% each). Rates of early onset of amphetamine/methamphetamine use were lower (1\% on average), with the highest proportions in Bulgaria (3\%) and Cyprus (2\%). Boys were more likely than girls to have used cannabis, amphetamine/methamphetamine, ecstasy or cocaine/crack at the age of 13 or younger.

Lifetime use of illicit drugs varied considerably across the ESPAD countries. In the Czech Republic, $37 \%$ of the students reported having used any illicit drug at least once, which was more than twice the average of $18 \%$. Students in Bulgaria, France, Liechtenstein and Monaco also exhibited high levels of drug use experience (30-32 \%). Particularly low levels (10\% or less) of illicit drug use were noted in Albania, Cyprus, the Faroes, Finland, the former Yugoslav Republic of Macedonia, Iceland, Moldova, Montenegro, Norway, Sweden and Ukraine. In all ESPAD countries apart from the Czech Republic, prevalence rates were higher among boys than girls. On average, $21 \%$ of boys and $15 \%$ of girls have tried illicit drugs at least once during their lifetime.

A general upward trend between 1995 and 2003 can be seen in the prevalence of illicit drug use. Since 2003, the prevalence has remained largely unchanged.

The most prevalent illicit drug in all ESPAD countries was cannabis. On average, $16 \%$ of the students have used cannabis at least once in their lifetime. The country with the highest prevalence was the Czech Republic (37\%).
High prevalence rates (30 \% or more) were also reported in France, Liechtenstein and Monaco. The lowest levels of cannabis use (4-7\%) were reported in Albania, Cyprus, the Faroes, the former Yugoslav Republic of Macedonia, Iceland, Moldova, Norway and Sweden. On average, more boys than girls reported lifetime cannabis use (19\% versus $14 \%$ ). On average, $7 \%$ of the students had used cannabis in the last 30 days. Cannabis use in the last month was highest in France (17\%), Italy (15\%) and the Czech Republic (13\%). Cannabis use in the last 30 days was also reported by more boys than girls ( $8 \%$ versus $5 \%$ ). Among students who had used cannabis in the last 12 months, the drug was used on average on 8.9 occasions, with higher frequencies in France, Iceland, Ireland, Italy and the Netherlands (11.5 or more times). Low frequencies of cannabis use were found in the Faroes and Moldova (3.6 or fewer times). Reported frequency of use was higher among boys than among girls.

Trends in cannabis use indicate a general increase in both lifetime and last-30-day use between 1995 and 2015, from $11 \%$ to $17 \%$ and from $4 \%$ to $7 \%$, respectively, with prevalence peaking in 2003 and slightly decreasing thereafter.

On average, 1-2\% of the ESPAD students have used an illicit drug other than cannabis at least once. After cannabis, the most frequently tried illicit drugs are ecstasy, amphetamine, cocaine and LSD or other hallucinogens. Less frequently tried illicit drugs were methamphetamine, crack, heroin and GHB (1\% lifetime prevalence). At the country level, rates of $5 \%$ or more were found in Bulgaria (ecstasy, amphetamine, methamphetamine, cocaine) and Poland (LSD or other hallucinogens).

\section{Other substance use}

Across the ESPAD countries, $4 \%$ of the students reported lifetime experience with new psychoactive substances (NPS), with the highest rates in Estonia and Poland (10\% each) and the lowest rates in Belgium (Flanders), Denmark, Finland, Norway and Portugal (1 \% each). The average prevalence of lifetime use of NPS was slightly higher among boys (5\%) than girls (4\%). On average, $3 \%$ of the students had used NPS in the last 12 months, with the highest prevalence in Bulgaria, Croatia, Estonia, Ireland, Italy and Poland (5-8 \%) and lowest in Belgium (Flanders), Denmark, the Faroes, Finland, the former Yugoslav Republic of Macedonia, Moldova, the Netherlands, Norway and Portugal, all at $1 \%$. Generally, differences in NPS use in the last 12 months between boys and girls were small.

The average prevalence of lifetime inhalant use was $7 \%$, with large differences between countries. The country with the highest rate was Croatia (25\%), followed by Slovenia 
(14\%). The lowest prevalence rates (1-2 \%) were found in the Faroes, the former Yugoslav Republic of Macedonia and Moldova. The average prevalence of lifetime inhalant use among ESPAD students was the same for boys and girls. The use of inhalants shows generally stable lifetime prevalence rates over the observed period. The gender-specific trends reveal a narrowing of the gender gap, with rates among boys slightly decreasing but rather unchanged rates among girls.

Lifetime use of tranquillisers or sedatives without prescription was most prevalent in Poland (17\%) and the Czech Republic (16\%). The lowest level of non-prescription use of tranquillisers or sedatives (1-2\%) was reported by students from Denmark, the Faroes, Moldova, Romania and Ukraine. On average, slightly more girls than boys reported use of tranquillisers or sedatives without prescription (8\% versus $5 \%$ ). Use of painkillers to get high was reported by $4 \%$ of the girls and $3 \%$ of the boys on average. Over the past two decades, the lifetime prevalence rates for tranquillisers or sedatives show a slightly downward trend, with rather parallel trends for boys and girls.

\section{Conditional probabilities of substance use}

Among the users across all countries who have used cigarettes at least once, $93 \%$ have also used alcohol, $32 \%$ cannabis, $12 \%$ inhalants, $10 \%$ tranquillisers or sedatives and $8 \%$ NPS. Almost every student ( $87 \%$ or more) that has used a licit or illicit substance also reported having used alcohol. Conversely, not every student who has tried alcohol has tried another substance. Among students who have used alcohol, $54 \%$ have also used cigarettes, $19 \%$ cannabis, $9 \%$ inhalants, $7 \%$ tranquillisers or sedatives and $5 \%$ or less NPS or other illicit drugs. Of the students that have used cannabis, $91 \%$ have also used cigarettes, $96 \%$ alcohol, $18 \%$ inhalants, $20 \%$ NPS and $16 \%$ tranquillisers or sedatives. Around one in ten has used ecstasy, cocaine, LSD or other hallucinogens (11\% each), painkillers (10\%) or amphetamines (9\%). Among the students who have used NPS, about a quarter have also used inhalants (26 \%) or tranquillisers or sedatives (25\%) and around three quarters (74\%) have used cannabis.

\section{Internet use, gaming, gambling}

Overall, the students stated that they had used the internet on average on 5.8 days within the last 7 days. The frequency of use was lower in Albania, Bulgaria, the former Yugoslav Republic of Macedonia, Georgia, Montenegro, Romania and Ukraine. Students in Denmark (6.8 days), Iceland (6.7 days), Finland, the Netherlands, Sweden (6.6 days each) and Estonia ( 6.5 days) were online every day of the week. No gender differences were observed. On average,
$78 \%$ of the students had used the internet for social media activities on 4 or more days in the last week and this was the predominant internet activity in all countries, with between $58 \%$ (Albania) and $94 \%$ (Finland) of students reporting this activity.

More than one in five students (23\%) regularly (at least four times in the last 7 days) used the internet for online gaming. Nearly half of the students from Denmark played regularly online (45\%). Regular online games were not so common in Georgia (13\%), the former Yugoslav Republic of Macedonia and Moldova (16 \% each). More boys (39\%) than girls (7\%) reported playing online.

On average, $14 \%$ of the students reported gambling for money at least once in the last 12 months, and $7 \%$ gambled frequently (2-4 times a month or more often). The highest rates of students with gambling experience (30 \%) and frequent gambling (16\%) in the last 12 months were found in Greece. Between a fifth and a quarter of the students in Cyprus, Finland, Montenegro and Slovenia reported gambling experience, and more than one in ten students in Finland and Ireland gambled frequently. In all countries, considerably more boys than girls have gambling experience ( $23 \%$ versus $5 \%$ on average) or gambled frequently (12\% versus $2 \%$ ) in the last 12 months.

\section{Acknowledgements}

The EMCDDA and the ESPAD group would like to acknowledge the contributions made to this report. In particular we are grateful to: the national authorities who have funded ESPAD studies; the Pompidou Group of the Council of Europe and the European Commission for supporting participation in the study: the generosity of the Swedish government who have provided long-term financial and practical support for both coordination and analytical activities; the technical input provided by CAN (Swedish Council for Information on Alcohol and Other Drugs) and IFT Institut für Therapieforschung for the reporting and analysis of the data. Finally, we note our immense gratitude to the schools, teachers and students without whose participation this report would not have been possible (a full list of acknowledgements can be found on page 91). 



\section{Introduction}

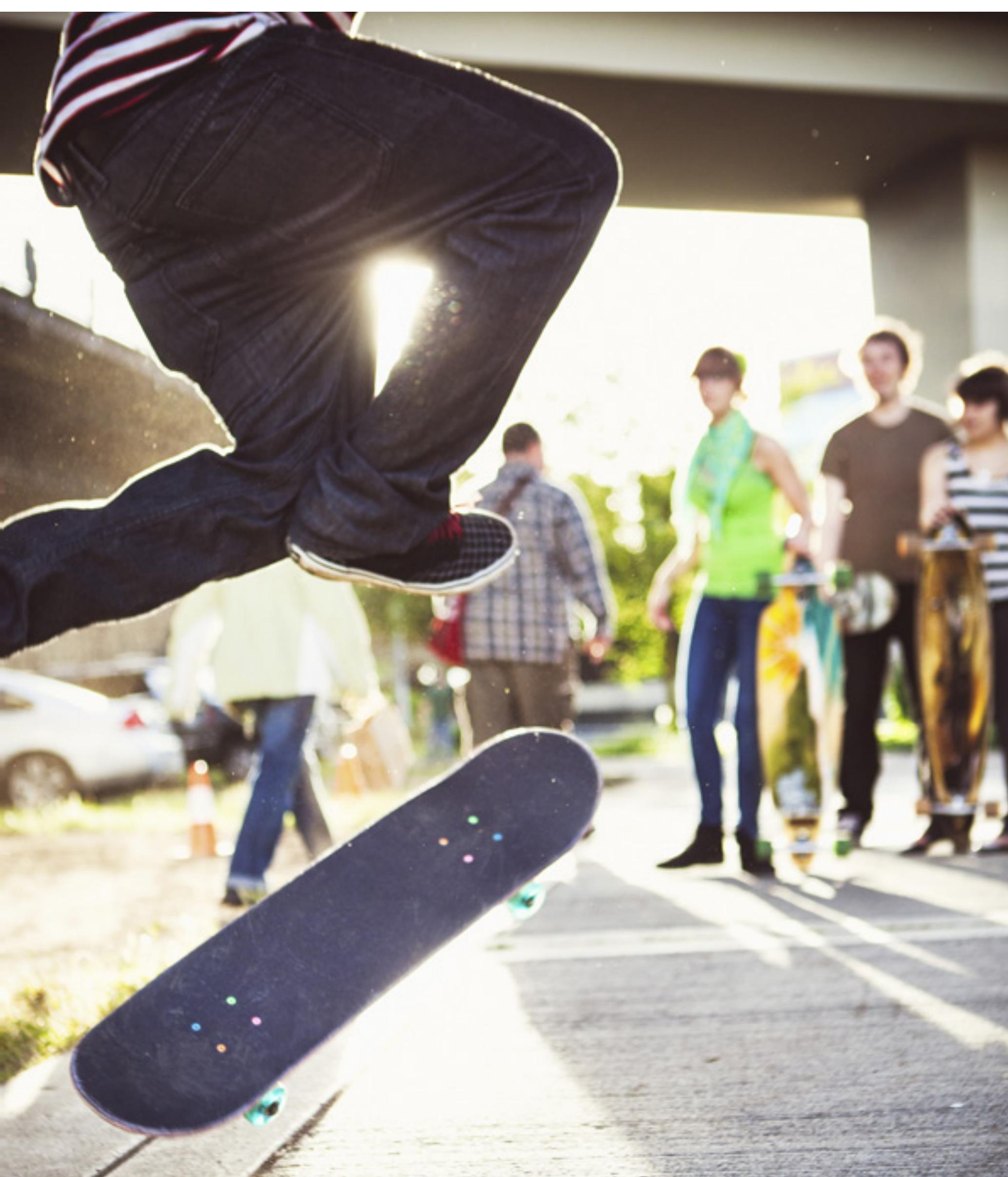




\section{Introduction}

Young people's well-being is of special concern in all societies and there are constant efforts to reduce all types of dangerous behaviour. These include consumption of tobacco, alcohol, illicit drugs and the use of non-prescribed pharmaceuticals, as well as extensive internet use, gaming and gambling. All countries have laws in place that restrict the availability of psychoactive substances and access to gambling activities. The legal framework may vary between countries but often includes restrictions specially meant to protect young people. Moreover, major international bodies such as the United Nations and the European Union are constantly looking for policy measures to reduce the negative impact of the use of different substances, for example the global strategy to reduce the harmful use of alcohol (World Health Organisation, 2014), the WHO Framework Convention on Tobacco Control (World Health Organisation, 2005), the European drugs strategy (Council of the European Union, 2012; Culley et al., 2012), or the European alcohol strategy (COWI Consortium, 2012).

Over the years, many studies have been conducted to improve the understanding of consumption patterns. However, despite the significant number of studies conducted in many countries, it has remained difficult to obtain a comprehensive picture of substance use in different European countries, especially of patterns of use among young people. With the launch of the European School Survey Project on Alcohol and Other Drugs (ESPAD) in 1995, data on substance use and risky behaviours became available that serve as a basis for the monitoring of substance use in Europe, as well as for analysing the risk factors, protective factors and time trends of such behaviours.

The main purpose of the ESPAD project is to collect comparable data on substance use among 15- to 16-yearold students in as many European countries as possible. The target group consists of students who turn 16 during the year of data collection, which in 2015 meant students born in 1999. The surveys are conducted in schools in the participating country, during the same period of time and using a common methodology. The ESPAD project provides comparable data in databases that have been and will be used by the research community for in-depth analyses to increase the understanding of substance use among European students (see http://www.espad.org/en/References--Literature).

Because of its common methodology, analyses based on ESPAD data have substantially contributed to the field of substance use. For instance, studies have been conducted on validity issues (Gmel et al., 2010; Molinaro et al., 2012; Steppan et al., 2013), methodological (Thrul et al., 2016) and theoretical issues (Brunborg et al., 2014), substance use policies (Bjarnason et al., 2010; Müller et al., 2010), risk and resilience factors (Kraus et al., 2010; Vorobjov et al., 2014), polysubstance use (Kokkevi et al., 2012; Mammone et al., 2014; Olszewski et al., 2010), attitudes (Beck et al., 2014) and risk perceptions (Piontek et al., 2013). In addition, ESPAD results have been used for the development of international action plans and strategies related to alcohol and other drugs and as such have impacted on public discussion and served as a basis for policy measures and preventive activities targeting young people.

Although the comparison of cross-sectional data on substance use across similar populations in countries of various social, economic and cultural origins is important, the possibility of investigating temporal changes across the majority of European countries is quite unique. The ESPAD project provides data that can be used to monitor trends in substance use among students in Europe and to compare trends between countries and between groups of countries (Fotiou et al., 2014; Molinaro et al., 2011). With the 2015 survey, ESPAD data cover substance use behaviours of 15- to 16-year-old students over a period of 20 years. Since 1995, when information on substance use was collected in 26 countries (Hibell et al., 1997), the survey has been repeated every fourth year in the same age group. In the second wave, in 1999, data were collected in 30 countries (Hibell et al., 2000), and the surveys of 2003 and 2007 covered 35 countries each (Hibell et al., 2004, 2009), with an additional five countries collecting data in 2008. The number of participating countries in the 2011 survey was 36 (Hibell et al., 2012), with three more countries collecting data in the autumn (Hibell and Guttormsson, 2013), and 35 countries collected data in the most recent (2015) survey.

\section{Background to ESPAD}

In the 1980s, a subgroup of collaborating investigators was formed within the Pompidou Expert Committee on Drug Epidemiology of the Council of Europe to develop a standardised school-survey questionnaire and methodology. The purpose of the work was to produce a standard survey instrument that would enable different countries to compare alcohol and drug use in student populations. A common questionnaire was used by eight countries, but the pilot study differed in sample size, representativeness and age range, and was not performed at the same time. The survey instrument, however, proved to be valid and reliable (Johnston et al., 1994). With the exception of Sweden, where school surveys had already been conducted on an annual basis since 1971, only a few countries conducted school surveys related to substance use on a more or less regular basis. In light of a growing 
Table 1. Overview of countries participating in ESPAD. 1995-2015

\begin{tabular}{|c|c|c|c|c|c|c|c|}
\hline Country & Principal investigator & 1995 & 1999 & 2003 & 2007 & 2011 & 2015 \\
\hline Albania & Ervin Toçi & . & . & & . & Yes & Yes \\
\hline Armenia & Artak Musheghyan & & . & & Yes & & \\
\hline Austria & Julian Strizek; Alfred Uhl & & . & Yes & Yes & & Yes \\
\hline Belgium (Flanders) & Patrick Lambrecht & & . & Yes & Yes $^{\text {a }}$ & Yes $^{b}$ & Yes $^{b}$ \\
\hline Belgium (Wallonia) & Danielle Piette & . & . & Yes & . & . & . \\
\hline $\begin{array}{l}\text { Bosnia and } \\
\text { Herzegovina (FBiH) }\end{array}$ & Aida Pilav & & . & & Yes $^{c}$ & Yes $^{\text {a }}$ & . \\
\hline $\begin{array}{l}\text { Bosnia and } \\
\text { Herzegovina (RS) }\end{array}$ & Sladjana Siljak & . & . & & Yes $^{c}$ & Yes & . \\
\hline Bulgaria & Anina Chileva & & Yes & Yes & Yes & Yes & Yes \\
\hline Croatia & Iva Pejnović Franelić & Yes & Yes & Yes & Yes & Yes & Yes \\
\hline Cyprus & Kyriakos Veresies & Yes & Yes & Yes & Yes & Yes & Yes \\
\hline Czech Republic & Ladislav Csèmy & Yes & Yes & Yes & Yes & Yes & Yes \\
\hline Denmark & Mette Vinther Skriver & Yes & Yes & Yes & Yes & Yes & Yes \\
\hline Estonia & Sigrid Vorobjov & Yes & Yes & Yes & Yes & Yes & Yes \\
\hline Faroes & Pál Weihe & Yes & Yes & Yes & Yes & Yes & Yes \\
\hline Finland & Kirsimarja Raitasalo & Yes & Yes & Yes & Yes & Yes & Yes \\
\hline FYR Macedonia ${ }^{e}$ & Silvana Oncheva & . & Yes & & Yes $^{c}$ & & Yes \\
\hline France & Stanislas Spilka & . & Yes & Yes & Yes & Yes & Yes \\
\hline Georgia & Lela Sturua & . & . & & 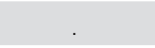 & & Yes $^{a}$ \\
\hline Germany & Ludwig Kraus & . & . & 6 Bundesl. & 7 Bundesl. & 5 Bundesl. & . \\
\hline Greece & Anna Kokkevi & . & Yes & Yes & Yes & Yes & Yes \\
\hline Greenland & Vacant & . & Yes & Yes & . & . & . \\
\hline Hungary & Zsuzsanna Elekes & Yes & Yes & Yes & Yes & Yes & Yes \\
\hline Iceland & Ársæll Már Arnarsson & Yes & Yes & Yes & Yes & Yes & Yes \\
\hline Ireland & Luke Clancy & Yes & Yes & Yes & Yes & Yes & Yes \\
\hline Isle of Man & Andreea Steriu & & . & Yes & Yes & Yes $^{d}$ & . \\
\hline Italy & Sabrina Molinaro & Yes & Yes & Yes & Yes & Yes & Yes \\
\hline $\begin{array}{l}\text { Kosovo (under } \\
\text { UNSCR 1244) }\end{array}$ & Mytaher Haskuka & & . & & . & Yes $^{a}$ & . \\
\hline Latvia & Marcis Trapencieris & Yes & Yes & Yes & Yes & Yes & Yes \\
\hline Liechtenstein & Esther Kocsis & . & . & . & . & Yes & Yes \\
\hline Lithuania & Liudmila Rupšienè & Yes & Yes & Yes & Yes & Yes & Yes \\
\hline Malta & Sharon Arpa & Yes & Yes & Yes & Yes & Yes & Yes \\
\hline Moldova & Mihai Ciocanu & & . & & Yes $^{c}$ & Yes & Yes \\
\hline Monaco & Stanislas Spilka & 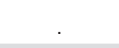 & . & & Yes & Yes & Yes \\
\hline Montenegro & Tatijana Djurisic & & . & & Yes $^{c}$ & Yes & Yes \\
\hline Netherlands & Karin Monshouwer & . & Yes & Yes & Yes & Yes $^{a}$ & Yes $^{a}$ \\
\hline Norway & Elin K. Bye & Yes & Yes & Yes & Yes & Yes & Yes \\
\hline Poland & Janusz Sieroslawski & Yes & Yes & Yes & Yes & Yes & Yes \\
\hline Portugal & Fernanda Feijão & Yes & Yes & Yes & Yes & Yes & Yes \\
\hline Romania & Silvia Florescu & . & Yes & Yes & Yes & Yes & Yes \\
\hline Russia & Eugenia Koshkina & . & Moscow & Moscow & Yes & Moscow & . \\
\hline Serbia & Spomenka Ciric-Jankovic & . & . & . & Yes $^{c}$ & Yes & . \\
\hline Slovakia & Alojz Nociar & Yes & Yes & Yes & Yes & Yes & Yes \\
\hline Slovenia & Tanja Urdih Lazar & Yes & Yes & Yes & Yes & Yes & Yes \\
\hline Sweden & Håkan Leifman & Yes & Yes & Yes & Yes & Yes & Yes \\
\hline Switzerland & Gerhard Gmel & . & . & Yes & Yes & . & . \\
\hline Turkey & Nesrin Dilbaz & Istanbul & . & 6 cities & . & . & . \\
\hline Ukraine & Olga Balakireva & Yes & Yes & Yes & Yes & Yes & Yes \\
\hline United Kingdom & Mark Bellis & Yes & Yes & Yes & Yes & Yes & . \\
\hline
\end{tabular}

a Data collected in autumn. $\quad$ b Data collected in previous autumn. $\quad$ c Data collected in spring 2008. d Data collected but not delivered.

e Official name former Yugoslav Republic of Macedonia. 
interest in school surveys in general and cross-country comparisons in particular, the Swedish Council for Information on Alcohol and Other Drugs (CAN) initiated a collaborative project in 1993 by contacting researchers in most European countries to explore the possibility of conducting simultaneous school surveys on tobacco, alcohol and drug use in association with the Pompidou Group. This enterprise resulted in the first ESPAD study in 1995.

In 2008, a cooperation framework was set up between the European Monitoring Centre for Drugs and Drug Addiction (EMCDDA) and ESPAD. This framework was meant to deepen the collaboration that had already existed on an ad hoc basis since the mid 1990s. ESPAD data have been regularly included in the EMCDDA's annual reporting on the drug situation in Europe. These data have provided crucial information on substance use among 15- to 16-year-old students, allowing trends over time to be assessed. The areas of collaboration covered in the cooperation framework included: (1) the integration of the ESPAD approach into the broader data-collection system at EU level; (2) the encouragement of countries' participation in ESPAD; (3) an agreement on analytical use of ESPAD data, by placing them in the context of EMCDDA data; and (4) contact between ESPAD experts and those working within the EMCDDA. Furthermore, it was agreed to enhance the exchange of information and expertise, improve the availability, quality and comparability of school survey data and gain maximum analytical insight from data available in this area (see http://www.espad.org/Uploads/Documents/EMCDDA_ Cooperation_Agreement-2008.pdf).

ESPAD still is and will continue to be an independent research project owned by the researchers involved. The main researcher in each participating country is appointed by ESPAD and is referred to either as a 'principal investigator' (PI) or as an 'ESPAD contact person'. Each of them should raise funds in his or her country and participate in ESPAD and the general assemblies independently and at his or her own expense. The data collected in the framework of the project are owned by each country independently (see Acknowledgements). The PI or contact person is responsible for the use of his or her national data set. Table 1 gives an overview of data that have been collected since 1995 in participating countries and the responsible persons.

\section{ESPAD Report 2015}

This report presents the key results of the 2015 ESPAD surveys that have been conducted in 35 countries: Albania, Austria, Belgium (Flanders), Bulgaria, Croatia, Cyprus, the Czech Republic, Denmark, Estonia, the Faroes, Finland, the former Yugoslav Republic of Macedonia, France, Georgia, Greece, Hungary, Iceland, Ireland, Italy, Latvia, Liechtenstein, Lithuania, Malta, Moldova, Monaco, Montenegro, the Netherlands, Norway, Poland, Portugal, Romania, Slovakia, Slovenia, Sweden and Ukraine. Firstly, the present report provides information on the availability of substances, early onset of substance use and prevalence estimates of substance use (cigarettes, alcohol, cannabis, illicit drugs, inhalants, new psychoactive substances and pharmaceuticals). The descriptive information also includes indicators of intensive substance use and prevalence estimates of internet use, gaming and gambling by country and gender. Secondly, overall ESPAD trends between 1995 and 2015 are presented. For selected indicators, ESPAD trends are shown based on data from 25 countries that participated in at least four (including the 2015 data collection) of the six surveys. Finally, for some indicators, country-specific trends are shown. For comparative reasons the tables of the 2015 ESPAD results contain, in addition to country-specific estimates, an unweighted average across all participating countries as well as prevalence estimates for Spain and the United States, which are both non-ESPAD countries. Data for Spain come from the Spanish national school survey collected between November 2014 and April 2015 (Spanish Observatory on Drugs and Drug Addiction, 2016a, b), and the US data stem from the 2015 'Monitoring the future' project (Johnston et al., 2016). The instruments used in the Spanish and US surveys overlap to a large degree with the ESPAD questionnaire, and the methodology used in all three surveys allows for rough comparisons across the countries. Many of the ESPAD questions were originally taken from the 'Monitoring the future' study. 


\section{Methodology}

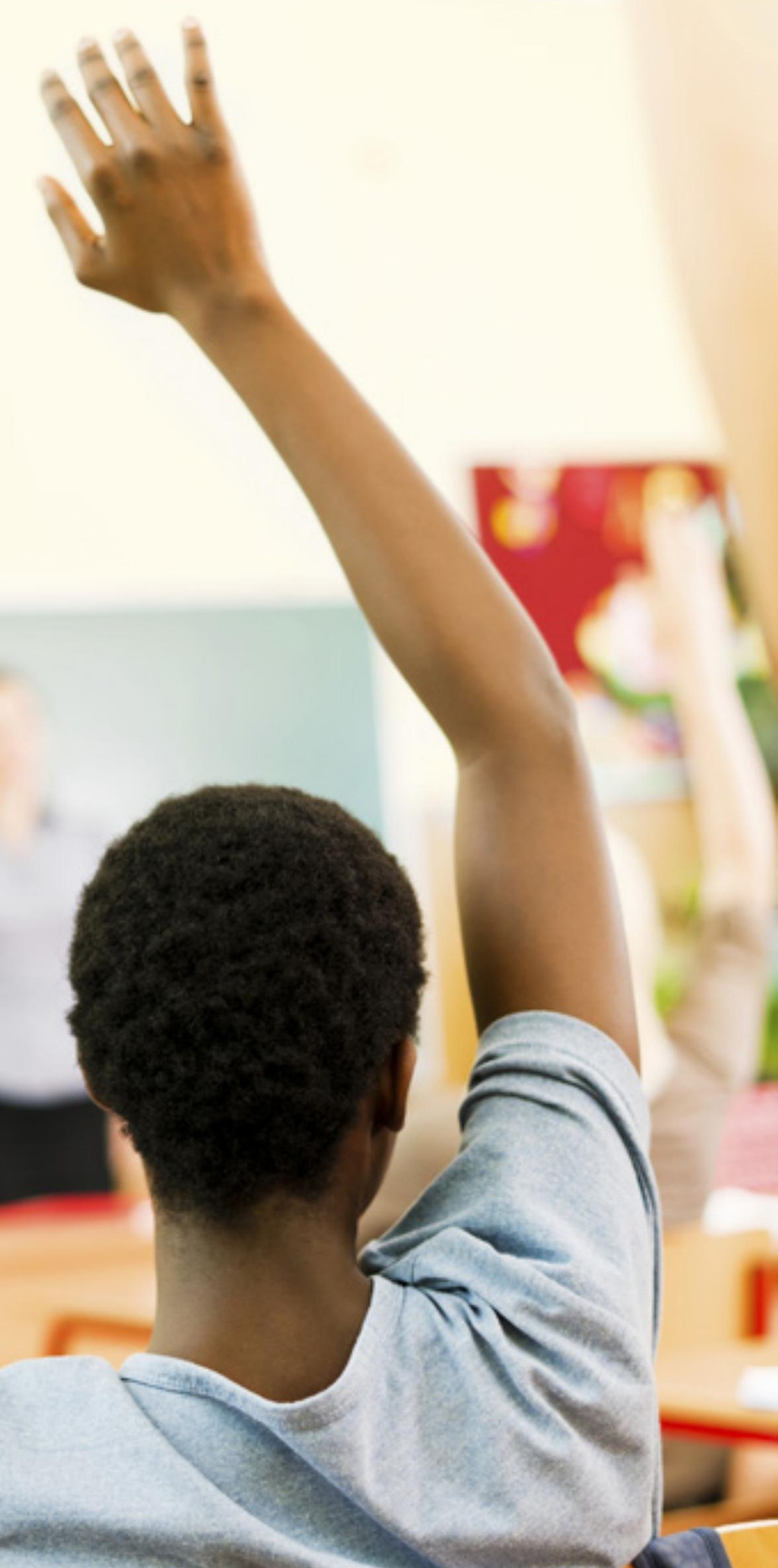




\section{Methodology}

\section{ESPAD 2015}

\section{Sample}

The ESPAD target population is defined as students who turn 16 in the calendar year of the survey and are present in the classroom on the day of the survey. Students who were enrolled in regular, vocational, general or academic studies were included, excluding those who were enrolled in either special schools or special classes for students with learning disorders or severe physical disabilities. Table 2 shows the main sample characteristics. The methods are largely comparable in all countries, although there are characteristics, for example sample type, mode of administration or time of data collection, that may differ between countries.

In each participating country, a cluster sampling design was used to sample the target population, except in the Faroes, Iceland, Liechtenstein, Malta, Monaco and Montenegro, where all 1999-born target students were included. Data were collected by self-administered questionnaires. All countries used a paper-and-pencil questionnaire, except for Austria, Latvia, Liechtenstein and the Netherlands, where students answered a web-based questionnaire. Based on a methodological study in Latvia, only small differences in students' responses to online and traditional paper-andpencil questionnaires were found (Trapencieris, 2013), and comparability was considered satisfactory. The students answered the questionnaires anonymously in the classroom, with teachers or research assistants functioning as survey leaders. The questionnaires were provided by school staff (18 countries), teachers (13 countries) or research assistants (four countries). In the majority of countries, data collection took place between February and May 2015, except for Belgium (Flanders), where data were collected 6 months earlier (autumn 2014), and Georgia and the Netherlands, where data were collected 6 months later (autumn 2015). In most countries, class was the last unit in a multistage stratified sampling process.

All samples were nationally representative, except for Belgium (only the Dutch-speaking part, Flanders), Cyprus (only government-controlled areas) and Moldova (Transnistria region not included). Sample sizes varied between 316 in Liechtenstein and 11822 in Poland. In 2015, data on 96043 students were collected in 35 countries covering $2.9 \%$ of the population of adolescents born in 1999. The school participation rate (share of selected schools taking part in the survey) ranged from $21 \%$ to $100 \%$ and the class participation rate (share of selected classes participating) varied between $17 \%$ and $100 \%$. The proportion of students of selected classes that were present on the day of the survey and answered the questionnaire was high (80-84 \%). At the time of data collection, students were on average 15.8 years old, with country means varying between 15.7 and 16.4 years. The coverage of students was very high, with 30 countries reaching $90 \%$ of the target population or more. Lower rates were reported in Denmark (78 \%) and Georgia (73\%). Data were weighted in 11 countries to account for the cluster sampling design and/or to adjust the sample to the sociodemographic composition of the target population.

\section{Measures}

The questionnaire covers young people's awareness of and experience with different licit and illicit substances, internet, gaming and gambling with money. The questions are designed to collect information on the use of psychoactive substances and the use of the internet for various activities in the lifetime, the last 12 months, the last 30 days or the last week previous to the survey, and consumption patterns such as frequency or quantity (e.g. volume, hours).

\section{Availability of substances}

The perceived availability of substances is a proxy measure for how easy or difficult it is for students to get a particular substance (cigarettes, alcohol or illicit drugs). Students were asked how easy they estimate it would be to get hold of particular substances within 24 hours if they wanted to. The response categories were 'impossible', 'very difficult', 'fairly difficult', 'fairly easy', 'very easy' and 'don't know'. The proportions of students in each country answering 'fairly easy' or 'very easy' were merged to indicate easy availability. Availability of each type of different alcoholic beverage (beer, wine and spirits) was evaluated separately. If considered relevant, countries included optional beverages such as cider or alcopops in the questionnaire.

\section{Age of first substance use}

Students were asked how old they were when they used a particular substance for the first time, started to use it on a daily basis (cigarettes) or experienced excessive use (alcohol intoxication). The response categories ranged from ' 9 years old or less' to '16 years or older', in increments of 1 year, and 'never'. An age of initiation of 13 years or younger was taken as an indicator of early onset. 


\section{Cigarette use}

Students were asked on how many occasions they had ever smoked cigarettes, with the response categories being ' 0 ', '1-2', '3-5', '6-9','10-19', '20-39' and '40 or more'. Quantity of cigarette use in the last 30 days was also collected. The response categories 'not at all', 'less than 1 cigarette per week', 'less than 1 cigarette per day', '1-5 cigarettes per day', '6-10 cigarettes per day', '11-20 cigarettes per day' and 'more than 20 cigarettes per day'. Lifetime prevalence (any use) and prevalence of daily use (at least 1-5 cigarettes per day) were calculated. Daily use of cigarettes was considered as having smoked a minimum of one cigarette each day.

\section{Alcohol use}

Students were asked on how many occasions they had consumed alcoholic beverages and had been intoxicated in their lifetime and during the last 30 days. The response categories '0', '1-2', '3-5', '6-9', '10-19', '20-39' and '40 or more'. The average number of occasions was calculated as the average based on the mean value of each response category, for example 29.5 for the category '20-39'. For the category ' 40 or more', the value 41 was used. Prevalence of any use (lifetime, last-30-day) and prevalence of experiencing any intoxication were also calculated $(\geq 1-2$ times). Moreover, heavy episodic drinking is defined as drinking a minimum of five alcoholic beverages on one occasion at least once in the last 30 days, which corresponds to a cut-off of approximately 9 centilitres of pure alcohol. The volume of alcohol intake was calculated as the total volume of pure ethanol summed across different alcoholic beverages (beer, wine, spirits, alcopops and cider).

\section{Illicit drug use}

To measure lifetime experience with illicit drugs, students were asked on how many occasions they had tried different drugs in their lifetime, with the response categories being ' 0 ', '1-2', '3-5', '6-9','10-19', '20-39' and '40 or more'. Frequency of use was asked for cannabis (marijuana or hashish), ecstasy, amphetamine, methamphetamine, cocaine, crack, LSD or other hallucinogens, heroin and GHB (gammahydroxybutyrate). The average number of occasions using cannabis was calculated as the average based on the mean value of each response category, for example 29.5 for the category '20-39'. For '40 or more' the value 41 was used.

\section{Inhalant use}

Students were asked how often they had used inhalants in their life, with the response categories being '0', '1-2', '3-5',
'6-9','10-19', '20-39' and '40 or more'. Prevalence of any use of inhalants was based on intake on at least one occasion.

\section{New psychoactive substance use}

New psychoactive substances (NPS) were defined as 'substances that imitate the effects of illicit drugs such as cannabis or ecstasy and are sometimes called "legal highs", "ethnobotanicals" or "research chemicals" and can come in different forms (herbal mixtures, powders, crystals or tablets)'. Students were asked how often they had used NPS in their life, with the response categories being ' 0 ', ' $1-2$ ', '3-5', '6-9','10-19', '20-39' and '40 or more'. Prevalence of any use of NPS was based on intake on at least one occasion.

\section{Pharmaceutical use}

To measure lifetime experience of use of pharmaceuticals, students were asked on how many occasions they had used tranquillisers or sedatives without a doctor's prescription, anabolic steroids or painkillers in order to get high, with the response categories being '0', '1-2', '3-5', '6-9', '10-19', '20-39' and ' 40 or more'. Prevalence of any use was based on intake on at least one occasion.

\section{Conditional probabilities of substance use}

Conditional prevalence rates were calculated as the prevalence of use of one substance conditional on the use of another substance. This analysis is based on substance users across all countries. It is neither assumed that the use of a particular substance has occurred before the use of another substance nor assumed that the use of a substance is caused by the use of another substance.

\section{Internet use, gaming and gambling}

To assess patterns of internet use, including online gaming and gambling (online and offline), students were asked on how many of the last 7 days had they used the internet, and how many hours had they spent on the internet on an average day on which they had used the internet. This information was asked for various online activities such as social media (communicating with others), searching for information, streaming or downloading music, buying/ selling, gaming (which is defined for the purpose of this study as playing games) and gambling for money. Based on that, the average number of days using the internet and the prevalence of using the internet at least four times for each of these activities in the last 7 days (also referred to as regular use) was calculated. Gambling for money was 
Table 2. Sampling characteristics of ESPAD 2015

\begin{tabular}{|c|c|c|c|c|c|c|c|c|c|c|}
\hline Country & $\begin{array}{l}\text { Geograph- } \\
\text { ic coverage }\end{array}$ & $\begin{array}{l}\text { Data } \\
\text { collection } \\
\text { mode }\end{array}$ & Sample type & $\begin{array}{l}\text { Sampling } \\
\text { unit(s) }\end{array}$ & $\begin{array}{c}\text { Data } \\
\text { weighted }\end{array}$ & $\begin{array}{c}\text { Student } \\
\text { represen- } \\
\text { tativeness } \\
(\%)^{a}\end{array}$ & $\begin{array}{l}\text { Class } \\
\text { participation } \\
\text { rate }(\%)^{b}\end{array}$ & $\begin{array}{l}\text { Students' } \\
\text { presence } \\
\text { rate (\%) }{ }^{c}\end{array}$ & $\begin{array}{l}\text { Mean } \\
\text { age }^{d}\end{array}$ & $n$ \\
\hline Albania & National & $\begin{array}{l}\text { Pen and } \\
\text { paper }\end{array}$ & $\begin{array}{l}\text { Stratified } \\
\text { random }\end{array}$ & School/class & No & 95 & 100 & 94 & 15.9 & 2553 \\
\hline Austria & National & $\begin{array}{l}\text { Web } \\
\text { survey }\end{array}$ & $\begin{array}{l}\text { Proportionate } \\
\text { random }\end{array}$ & School/class & Yes & 90 & $17^{e}$ & 90 & 15.9 & 3684 \\
\hline Belgium $^{f}$ & Flanders $\mathrm{g}$ & $\begin{array}{l}\text { Pen and } \\
\text { paper }^{h}\end{array}$ & $\begin{array}{l}\text { Stratified } \\
\text { random }\end{array}$ & School/class & Yes & 94 & $56^{i}$ & 94 & 15.8 & 1771 \\
\hline Bulgaria & National & $\begin{array}{l}\text { Pen and } \\
\text { paper }\end{array}$ & $\begin{array}{l}\text { Simple } \\
\text { random }\end{array}$ & Class & No & 99 & 98 & 84 & 16.0 & 2922 \\
\hline Croatia & National & $\begin{array}{l}\text { Pen and } \\
\text { paper }\end{array}$ & $\begin{array}{l}\text { Stratified } \\
\text { simple random }\end{array}$ & School/class & No & 94 & 98 & 89 & 15.7 & 2558 \\
\hline Cyprus & National ${ }^{\mathrm{j}}$ & $\begin{array}{l}\text { Pen and } \\
\text { paper }\end{array}$ & $\begin{array}{l}\text { Stratified } \\
\text { random }\end{array}$ & Class & No & $>90$ & 85 & n.a. & 15.8 & 2098 \\
\hline $\begin{array}{l}\text { Czech } \\
\text { Republic }\end{array}$ & National & $\begin{array}{l}\text { Pen and } \\
\text { paper }\end{array}$ & $\begin{array}{l}\text { Stratified } \\
\text { random }\end{array}$ & School/class & Yes & $>95$ & $96^{i}$ & 83 & 16.0 & 2738 \\
\hline Denmark & National & $\begin{array}{l}\text { Pen and } \\
\text { paper }\end{array}$ & $\begin{array}{l}\text { Stratified } \\
\text { simple random }\end{array}$ & School/class & No & $78^{k}$ & $26^{i}$ & 88 & 15.8 & 1670 \\
\hline Estonia & National & $\begin{array}{l}\text { Pen and } \\
\text { paper }\end{array}$ & $\begin{array}{l}\text { Stratified } \\
\text { random }\end{array}$ & School/class & No & $97^{1}$ & 90 & 83 & 15.7 & 2452 \\
\hline Faroes & National & $\begin{array}{l}\text { Pen and } \\
\text { paper }\end{array}$ & Total & No sample & No & 88 & 100 & 92 & 15.7 & 511 \\
\hline Finland & National $\mathrm{m}$ & $\begin{array}{l}\text { Pen and } \\
\text { paper }\end{array}$ & $\begin{array}{l}\text { Stratified } \\
\text { random }\end{array}$ & School/class & No & 93 & 85 & 89 & 15.8 & 4049 \\
\hline $\begin{array}{l}\text { FYR } \\
\text { Macedonia w }\end{array}$ & National & $\begin{array}{l}\text { Pen and } \\
\text { paper }\end{array}$ & $\begin{array}{l}\text { Systematic } \\
\text { random }\end{array}$ & Class & No & $92^{q}$ & 98 & 88 & 15.8 & 2428 \\
\hline France & National $^{\mathrm{n}}$ & $\begin{array}{l}\text { Pen and } \\
\text { paper }\end{array}$ & $\begin{array}{l}\text { Stratified } \\
\text { random }\end{array}$ & School/class & Yes & 94 & 93 & 87 & 15.9 & 2714 \\
\hline Georgia ${ }^{\circ}$ & National & $\begin{array}{l}\text { Pen and } \\
\text { paper }\end{array}$ & $\begin{array}{l}\text { Proportionate } \\
\text { simple random }\end{array}$ & School/class & No & 73 & 98 & 86 & 16.4 & 1966 \\
\hline Greece & National & $\begin{array}{l}\text { Pen and } \\
\text { paper }\end{array}$ & $\begin{array}{l}\text { Stratified } \\
\text { random }\end{array}$ & Class & Yes & 91 & 95 & 92 & 15.8 & 3202 \\
\hline Hungary & National & $\begin{array}{l}\text { Pen and } \\
\text { paper }\end{array}$ & $\begin{array}{l}\text { Stratified } \\
\text { random }\end{array}$ & Class & Yes & 97 & 93 & 85 & 15.7 & 2735 \\
\hline Iceland & National & $\begin{array}{l}\text { Pen and } \\
\text { paper }\end{array}$ & Total & No sample & No & 96 & 79 & 86 & 15.8 & 2663 \\
\hline Ireland & National & $\begin{array}{l}\text { Pen and } \\
\text { paper }\end{array}$ & $\begin{array}{l}\text { Stratified } \\
\text { systematic } \\
\text { random }\end{array}$ & School/class & No & 98 & $18^{e}$ & 86 & 15.9 & 1470 \\
\hline Italy & National & $\begin{array}{l}\text { Pen and } \\
\text { paper }\end{array}$ & $\begin{array}{l}\text { Stratified } \\
\text { proportionate } \\
\text { random }\end{array}$ & Class & No & 99 & 85 & 88 & 15.7 & 4059 \\
\hline Latvia & National & $\begin{array}{l}\text { Web } \\
\text { survey }\end{array}$ & $\begin{array}{l}\text { Stratified } \\
\text { random cluster } \\
\text { sampling }\end{array}$ & Class & Yes & $95^{p}$ & 42 & 85 & 15.9 & 1119 \\
\hline Liechtenstein & National & $\begin{array}{l}\text { Web } \\
\text { survey }\end{array}$ & Total & No sample & No & $\sim 99$ & 100 & 93 & 15.7 & 316 \\
\hline Lithuania & National & $\begin{array}{l}\text { Pen and } \\
\text { paper }\end{array}$ & $\begin{array}{l}\text { Stratified } \\
\text { random }\end{array}$ & School/class & No & 85 & 99 & 88 & 15.7 & 2573 \\
\hline Malta & National & $\begin{array}{l}\text { Pen and } \\
\text { paper }\end{array}$ & Total & No sample & No & 93 & 98 & 83 & 15.7 & 3326 \\
\hline Moldova & National $^{r}$ & $\begin{array}{l}\text { Pen and } \\
\text { paper }\end{array}$ & $\begin{array}{l}\text { Simple } \\
\text { random }\end{array}$ & Class & No & 90 & 100 & 87 & 15.9 & 2586 \\
\hline Monaco & National & $\begin{array}{l}\text { Pen and } \\
\text { paper }\end{array}$ & Total & No sample & No & $\sim 99$ & 100 & 91 & 15.8 & 397 \\
\hline
\end{tabular}




\begin{tabular}{|c|c|c|c|c|c|c|c|c|c|c|}
\hline Country & $\begin{array}{l}\text { Geograph- } \\
\text { ic coverage }\end{array}$ & $\begin{array}{l}\text { Data } \\
\text { collection } \\
\text { mode }\end{array}$ & Sample type & $\begin{array}{l}\text { Sampling } \\
\text { unit(s) }\end{array}$ & $\begin{array}{c}\text { Data } \\
\text { weighted }\end{array}$ & $\begin{array}{c}\text { Student } \\
\text { represen- } \\
\text { tativeness } \\
(\%)^{\mathrm{a}}\end{array}$ & $\begin{array}{c}\text { Class } \\
\text { participation } \\
\text { rate }(\%)^{b}\end{array}$ & $\begin{array}{l}\text { Students' } \\
\text { presence } \\
\text { rate (\%) }\end{array}$ & $\begin{array}{l}\text { Mean } \\
\text { age }^{d}\end{array}$ & $n$ \\
\hline Montenegro & National & $\begin{array}{l}\text { Pen and } \\
\text { paper }\end{array}$ & $\begin{array}{l}\text { Proportionate } \\
\text { simple random }\end{array}$ & Student & No & 94 & 100 & 87 & 15.9 & 3844 \\
\hline Netherlands ${ }^{\circ}$ & National & $\begin{array}{l}\text { Web } \\
\text { survey }\end{array}$ & $\begin{array}{l}\text { Stratified } \\
\text { simple random }\end{array}$ & School/class & Yes & 94 & $43^{i}$ & 90 & 15.9 & 1684 \\
\hline Norway & National & $\begin{array}{l}\text { Pen and } \\
\text { paper }\end{array}$ & $\begin{array}{l}\text { Stratified } \\
\text { random }\end{array}$ & School/class & Yes & $98^{s}$ & 53 & 93 & 15.8 & 2584 \\
\hline Poland & National & $\begin{array}{l}\text { Pen and } \\
\text { paper }\end{array}$ & $\begin{array}{l}\text { Stratified } \\
\text { random }\end{array}$ & School/class & Yes & 95 & 94 & 83 & 16.0 & 11822 \\
\hline Portugal & National ${ }^{\mathrm{t}}$ & $\begin{array}{l}\text { Pen and } \\
\text { paper }\end{array}$ & $\begin{array}{l}\text { Stratified } \\
\text { systematic } \\
\text { random }\end{array}$ & Class & No & $86^{9}$ & 96 & 93 & 15.9 & 3456 \\
\hline Romania & National & $\begin{array}{l}\text { Pen and } \\
\text { paper }\end{array}$ & $\begin{array}{l}\text { Systematic } \\
\text { random }\end{array}$ & School/class & No & $91^{\mathrm{s}}$ & 100 & 84 & 15.9 & 3500 \\
\hline Slovakia & National & $\begin{array}{l}\text { Pen and } \\
\text { paper }\end{array}$ & $\begin{array}{l}\text { Stratified } \\
\text { proportional } \\
\text { random }\end{array}$ & School/class & No & 98 & 100 & 89 & 15.8 & 2208 \\
\hline Slovenia & National & $\begin{array}{l}\text { Pen and } \\
\text { paper }\end{array}$ & $\begin{array}{l}\text { Stratified } \\
\text { random }\end{array}$ & Class & No & 94 & 99 & 88 & 15.8 & 3484 \\
\hline Sweden & National & $\begin{array}{l}\text { Pen and } \\
\text { paper }\end{array}$ & $\begin{array}{l}\text { Simple } \\
\text { random }\end{array}$ & School/class & No & 95 & 83 & 86 & 15.7 & 2551 \\
\hline Ukraine & National ${ }^{\mathrm{u}}$ & $\begin{array}{l}\text { Pen and } \\
\text { paper }\end{array}$ & $\begin{array}{l}\text { Stratified } \\
\text { systematic } \\
\text { random }\end{array}$ & School/class & Yes & 92 & 98 & 80 & 16.0 & 2350 \\
\hline
\end{tabular}

a Proportion of ESPAD target students covered by the sampling frame.

b Proportion of selected classes participating in the survey.

c Proportion of students of participating classes answering the questionnaire.

d Based on the data collection period.

e Estimated from the maximum number of classes that could participate.

f Data collected in previous autumn instead of spring.

g Geographic population coverage 61 \%: only Flanders and Dutch-speaking schools in the Brussels Capital region are covered by the sampling frame.

h A few classes in the ESPAD sample answered the online version.

i School participation rate (class participant rate unknown).

j Geographic population coverage approx. 80 \%: only government-controlled areas are covered by the sampling frame.

k Boarding schools not included.

I Vocational schools not included (less than $2 \%$ of students born in 1999).

m Geographic population coverage $99 \%$ : the Åland Islands are not covered by the sampling frame.

n Geographic population coverage $96.5 \%$ : DOM-TOM territories (overseas departments and territories such as French Guiana, Réunion and those in the Caribbean) are not covered by the sampling frame.

- Data collected in autumn instead of spring.

p Vocational schools not included (1.7\% of students born in 1999).

q Private schools not included.

$r$ Geographic population coverage $85 \%$ : the Transnistria region is not covered by the sampling frame.

s Estimations by principal investigator.

${ }^{t}$ Geographic population coverage $95 \%$ : the islands of the Azores and Madeira are not covered by the sampling frame.

u Geographic population coverage $95 \%$ : AR Crimea is not covered by the sampling frame.

$\checkmark$ Only countries with class participation rates excluding Belgium (Flanders), the Czech Republic, Denmark and the Netherlands.

w Official name former Yugoslav Republic of Macedonia. 
further assessed by asking students about the frequency of particular gambling activities in the last 12 months (playing slot machines, cards or dice, lotteries or betting on sports or animals). The response categories were 'not gambled', 'monthly or less', '2-4 times a month', '2-3 times a week', ' $4-5$ times a week' and ' 6 or more times a week'. Prevalence rates were calculated for last-12-month (at least once) and frequent (2-4 times a month or more) gambling.

\section{Data processing and data quality}

Data were centrally cleaned in two steps. First, all cases with missing information on gender were excluded from the database. The other major reason for exclusion was poor data quality. All cases with responses to less than half of the core items were discarded, as were all cases where the respondent appeared to have followed patterns involving repetitive marking of extreme values. Across all ESPAD countries, an average of $1.8 \%(0.0-7.6 \%)$ of cases were excluded because of poor data quality or missing information on gender.

Second, logical substitution of missing values was performed in a rather conservative way. In cases where students had indicated that they had never used a specific substance and subsequently did not respond to further questions about such use, any missing values were substituted with no use for that particular substance. However, no substitutions were made if any contradictory indications of use were at hand. For the seven substance use variables where substitutions were performed, the average reduction of the non-response rate was rather small, ranging from $0.1 \%$ to $0.5 \%$. The single highest country-specific reduction was found in Norway, where the non-response rate for lifetime inhalant use was reduced by 2.7 percentage points. Norway, the former Yugoslav Republic of Macedonia and Latvia were the countries where the logical substitution of missing values had the biggest impact. However, the reductions in nonresponses had only minor effects on the final prevalence estimates.

A few countries experienced modest methodological problems but, with the exception of Latvia, not of such a magnitude as to seriously threaten the comparability of the results. Compared to the ESPAD average, higher rates of inconsistencies indicate a somewhat lower data quality in Albania, Bulgaria and Cyprus. Low school/class participation rates in Austria (17\%), Denmark (26\%), Ireland (18\%), Latvia (42\%) and the Netherlands (43\%) resulted in turn in relatively small net sample sizes. In Austria (4.2\%), Cyprus (3.8\%), Latvia (7.6\%) and Norway (4.2\%), a relatively high proportion of cases had to be discarded in the central datacleaning process. Due to sampling of only one school grade or not including boarding schools, the coverage of the target student population in Denmark (78\%), the former Yugoslav Republic of Macedonia (79\%) and Georgia (73\%) was below average. Finally, a relatively high proportion of parents refused permission for their child to participate in the survey in Portugal and Romania (6.9\% each).

Due to the uncertainty of data-collection procedures, Latvia is excluded from the standard reporting and the calculation of the ESPAD average. In all tables, Latvia is reported separately to illustrate difficulties in comparability. More details on the ESPAD methodology are available online (http://www.espad.org).

\section{Analysis}

Prevalence estimates and means were calculated for each participating country, taking weights into account where necessary. In all tables, totals and gender-specific estimates for boys and girls are presented by country. Gender differences reported in Figures 1-9 were tested using either simple linear regression for quasi-continuous frequency measures or logistic regression for prevalence, with gender as predictor. Conditional probabilities expressing the use of one substance given the use of another substance were calculated for cigarettes, alcohol, cannabis, ecstasy, amphetamine, methamphetamine, cocaine, crack, LSD or other hallucinogens, heroin, GHB, inhalants, NPS, tranquillisers or sedatives, painkillers and anabolic steroids. The ESPAD average is based on 35 countries assigning equal weight to each country. Latvia was excluded from the calculation of the ESPAD average due to validity concerns. All percentages in the report were calculated on the basis of valid responses and are shown for totals, boys and girls. With the exception of frequency of alcohol use (Figures 2a, 2b), alcohol intake (Figures 3a, 3b), preference of alcoholic beverages (Figures 4a, 4b) and frequency of cannabis use (Figures 7a, 7b), where the estimates are based on consumers of a particular substance, all estimates are based on the total sample and represent population estimates.

\section{Trend analyses}

For temporal trends, country estimates were averaged across 25 countries with full coverage and valid estimates on at least four (including 2015) out of six time points. The countries included are Bulgaria, Croatia, Cyprus, the Czech Republic, Denmark, Estonia, the Faroes, Finland, France, Greece, Hungary, Iceland, Ireland, Italy, Lithuania, Malta, the Netherlands, Norway, Poland, Portugal, Romania, Slovakia, Slovenia, Sweden and Ukraine. The average across the 25 country means was calculated using a weight of 1 , and data for each survey year were summed and divided by the number of countries with valid data for that particular year. 
Data across all six time points were complete in 20 countries with data on five countries missing in 1995 (Bulgaria, France, Greece, the Netherlands and Romania), and data on one country missing in 1999 (the Netherlands; data collected but not considered comparable) and 2007 (Denmark; data collected but not considered comparable). Trends across the 25 countries are shown for a number of selected indicators by gender. Country-specific trends are shown for all countries with at least two valid data points over the period 1995-2015. Country-specific prevalence estimates before the 2007 ESPAD survey are only available on aggregate level, preventing statistical testing of temporal changes. Instead, a standardised procedure is used where a difference of less than \pm 3 percentage points is not considered as 'real difference'. Trends are illustrated graphically, with decreases of 3 or more percentage points between successive surveys indicated in green, increases of 3 or more percentage points in red and unchanged situations in yellow (less than \pm 3 percentage points).

\section{Comparability of variables}

After the 2003 survey, a working group was set up to improve and revise some of the questions that had caused problems in the previous surveys. Modified questions were tested on differences in outcome using a split-half design in eight countries. In general, most of the revised questions were found to be comparable with the earlier versions (Hibell and Bjarnason, 2008).

\section{Availability of substances}

In the surveys until 2003, perceived availability of substances was asked in one single question. Since 2007, the questionnaire has contained separate questions for each substance. A questionnaire test in eight countries showed some differences between the two versions.

\section{Alcohol use}

In the surveys until 2003, the question on heavy episodic drinking read 'How many times (if any) have you had five or more drinks in a row? A "drink" is a glass of wine (approximately 15 centilitres), a bottle or can of beer (approximately 50 centilitres), a shot glass of spirits (approximately 5 centilitres) or a mixed drink.' Cider or alcopops were not included. Since 2007, the definition has read: 'How many times (if any) have you had five or more drinks on one occasion? A "drink" is a glass/bottle/ can of beer (approximately 50 centilitres), a glass/bottle/ can of cider (approximately 50 centilitres), two glasses/ bottles of alcopops (approximately 50 centilitres), a glass of wine (approximately 15 centilitres), a glass of spirits (approximately 5 centilitres) or a mixed drink.' The questionnaire test revealed no significant differences between the two versions.

\section{Illicit drugs other than cannabis}

The questionnaire collects data on the use of illicit drugs other than cannabis, including amphetamine, cocaine, crack, ecstasy, LSD or other hallucinogens, heroin, GHB (since 2007) and methamphetamine (since 2015). In 2015, crack was not included in Denmark, Estonia, Finland and Sweden.

\section{Inhalant use}

In the earlier rounds of the survey, the question on inhalant use read 'Did you try inhalants (glue, etc.) to get high?'. In 2007, the question was rephrased to refer to 'the use of inhalants to get high'. The questionnaire test found no significant differences between the old and new versions. Since 2011, countries have been instructed to add nationally relevant examples in the questionnaire.

\section{Reporting}

Based on the 2015 ESPAD data, selected substance use indicators are presented comprising students' perceptions of the availability of cigarettes, alcohol and illicit drugs, early onset of substance use and prevalence estimates of substance use. Whenever available, corresponding figures of the two non-ESPAD countries, Spain and the United States, are also presented in tables and maps. The Spanish data relate to students born in 1997 who took part in a broader national survey carried out in 2013 . The US data relate to students in grade 10, of whom just over half were born in 1999. The two samples differ from the ESPAD sample also with respect to age. The mean ages of the ESPAD, the Spanish and the US samples are 15.8, 15.6 and 16.2 years, respectively. Due to differences in the sampling protocol and consequently in sample composition, comparisons should be made with caution.

In addition, patterns of current drug use among users of the specific substance are presented for cigarettes (prevalence for daily smoking), alcohol use (mean number of occasions in the last 30 days, beverage preference and volume on the last drinking occasion), heavy episodic drinking (consumption of five or more drinks on at least one occasion in the last 30 days), cannabis use (prevalence in the last 30 days and mean number of occasions of cannabis use in the last 12 months), inhalant use (prevalence in the last 30 days) and NPS use (prevalence in the last 12 months). The results 
are presented in maps and bar charts. Gender differences are also graphically shown by country, including tests for significance (Figures 1-9). In the maps, Belgium (Flanders), Cyprus and Moldova are presented with a lined pattern, as the Belgian data are representative only for Flanders, the Cypriot data are representative only for the governmentcontrolled part of Cyprus and in Moldova the Transnistria region was not included.

In the section on 'Trends 1995-2015' (pages 70-81), temporal trends between 1995 and 2015 are presented for the average across 25 country means (pages 70-75) and for all ESPAD countries separately (pages 76-81)

\section{Changes in reporting}

The results of the 2015 ESPAD survey are presented in both a print and an online report. The present print report contains selected key results rather than the full range of results and tables. The online report, including all tables in the usual ESPAD format, is available at http://www. espad.org. All tables can be downloaded in Excel format and used for further analysis. 


\section{The situation in 2015}

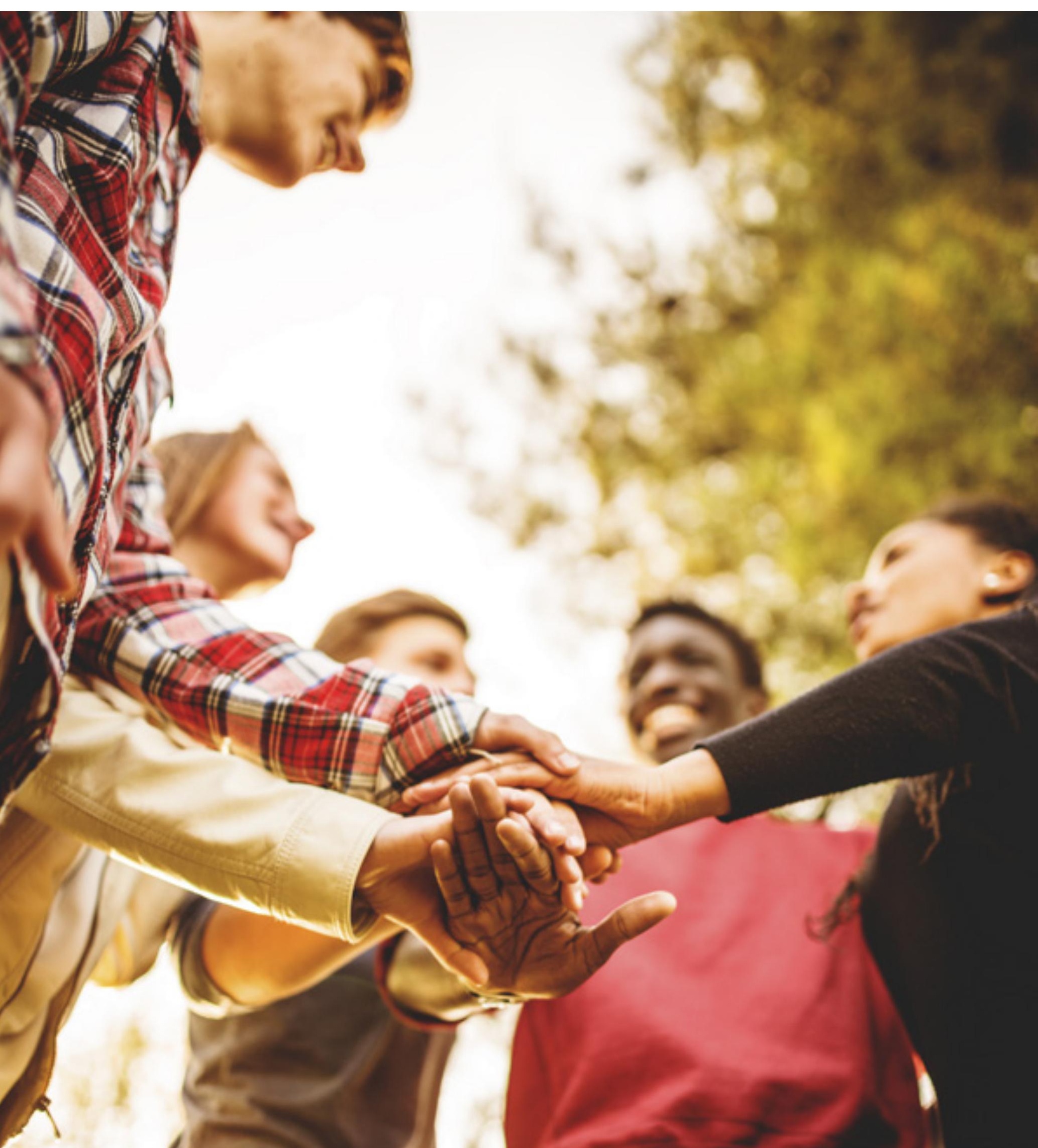




\section{The situation in 2015}

This chapter presents selected indicators of the drug situation in the 35 ESPAD countries in 2015. Each result section will start with a box containing a summary of the main results with an ESPAD average estimate and the country range: minimum (min.) and maximum (max.) for each selected measure.

\section{Availability of substances}

\begin{tabular}{|l|r|r|c}
\multicolumn{4}{c}{ ESPAD average } \\
\hline & Perceived availability of substances (\%) & \\
\hline Cigarettes & Average & Min. & Max. \\
\hline Alcohol & 61 & 22 & 80 \\
\hline Cannabis & 78 & 52 & 96 \\
\hline Ecstasy & 30 & 5 & 50 \\
\hline Amphetamine & 12 & 2 & 24 \\
\hline Methamphetamine & 9 & 2 & 23 \\
\hline Cocaine & 7 & 1 & 17 \\
\hline Crack & 11 & 2 & 19 \\
\hline
\end{tabular}

a Percentage of students rating a substance as either 'fairly easy' or 'very easy' to obtain.

\section{Cigarettes}

Over $60 \%$ of the students in the participating countries replied that they would find it fairly or very easy (hereafter referred to as easy) to get hold of cigarettes if they wanted to (Table 3a). Students in the Czech Republic were most likely to find it easy (80 \%). In Austria, Liechtenstein and Denmark, the perceived availability was also comparatively high, with $79 \%, 77 \%$ and $76 \%$ of the students, respectively, reporting access to be easy. Particularly low figures of perceived availability were found in Moldova (22 \%) and figures of less than $40 \%$ were observed in three other countries in the eastern part of Europe: the former Yugoslav Republic of Macedonia (38 \%), Romania (37\%) and Ukraine (39\%). Gender differences were negligible at the aggregate level (62\% for boys versus $60 \%$ for girls). Where differences were observed, figures were generally higher for boys than girls. In Albania, Belgium (Flanders), Finland and Moldova, differences between the genders reached 10 percentage points or more. In 10 countries, figures of availability were higher for girls than boys, with rates for girls 6 percentage points higher in Bulgaria.

\section{Alcohol}

Alcoholic beverages were perceived to be easily available in most countries and gender differences were rather uncommon (Table 3a). More than three in four students (78 \%) stated that they would find it easy to acquire alcoholic beverages if they wanted to. In the Czech Republic, Denmark and Greece, more than $90 \%$ of the students reported easy access. The lowest proportions were found in Moldova (52\%), the former Yugoslav Republic of Macedonia (53\%) and Romania (60\%). In most countries, perceptions of availability among boys and girls were rather similar. Notable gender differences could be found in Liechtenstein, Moldova and Romania (9-10 percentage points), with rates among boys being higher than among girls, and in the Faroes and Sweden, with a higher rate among girls than boys (5 percentage points).

\section{Illicit drugs}

About three in ten students (30\%) rated cannabis to be easily obtainable (Table 3a). In the Czech Republic (50 \%), more students than in any other ESPAD country perceived cannabis to be easily available. High proportions were also found in Slovenia (45 \%) as well as in Liechtenstein and Bulgaria (44\% each). The countries with the lowest perceived availability of cannabis were Moldova (5\%) and Ukraine (11\%). Boys were more likely than girls to consider cannabis to be easily available (ESPAD average: $32 \%$ versus $29 \%$ ). This was the case in most countries, with differences between the genders of up to 15 percentage points.

Countries in which more girls than boys (5 percentage points or more) reported easy availability of cannabis were Bulgaria (47\% versus $40 \%$ ) and Slovakia (46\% versus $41 \%$ ).

Perceived availability of other illicit drugs was relatively low (Table 3a, 3b): ecstasy (12\%), cocaine (11\%), amphetamine (9\%), methamphetamine (7\%) and crack (8\%). In Bulgaria (e.g. amphetamine $23 \%$, methamphetamine $17 \%$ ), illicit drugs were overall perceived as more easily available than elsewhere in Europe. In addition, 10 \% or more of the students in Croatia, the Netherlands, Norway and Poland thought that any of the listed illicit drugs were easily available. Perceived availability of ecstasy was highest in Bulgaria, the Czech Republic and Ireland (over $20 \%$ ), and perceived availability of cocaine was highest in Bulgaria, Ireland, Liechtenstein and Poland (17-19\%). The countries with the lowest perceptions of availability on nearly all illicit drugs were the Faroes, Finland, Georgia, Moldova and Ukraine. Countries with noticeable gender differences for all illicit drugs were Liechtenstein and the Netherlands (higher rates for boys than girls), Bulgaria and Slovakia (higher rates for girls than boys). 
Table 3a. $\quad$ Perceived availability of substances: prevalence of students responding substance 'fairly easy' or 'very easy' to obtain (percentage)

\begin{tabular}{|c|c|c|c|c|c|c|c|c|c|c|c|c|}
\hline \multirow{2}{*}{ Country } & \multirow{2}{*}{ Cigarettes } & \multirow{2}{*}{ Alcohol } & \multirow{2}{*}{ Cannabis } & \multirow{2}{*}{ Ecstasy } & \multicolumn{2}{|c|}{ Cigarettes } & \multicolumn{2}{|c|}{ Alcohol } & \multicolumn{2}{|c|}{ Cannabis } & \multicolumn{2}{|c|}{ Ecstasy } \\
\hline & & & & & Boys & Girls & Boys & Girls & Boys & Girls & Boys & Girls \\
\hline Albania & 51 & 71 & 22 & 14 & 56 & 46 & 72 & 69 & 28 & 16 & 14 & 14 \\
\hline Austria & 79 & 89 & 39 & 12 & 80 & 79 & 88 & 90 & 40 & 37 & 12 & 12 \\
\hline Belgium (Flanders) & 61 & 81 & 36 & 13 & 66 & 56 & 81 & 80 & 41 & 32 & 13 & 12 \\
\hline Bulgaria & 68 & 88 & 44 & 21 & 65 & 71 & 87 & 90 & 40 & 47 & 18 & 25 \\
\hline Croatia & 72 & 87 & 42 & 17 & 73 & 72 & 86 & 87 & 41 & 42 & 15 & 20 \\
\hline Cyprus & 56 & 88 & 21 & 10 & 58 & 54 & 88 & 88 & 24 & 18 & 11 & 8 \\
\hline Czech Republic & 80 & 92 & 50 & 24 & 79 & 81 & 91 & 93 & 48 & 51 & 23 & 24 \\
\hline Denmark & 76 & 96 & 40 & 14 & 79 & 73 & 96 & 95 & 44 & 37 & 15 & 13 \\
\hline Estonia & 58 & 73 & 34 & 11 & 60 & 56 & 71 & 75 & 34 & 33 & 10 & 13 \\
\hline Faroes & 64 & 76 & 15 & 5 & 64 & 65 & 73 & 78 & 15 & 15 & 4 & 7 \\
\hline Finland & 65 & 71 & 15 & 5 & 71 & 61 & 72 & 71 & 17 & 14 & 6 & 5 \\
\hline FYR of Macedonia ${ }^{a}$ & 38 & 53 & 14 & 7 & 39 & 36 & 56 & 50 & 17 & 10 & 9 & 6 \\
\hline France & 59 & 76 & 41 & 10 & 62 & 56 & 78 & 75 & 43 & 38 & 10 & 9 \\
\hline Georgia & 60 & 81 & 21 & 9 & 61 & 59 & 81 & 81 & 23 & 18 & 11 & 8 \\
\hline Greece & 65 & 91 & 23 & 8 & 64 & 66 & 90 & 91 & 25 & 20 & 9 & 6 \\
\hline Hungary & 68 & 84 & 25 & 13 & 68 & 67 & 85 & 83 & 25 & 26 & 11 & 14 \\
\hline Iceland & 44 & 61 & 27 & 11 & 44 & 44 & 60 & 62 & 29 & 26 & 11 & 11 \\
\hline Ireland & 62 & 77 & 43 & 22 & 65 & 58 & 75 & 79 & 47 & 39 & 26 & 19 \\
\hline Italy & 63 & 81 & 37 & 8 & 62 & 65 & 81 & 81 & 41 & 34 & 9 & 8 \\
\hline Liechtenstein & 77 & 88 & 44 & 13 & 81 & 74 & 93 & 84 & 52 & 38 & 18 & 9 \\
\hline Lithuania & 64 & 70 & 25 & 9 & 65 & 63 & 69 & 72 & 26 & 24 & 7 & 10 \\
\hline Malta & 56 & 85 & 26 & 13 & 54 & 57 & 83 & 87 & 26 & 26 & 12 & 15 \\
\hline Moldova & 22 & 52 & 5 & 2 & 28 & 15 & 56 & 47 & 6 & 4 & 2 & 2 \\
\hline Monaco & 58 & 75 & 34 & 6 & 56 & 60 & 74 & 75 & 36 & 31 & 6 & 7 \\
\hline Montenegro & 63 & 72 & 27 & 18 & 64 & 61 & 75 & 69 & 30 & 23 & 19 & 17 \\
\hline Netherlands & 61 & 78 & 42 & 18 & 64 & 59 & 78 & 77 & 50 & 34 & 21 & 15 \\
\hline Norway & 64 & 74 & 30 & 10 & 66 & 63 & 72 & 76 & 33 & 27 & 11 & 10 \\
\hline Poland & 73 & 82 & 39 & 16 & 73 & 73 & 81 & 83 & 41 & 38 & 16 & 16 \\
\hline Portugal & 60 & 79 & 31 & 10 & 60 & 60 & 78 & 81 & 32 & 31 & 10 & 9 \\
\hline Romania & 37 & 60 & 14 & 6 & 38 & 36 & 65 & 55 & 15 & 13 & 5 & 7 \\
\hline Slovakia & 70 & 88 & 43 & 15 & 70 & 70 & 86 & 90 & 41 & 46 & 12 & 18 \\
\hline Slovenia & 66 & 85 & 45 & 17 & 66 & 66 & 84 & 86 & 47 & 44 & 16 & 18 \\
\hline Sweden & 74 & 77 & 28 & 13 & 72 & 75 & 75 & 80 & 27 & 29 & 13 & 13 \\
\hline Ukraine & 39 & 66 & 11 & 3 & 42 & 37 & 65 & 68 & 13 & 8 & 3 & 3 \\
\hline AVERAGE & 61 & 78 & 30 & 12 & 62 & 60 & 78 & 78 & 32 & 29 & 12 & 12 \\
\hline Latvia & 60 & 70 & 24 & 9 & 62 & 58 & 68 & 72 & 24 & 23 & 7 & 11 \\
\hline Spain & 78 & 92 & 45 & 10 & 75 & 81 & 91 & 92 & 47 & 43 & 12 & 9 \\
\hline United States & 67 & 75 & 66 & 19 & 65 & 68 & 73 & 77 & 65 & 66 & 19 & 19 \\
\hline
\end{tabular}

a Official name former Yugoslav Republic of Macedonia. 
Table 3b. Perceived availability of substances: prevalence of students responding substance 'fairly easy' or 'very easy' to obtain (percentage)

\begin{tabular}{|c|c|c|c|c|c|c|c|c|c|c|c|c|}
\hline \multirow{2}{*}{ Country } & \multirow{2}{*}{$\begin{array}{l}\text { Amphet- } \\
\text { amine }\end{array}$} & \multirow{2}{*}{$\begin{array}{l}\text { Meth- } \\
\text { amphet- } \\
\text { amine }\end{array}$} & \multirow{2}{*}{ Cocaine } & \multirow{2}{*}{ Crack } & \multicolumn{2}{|c|}{ Amphetamine } & \multicolumn{2}{|c|}{$\begin{array}{l}\text { Metham- } \\
\text { phetamine }\end{array}$} & \multicolumn{2}{|c|}{ Cocaine } & \multicolumn{2}{|c|}{ Crack } \\
\hline & & & & & Boys & Girls & Boys & Girls & Boys & Girls & Boys & Girls \\
\hline Albania & 6 & 6 & 11 & 6 & 6 & 6 & 6 & 6 & 13 & 9 & 7 & 4 \\
\hline Austria & 13 & 7 & 13 & 9 & 13 & 14 & 6 & 7 & 12 & 13 & 9 & 8 \\
\hline Belgium (Flanders) & 10 & 5 & 14 & 8 & 10 & 10 & 5 & 5 & 13 & 15 & 8 & 7 \\
\hline Bulgaria & 23 & 17 & 19 & 13 & 19 & 28 & 14 & 20 & 16 & 23 & 11 & 16 \\
\hline Croatia & 16 & 11 & 14 & 12 & 16 & 17 & 10 & 12 & 12 & 17 & 11 & 13 \\
\hline Cyprus & 7 & 6 & 11 & 8 & 8 & 6 & 7 & 6 & 12 & 10 & 8 & 7 \\
\hline Czech Republic & 7 & 12 & 11 & 8 & 7 & 8 & 12 & 13 & 10 & 12 & 9 & 8 \\
\hline Denmark & 12 & 8 & 16 & 9 & 14 & 10 & 9 & 7 & 18 & 15 & 10 & 7 \\
\hline Estonia & 9 & . & 10 & . & 8 & 10 & & & 6 & 13 & & \\
\hline Faroes & 2 & 2 & 5 & 4 & 1 & 4 & 1 & 3 & 3 & 7 & 4 & 4 \\
\hline Finland & 3 & 3 & 4 & 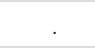 & 4 & 3 & 3 & 2 & 4 & 4 & . & . \\
\hline FYR Macedonia ${ }^{a}$ & 5 & 5 & 6 & 4 & 6 & 5 & 6 & 3 & 6 & 6 & 5 & 3 \\
\hline France & 10 & 6 & 13 & 10 & 10 & 10 & 6 & 6 & 13 & 13 & 10 & 11 \\
\hline Georgia & 6 & 5 & 3 & 3 & 7 & 4 & 7 & 3 & 4 & 3 & 3 & 2 \\
\hline Greece & 5 & 4 & 8 & 5 & 6 & 4 & 5 & 4 & 9 & 8 & 6 & 4 \\
\hline Hungary & 12 & 10 & 12 & 7 & 11 & 13 & 10 & 11 & 11 & 13 & 8 & 7 \\
\hline Iceland & 12 & 7 & 9 & 6 & 12 & 12 & 7 & 7 & 9 & 10 & 6 & 7 \\
\hline Ireland & 14 & 8 & 19 & 14 & 15 & 14 & 9 & 6 & 19 & 19 & 13 & 15 \\
\hline Italy & 8 & 6 & 11 & 8 & 8 & 8 & 7 & 5 & 12 & 11 & 8 & 7 \\
\hline Liechtenstein & 15 & 7 & 17 & 8 & 21 & 11 & 11 & 4 & 21 & 13 & 11 & 5 \\
\hline Lithuania & 6 & 5 & 9 & 5 & 5 & 6 & 5 & 5 & 8 & 10 & 5 & 5 \\
\hline Malta & 9 & 5 & 15 & 10 & 8 & 10 & 5 & 5 & 12 & 18 & 8 & 11 \\
\hline Moldova & 2 & 1 & 2 & 1 & 2 & 2 & 2 & 1 & 2 & 1 & 1 & 1 \\
\hline Monaco & 7 & 4 & 9 & 6 & 7 & 8 & 4 & 5 & 9 & 10 & 7 & 5 \\
\hline Montenegro & 13 & 10 & 12 & 8 & 14 & 12 & 11 & 8 & 13 & 11 & 10 & 7 \\
\hline Netherlands & 14 & 10 & 14 & 11 & 17 & 12 & 12 & 8 & 17 & 11 & 14 & 9 \\
\hline Norway & 11 & . & 11 & 11 & 11 & 10 & . & . & 11 & 11 & 11 & 10 \\
\hline Poland & 17 & 13 & 17 & 11 & 16 & 18 & 12 & 14 & 16 & 19 & 11 & 11 \\
\hline Portugal & 7 & 6 & 11 & 6 & 8 & 7 & 6 & 5 & 11 & 12 & 7 & 5 \\
\hline Romania & 4 & 4 & 7 & 4 & 4 & 5 & 4 & 4 & 6 & 8 & 4 & 4 \\
\hline Slovakia & 8 & 11 & 12 & 8 & 7 & 9 & 9 & 13 & 9 & 16 & 7 & 9 \\
\hline Slovenia & 8 & 8 & 16 & 12 & 8 & 8 & 8 & 9 & 14 & 19 & 11 & 12 \\
\hline Sweden & 9 & 8 & 13 & 10 & 9 & 10 & 8 & 8 & 11 & 15 & 9 & 11 \\
\hline Ukraine & 3 & 3 & 2 & 2 & 4 & 3 & 4 & 2 & 2 & 2 & 3 & 1 \\
\hline AVERAGE & 9 & 7 & 11 & 8 & 9 & 9 & 7 & 7 & 11 & 12 & 8 & 7 \\
\hline Latvia & 7 & 6 & 9 & & 6 & 8 & 5 & 7 & 7 & 10 & . & \\
\hline Spain & 11 & 16 & 15 & 15 & 13 & 10 & 19 & 14 & 16 & 14 & 16 & 14 \\
\hline United States & 27 & & 16 & 14 & 26 & 28 & . & . & 15 & 17 & 13 & 16 \\
\hline
\end{tabular}

a Official name former Yugoslav Republic of Macedonia. 


\section{Early onset of substance use}

\begin{tabular}{|l|r|r|r|}
\multicolumn{4}{c}{$\begin{array}{c}\text { ESPAD average } \\
\text { Early onset of substance use (\%) a }\end{array}$} \\
\hline Cigarettes & Average & Min. & Max. \\
\hline Daily smoking & 23 & 9 & 46 \\
\hline Alcohol & 4 & 1 & 8 \\
\hline Intoxication & 47 & 14 & 72 \\
\hline Cannabis & 8 & 2 & 22 \\
\hline Ecstasy & 3 & 1 & 8 \\
\hline Amphetamine/methamphetamine & 1 & 0 & 2 \\
\hline Cocaine/crack & 1 & 0 & 3 \\
\hline
\end{tabular}

a Percentage of students using a substance at the age of 13 or younger.

\section{Cigarettes}

More than one in five ESPAD students (23\%) had smoked cigarettes at the age of 13 or younger (Table $4 a$ ). The proportions vary considerably across countries, from $46 \%$ in Estonia and $45 \%$ in Lithuania to 9-13\% in the former Yugoslav Republic of Macedonia, Iceland, Malta and Norway. Both on average and in most individual countries, more boys than girls have smoked cigarettes at the age of 13 or younger. The largest difference between boys and girls was found in Moldova (33\% versus $8 \%$ ). The highest rates among boys (50-51\%) were found in Estonia and Lithuania. The Czech Republic and the three Baltic countries of Estonia, Latvia and Lithuania had the highest rates among girls (40-41\%).

The ESPAD average for students who began smoking cigarettes on a daily basis at the age of 13 or younger is $4 \%$. The rates were highest in Estonia and Slovakia (8\%) and lowest in Norway (1\%). Due to the small proportion of students reporting onset of daily smoking at an early age, gender differences were generally less than 3 percentage points (ESPAD average: boys $5 \%$, girls $3 \%$ ), even though in the majority of countries more boys than girls reported early onset of daily smoking. The countries with the highest prevalence estimates for boys were Estonia, Lithuania and Slovakia (9\%). Among girls, Bulgaria and Estonia (7\%) were the countries with the highest rates.

\section{Alcohol}

Nearly half of the students (47\%) reported alcohol use at the age of 13 or younger (Table $4 a$ ). The highest proportions of students reporting alcohol use at an early age were found in Georgia (72\%), the Czech Republic (68 \%) and Cyprus (66\%). The countries with the lowest rates were Iceland (14\%) and Norway (19\%). Boys were more likely than girls to have used alcohol at the age of 13 or younger, with the highest gender difference found in Albania (61\% for boys versus $37 \%$ for girls) and Montenegro (58\% versus $36 \%$ ).

One in twelve students experienced intoxication at the age of 13 or younger. The proportion of students reporting intoxication at an early age varied across countries: Georgia (22\%) and Estonia (15\%) were at the high end and Iceland (2\%) and Belgium (Flanders) (3\%) were at the low end of the scale. Higher rates were more likely to be found in the eastern part of Europe. In general, more boys than girls reported intoxication at an early age (ESPAD average: $9 \%$ versus $6 \%$, respectively).

\section{Illicit drugs}

On average, $3 \%$ of the students reported that they had first used cannabis at the age of 13 or younger (Table $4 b)$. The highest proportions were found in Monaco (8\%), France and Liechtenstein (6 \% each). Rates of early onset of amphetamine/methamphetamine use were lower (ESPAD average: $1 \%)$, with the highest proportions in Bulgaria (3\%) and Cyprus (2\%). Boys were more likely than girls to have used cannabis or amphetamine/methamphetamine at the age of 13 or younger. Similar results were found for early onset of ecstasy and cocaine/crack use. 
Table 4a. Early onset of substance use: prevalence of students experiencing substance use (cigarettes, daily smoking, alcohol, intoxication) at the age of 13 or younger (percentage)

\begin{tabular}{|c|c|c|c|c|c|c|c|c|c|c|c|c|}
\hline \multirow{2}{*}{ Country } & \multirow{2}{*}{ Cigarettes } & \multirow{2}{*}{$\begin{array}{c}\text { Daily } \\
\text { smoking }\end{array}$} & \multirow{2}{*}{ Alcohol } & \multirow{2}{*}{$\begin{array}{l}\text { Intoxi- } \\
\text { cation }\end{array}$} & \multicolumn{2}{|c|}{ Cigarettes } & \multicolumn{2}{|c|}{ Daily smoking } & \multicolumn{2}{|c|}{ Alcohol } & \multicolumn{2}{|c|}{ Intoxication } \\
\hline & & & & & Boys & Girls & Boys & Girls & Boys & Girls & Boys & Girls \\
\hline Albania & 23 & 2 & 48 & 7 & 31 & 16 & 3 & 1 & 61 & 37 & 11 & 3 \\
\hline Austria & 24 & 3 & 36 & 6 & 26 & 22 & 3 & 3 & 37 & 34 & 8 & 5 \\
\hline Belgium (Flanders) & 14 & 3 & 32 & 3 & 16 & 12 & 3 & 2 & 35 & 29 & 4 & 2 \\
\hline Bulgaria & 25 & 7 & 65 & 13 & 24 & 26 & 7 & 7 & 69 & 61 & 17 & 9 \\
\hline Croatia & 32 & 5 & 64 & 11 & 35 & 29 & 7 & 4 & 70 & 59 & 14 & 7 \\
\hline Cyprus & 17 & 4 & 66 & 8 & 22 & 11 & 6 & 3 & 73 & 60 & 12 & 5 \\
\hline Czech Republic & 43 & 6 & 68 & 10 & 45 & 40 & 7 & 6 & 72 & 65 & 11 & 9 \\
\hline Denmark & 14 & 2 & 50 & 7 & 16 & 13 & 2 & 2 & 55 & 45 & 7 & 6 \\
\hline Estonia & 46 & 8 & 58 & 15 & 51 & 41 & 9 & 7 & 59 & 56 & 17 & 14 \\
\hline Faroes & 21 & 2 & 31 & 5 & 27 & 15 & 2 & 2 & 36 & 26 & 7 & 3 \\
\hline Finland & 27 & 6 & 33 & 8 & 32 & 23 & 8 & 4 & 37 & 28 & 9 & 8 \\
\hline FYR Macedonia ${ }^{a}$ & 12 & 3 & 32 & 5 & 17 & 7 & 4 & 2 & 41 & 23 & 9 & 2 \\
\hline France & 27 & 5 & 57 & 4 & 30 & 24 & 5 & 5 & 60 & 53 & 5 & 3 \\
\hline Georgia & 21 & 4 & 72 & 22 & 28 & 13 & 6 & 2 & 78 & 65 & 29 & 13 \\
\hline Greece & 14 & 2 & 62 & 5 & 18 & 11 & 2 & 1 & 70 & 54 & 7 & 3 \\
\hline Hungary & 28 & 5 & 63 & 10 & 32 & 25 & 6 & 5 & 69 & 58 & 12 & 8 \\
\hline Iceland & 9 & 2 & 14 & 2 & 11 & 7 & 2 & 2 & 16 & 12 & 2 & 2 \\
\hline Ireland & 16 & 3 & 27 & 7 & 19 & 13 & 4 & 2 & 31 & 23 & 8 & 6 \\
\hline Italy & 21 & 4 & 45 & 4 & 23 & 20 & 4 & 3 & 51 & 38 & 6 & 2 \\
\hline Liechtenstein & 23 & 5 & 35 & 8 & 22 & 24 & 4 & 5 & 34 & 36 & 9 & 8 \\
\hline Lithuania & 45 & 7 & 52 & 9 & 50 & 40 & 9 & 5 & 53 & 51 & 11 & 6 \\
\hline Malta & 13 & 3 & 54 & 8 & 11 & 14 & 3 & 4 & 54 & 53 & 8 & 8 \\
\hline Moldova & 21 & 2 & 56 & 7 & 33 & 8 & 3 & 1 & 62 & 48 & 10 & 3 \\
\hline Monaco & 31 & 6 & 61 & 7 & 33 & 28 & 6 & 6 & 65 & 56 & 9 & 6 \\
\hline Montenegro & 17 & 3 & 47 & 6 & 19 & 14 & 4 & 2 & 58 & 36 & 10 & 2 \\
\hline Netherlands & 16 & 3 & 26 & 4 & 19 & 14 & 4 & 3 & 28 & 24 & 4 & 4 \\
\hline Norway & 13 & 1 & 19 & 4 & 15 & 11 & 1 & 1 & 21 & 16 & 4 & 3 \\
\hline Poland & 28 & 4 & 41 & 6 & 32 & 24 & 5 & 4 & 45 & 38 & 8 & 5 \\
\hline Portugal & 24 & 5 & 41 & 5 & 25 & 23 & 4 & 5 & 43 & 39 & 6 & 5 \\
\hline Romania & 23 & 5 & 51 & 8 & 27 & 19 & 7 & 4 & 59 & 44 & 13 & 4 \\
\hline Slovakia & 36 & 8 & 63 & 14 & 41 & 30 & 9 & 6 & 66 & 60 & 14 & 13 \\
\hline Slovenia & 21 & 2 & 59 & 7 & 21 & 20 & 2 & 2 & 64 & 54 & 9 & 5 \\
\hline Sweden & 16 & 3 & 26 & 6 & 16 & 16 & 2 & 3 & 29 & 23 & 6 & 6 \\
\hline Ukraine & 31 & 5 & 53 & 6 & 37 & 25 & 8 & 2 & 54 & 53 & 8 & 5 \\
\hline AVERAGE & 23 & 4 & 47 & 8 & 27 & 20 & 5 & 3 & 52 & 43 & 9 & 6 \\
\hline Latvia & 47 & 10 & 63 & 15 & 54 & 41 & 11 & 8 & 65 & 61 & 16 & 13 \\
\hline Spain & 14 & 3 & & & 14 & 14 & 3 & 3 & . & . & & . \\
\hline United States & 12 & 2 & 23 & 9 & & . & . & . & . & & & \\
\hline
\end{tabular}

a Official name former Yugoslav Republic of Macedonia. 
Table 4b. Early onset of substance use: prevalence of students experiencing substance use (cannabis, ecstasy, amphetamine/methamphetamine, cocaine/crack) at the age of 13 or younger (percentage)

\begin{tabular}{|c|c|c|c|c|c|c|c|c|c|c|c|c|}
\hline \multirow[t]{2}{*}{ Country } & \multirow[t]{2}{*}{ Cannabis } & \multirow[t]{2}{*}{ Ecstasy } & \multirow{2}{*}{$\begin{array}{l}\text { Amphet- } \\
\text { amine/meth- } \\
\text { amphetamine }\end{array}$} & \multirow[t]{2}{*}{$\begin{array}{l}\text { Co- } \\
\text { caine/ } \\
\text { crack }\end{array}$} & \multicolumn{2}{|c|}{ Cannabis } & \multicolumn{2}{|c|}{ Ecstasy } & \multicolumn{2}{|c|}{$\begin{array}{l}\text { Amphetamine/ } \\
\text { methaphet- } \\
\text { amine }\end{array}$} & \multicolumn{2}{|c|}{ Cocaine/crack } \\
\hline & & & & & Boys & Girls & Boys & Girls & Boys & Girls & Boys & Girls \\
\hline Albania & 3 & 1 & 1 & 1 & 5 & 0 & 1 & 1 & 2 & 1 & 1 & 1 \\
\hline Austria & 2 & 0 & 0 & 0 & 2 & 2 & 0 & 0 & 0 & 0 & 0 & 0 \\
\hline Belgium (Flanders) & 2 & 0 & 0 & 0 & 3 & 1 & 0 & 0 & 0 & 0 & 0 & 0 \\
\hline Bulgaria & 5 & 2 & 3 & 2 & 6 & 4 & 2 & 1 & 3 & 2 & 3 & 1 \\
\hline Croatia & 3 & 1 & 1 & 1 & 4 & 2 & 1 & 0 & 1 & 0 & 1 & 0 \\
\hline Cyprus & 2 & 2 & 2 & 2 & 3 & 1 & 3 & 0 & 3 & 1 & 3 & 0 \\
\hline Czech Republic & 5 & 0 & 0 & 0 & 5 & 5 & 0 & 0 & 0 & 0 & 1 & 0 \\
\hline Denmark & 2 & 0 & 0 & 0 & 3 & 1 & 1 & 0 & 0 & 0 & 1 & 0 \\
\hline Estonia & 4 & 0 & 0 & 0 & 5 & 3 & 1 & 0 & 0 & 0 & 0 & 0 \\
\hline Faroes & 2 & 0 & 0 & 0 & 1 & 3 & 0 & 0 & 0 & 0 & 0 & 0 \\
\hline Finland & 1 & 0 & 0 & 0 & 1 & 1 & 0 & 0 & 0 & 0 & 0 & 0 \\
\hline FYR Macedonia ${ }^{\mathrm{b}}$ & 1 & 0 & 1 & 0 & 2 & 1 & 1 & 0 & 1 & 0 & 1 & 0 \\
\hline France & 6 & 1 & 1 & 1 & 8 & 5 & 1 & 1 & 1 & 0 & 1 & 1 \\
\hline Georgia & 2 & 1 & 0 & 1 & 4 & 1 & 1 & 0 & 1 & 0 & 1 & 0 \\
\hline Greece & 1 & 1 & 0 & 1 & 2 & 1 & 1 & 0 & 1 & 0 & 1 & 0 \\
\hline Hungary & 2 & 1 & 1 & 0 & 2 & 1 & 1 & 1 & 1 & 1 & 0 & 1 \\
\hline Iceland & 2 & 0 & 1 & 1 & 3 & 2 & 1 & 0 & 1 & 1 & 1 & 0 \\
\hline Ireland & 5 & 1 & 1 & 1 & 6 & 3 & 2 & 0 & 1 & 0 & 1 & 0 \\
\hline Italy & 4 & 1 & 1 & 1 & 6 & 3 & 1 & 0 & 1 & 0 & 1 & 0 \\
\hline Liechtenstein & 6 & 0 & 0 & 0 & 6 & 6 & 1 & 0 & 1 & 0 & 1 & 0 \\
\hline Lithuania & 2 & 1 & 1 & 1 & 3 & 2 & 1 & 0 & 1 & 0 & 1 & 0 \\
\hline Malta & 3 & 1 & 0 & 0 & 3 & 2 & 1 & 0 & 0 & 0 & 0 & 0 \\
\hline Moldova & 1 & 0 & 0 & 0 & 1 & 1 & 0 & 0 & 1 & 0 & 0 & 0 \\
\hline Monaco & 8 & 1 & 1 & 1 & 10 & 7 & 1 & 0 & 1 & 1 & 1 & 1 \\
\hline Montenegro & 2 & 1 & 1 & 1 & 3 & 1 & 2 & 0 & 2 & 0 & 2 & 0 \\
\hline Netherlands & 5 & 1 & 1 & 1 & 6 & 3 & 1 & 1 & 1 & 0 & 0 & 1 \\
\hline Norway & 1 & 0 & 0 & 0 & 2 & 0 & 0 & 0 & 0 & 0 & 0 & 0 \\
\hline Poland & 5 & 1 & 1 & 1 & 6 & 3 & 1 & 1 & 2 & 1 & 1 & 1 \\
\hline Portugal & 3 & 0 & 0 & & 4 & 2 & 0 & 0 & 0 & 0 & & \\
\hline Romania & 1 & 1 & 1 & 1 & 2 & 1 & 1 & 0 & 1 & 0 & 1 & 0 \\
\hline Slovakia & 5 & 0 & 1 & 0 & 6 & 5 & 0 & 0 & 1 & 0 & 0 & 0 \\
\hline Slovenia & 4 & 0 & 0 & 0 & 4 & 3 & 0 & 0 & 1 & 0 & 1 & 0 \\
\hline Sweden & 1 & 0 & 1 & 0 & 2 & 1 & 1 & 0 & 1 & 0 & 1 & 0 \\
\hline Ukraine & 1 & 0 & 0 & 0 & 2 & 0 & 1 & 0 & 1 & 0 & 1 & 0 \\
\hline AVERAGE & 3 & 1 & 1 & 1 & 4 & 2 & 1 & 0 & 1 & 0 & 1 & 0 \\
\hline Latvia & 4 & 1 & 1 & 2 & 5 & 2 & 2 & 1 & 2 & 0 & 2 & 1 \\
\hline Spain & 4 & 0 & 0 & 0 & 5 & 3 & 0 & 0 & 0 & 0 & 1 & 0 \\
\hline United States a & 13 & 1 & 3 & 1 & . & & . & . & . & . & . & . \\
\hline
\end{tabular}

a Used by end of 8th grade, approximate age is 13 (amphetamines only, cocaine only, tranquillisers only).

b Official name former Yugoslav Republic of Macedonia. 


\section{Cigarette use}

\begin{tabular}{l|c|c|c|}
\multicolumn{4}{c}{$\begin{array}{c}\text { ESPAD average } \\
\text { Cigarette use (\%) }\end{array}$} \\
\hline & Average & Min. & Max. \\
\hline Lifetime & 46 & 16 & 66 \\
\hline Last 30 days & 21 & 6 & 37 \\
\hline
\end{tabular}

a Percentage of students reporting use of cigarettes.

\section{Lifetime}

Lifetime prevalence rates of cigarette smoking range between $16 \%$ and $66 \%$ (Table 5). In 15 of the 35 ESPAD countries, more than half of the students had tried smoking at least once. The highest prevalence rates were found in the Czech Republic (66 \%), followed by Lithuania (65 \%), Croatia and Slovakia (62\% each). The lowest rates were found in Iceland (16\%), Norway (28\%) and Malta (29\%). These rates were well below the average of $46 \%$ for all

Table 5. $\quad$ Cigarette use: prevalence of lifetime and 30-day use (percentage)

\begin{tabular}{|c|c|c|c|c|c|c|}
\hline \multirow{2}{*}{ Country } & \multirow{2}{*}{ Lifetime } & \multirow{2}{*}{ 30-day } & \multicolumn{2}{|c|}{ Lifetime } & \multicolumn{2}{|c|}{ 30-day } \\
\hline & & & Boys & Girls & Boys & Girls \\
\hline Albania & 37 & 11 & 49 & 27 & 18 & 5 \\
\hline Austria & 53 & 28 & 54 & 53 & 27 & 28 \\
\hline Belgium (Flanders) & 31 & 15 & 33 & 29 & 16 & 14 \\
\hline Bulgaria & 55 & 33 & 51 & 60 & 30 & 37 \\
\hline Croatia & 62 & 33 & 61 & 63 & 32 & 34 \\
\hline Cyprus & 35 & 18 & 40 & 31 & 22 & 13 \\
\hline Czech Republic & 66 & 30 & 65 & 67 & 27 & 32 \\
\hline Denmark & 39 & 19 & 37 & 41 & 17 & 21 \\
\hline Estonia & 60 & 21 & 62 & 57 & 22 & 21 \\
\hline Faroes & 49 & 19 & 50 & 49 & 17 & 20 \\
\hline Finland & 47 & 22 & 50 & 44 & 22 & 21 \\
\hline FYR Macedonia $^{a}$ & 38 & 24 & 44 & 33 & 27 & 21 \\
\hline France & 55 & 26 & 54 & 56 & 24 & 28 \\
\hline Georgia & 43 & 18 & 54 & 30 & 26 & 9 \\
\hline Greece & 39 & 19 & 41 & 37 & 21 & 17 \\
\hline Hungary & 55 & 29 & 55 & 55 & 28 & 30 \\
\hline Iceland & 16 & 6 & 16 & 16 & 5 & 7 \\
\hline Ireland & 32 & 13 & 33 & 32 & 13 & 13 \\
\hline Italy & 58 & 37 & 55 & 60 & 35 & 40 \\
\hline Liechtenstein & 57 & 29 & 56 & 58 & 27 & 31 \\
\hline Lithuania & 65 & 24 & 69 & 60 & 27 & 22 \\
\hline Malta & 29 & 15 & 25 & 33 & 12 & 18 \\
\hline Moldova & 33 & 9 & 50 & 15 & 16 & 3 \\
\hline Monaco & 56 & 26 & 51 & 61 & 20 & 33 \\
\hline Montenegro & 34 & 15 & 37 & 31 & 18 & 12 \\
\hline Netherlands & 39 & 21 & 38 & 39 & 20 & 21 \\
\hline Norway & 28 & 10 & 29 & 26 & 10 & 10 \\
\hline Poland & 55 & 25 & 56 & 54 & 24 & 25 \\
\hline Portugal & 37 & 19 & 37 & 37 & 18 & 21 \\
\hline Romania & 52 & 30 & 53 & 51 & 31 & 30 \\
\hline Slovakia & 62 & 31 & 62 & 61 & 29 & 34 \\
\hline Slovenia & 47 & 22 & 44 & 50 & 19 & 25 \\
\hline Sweden & 33 & 13 & 33 & 34 & 11 & 14 \\
\hline Ukraine & 51 & 18 & 59 & 44 & 23 & 13 \\
\hline AVERAGE & 46 & 21 & 47 & 44 & 22 & 21 \\
\hline Latvia & 66 & 24 & 70 & 61 & 24 & 25 \\
\hline Spain & 37 & 22 & 35 & 39 & 20 & 23 \\
\hline United States & 20 & 6 & 20 & 19 & 6 & 6 \\
\hline
\end{tabular}

a Official name former Yugoslav Republic of Macedonia. 
ESPAD countries. The average prevalence of cigarette smoking was about the same among boys (47\%) and girls (44\%). Across countries, boys were generally more likely than girls to have tried cigarettes. Countries with the largest gender differences were Moldova (50\% for boys versus $15 \%$ for girls), Georgia (54 \% versus $30 \%$ ) and Albania (49\% versus $27 \%$ ). The largest gender differences where girls reported higher rates were found in Monaco (61\% for girls versus $51 \%$ for boys), Bulgaria (60 \% versus $51 \%$ ) and Malta (33 \% versus $25 \%$ ).

\section{Last 30 days}

On average, $21 \%$ of the students in the ESPAD countries had used cigarettes during the last 30 days. The highest rates were found in Italy (37\%), Bulgaria and Croatia (33\% each). Countries which reported last-30-day prevalence of $10 \%$ or lower include Iceland (6 \%), Moldova (9\%) and Norway (10 \%). Countries with high smoking rates for boys were Italy, Romania and Croatia (31-35 \%), and countries with high smoking rates for girls were Italy, Bulgaria, Slovakia and Croatia (34-40 \%). The average ESPAD rates for boys and girls were about the same, and the gender rates were also close in most countries. In four countries, there are noticeable gender differences, with higher rates among boys than among girls: Georgia (26\% versus $9 \%$ ), Moldova (16\% versus $3 \%$ ), Albania (18\% versus $5 \%$ ) and Ukraine (23\% versus $13 \%$ ). In Monaco, rates were higher among girls than boys (33\% versus $20 \%$ ) as well as in Slovenia (25\% versus $19 \%$ ) and Malta (18\% versus $12 \%$ ).

\section{Alcohol use}

\begin{tabular}{l|c|c|c|}
\multicolumn{4}{c}{$\begin{array}{l}\text { ESPAD average } \\
\text { Alcohol use (\%) }\end{array}$} \\
\hline & Average & Min. & Max. \\
\hline Lifetime & 80 & 35 & 96 \\
\hline Last 30 days & 48 & 9 & 73 \\
\hline Intoxication $^{\mathrm{b}}$ & 13 & 3 & 32 \\
\hline
\end{tabular}

a Percentage of students reporting use of alcohol.

b Percentage of students having been intoxicated at least once in the last 30 days.

\section{Lifetime}

In all ESPAD countries except Iceland (35\%), over half of the students have drunk alcohol at least once during their lifetime (Table 6). The ESPAD average was $80 \%$ (range: 35-96 \%). The highest rates of lifetime alcohol prevalence (93\% or more) were found in the Czech Republic, Greece and Hungary. In addition to Iceland, countries with relatively low rates (60\% or less) were Albania, the former Yugoslav Republic of Macedonia and Norway. Large differences between boys and girls were observed in Albania (71\% versus $51 \%$ ), the former Yugoslav Republic of Macedonia (64 \% versus $51 \%$ ) and Montenegro (83 \% versus $72 \%$ ). A higher proportion for girls than boys was found in Belgium (Flanders) (83\% versus $77 \%$ ).

\section{Last 30 days}

Overall, $48 \%$ of the students in the ESPAD countries had consumed alcohol during the 30 days prior to the survey. In Austria, Cyprus, the Czech Republic, Denmark and Greece, two thirds (66 \%) or more had done so. A particularly low prevalence rate was reported from Iceland ( $9 \%$ ). All of the Nordic countries except Denmark reported relatively low rates (below $40 \%$ ). This was also the case for Albania, Estonia, the Faroes, the former Yugoslav Republic of Macedonia, Ireland, Lithuania and Ukraine. On average, more boys than girls have drunk alcohol during the 30 days prior to the survey. Countries with particularly large gender differences in this direction (18-20 percentage points) were Albania, Georgia, Montenegro and Romania. In four countries, more girls than boys (5 percentage points and more) reported alcohol use during the last 30 days (Sweden, the Faroes, Monaco and Norway)

\section{Intoxication}

An average of $13 \%$ of students reported having been intoxicated during the last 30 days. Denmark had the highest prevalence at almost one third of the students (32\%). Countries with levels of $10 \%$ or less were Albania, Estonia, the Faroes, the former Yugoslav Republic of Macedonia, Georgia, Greece, Iceland, Moldova, Montenegro, Norway, Portugal, Sweden and Ukraine. On average, slightly more boys (13\%) than girls (12\%) reported that they had been intoxicated during the 30 days prior to the survey, with the highest differences in Cyprus (19\% for boys and $10 \%$ for girls), Romania (16\% versus $7 \%$ ) and Montenegro (12\% versus $4 \%$ ). In the Faroes and Malta, noticeably more girls than boys reported intoxication. 
Table 6. Alcohol use: prevalence of lifetime use, 30-day use and intoxication (percentage)

\begin{tabular}{|c|c|c|c|c|c|c|c|c|c|}
\hline \multirow{2}{*}{ Country } & \multirow{2}{*}{ Lifetime use } & \multirow{2}{*}{ 30-day use } & \multirow{2}{*}{$\begin{array}{l}\text { Intoxication } \\
\text { last } 30 \text { days }\end{array}$} & \multicolumn{2}{|c|}{ Lifetime use } & \multicolumn{2}{|c|}{ 30-day use } & \multicolumn{2}{|c|}{ Intoxication } \\
\hline & & & & Boys & Girls & Boys & Girls & Boys & Girls \\
\hline Albania & 60 & 32 & 7 & 71 & 51 & 42 & 23 & 10 & 4 \\
\hline Austria & 88 & 68 & 21 & 86 & 90 & 67 & 69 & 22 & 19 \\
\hline Belgium (Flanders) & 80 & 56 & 12 & 77 & 83 & 55 & 58 & 11 & 12 \\
\hline Bulgaria & 86 & 59 & 17 & 88 & 85 & 60 & 57 & 20 & 14 \\
\hline Croatia & 92 & 55 & 16 & 94 & 91 & 60 & 49 & 17 & 14 \\
\hline Cyprus & 88 & 68 & 14 & 90 & 87 & 72 & 63 & 19 & 10 \\
\hline Czech Republic & 96 & 68 & 15 & 95 & 97 & 70 & 67 & 18 & 12 \\
\hline Denmark & 92 & 73 & 32 & 93 & 92 & 74 & 73 & 31 & 32 \\
\hline Estonia & 86 & 38 & 8 & 87 & 86 & 36 & 39 & 8 & 7 \\
\hline Faroes & 81 & 38 & 10 & 84 & 78 & 35 & 41 & 7 & 13 \\
\hline Finland & 74 & 32 & 13 & 75 & 72 & 32 & 32 & 13 & 13 \\
\hline FYR Macedonia ${ }^{a}$ & 57 & 38 & 8 & 64 & 51 & 45 & 32 & 10 & 6 \\
\hline France & 84 & 53 & 13 & 85 & 83 & 56 & 51 & 14 & 12 \\
\hline Georgia & 85 & 43 & 10 & 86 & 83 & 53 & 33 & 13 & 7 \\
\hline Greece & 94 & 66 & 10 & 95 & 93 & 68 & 65 & 11 & 9 \\
\hline Hungary & 93 & 55 & 20 & 94 & 92 & 59 & 52 & 21 & 19 \\
\hline Iceland & 35 & 9 & 3 & 36 & 33 & 9 & 10 & 3 & 3 \\
\hline Ireland & 74 & 35 & 13 & 72 & 75 & 34 & 36 & 14 & 13 \\
\hline Italy & 84 & 57 & 13 & 85 & 84 & 60 & 53 & 14 & 13 \\
\hline Liechtenstein & 89 & 59 & 17 & 93 & 86 & 60 & 59 & 19 & 16 \\
\hline Lithuania & 87 & 34 & 11 & 85 & 89 & 32 & 36 & 10 & 11 \\
\hline Malta & 86 & 54 & 14 & 84 & 88 & 52 & 56 & 12 & 17 \\
\hline Moldova & 82 & 56 & 8 & 86 & 78 & 62 & 50 & 11 & 5 \\
\hline Monaco & 89 & 54 & 17 & 88 & 90 & 52 & 57 & 15 & 18 \\
\hline Montenegro & 78 & 40 & 8 & 83 & 72 & 50 & 31 & 12 & 4 \\
\hline Netherlands & 73 & 49 & 14 & 73 & 73 & 50 & 49 & 13 & 16 \\
\hline Norway & 57 & 22 & 8 & 56 & 58 & 20 & 25 & 8 & 9 \\
\hline Poland & 83 & 47 & 11 & 84 & 83 & 49 & 46 & 12 & 11 \\
\hline Portugal & 71 & 42 & 9 & 73 & 70 & 43 & 41 & 9 & 9 \\
\hline Romania & 78 & 47 & 12 & 84 & 72 & 56 & 38 & 16 & 7 \\
\hline Slovakia & 91 & 49 & 13 & 90 & 91 & 48 & 51 & 12 & 13 \\
\hline Slovenia & 89 & 52 & 14 & 90 & 88 & 55 & 50 & 14 & 14 \\
\hline Sweden & 65 & 26 & 9 & 64 & 66 & 22 & 29 & 7 & 11 \\
\hline Ukraine & 84 & 39 & 9 & 82 & 86 & 38 & 40 & 9 & 8 \\
\hline AVERAGE & 80 & 48 & 13 & 81 & 79 & 49 & 46 & 13 & 12 \\
\hline Latvia & 89 & 44 & 12 & 88 & 90 & 42 & 45 & 14 & 11 \\
\hline Spain & 78 & 65 & 21 & 76 & 80 & 63 & 68 & 20 & 21 \\
\hline United States & 47 & 22 & 10 & 44 & 50 & 21 & 22 & 10 & 10 \\
\hline
\end{tabular}

a Official name former Yugoslav Republic of Macedonia. 


\section{Illicit drug use}

\begin{tabular}{l|c|c|c|}
\multicolumn{4}{c}{ ESPAD average } \\
Lifetime use of illicit drugs (\%) & & \\
\hline & Average & Min. & Max. \\
\hline Any illicit drug & 18 & 6 & 37 \\
\hline Cannabis & 16 & 4 & 37 \\
\hline Ecstasy & 2 & 0 & 5 \\
\hline Amphetamine & 2 & 0 & 6 \\
\hline Methamphetamine & 1 & 0 & 5 \\
\hline Cocaine & 2 & 0 & 5 \\
\hline Crack & 1 & 0 & 3 \\
\hline LSD or other hallucinogens & 2 & 0 & 5 \\
\hline Heroin & 1 & 0 & 3 \\
\hline GHB & 1 & 0 & 3 \\
\hline
\end{tabular}

a Percentage of students reporting use of illicit drugs.

\section{Any drug use}

Lifetime use of illicit drugs varied considerably across the ESPAD countries (Table 7a). In the Czech Republic, $37 \%$ of the students reported having used any illicit drug at least once, which was more than twice the ESPAD average of $18 \%$. Students in Bulgaria, France, Liechtenstein and Monaco also exhibit high levels of drug use experience (30-32 \%). Particularly low levels (10\% or less) of illicit drug use were noted in Albania, Cyprus, the Faroes, Finland, the former Yugoslav Republic of Macedonia, Iceland, Moldova, Montenegro, Norway, Sweden and Ukraine. On average, 21 \% of boys and $15 \%$ of girls have tried illicit drugs at least once during their lifetime. In most ESPAD countries, prevalence rates were higher among boys than among girls. Noticeable gender differences were found in Georgia ( $24 \%$ for boys and $6 \%$ for girls), Liechtenstein (40 \% versus $23 \%$ ) and Albania (18\% versus $4 \%$ ).

\section{Cannabis use}

The most prevalent illicit drug in all ESPAD countries is cannabis. On average, $16 \%$ of the students have used cannabis at least once in their lifetime (Table 7a). The country with the highest prevalence of cannabis use was the Czech Republic (37\%). High prevalence rates (30\% or more) were also reported in France, Liechtenstein and Monaco. The lowest levels of cannabis use (4-7 \%) were reported in Albania, Cyprus, the Faroes, the former Yugoslav Republic of Macedonia, Iceland, Moldova, Norway and Sweden. On average, boys reported cannabis use to a larger extent than girls (19\% versus $14 \%$ ). This was the case in nearly all countries except the Czech Republic, the Faroes, Hungary, Iceland, Malta, Slovenia and Sweden, where rates were about the same for boys and girls. The largest gender differences (10 percentage points or more, higher rates among boys) were found in Albania, Georgia and Liechtenstein.

\section{Other illicit drug use}

Besides cannabis, some students have also used other illicit substances. In some cases, they have done so without any experience of cannabis at all. Among the most frequently tried illicit drugs are ecstasy, amphetamine, cocaine and LSD or other hallucinogens (Tables 7a, 7b). In the case of illicit drugs other than cannabis, on average, 1-2\% of the ESPAD students reported having used them at least once. Lifetime prevalence rates for methamphetamine, crack, heroin and GHB were lower than those for the other illicit drugs ( $1 \%$ on average). At the country level, higher rates ( $5 \%$ or more) were found in Bulgaria (ecstasy, amphetamine, methamphetamine, cocaine) and Poland (LSD or other hallucinogens). The most marked gender differences are seen in Georgia (ecstasy: $7 \%$ for boys and $1 \%$ for girls) and Albania (cocaine: $6 \%$ versus $1 \%$ ). 
Table 7a. Illicit drug use: lifetime prevalence of the use of any drug, cannabis, ecstasy, amphetamine and methamphetamine (percentage)

\begin{tabular}{|c|c|c|c|c|c|c|c|c|c|c|c|c|c|c|c|}
\hline \multirow{2}{*}{ Country } & \multirow{2}{*}{$\begin{array}{l}\text { Any } \\
\text { drug }\end{array}$} & \multirow{2}{*}{$\begin{array}{l}\text { Can- } \\
\text { nabis }\end{array}$} & \multirow{2}{*}{$\begin{array}{l}\text { Ec- } \\
\text { stasy }\end{array}$} & \multirow{2}{*}{$\begin{array}{l}\text { Am- } \\
\text { phet- } \\
\text { amine }\end{array}$} & \multirow{2}{*}{$\begin{array}{l}\text { Meth- } \\
\text { am- } \\
\text { phet- } \\
\text { amine }\end{array}$} & \multicolumn{2}{|c|}{ Any drug } & \multicolumn{2}{|c|}{ Cannabis } & \multicolumn{2}{|c|}{ Ecstasy } & \multicolumn{2}{|c|}{ Amphetamine } & \multicolumn{2}{|c|}{$\begin{array}{l}\text { Metham- } \\
\text { phetamine }\end{array}$} \\
\hline & & & & & & Boys & Girls & Boys & Girls & Boys & Girls & Boys & Girls & Boys & Girls \\
\hline Albania & 10 & 7 & 3 & 2 & 2 & 18 & 4 & 13 & 2 & 4 & 1 & 2 & 1 & 2 & 1 \\
\hline Austria & 21 & 20 & 2 & 3 & 1 & 23 & 19 & 22 & 18 & 2 & 2 & 3 & 3 & 1 & 1 \\
\hline $\begin{array}{l}\text { Belgium } \\
\text { (Flanders) }\end{array}$ & 18 & 17 & 3 & 2 & 1 & 21 & 15 & 21 & 14 & 3 & 3 & 2 & 3 & 1 & 1 \\
\hline Bulgaria & 30 & 27 & 5 & 6 & 5 & 32 & 27 & 29 & 25 & 6 & 4 & 7 & 6 & 6 & 4 \\
\hline Croatia & 22 & 21 & 2 & 3 & 1 & 25 & 20 & 24 & 19 & 2 & 2 & 3 & 2 & 2 & 1 \\
\hline Cyprus & 10 & 7 & 3 & 3 & 2 & 14 & 7 & 10 & 5 & 4 & 1 & 4 & 1 & 3 & 1 \\
\hline Czech Republic & 37 & 37 & 3 & 1 & 1 & 36 & 38 & 36 & 38 & 3 & 2 & 1 & 1 & 1 & 2 \\
\hline Denmark & 13 & 12 & 1 & 1 & 0 & 16 & 10 & 15 & 10 & 1 & 0 & 1 & 0 & 1 & 0 \\
\hline Estonia & 26 & 25 & 3 & 2 & . & 30 & 22 & 30 & 21 & 3 & 2 & 2 & 2 & . & . \\
\hline Faroes & 6 & 6 & 0 & 0 & 0 & 6 & 6 & 6 & 6 & 0 & 1 & 0 & 0 & 0 & 1 \\
\hline Finland & 9 & 8 & 1 & 1 & 0 & 10 & 8 & 10 & 7 & 1 & 1 & 1 & 1 & 1 & 0 \\
\hline $\begin{array}{l}\text { FYR } \\
\text { Macedonia }^{a}\end{array}$ & 7 & 5 & 2 & 1 & 1 & 10 & 4 & 8 & 3 & 3 & 2 & 2 & 1 & 2 & 0 \\
\hline France & 32 & 31 & 2 & 2 & 2 & 35 & 30 & 34 & 29 & 2 & 2 & 2 & 3 & 1 & 2 \\
\hline Georgia & 15 & 11 & 4 & 2 & 1 & 24 & 6 & 19 & 3 & 7 & 1 & 3 & 1 & 2 & 0 \\
\hline Greece & 11 & 9 & 1 & 2 & 1 & 15 & 6 & 12 & 6 & 2 & 0 & 2 & 1 & 1 & 1 \\
\hline Hungary & 14 & 13 & 2 & 3 & 2 & 15 & 13 & 14 & 12 & 2 & 2 & 3 & 3 & 2 & 2 \\
\hline Iceland & 8 & 7 & 2 & 2 & 1 & 8 & 8 & 7 & 8 & 2 & 2 & 2 & 2 & 1 & 1 \\
\hline Ireland & 20 & 19 & 4 & 3 & 2 & 23 & 16 & 22 & 15 & 5 & 2 & 3 & 2 & 2 & 1 \\
\hline Italy & 28 & 27 & 3 & 2 & 2 & 33 & 24 & 31 & 23 & 3 & 2 & 3 & 1 & 3 & 1 \\
\hline Liechtenstein & 31 & 30 & 2 & 2 & 0 & 40 & 23 & 40 & 22 & 2 & 1 & 1 & 2 & 1 & 0 \\
\hline Lithuania & 19 & 18 & 2 & 1 & 1 & 21 & 16 & 20 & 15 & 2 & 1 & 1 & 1 & 1 & 1 \\
\hline Malta & 14 & 13 & 2 & 2 & 1 & 14 & 14 & 13 & 12 & 2 & 2 & 2 & 2 & 1 & 1 \\
\hline Moldova & 6 & 4 & 1 & 1 & 0 & 9 & 3 & 7 & 2 & 2 & 1 & 1 & 0 & 1 & 0 \\
\hline Monaco & 31 & 31 & 2 & 2 & 2 & 34 & 29 & 34 & 29 & 2 & 2 & 2 & 2 & 2 & 2 \\
\hline Montenegro & 10 & 8 & 3 & 3 & 2 & 14 & 6 & 11 & 5 & 4 & 3 & 4 & 2 & 3 & 1 \\
\hline Netherlands & 23 & 22 & 3 & 2 & 1 & 25 & 21 & 25 & 20 & 4 & 2 & 3 & 2 & 1 & 0 \\
\hline Norway & 7 & 7 & 1 & 1 & . & 10 & 4 & 9 & 4 & 1 & 1 & 1 & 0 & . & . \\
\hline Poland & 25 & 24 & 3 & 4 & 3 & 29 & 21 & 28 & 20 & 4 & 3 & 5 & 4 & 3 & 3 \\
\hline Portugal & 16 & 15 & 2 & 1 & 1 & 17 & 15 & 17 & 14 & 2 & 2 & 1 & 1 & 1 & 1 \\
\hline Romania & 11 & 8 & 2 & 1 & 1 & 14 & 8 & 10 & 6 & 2 & 2 & 2 & 1 & 1 & 1 \\
\hline Slovakia & 28 & 26 & 3 & 1 & 2 & 29 & 27 & 28 & 25 & 3 & 4 & 1 & 1 & 2 & 1 \\
\hline Slovenia & 26 & 25 & 2 & 1 & 2 & 27 & 25 & 26 & 24 & 2 & 2 & 1 & 1 & 2 & 2 \\
\hline Sweden & 8 & 7 & 1 & 1 & . & 8 & 7 & 7 & 6 & 1 & 1 & 1 & 1 & . & . \\
\hline Ukraine & 10 & 9 & 1 & 1 & 1 & 14 & 7 & 13 & 6 & 2 & 1 & 2 & 1 & 1 & 0 \\
\hline AVERAGE & 18 & 16 & 2 & 2 & 1 & 21 & 15 & 19 & 14 & 3 & 2 & 2 & 2 & 2 & 1 \\
\hline Latvia & 19 & 17 & 3 & 3 & 2 & 23 & 15 & 21 & 12 & 3 & 2 & 2 & 4 & 3 & 2 \\
\hline Spain & 28 & 27 & 1 & 1 & 1 & 30 & 27 & 28 & 25 & 1 & 1 & 2 & 1 & 1 & 0 \\
\hline United States & 35 & 31 & 4 & 10 & 1 & 35 & 35 & 32 & 30 & 4 & 3 & 9 & 11 & 1 & 2 \\
\hline
\end{tabular}

a Official name former Yugoslav Republic of Macedonia. 
Table 7b. Illicit drug use: lifetime prevalence of the use of cocaine, crack, LSD or other hallucinogens, heroin and GHB (percentage)

\begin{tabular}{|c|c|c|c|c|c|c|c|c|c|c|c|c|c|c|c|}
\hline \multirow{2}{*}{ Country } & \multirow{2}{*}{ Cocaine } & \multirow{2}{*}{ Crack } & \multirow{2}{*}{$\begin{array}{l}\text { LSD/other } \\
\text { hallucino- } \\
\text { gens }\end{array}$} & \multirow{2}{*}{ Heroin } & \multirow{2}{*}{ GHB } & \multicolumn{2}{|c|}{ Cocaine } & \multicolumn{2}{|c|}{ Crack } & \multicolumn{2}{|c|}{$\begin{array}{l}\text { LSD/other } \\
\text { Hallucinogens }\end{array}$} & \multicolumn{2}{|c|}{ Heroin } & \multicolumn{2}{|c|}{ GHB } \\
\hline & & & & & & Boys & Girls & Boys & Girls & Boys & Girls & Boys & Girls & Boys & Girls \\
\hline Albania & 3 & 2 & 2 & 2 & 1 & 6 & 1 & 3 & 1 & 3 & 1 & 2 & 1 & 2 & 1 \\
\hline Austria & 2 & 1 & 2 & 1 & 1 & 2 & 2 & 1 & 1 & 2 & 2 & 0 & 1 & 1 & 1 \\
\hline $\begin{array}{l}\text { Belgium } \\
\text { (Flanders) }\end{array}$ & 3 & 1 & 2 & 1 & 1 & 2 & 3 & 1 & 1 & 2 & 1 & 1 & 0 & 0 & 1 \\
\hline Bulgaria & 5 & 3 & 4 & 3 & 3 & 6 & 3 & 5 & 2 & 6 & 3 & 5 & 2 & 4 & 1 \\
\hline Croatia & 2 & 1 & 2 & 1 & 1 & 2 & 2 & 2 & 1 & 3 & 2 & 1 & 1 & 1 & 0 \\
\hline Cyprus & 3 & 2 & 3 & 3 & 2 & 5 & 2 & 4 & 1 & 5 & 2 & 4 & 1 & 4 & 1 \\
\hline Czech Republic & 1 & 1 & 4 & 1 & 0 & 2 & 1 & 1 & 1 & 4 & 4 & 1 & 0 & 0 & 0 \\
\hline Denmark & 2 & 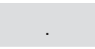 & 1 & 1 & 0 & 3 & 1 & . & . & 2 & 1 & 1 & 0 & 1 & 0 \\
\hline Estonia & 1 & . & 3 & 1 & 1 & 1 & 2 & & . & 3 & 3 & 1 & 1 & 1 & 1 \\
\hline Faroes & 0 & 0 & 0 & 0 & 0 & 0 & 1 & 0 & 0 & 0 & 1 & 0 & 0 & 0 & 0 \\
\hline Finland & 1 & . & 1 & 1 & 0 & 1 & 1 & . & . & 1 & 1 & 1 & 1 & 1 & 0 \\
\hline $\begin{array}{l}\text { FYR } \\
\text { Macedonia }\end{array}$ & 1 & 1 & 1 & 1 & 1 & 2 & 0 & 1 & 0 & 1 & 0 & 1 & 0 & 1 & 0 \\
\hline France & 4 & 3 & 2 & 2 & 1 & 4 & 4 & 3 & 3 & 2 & 2 & 2 & 2 & 1 & 1 \\
\hline Georgia & 2 & 1 & 2 & 2 & 1 & 2 & 1 & 2 & 0 & 4 & 1 & 3 & 1 & 1 & 0 \\
\hline Greece & 1 & 1 & 2 & 1 & 0 & 2 & 0 & 1 & 1 & 3 & 1 & 1 & 0 & 1 & 0 \\
\hline Hungary & 2 & 1 & 2 & 1 & 1 & 3 & 2 & 1 & 1 & 3 & 2 & 1 & 1 & 1 & 2 \\
\hline Iceland & 2 & 1 & 1 & 1 & 0 & 2 & 2 & 1 & 1 & 1 & 2 & 1 & 1 & 0 & 0 \\
\hline Ireland & 3 & 2 & 3 & 1 & 1 & 4 & 2 & 3 & 1 & 3 & 2 & 2 & 0 & 1 & 0 \\
\hline Italy & 3 & 3 & 3 & 2 & 1 & 5 & 2 & 4 & 2 & 4 & 2 & 3 & 1 & 2 & 1 \\
\hline Liechtenstein & 2 & 1 & 2 & 0 & 1 & 2 & 2 & 1 & 0 & 2 & 2 & 0 & 1 & 1 & 1 \\
\hline Lithuania & 2 & 1 & 2 & 1 & 1 & 2 & 2 & 1 & 1 & 2 & 2 & 2 & 1 & 1 & 0 \\
\hline Malta & 3 & 1 & 1 & 1 & 0 & 2 & 3 & 1 & 1 & 1 & 1 & 1 & 1 & 0 & 0 \\
\hline Moldova & 1 & 0 & 1 & 0 & 1 & 1 & 0 & 1 & 0 & 1 & 0 & 1 & 0 & 1 & 0 \\
\hline Monaco & 3 & 2 & 1 & 2 & 1 & 2 & 3 & 2 & 2 & 2 & 0 & 2 & 2 & 1 & 1 \\
\hline Montenegro & 3 & 2 & 3 & 2 & 2 & 5 & 2 & 3 & 1 & 4 & 1 & 3 & 1 & 3 & 1 \\
\hline Netherlands & 2 & 1 & 2 & 1 & 1 & 2 & 1 & 1 & 1 & 2 & 1 & 1 & 1 & 1 & 1 \\
\hline Norway & 1 & 1 & 1 & 0 & 0 & 1 & 0 & 1 & 0 & 1 & 1 & 0 & 0 & 0 & 0 \\
\hline Poland & 4 & 2 & 5 & 2 & 2 & 4 & 3 & 2 & 2 & 5 & 5 & 3 & 2 & 2 & 1 \\
\hline Portugal & 2 & 1 & 1 & 1 & 1 & 2 & 2 & 1 & 1 & 2 & 1 & 1 & 1 & 1 & 0 \\
\hline Romania & 3 & 1 & 2 & 2 & 1 & 3 & 3 & 2 & 1 & 3 & 1 & 2 & 1 & 1 & 1 \\
\hline Slovakia & 2 & 1 & 3 & 1 & 2 & 1 & 2 & 1 & 1 & 3 & 3 & 1 & 2 & 2 & 1 \\
\hline Slovenia & 2 & 1 & 1 & 1 & 0 & 2 & 3 & 1 & 1 & 1 & 2 & 1 & 1 & 0 & 0 \\
\hline Sweden & 2 & . & 1 & 1 & 0 & 2 & 2 & . & . & 2 & 1 & 1 & 1 & 0 & 0 \\
\hline Ukraine & 1 & 1 & 1 & 1 & 0 & 1 & 1 & 1 & 1 & 1 & 1 & 1 & 0 & 1 & 0 \\
\hline AVERAGE & 2 & 1 & 2 & 1 & 1 & 3 & 2 & 2 & 1 & 2 & 2 & 1 & 1 & 1 & 1 \\
\hline Latvia & 2 & 2 & 4 & 2 & 1 & 3 & 2 & 4 & 1 & 3 & 4 & 3 & 1 & 1 & 1 \\
\hline Spain & 2 & 3 & 2 & 1 & 1 & 2 & 2 & 3 & 2 & 2 & 1 & 1 & 0 & 1 & 1 \\
\hline United States & 3 & 1 & 5 & 1 & . & 3 & 2 & 1 & 1 & 5 & 4 & 1 & 1 & & \\
\hline
\end{tabular}

a Official name former Yugoslav Republic of Macedonia. 


\section{Inhalant use}

\begin{tabular}{|l|c|c|c|}
\hline \multicolumn{4}{c}{ ESPAD average } \\
Lifetime use of inhalants (\%) ${ }^{\text {a }}$ \\
\hline & Average & Min. & Max. \\
\hline Inhalants & 7 & 1 & 25 \\
\hline
\end{tabular}

a Percentage of students reporting use of inhalants.
The ESPAD average for lifetime inhalant use was $7 \%$, with large differences between countries (Table 8). The country with the highest proportion of students who have tried inhalants was Croatia (25\%), followed by Slovenia (14\%). The lowest rates (1-2 \%) were found in the Faroes, the former Yugoslav Republic of Macedonia and Moldova. The average prevalence of lifetime inhalant use among ESPAD students was the same for boys and girls. Similar rates for both genders were found in most countries. A noticeable gender difference in the rate of inhalant use was reported in Croatia (19\% for boys versus $32 \%$ for girls).

Table 8. Inhalants and new psychoactive substances (NPS): prevalence of lifetime use (percentage)

\begin{tabular}{|c|c|c|c|c|c|c|}
\hline \multirow{2}{*}{ Country } & \multirow{2}{*}{ Inhalants } & \multirow{2}{*}{ NPS } & \multicolumn{2}{|c|}{ Inhalants } & \multicolumn{2}{|c|}{ NPS } \\
\hline & & & Boys & Girls & Boys & Girls \\
\hline Albania & 4 & 4 & 6 & 2 & 6 & 2 \\
\hline Austria & 10 & 3 & 10 & 9 & 4 & 3 \\
\hline Belgium (Flanders) & 3 & 1 & 3 & 3 & 1 & 0 \\
\hline Bulgaria & 3 & 8 & 4 & 2 & 10 & 7 \\
\hline Croatia & 25 & 7 & 19 & 32 & 7 & 7 \\
\hline Cyprus & 8 & 4 & 9 & 7 & 6 & 2 \\
\hline Czech Republic & 6 & 7 & 5 & 6 & 6 & 7 \\
\hline Denmark & 4 & 1 & 4 & 3 & 2 & 1 \\
\hline Estonia & 13 & 10 & 11 & 14 & 10 & 9 \\
\hline Faroes & 2 & 3 & 3 & 2 & 3 & 4 \\
\hline Finland & 8 & 1 & 7 & 8 & 2 & 1 \\
\hline FYR Macedonia $^{a}$ & 2 & 4 & 3 & 1 & 5 & 3 \\
\hline France & 6 & 4 & 5 & 7 & 5 & 4 \\
\hline Georgia & 12 & 7 & 10 & 14 & 10 & 3 \\
\hline Greece & 13 & 3 & 13 & 13 & 4 & 2 \\
\hline Hungary & 7 & 4 & 6 & 7 & 3 & 4 \\
\hline Iceland & 3 & 3 & 2 & 4 & 2 & 3 \\
\hline Ireland & 11 & 7 & 11 & 10 & 8 & 5 \\
\hline Italy & 3 & 6 & 4 & 3 & 6 & 5 \\
\hline Liechtenstein & 8 & 4 & 11 & 6 & 6 & 3 \\
\hline Lithuania & 8 & 5 & 9 & 7 & 6 & 5 \\
\hline Malta & 8 & 4 & 7 & 9 & 4 & 4 \\
\hline Moldova & 1 & 2 & 2 & 1 & 3 & 1 \\
\hline Monaco & 8 & 4 & 7 & 9 & 4 & 5 \\
\hline Montenegro & 7 & 3 & 8 & 6 & 4 & 2 \\
\hline Netherlands & 5 & 2 & 6 & 4 & 3 & 2 \\
\hline Norway & 5 & 1 & 5 & 5 & 2 & 1 \\
\hline Poland & 11 & 10 & 11 & 11 & 10 & 9 \\
\hline Portugal & 4 & 1 & 5 & 4 & 1 & 1 \\
\hline Romania & 4 & 5 & 3 & 4 & 6 & 5 \\
\hline Slovakia & 8 & 4 & 8 & 8 & 4 & 4 \\
\hline Slovenia & 14 & 3 & 14 & 14 & 3 & 3 \\
\hline Sweden & 7 & 4 & 7 & 7 & 3 & 4 \\
\hline Ukraine & 5 & 4 & 4 & 5 & 5 & 4 \\
\hline AVERAGE & 7 & 4 & 7 & 7 & 5 & 4 \\
\hline Latvia & 18 & 7 & 14 & 22 & 8 & 5 \\
\hline Spain & 1 & 4 & 1 & 1 & 5 & 3 \\
\hline United States & 7 & & 7 & 8 & & \\
\hline
\end{tabular}

a Official name former Yugoslav Republic of Macedonia. 


\section{New psychoactive substance use}

\begin{tabular}{l|c|c|c|}
\multicolumn{5}{c}{ ESPAD average } \\
Lifetime use of NPS (\%) ${ }^{\text {a }}$ \\
\hline NPS & Average & Min. & Max. \\
\hline & 4 & 1 & 10 \\
\hline
\end{tabular}

a Percentage of students reporting use of NPS.

The ESPAD average of lifetime experience with NPS was $4 \%$ (Table 8), with the highest rates in Estonia and Poland (10\% each), and the lowest in Belgium (Flanders), Denmark, Finland, Norway and Portugal, with rates of $1 \%$. The average prevalence of lifetime use was $5 \%$ among boys and $4 \%$ among girls. Gender differences within ESPAD countries are generally small, with the exception of Georgia, where $10 \%$ of boys and $3 \%$ of girls reported NPS use, Albania and Cyprus (both $6 \%$ versus $2 \%$ ).

\section{Pharmaceutical use}

\begin{tabular}{|c|c|c|c|}
\hline \multicolumn{4}{|c|}{$\begin{array}{c}\text { ESPAD average } \\
\text { Lifetime use of pharmaceuticals (\%) }{ }^{\text {a }}\end{array}$} \\
\hline & Average & Min. & Max. \\
\hline $\begin{array}{l}\text { Tranquillisers or sedatives } \\
\text { without prescription }\end{array}$ & 6 & 1 & 17 \\
\hline Painkillers to get high & 4 & 1 & 12 \\
\hline Anabolic steroids & 1 & 0 & 4 \\
\hline
\end{tabular}

a Percentage of students reporting use of pharmaceuticals.

\section{Tranquillisers or sedatives}

Use of tranquillisers or sedatives without prescription was most prevalent in Poland (17\%) and the Czech Republic (16 \%) (Table 9). The lowest levels of non-prescription use of tranquillisers or sedatives (1-2\%) were reported by students from Denmark, the Faroes, Moldova, Romania and Ukraine. On average, slightly more girls than boys reported use of tranquillisers or sedatives without prescription (8\% versus 5 \%). In Belgium (Flanders), the Czech Republic, Estonia, France, the former Yugoslav Republic of Macedonia, Hungary, Lithuania, the Netherlands, Poland, Portugal and Slovakia, more girls than boys have used non-prescription tranquillisers or sedatives (difference: 5 percentage points or more).

\section{Painkillers}

On average, use of painkillers to get high was reported by $4 \%$ of the students. The countries with the highest prevalence rates are Romania (12\%) and Croatia (10 \%). Like tranquillisers, slightly more girls (4 \%) than boys (3\%) reported the use of painkillers. Larger gender differences (5 percentage points or more) were found in Belgium (Flanders), Croatia, Hungary, Poland and Romania.

\section{Anabolic steroids}

Few students in the ESPAD countries reported experience with anabolic steroids (ESPAD average: $1 \%$ ). The highest proportions were found in Bulgaria (4\%), Cyprus, the Czech Republic and Poland (3 \% each). Noticeable gender differences are seen in Bulgaria (7\% for boys and $2 \%$ for girls) and Cyprus (5 \% versus $1 \%$ ). 
Table 9. Pharmaceuticals: lifetime prevalence of the use of painkillers to get high, tranquillisers or sedatives without prescription and anabolic steroids (percentage)

\begin{tabular}{|c|c|c|c|c|c|c|c|c|c|}
\hline \multirow[t]{2}{*}{ Country } & \multirow[t]{2}{*}{ Painkillers } & \multirow{2}{*}{$\begin{array}{l}\text { Tranquillisers/ } \\
\text { sedatives }\end{array}$} & \multirow{2}{*}{$\begin{array}{l}\text { Anabolic } \\
\text { steroids }\end{array}$} & \multicolumn{2}{|c|}{ Painkillers } & \multicolumn{2}{|c|}{$\begin{array}{c}\text { Tranquillisers/ } \\
\text { sedatives }\end{array}$} & \multicolumn{2}{|c|}{ Anabolic steroids } \\
\hline & & & & Boys & Girls & Boys & Girls & Boys & Girls \\
\hline Albania & 4 & 8 & 1 & 3 & 4 & 7 & 8 & 2 & 1 \\
\hline Austria & 2 & 4 & 1 & 2 & 3 & 3 & 5 & 1 & 0 \\
\hline Belgium (Flanders) & 7 & 6 & 0 & 3 & 10 & 4 & 9 & 0 & 0 \\
\hline Bulgaria & 4 & 4 & 4 & 5 & 3 & 4 & 3 & 7 & 2 \\
\hline Croatia & 10 & 4 & 2 & 7 & 14 & 3 & 5 & 3 & 1 \\
\hline Cyprus & 3 & 5 & 3 & 5 & 1 & 5 & 4 & 5 & 1 \\
\hline Czech Republic &.${ }^{\mathrm{a}}$ & 16 & 3 &..${ }^{\mathrm{a}}$ &.${ }^{\mathrm{a}}$ & 11 & 20 & 4 & 3 \\
\hline Denmark & 1 & 2 & 0 & 1 & 2 & 2 & 3 & 0 & 0 \\
\hline Estonia & 2 & 9 & 1 & 1 & 2 & 6 & 12 & 2 & 1 \\
\hline Faroes & 1 & 2 & 0 & 0 & 2 & 1 & 3 & 0 & 0 \\
\hline Finland & 5 & 6 & 0 & 2 & 7 & 4 & 8 & 1 & 0 \\
\hline FYR Macedonia ${ }^{c}$ & 4 & 11 & 1 & 4 & 5 & 9 & 13 & 1 & 0 \\
\hline France & 4 & 10 & 1 & 3 & 6 & 8 & 12 & 1 & 0 \\
\hline Georgia & 2 & 11 & 1 & 3 & 1 & 10 & 13 & 1 & 0 \\
\hline Greece & 2 & 4 & 2 & 2 & 2 & 4 & 4 & 2 & 1 \\
\hline Hungary & 6 & 7 & 1 & 3 & 8 & 5 & 9 & 1 & 0 \\
\hline Iceland & 3 & 5 & 1 & 2 & 3 & 5 & 6 & 1 & 1 \\
\hline Ireland & 5 & 3 & 2 & 4 & 5 & 3 & 3 & 3 & 1 \\
\hline Italy & 2 & 5 & 2 & 2 & 1 & 5 & 6 & 3 & 1 \\
\hline Liechtenstein & 3 & 3 & 1 & 1 & 4 & 6 & 1 & 1 & 1 \\
\hline Lithuania & 2 & 9 & 1 & 1 & 2 & 5 & 12 & 2 & 0 \\
\hline Malta & 3 & 3 & 1 & 2 & 4 & 2 & 4 & 1 & 1 \\
\hline Moldova & 2 & 1 & 1 & 2 & 2 & 1 & 1 & 1 & 0 \\
\hline Monaco & 4 & 10 & 1 & 2 & 5 & 8 & 12 & 2 & 1 \\
\hline Montenegro & 5 & 10 & 2 & 4 & 5 & 8 & 13 & 3 & 1 \\
\hline Netherlands & 1 & 8 & 1 & 1 & 2 & 5 & 11 & 1 & 1 \\
\hline Norway & 3 & 6 & 0 & 2 & 4 & 5 & 7 & 1 & 0 \\
\hline Poland & 7 & 17 & 3 & 4 & 10 & 11 & 23 & 3 & 2 \\
\hline Portugal & 1 & 5 & 0 & 1 & 2 & 2 & 8 & 1 & 0 \\
\hline Romania & 12 & 2 & 1 & 9 & 15 & 1 & 3 & 2 & 0 \\
\hline Slovakia & & 7 & 2 & & 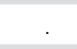 & 4 & 9 & 3 & 1 \\
\hline Slovenia & 2 & 3 & 0 & 1 & 3 & 2 & 4 & 1 & 0 \\
\hline Sweden & 3 & 7 & 1 & 2 & 4 & 5 & 9 & 1 & 0 \\
\hline Ukraine & 1 & 2 & 1 & 1 & 1 & 2 & 2 & 1 & 0 \\
\hline AVERAGE & 4 & 6 & 1 & 3 & 4 & 5 & 8 & 2 & 1 \\
\hline Latvia & 2 & 5 & 1 & 2 & 3 & 4 & 6 & 2 & 1 \\
\hline Spain & & 8 & 1 & & & 6 & 9 & 1 & 0 \\
\hline United States & & $6^{a}$ & 1 & & & $4^{b}$ & $7 b$ & 2 & 1 \\
\hline
\end{tabular}

a Did not specify 'in order to get high'.

${ }^{\mathrm{b}}$ Data for tranquillisers only.

${ }^{\mathrm{c}}$ Official name former Yugoslav Republic of Macedonia. 
Table 10. Prevalence of lifetime use of substance B conditional on the lifetime use of substance A (percentage) and number of users of substance $A(n)$

\begin{tabular}{|c|c|c|c|c|c|c|c|c|c|c|c|c|c|c|c|c|c|c|}
\hline \multirow[b]{2}{*}{ Substance A } & \multirow[b]{2}{*}{$n$} & \multirow[b]{2}{*}{$\begin{array}{l}\text { Lifetime } \\
\text { prevalence }\end{array}$} & \multicolumn{16}{|c|}{ Substance B } \\
\hline & & & 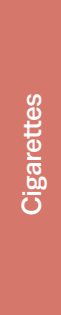 & $\begin{array}{l}\overline{0} \\
\frac{0}{0} \\
\frac{0}{4}\end{array}$ & $\begin{array}{l}\frac{\infty}{0} \\
\frac{0}{0} \\
\frac{D}{\mathbb{E}} \\
心\end{array}$ & 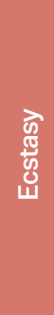 & 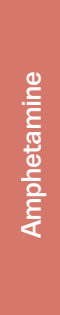 & 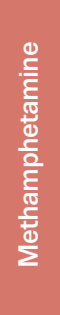 & 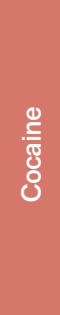 & $\begin{array}{l}\text { 응 } \\
\text { ভٓ }\end{array}$ & 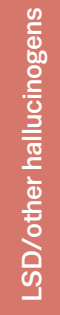 & $\begin{array}{l}\frac{5}{\overline{0}} \\
\frac{\mathrm{d}}{\mathrm{I}}\end{array}$ & 愛 & 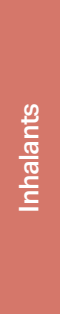 & $\frac{\infty}{2}$ & 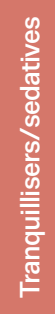 & 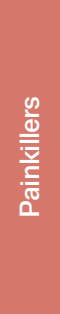 & $\begin{array}{l}\frac{0}{0} \\
\overline{0} \\
\frac{0}{5} \\
\frac{5}{0} \\
\frac{0}{0} \\
\frac{0}{0} \\
\frac{5}{4}\end{array}$ \\
\hline Cigarette & 39914 & 46 & & 93 & 32 & 4 & 4 & 2 & 4 & 2 & 4 & 2 & 2 & 12 & 8 & 10 & 6 & 2 \\
\hline Alcohol & 69189 & 79 & 54 & & 19 & 3 & 2 & 2 & 3 & 1 & 2 & 1 & 1 & 9 & 5 & 7 & 4 & 1 \\
\hline Cannabis & 13988 & 16 & 91 & 96 & & 11 & 9 & 7 & 11 & 6 & 11 & 6 & 4 & 18 & 20 & 16 & 10 & 5 \\
\hline Ecstasy & 2013 & 2 & 84 & 92 & 77 & & 47 & 36 & 46 & 29 & 44 & 29 & 25 & 38 & 40 & 40 & 33 & 22 \\
\hline Amphetamine & 1693 & 2 & 86 & 92 & 77 & 56 & & 45 & 51 & 33 & 46 & 33 & 28 & 44 & 42 & 46 & 39 & 27 \\
\hline Methamphetamine & 1162 & 1 & 85 & 92 & 79 & 62 & 66 & & 60 & 47 & 55 & 44 & 36 & 50 & 46 & 49 & 46 & 35 \\
\hline Cocaine & 1959 & 2 & 85 & 91 & 79 & 48 & 44 & 36 & . & 34 & 43 & 37 & 26 & 44 & 39 & 39 & 35 & 24 \\
\hline Crack & 1074 & 1 & 83 & 89 & 79 & 55 & 52 & 51 & 62 & & 51 & 47 & 38 & 55 & 43 & 45 & 45 & 36 \\
\hline $\begin{array}{l}\text { LSD/other } \\
\text { hallucinogens }\end{array}$ & 1843 & 2 & 87 & 93 & 80 & 48 & 42 & 34 & 45 & 30 & . & 36 & 30 & 44 & 44 & 48 & 41 & 30 \\
\hline Heroin & 1068 & 1 & 81 & 87 & 75 & 55 & 52 & 48 & 68 & 47 & 62 & & 49 & 55 & 47 & 56 & 53 & 47 \\
\hline GHB & 788 & 1 & 80 & 87 & 73 & 63 & 60 & 53 & 63 & 52 & 71 & 66 & & 57 & 48 & 58 & 61 & 60 \\
\hline Inhalants & 6507 & 7 & 71 & 93 & 38 & 12 & 11 & 9 & 13 & 9 & 13 & 9 & 7 & & 15 & 23 & 18 & 8 \\
\hline NPS & 3723 & 4 & 83 & 92 & 74 & 22 & 19 & 14 & 20 & 13 & 22 & 14 & 10 & 26 & . & 25 & 20 & 11 \\
\hline $\begin{array}{l}\text { Tranquillisers/ } \\
\text { sedatives }\end{array}$ & 5605 & 6 & 70 & 90 & 39 & 14 & 14 & 10 & 13 & 9 & 16 & 11 & 8 & 27 & 17 & & 25 & 10 \\
\hline Painkillers & 3024 & 4 & 75 & 91 & 47 & 22 & 22 & 18 & 23 & 16 & 25 & 19 & 16 & 39 & 25 & 46 & . & 17 \\
\hline Anabolic steroids & 1094 & 1 & 77 & 90 & 60 & 41 & 41 & 37 & 44 & 35 & 50 & 46 & 43 & 48 & 36 & 49 & 48 & \\
\hline
\end{tabular}

\section{Conditional probabilities of substance use}

Among students who have used cigarettes at least once, $93 \%$ have also used alcohol, $32 \%$ cannabis, $12 \%$ inhalants, $10 \%$ tranquillisers or sedatives and $8 \%$ NPS Table 10 Almost every student (87\% or more) that has used a licit or illicit substance also reported having used alcohol, but not every student who has tried alcohol has also tried another substance. Among students that have used alcohol, $54 \%$ have also used cigarettes, $19 \%$ cannabis, $9 \%$ inhalants, $7 \%$ tranquillisers or sedatives and $5 \%$ or less NPS or other illicit drugs.

Of the students that have used cannabis, $91 \%$ have also used cigarettes and $96 \%$ alcohol, inhalants (18\%), NPS (20\%) or tranquillisers or sedatives (16\%). Approximately one in ten or fewer of these students (4-11\%) reported having used each of the other illicit substances included in the questionnaire in addition to cannabis. Among users of ecstasy, amphetamine, methamphetamine, cocaine, crack, LSD or other hallucinogens, heroin or GHB, $80 \%$ or more have also used cigarettes and $73 \%$ or more have tried cannabis. With respect to users of one of the drugs other than cannabis, the lowest probability of using one of the other drugs was $25 \%$ of ecstasy users who said they had also used GHB. The highest probability was seen with respect to LSD use by students who had used GHB (71\%).

Finally, among the students that have used substances from the two groups, inhalants and tranquillisers or sedatives, about a quarter have used substances from both of the groups. Among the users of both groups of substances, $70 \%$ stated they have also used cigarettes. Of the students that have used painkillers for getting high, almost half reported the use of tranquillisers or sedatives (46\%). Among students reporting use of NPS, a quarter have also used inhalants (26\%) or tranquillisers or sedatives (25\%) and $74 \%$ have used cannabis. Use of illicit substances among the small group of students that have used anabolic steroids ranged from $35 \%$ (crack) to $60 \%$ (cannabis). 


\section{Patterns of current use}

\section{Daily cigarette use}

Overall, $12 \%$ of the students smoked every day in the last 30 days (Figure 1a). Daily smoking at levels of approximately twice the ESPAD average were found in Bulgaria, Croatia, Italy, Liechtenstein and Romania.
Considerably lower-than-average rates were observed in Albania, Iceland, Moldova and Norway (5\% or less). Significant differences in daily smoking between boys and girls (Figure 1b) were found in Albania, Cyprus, Finland, the former Yugoslav Republic of Macedonia, Georgia, Greece, Ireland, Lithuania, Moldova, Montenegro and Ukraine (higher rates for boys) and Bulgaria, Monaco and Sweden (higher rates for girls).

Figure 1a. Daily cigarette use: prevalence in the last 30 days (percentage)

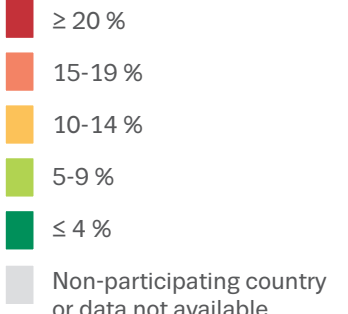
or data not available

Cross-hatching indicates limited comparability or limited geographical coverage.

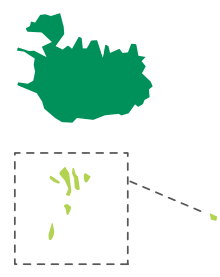

\section{United States}
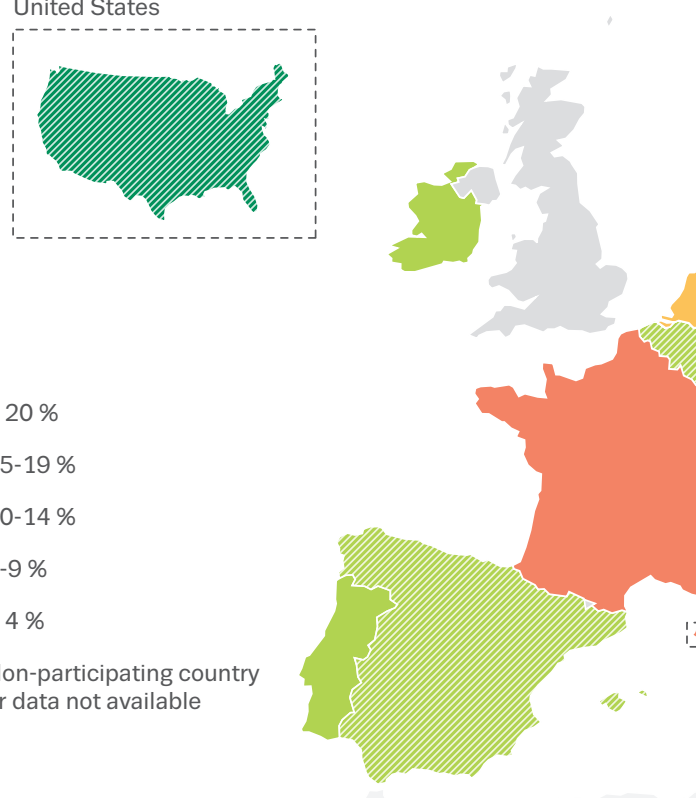

$\because 1$

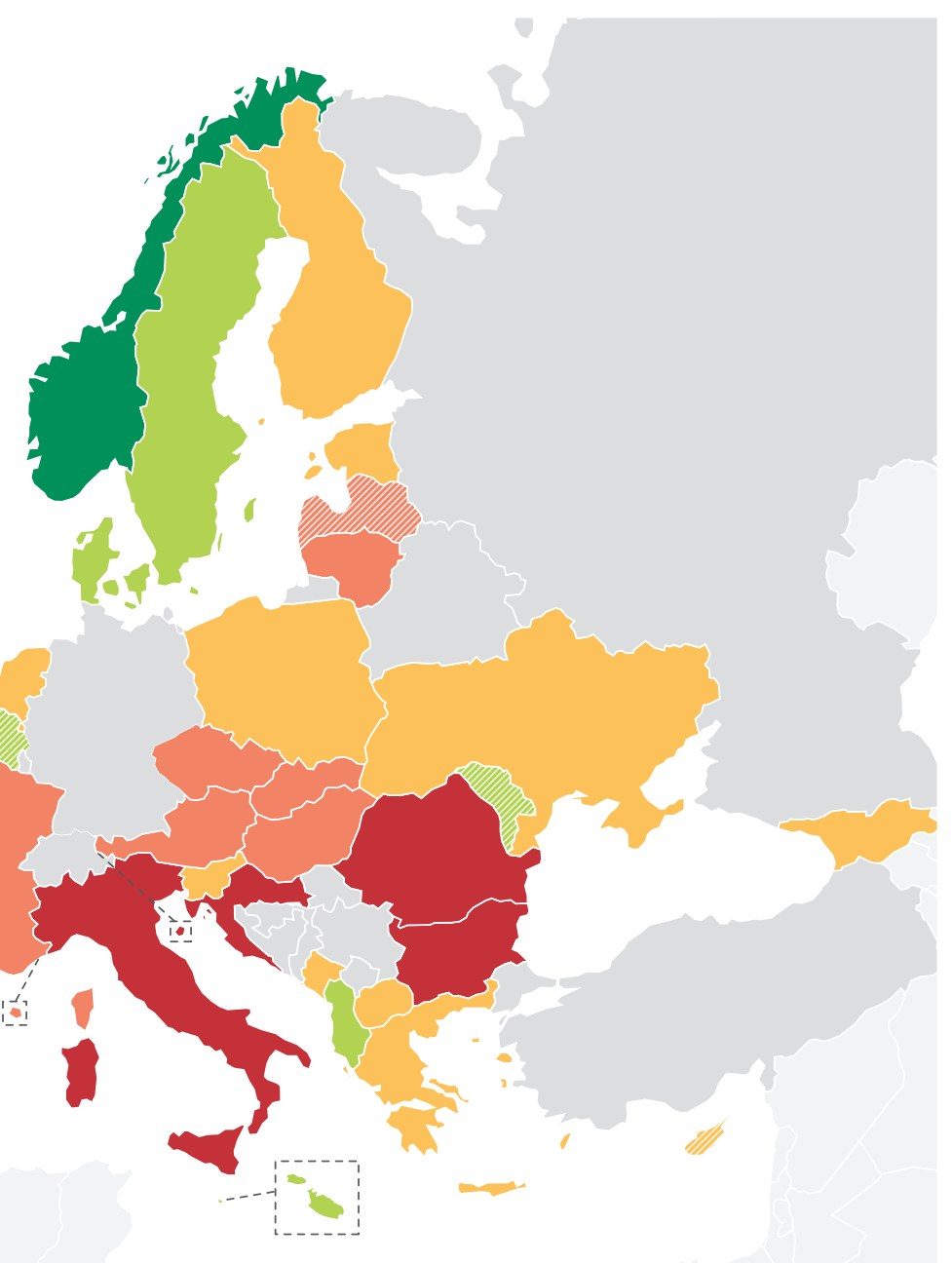


Figure 1b. Daily cigarette use: prevalence in the last 30 days by gender (percentage)

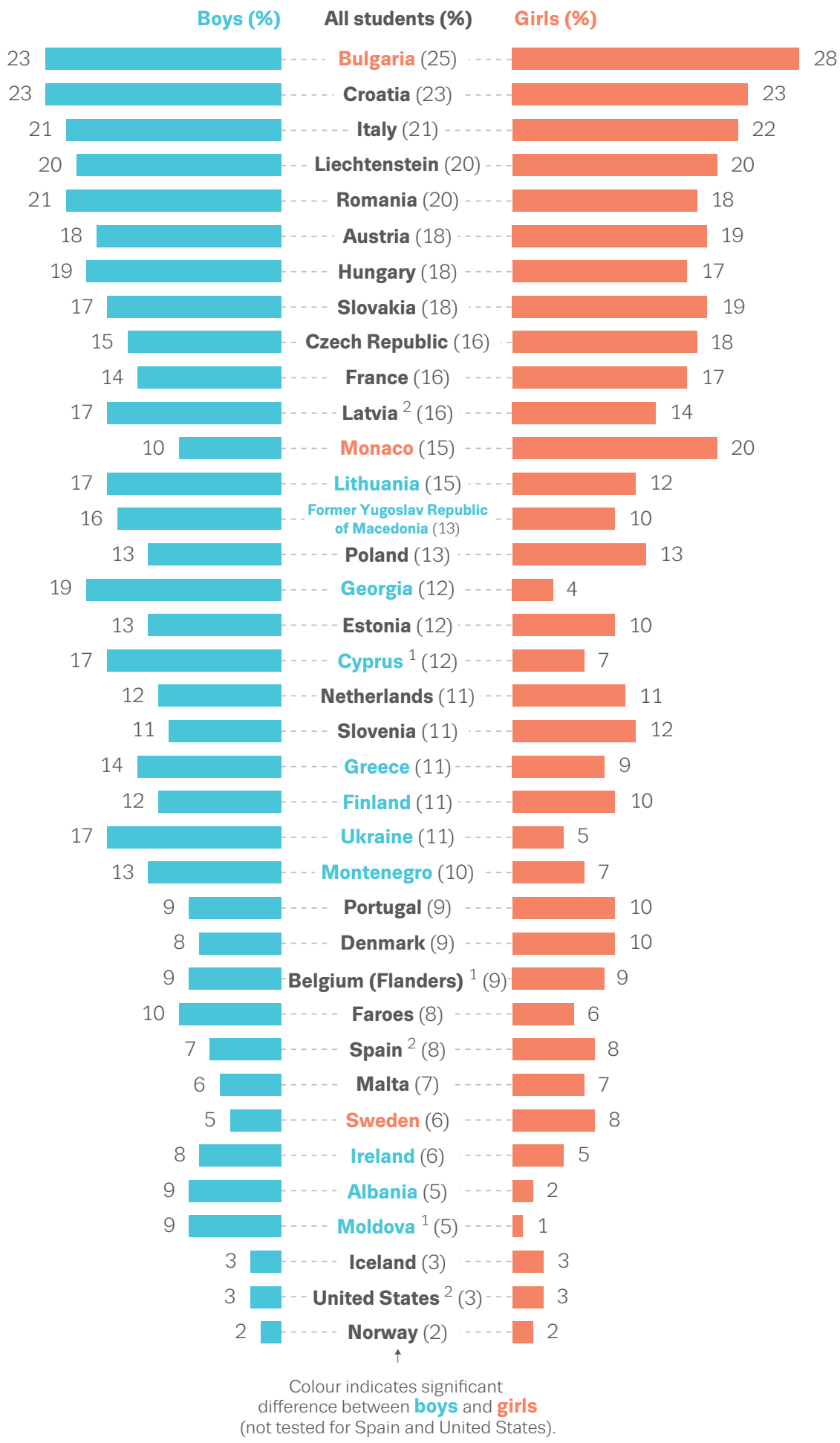

1 Belgium (Flanders), Cyprus and Moldova: limited geographical coverage.

2 Latvia, Spain and United States: limited comparability. 


\section{Frequency of alcohol use in the last 30 days}

Among all students who had used alcohol, the frequency of drinking alcohol was 5.4 occasions on average in the last 30 days (Figure 2a). Students from Cyprus and Liechtenstein consumed alcohol on 8.2 and 9.1 occasions, respectively, and students from Estonia, Finland, Iceland, Lithuania, Moldova, Norway and Sweden drank alcohol on fewer than four occasions on average. In most countries, boys who drank did so more frequently than girls did, with differences of more than three occasions in the last 30 days in Bulgaria and the former Yugoslav Republic of Macedonia. Only in the Faroes did girls drink alcohol more frequently than boys did, with a difference of over one occasion in the last 30 days. In most countries, the difference between boys and girls in the number of drinking occasions was significant (Figure 2b).

Figure 2a. Frequency of alcohol intake in the last 30 days (mean number of occasions among users)

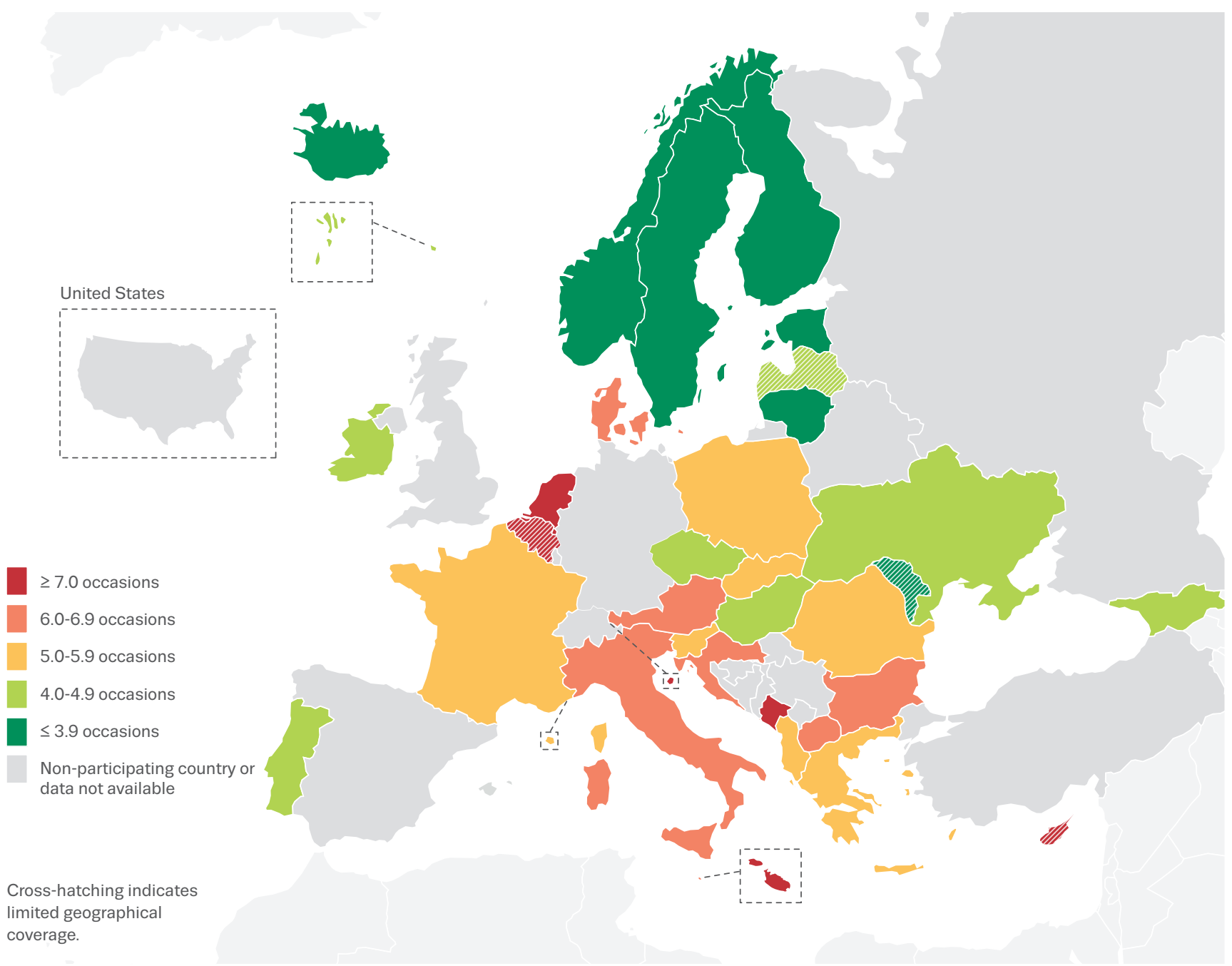


Figure 2b. Frequency of alcohol intake in the last 30 days by gender (mean number of occasions among users)

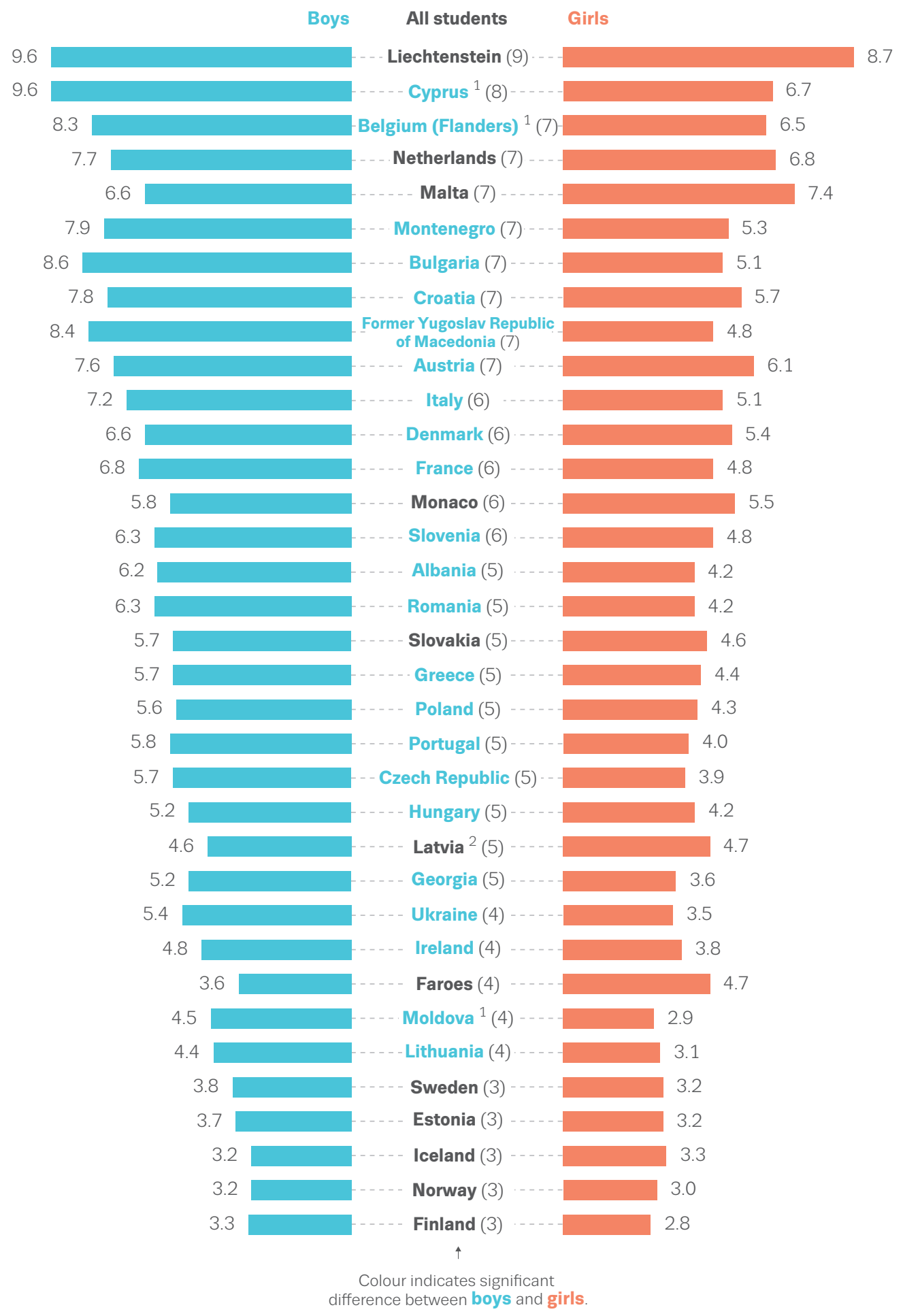

1 Belgium (Flanders), Cyprus and Moldova: limited geographical coverage.

2 Latvia: limited comparability 


\section{Alcohol intake on the last drinking occasion}

The amount of alcohol consumed was calculated as the average volume of ethanol (in centilitres) consumed on the last drinking day. The students drank an average of 4.7 centilitres of alcohol on the last drinking day (Figure 3a). The amount of alcohol consumed was highest in Denmark ( 9.3 centilitres), Estonia (6.2 centilitres), Sweden
(6. 1 centilitres), Finland and Ireland (each 6.0 centilitres), and lowest in Moldova (2.1 centilitres) and Romania (2.8 centilitres). Boys reported consuming higher volumes than girls, with significant differences in most countries (Figure 3b). On average, the difference between boys and girls in the amount of alcohol consumed was 1.0 centilitres, with the highest differences in Georgia (2.6 centilitres), Montenegro (2.1 centilitres) and Austria (2.0 centilitres).

Figure 3a. Average alcohol intake on the last drinking day in centilitres of ethanol among users

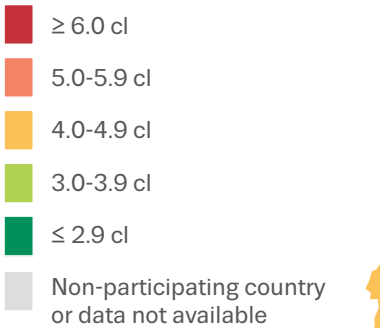

Cross-hatching indicates limited comparability or limited geographical coverage.
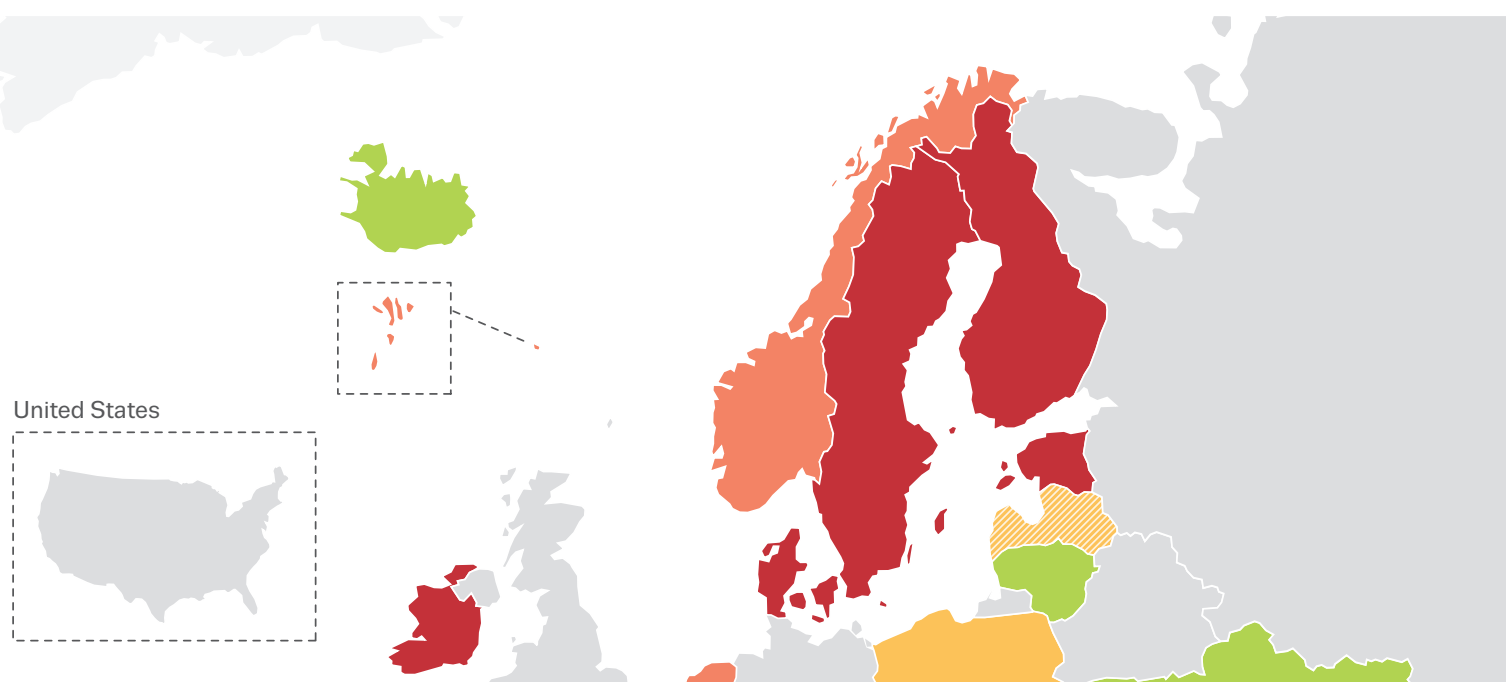
Figure 3b. Average alcohol intake on the last drinking day in centilitres of ethanol among users by gender

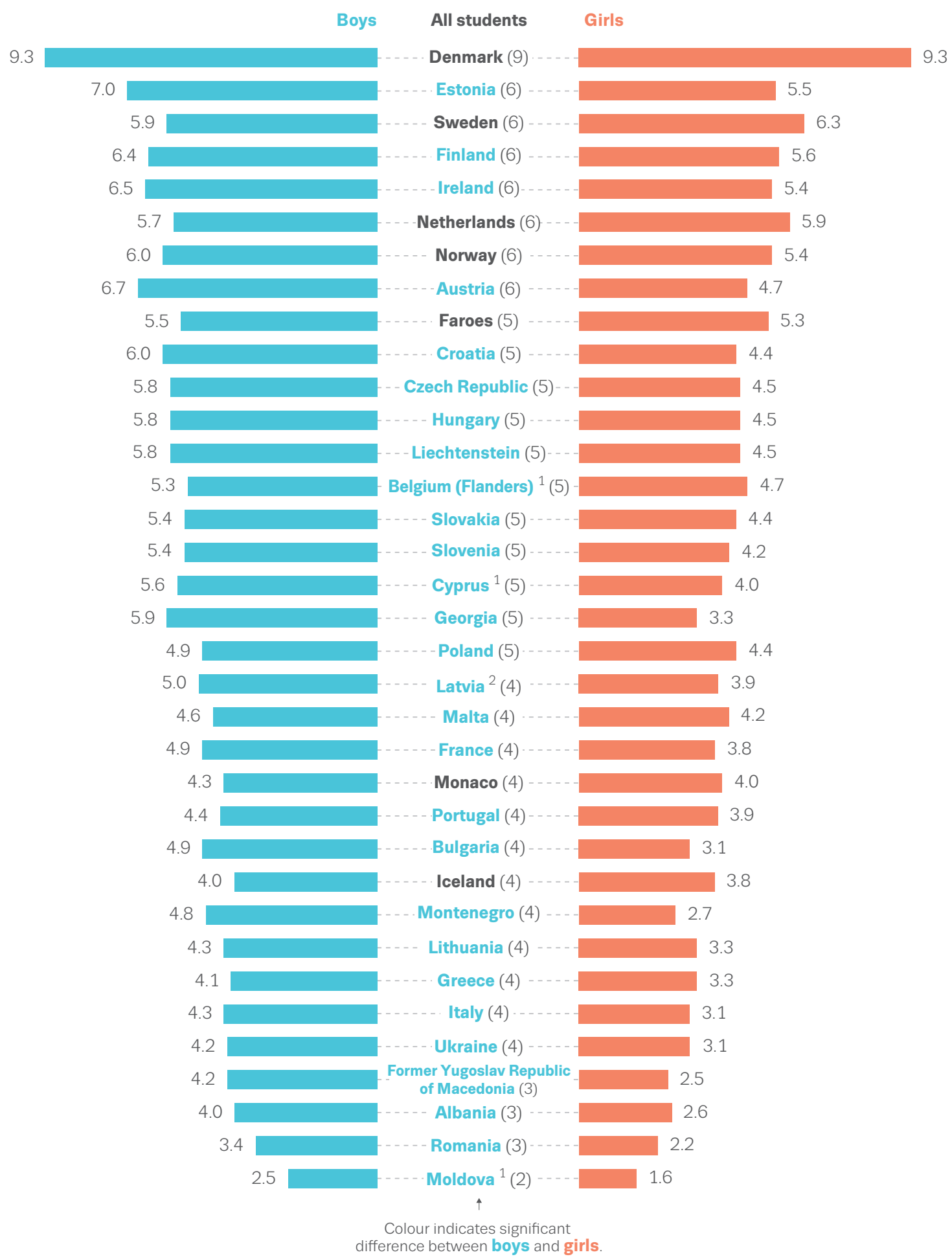

1 Belgium (Flanders), Cyprus and Moldova: limited geographical coverage.

2 Latvia: limited comparability. 


\section{Preferences of alcoholic beverages on the last drinking day}

The relative contribution of each beverage (in centilitres of ethanol) to the total amount of alcohol consumed is taken as an indicator of preference in alcoholic beverages. On average, beer (35\%) and spirits (34\%) were the preferred alcoholic beverages (Figure 4a). In Albania (68\%), Belgium (Flanders) (58\%), the former Yugoslav Republic of Macedonia (54 \%), Romania (52\%) and Poland (52\%), more than every second student who had drunk alcohol preferred beer, and in Malta (60\%), Portugal (53\%), Slovakia (53\%), France (48\%) and Monaco (48\%), every second student preferred spirits. Wine was preferred over beer and spirits in Ukraine (44\%), Moldova (41\%) and Georgia (39\%), and alcopops were the alcoholic drink of preference in Liechtenstein (36 \%). In Denmark, Estonia, Faroes, Ireland, Norway and Sweden, cider accounted for at least one quarter of the total amount of alcohol consumed. In these countries, cider was the second most preferred alcoholic beverage after beer or spirits.

Differences in beverage preferences were found between boys and girls (Figure 4b). In more than half of the countries, boys preferred beer (overall average: $43 \%$ ) over other alcoholic beverages. In Estonia, the Faroes, Greece, Hungary, Lithuania, Malta, Portugal, Slovakia and Sweden, boys preferred spirits over beer. A generally lower preference for cider and wine was found among boys than among girls in more than half of the countries. Among girls, in Sweden, Estonia, Denmark and the Faroes, cider was the second choice after spirits, and in Norway cider was the most preferred alcoholic beverage (33\%). In Georgia, Moldova, Montenegro and Ukraine, girls preferred wine over spirits. The preference for alcopops was generally higher among girls than among boys (11\% versus $7 \%$ ), with a share of $24 \%$ or more in Cyprus, Finland, Iceland and Italy among girls, and in Liechtenstein among both genders. 
Figure 4a. Preferences of alcoholic beverages on the last drinking day; proportion of alcohol volume in centilitres of ethanol for each beverage on total consumption
Figure 4b.

Preferences of alcoholic beverages on the last drinking day by gender; proportion of alcohol volume in centilitres of ethanol for each beverage on total consumption

Beverage preferences: boys presented in the top horizontal bars, girls in the bottom bar

$\begin{array}{lllll}0 & 20 \% & 40 \% & 60 \% & 80\end{array} \quad 100 \%$
$0 \%$
$20 \%$
$40 \%$
$60 \%$
$80 \%$
$100 \%$
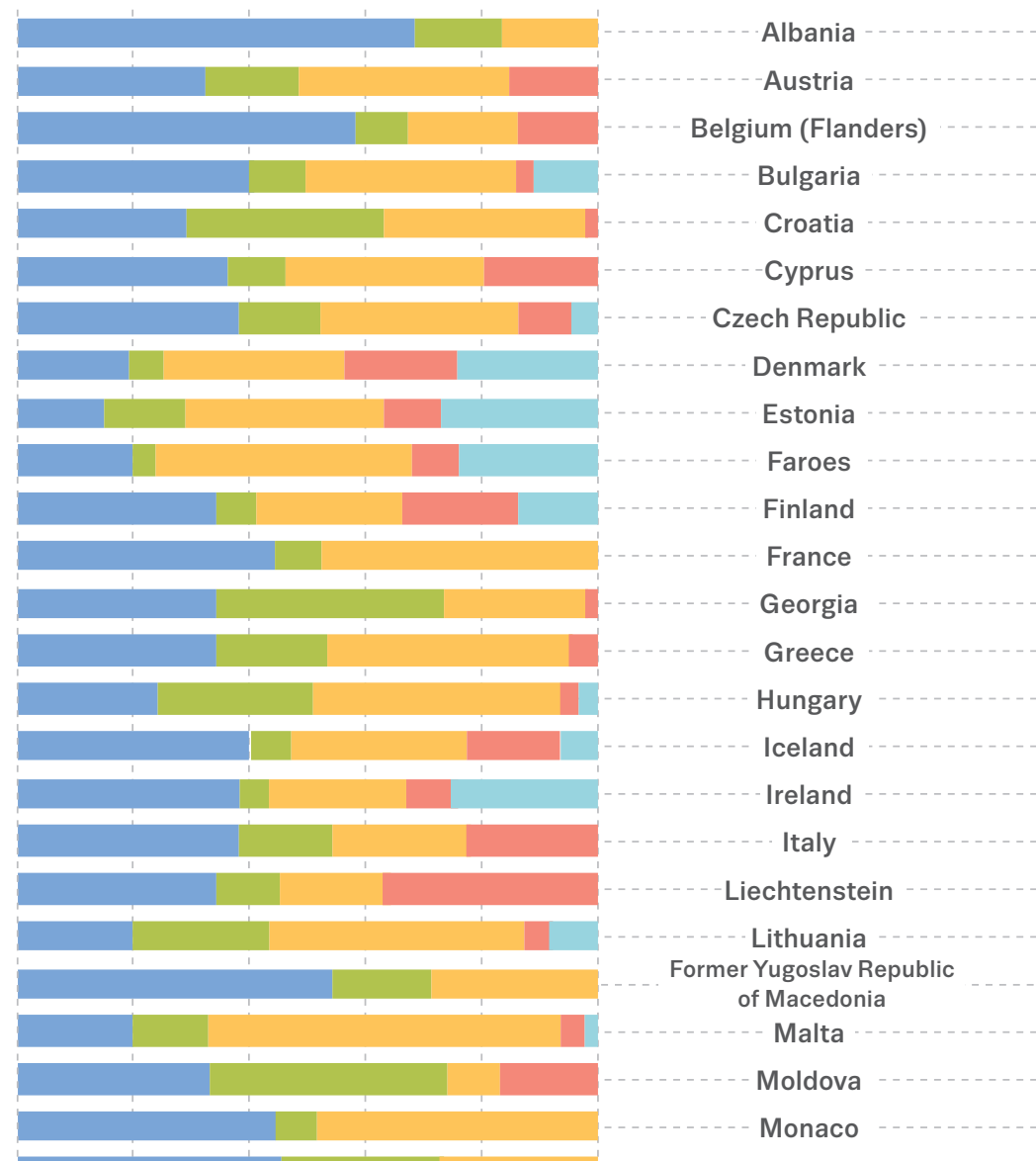

Albania
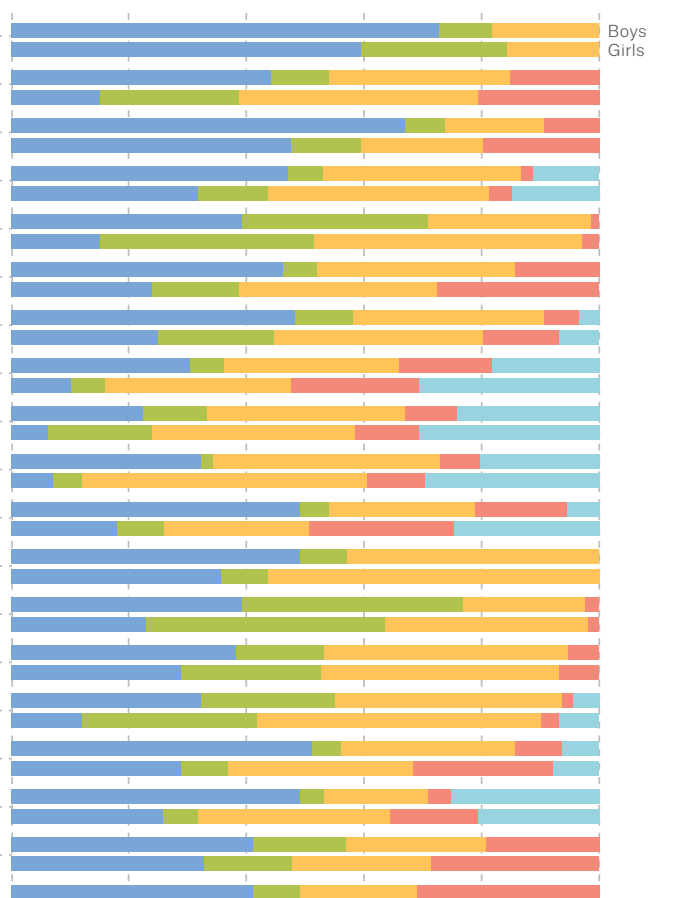

Czech Republic

Denmark

Estonia

Faroes

Finland

France

Georgia

Greece

Hungary

Iceland

Ireland

Italy

-Liechtenstein

..... Lithuania

Former Yugoslav Republic of Macedonia

Malta

Moldova

Monaco

Montenegro

Netherlands

Norway

Poland

Portugal

Romania

Slovakia

Slovenia

Sweden

Ukraine

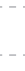

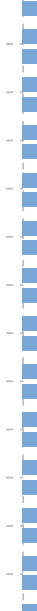
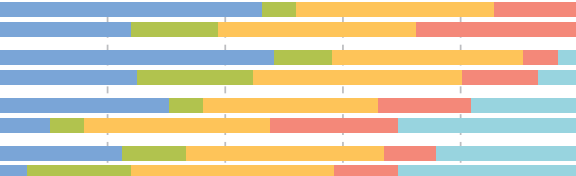

-

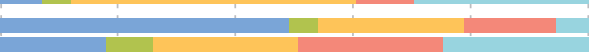

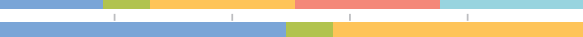

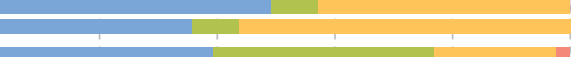

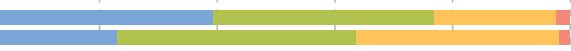
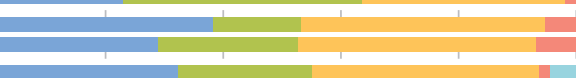

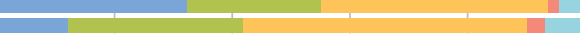

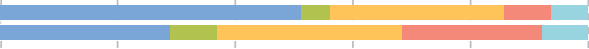

-

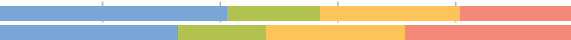

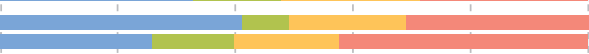

-
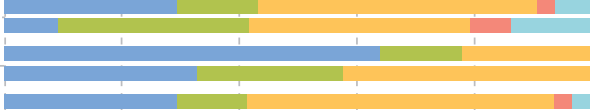

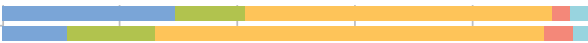

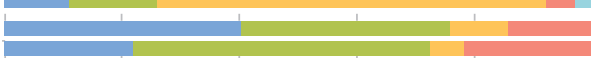
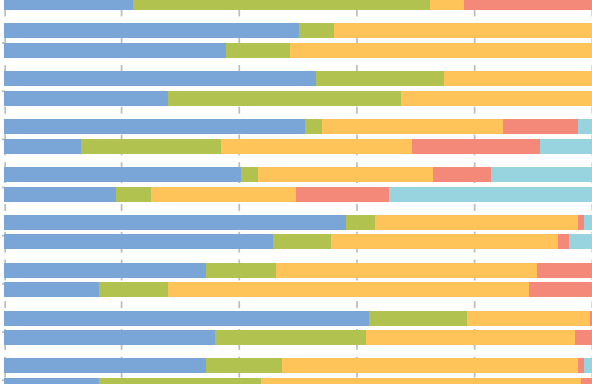
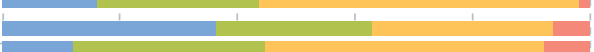

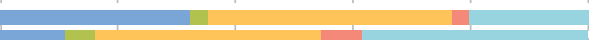

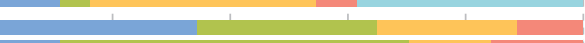
Beer
Wine
Spirits
Alcopops
Cide 


\section{Heavy episodic drinking in the last 30 days}

Every third student (35 \%) reported heavy episodic drinking during the last 30 days (Figure 5a). This drinking pattern was found more often in Austria, Cyprus and Denmark, with about every second student reporting heavy episodic drinking. The lowest figures were found in Norway (19\%) and Iceland ( $8 \%$ ). The difference between boys and girls was about 5 percentage points on average, with generally higher figures for boys (Figure 5b). Significant gender differences were found in half of the countries, with the largest differences in Montenegro (22 percentage points), Georgia (21), Romania (15) and Albania (14). However, in Monaco, significantly more girls than boys reported heavy episodic drinking at least once in the last 30 days (32\% for girls versus $21 \%$ for boys).

Figure 5a. Prevalence of five or more drinks at least once in the last 30 days; one drink contains approximately 2 centilitres of ethanol (percentage)

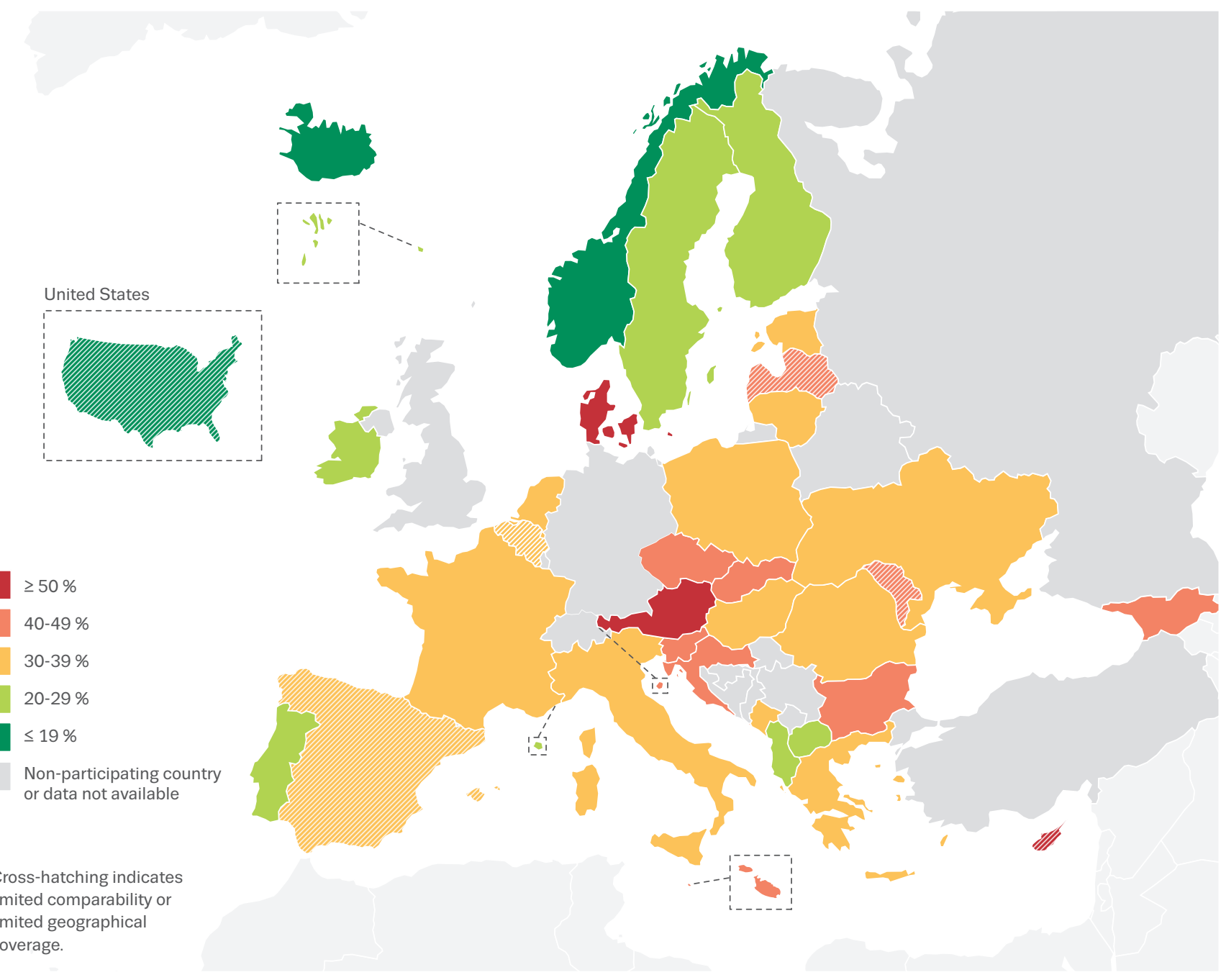


Figure 5b. Prevalence of five or more drinks at least once in the last 30 days by gender; one drink contains approximately 2 centilitres of ethanol (percentage)

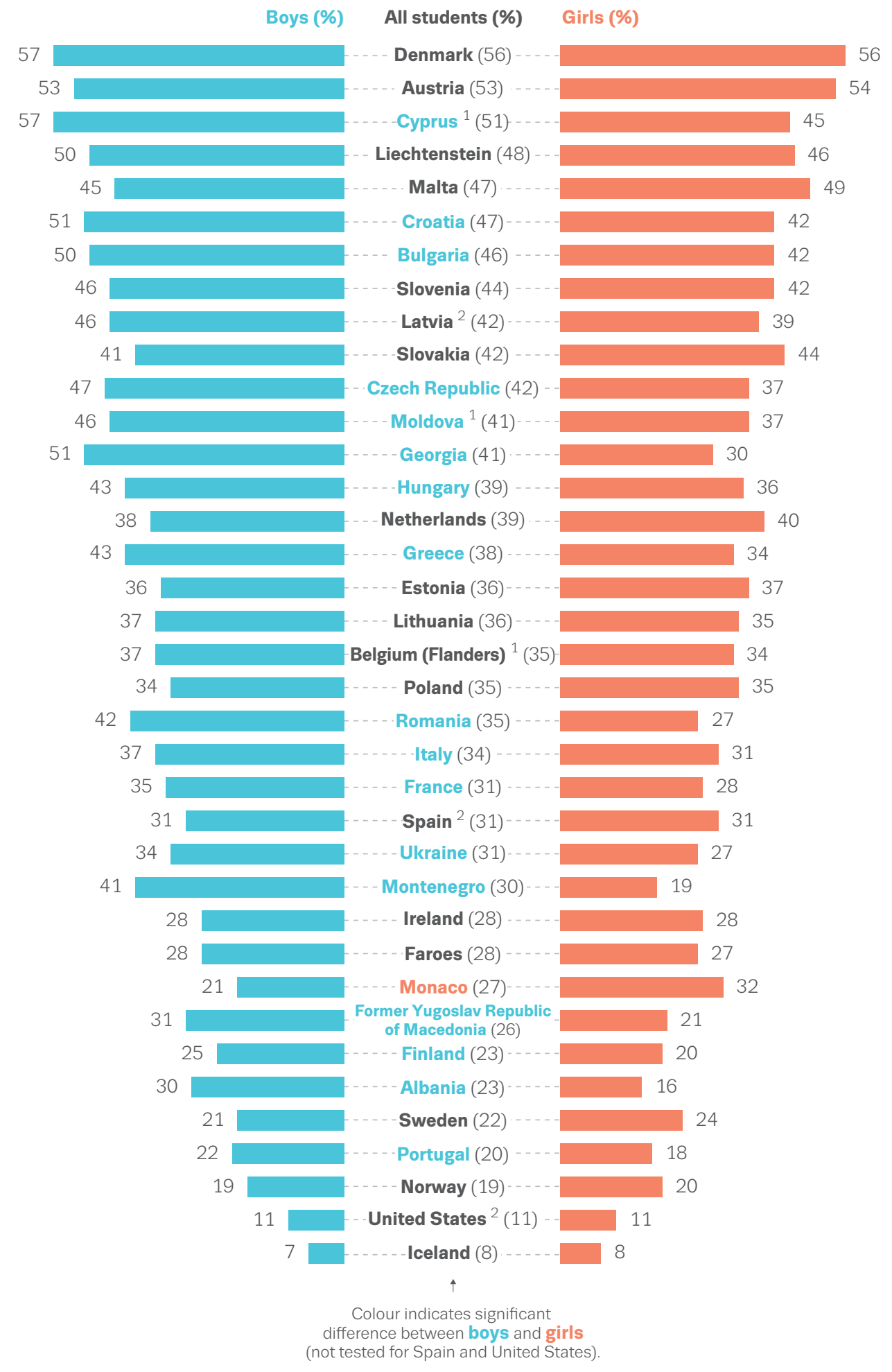

1 Belgium (Flanders), Cyprus and Moldova: limited geographical coverage.

2 Latvia, Spain and United States: limited comparability. 


\section{Current cannabis use}

Overall, $7 \%$ of the students had used cannabis in the last 30 days (Figure 6a). About twice as many students had used cannabis at least once in the last month in France (17\%), Italy (15\%) and the Czech Republic (13\%), compared with their counterparts in other ESPAD countries. More boys than girls reported cannabis use in the last 30 days (8 \% versus $5 \%$ ). In half of the countries, gender differences were statistically significant (Figure 6b), with the largest differences found in Albania, Belgium (Flanders), Bulgaria, Georgia, Ireland, Italy, Liechtenstein and the Netherlands (5-8 percentage points).

Figure 6a. Prevalence of cannabis use in the last 30 days (percentage)

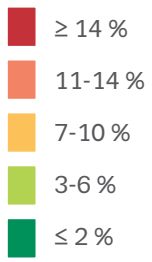

$\leq 2 \%$

Non-participating country or data not available

Cross-hatching indicates limited comparability or limited geographical coverage.

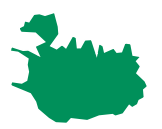

United States
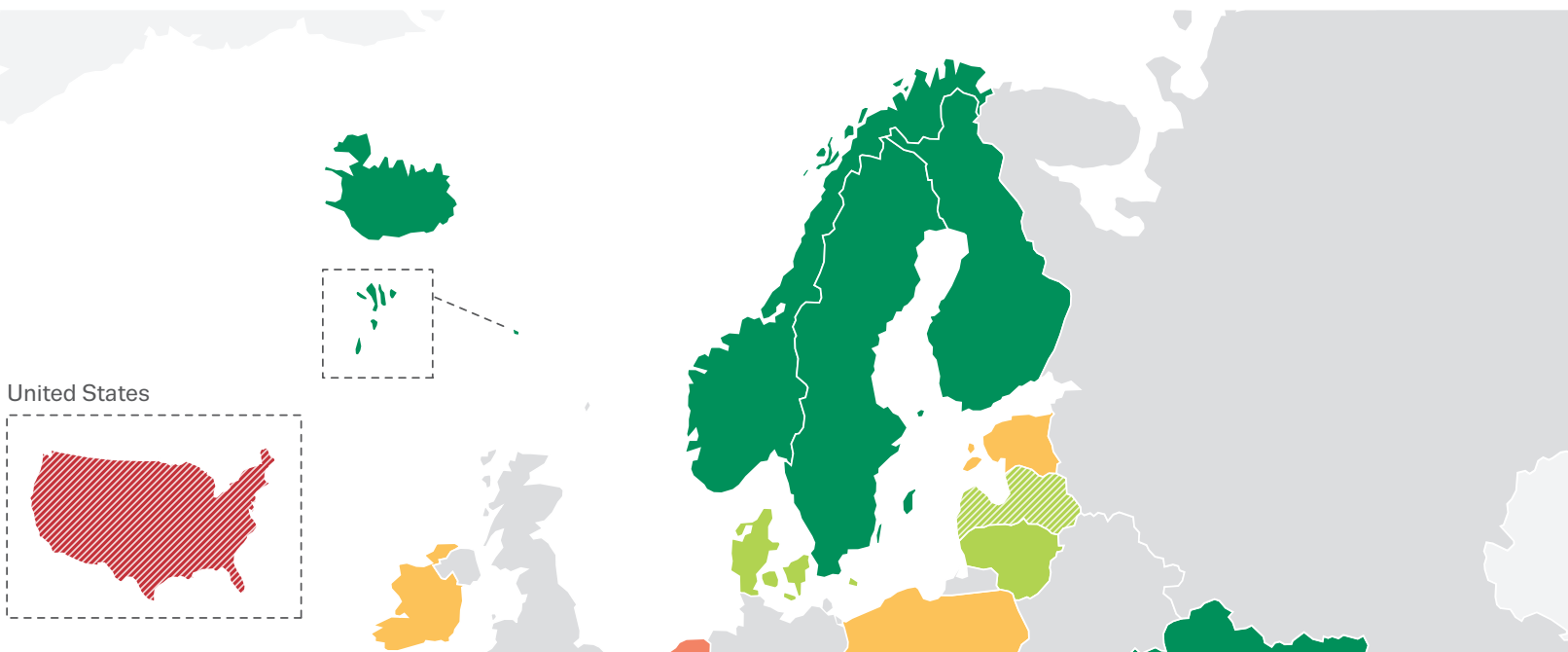
Figure 6b. Prevalence of cannabis use in the last 30 days by gender (percentage)

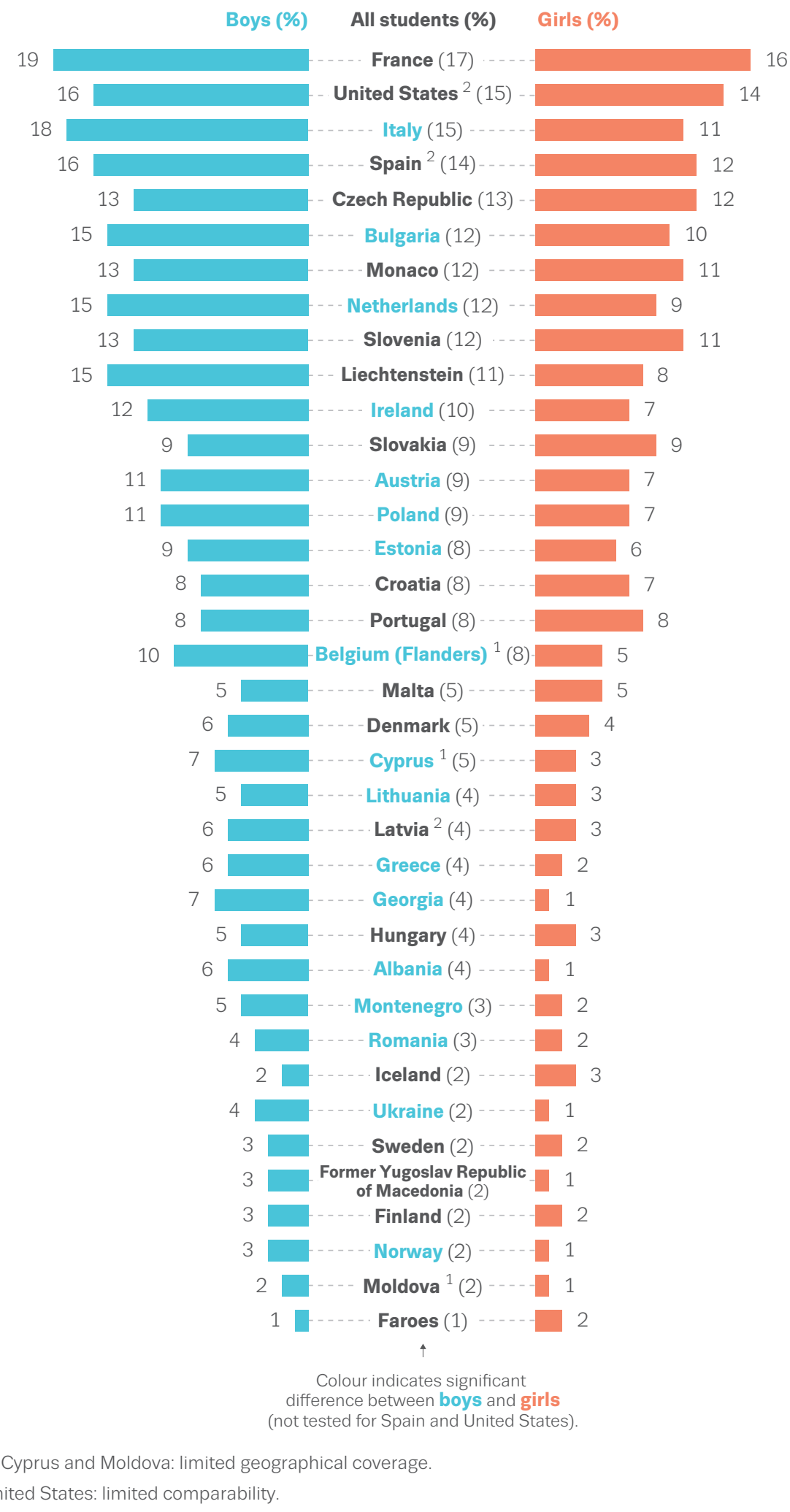




\section{Frequency of cannabis use in the last 12 months}

Among all students who had used cannabis, on average, the drug was used on 8.9 occasions in the last 12 months (Figure 7a). In France, Iceland, Ireland, Italy and the Netherlands, cannabis was used once a month on average (11.5 or more times). The lowest frequencies of cannabis use were found in the Faroes and Moldova (3.6 or fewer).
Overall, boys reported a higher frequency of cannabis use than girls (Figure 7b), with significant gender differences in Austria, Bulgaria, the Czech Republic, Denmark, Estonia, France, Italy, the Netherlands, Poland and Ukraine. In Cyprus, Latvia, Monaco, Montenegro and Romania, cannabis was used more frequently by girls than boys, even though these differences were not statistically significant.

Figure 7a. Frequency of cannabis use in the last 12 months (mean number of occasions among users)

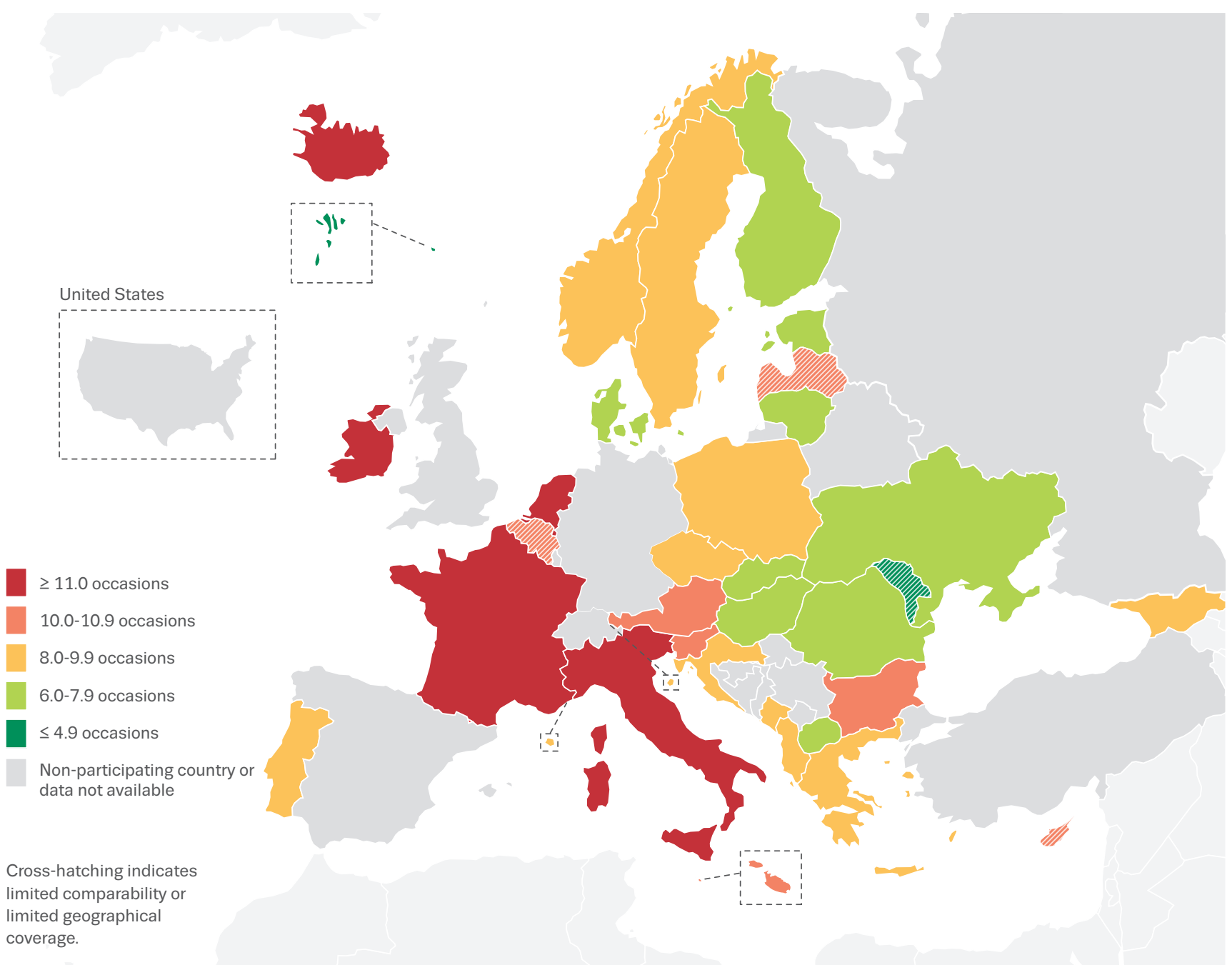


Figure 7b. Frequency of cannabis use in the last 12 months by gender (mean number of occasions among users)

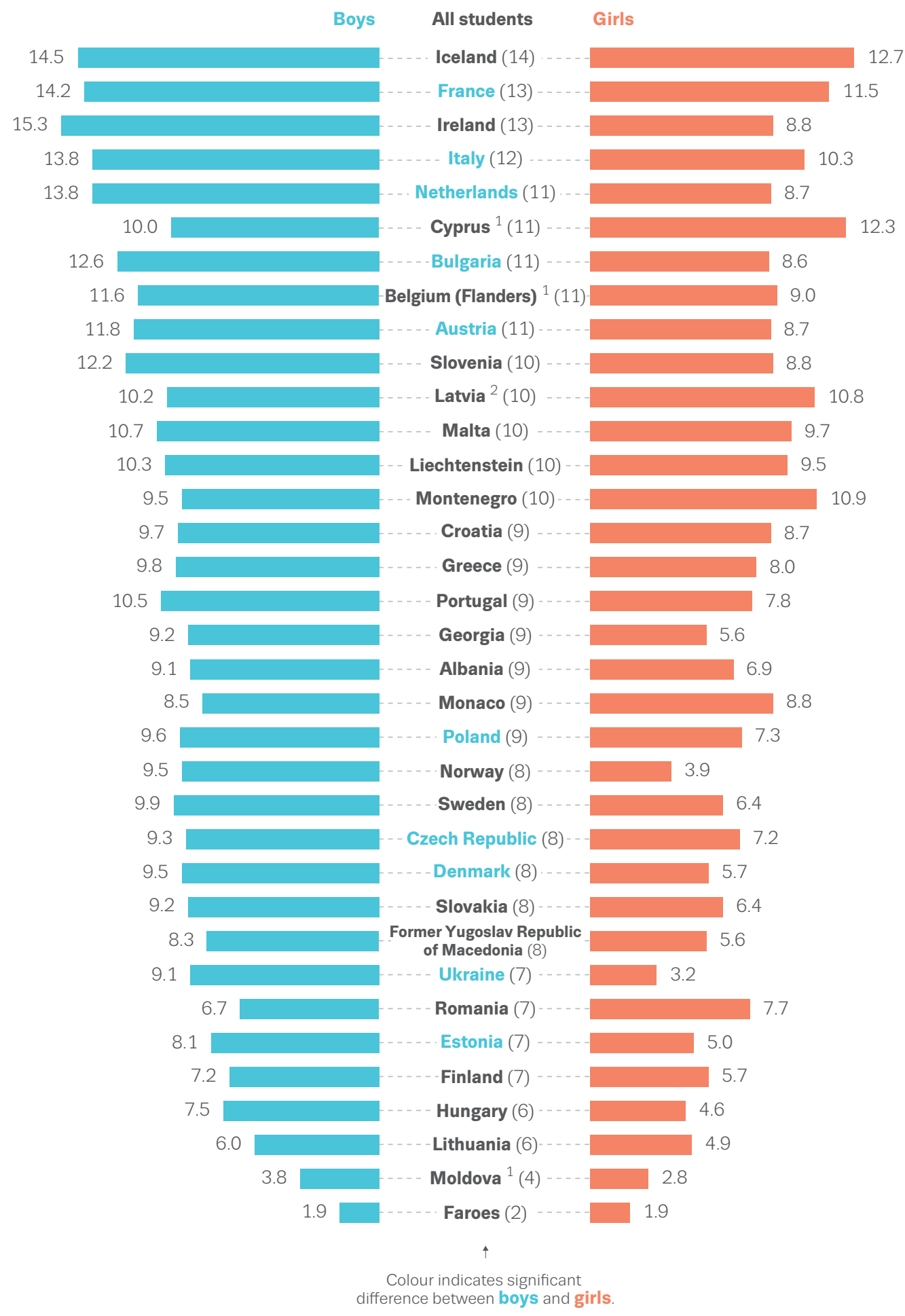

1 Belgium (Flanders), Cyprus and Moldova: limited geographical coverage.

2 Latvia: limited comparability. 


\section{Current inhalant use}

Use of inhalants in the last 30 days was relatively rare. On average, $2 \%$ of the students reported use of inhalants to get high in the last 30 days (Figure 8a). The highest prevalence rates were found in Croatia (7\%) and Cyprus (5\%). Girls reported inhalant use more frequently than boys in Estonia, Croatia and Latvia, whereas in Albania, Austria, Bulgaria, Cyprus, the former Yugoslav Republic of Macedonia, Ireland, Italy, Liechtenstein and Lithuania, inhalant use was more frequently reported among boys. Gender differences were generally small (Figure 8b).

Figure 8a. Prevalence of inhalant use in the last 30 days (percentage)

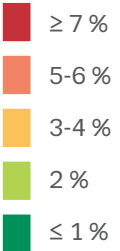

Non-participating country or data not available

Cross-hatching indicates limited comparability or limited geographical coverage.
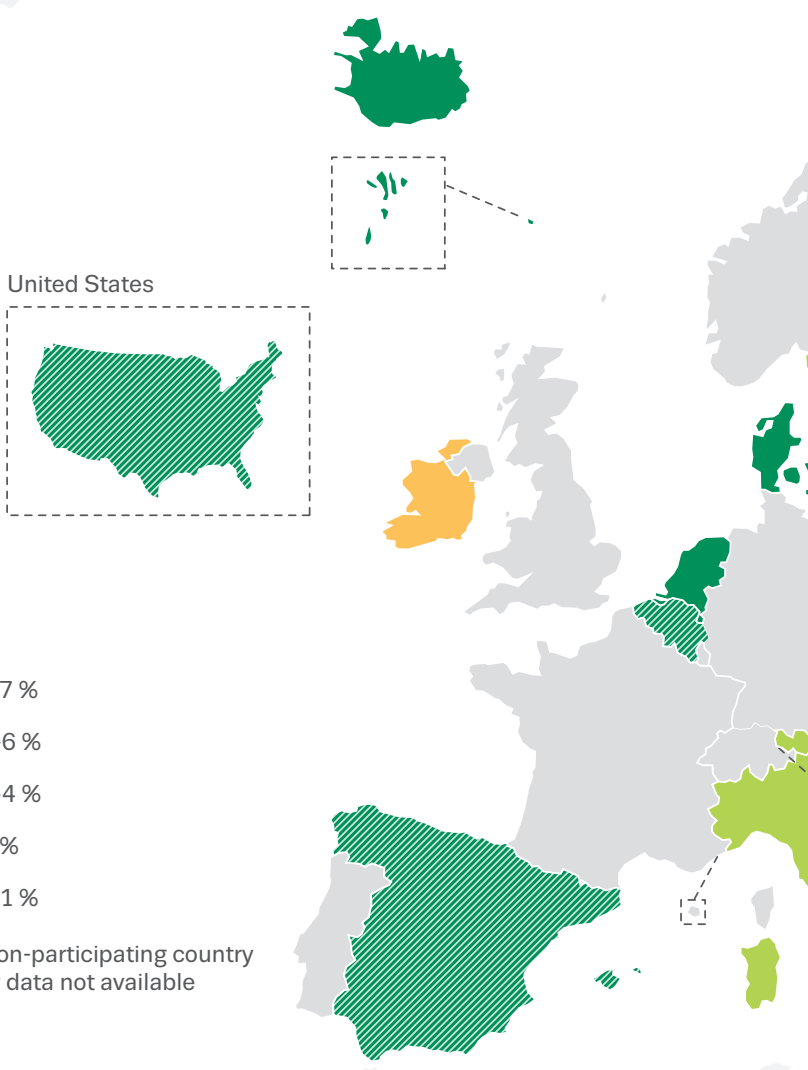
Figure $8 b . \quad$ Prevalence of inhalant use in the last 30 days by gender (percentage)

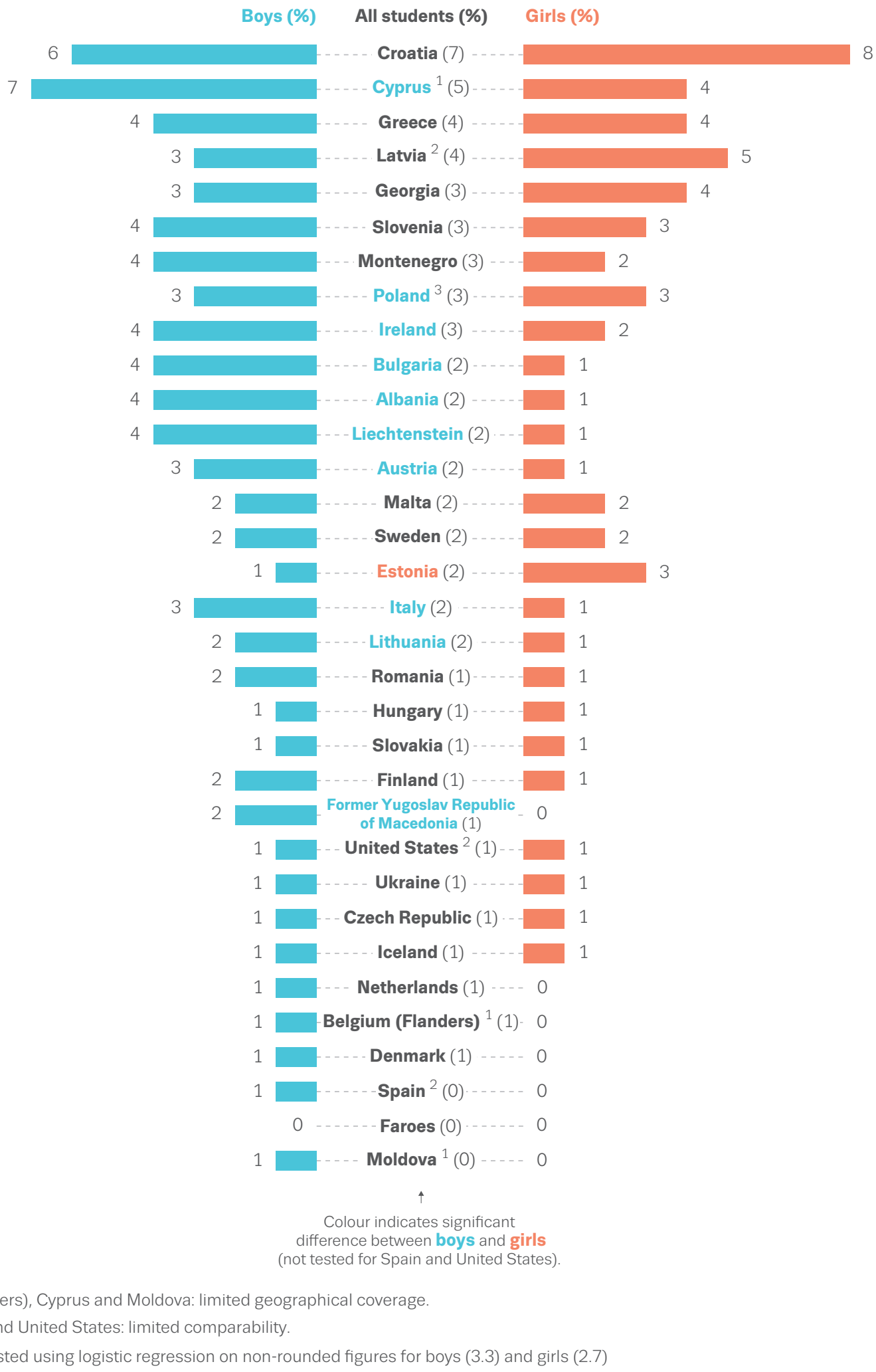




\section{New psychoactive substance use}

Overall, an average of $3 \%$ of the students had used NPS at least once in the last 12 months, with the highest prevalence figures in Bulgaria, Croatia, Estonia, Ireland, Italy and Poland (5-8\%), and the lowest in Belgium (Flanders), Denmark, the Faroes, Finland, the former Yugoslav Republic of Macedonia,
Moldova, the Netherlands, Norway and Portugal, with $1 \%$ each (Figure 9a). Generally, differences in NPS use between boys and girls were small. However, significantly more boys than girls reported the use of NPS in Albania, Cyprus, Georgia, Greece, Moldova, Montenegro, the Netherlands, and significantly more girls than boys in the Czech Republic and Iceland (Figure 9b).

Figure 9a. Prevalence of new psychoactive substance use in the last 12 months (percentage)

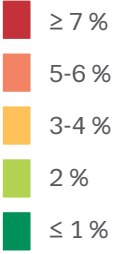

$\leq 1 \%$

Non-participating country or data not available

Cross-hatching indicates limited comparability or limited geographical coverage.

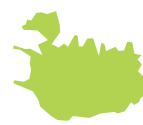

United States
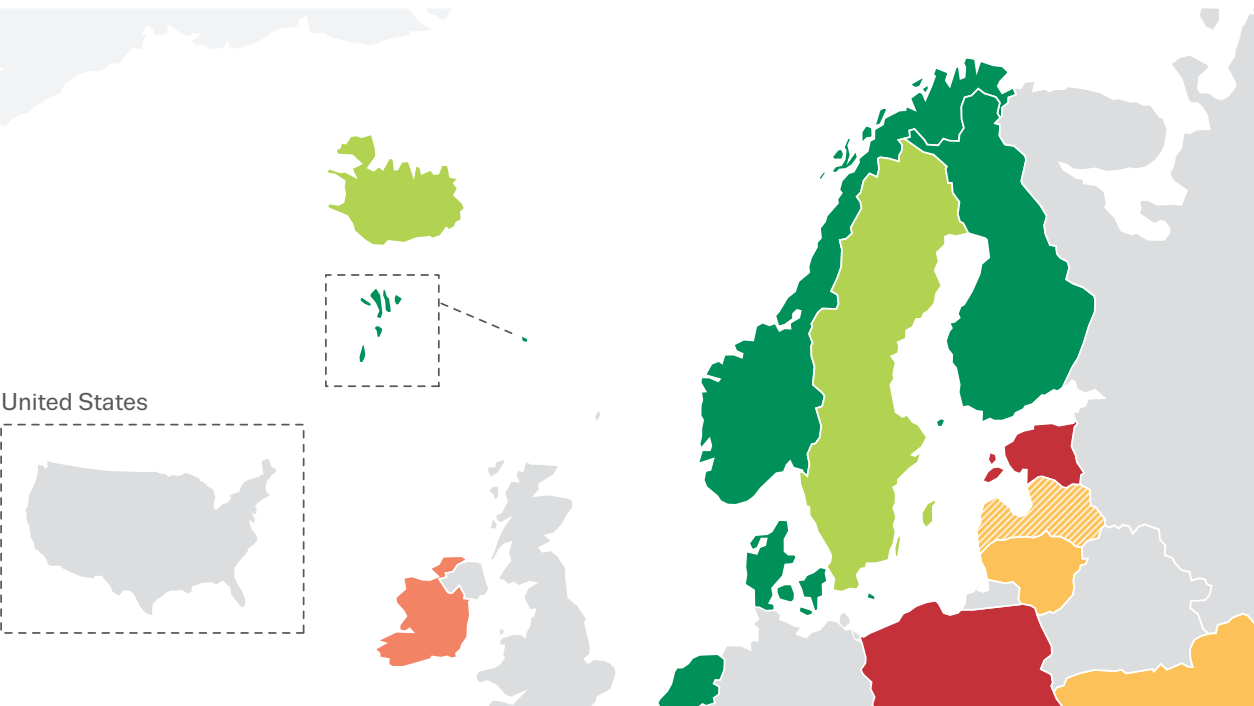

(1) 
Figure 9b. Prevalence of new psychoactive substance use in the last 12 months by gender (percentage)

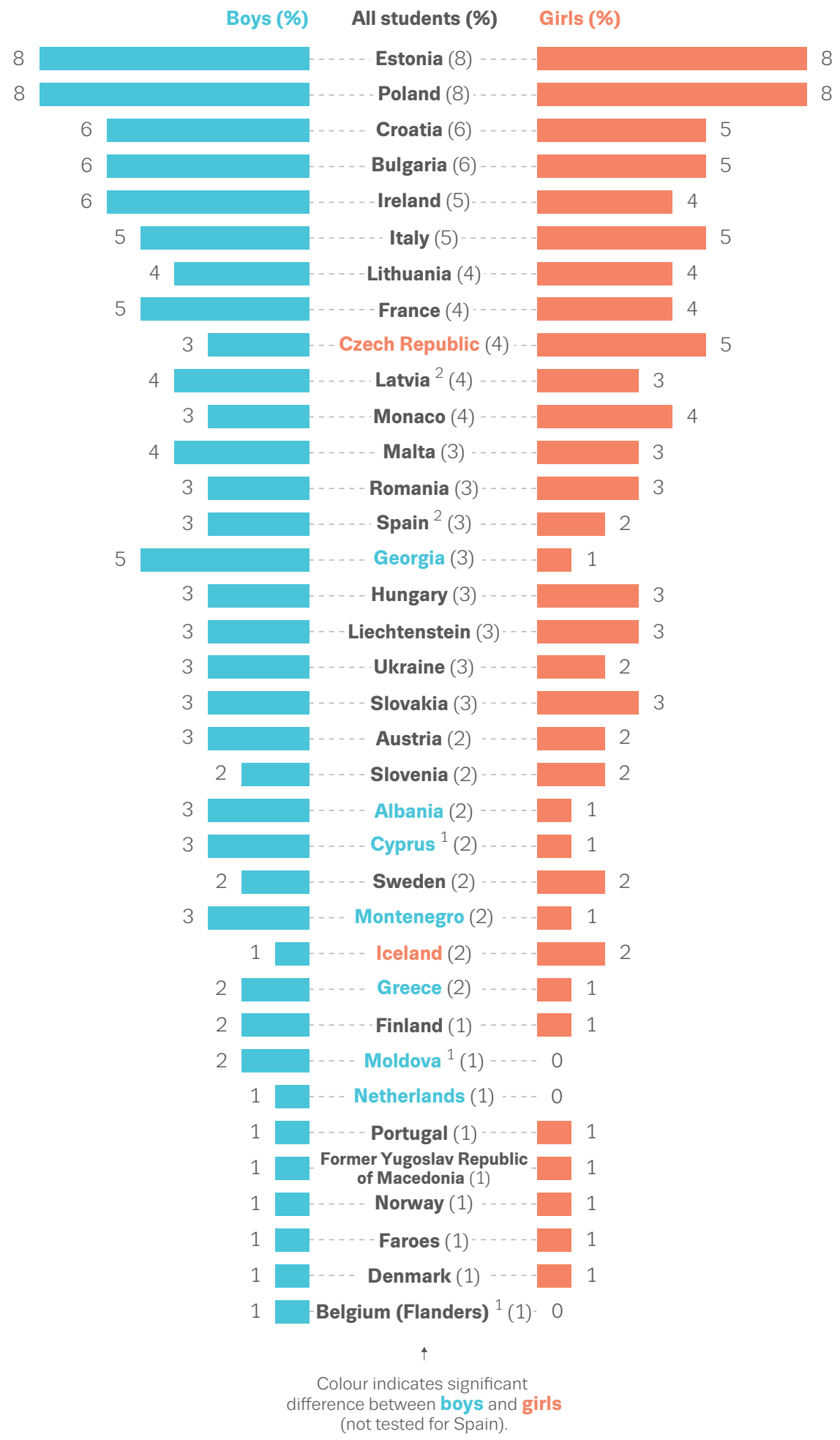

1 Belgium (Flanders), Cyprus and Moldova: limited geographical coverage.

2 Latvia and Spain: limited comparability. 


\section{Internet use, gaming, gambling}

\begin{tabular}{|c|c|c|c|}
\hline \multicolumn{4}{|c|}{$\begin{array}{c}\text { ESPAD average } \\
\text { Internet use, gaming and gambling (mean, \%) }\end{array}$} \\
\hline & Average & Min. & Max. \\
\hline Days online (mean) ${ }^{a}$ & 5.8 & 3.8 & 6.8 \\
\hline \multicolumn{4}{|l|}{ Internet activities (\%) b } \\
\hline Social media & 78 & 58 & 94 \\
\hline Information seeking/surfing & 43 & 26 & 63 \\
\hline Streaming/downloading & 48 & 28 & 80 \\
\hline Gaming & 23 & 13 & 45 \\
\hline Money gambling & 3 & 1 & 8 \\
\hline Buying/selling & 9 & 3 & 19 \\
\hline \multicolumn{4}{|l|}{ Gambling (\%) ${ }^{c}$} \\
\hline At least once & 14 & 5 & 30 \\
\hline Frequently ${ }^{d}$ & 7 & 3 & 16 \\
\hline
\end{tabular}

a Number of days spent on the internet in the last 7 days.

b Percentage of students spending 4 or more days on the internet in the last 7 days.

c Percentage of students involved in gambling with money in the last 12 months.

d Percentage of students reporting gambling with money 2-4 times a month or more often.

\section{Internet use}

On average, the students reported use of the internet on 5.8 days within the last 7 days prior to the survey (Table 11a). The frequency of use was lower in Albania, Bulgaria, the former Yugoslav Republic of Macedonia, Georgia, Montenegro, Romania and Ukraine (3.8-5.1 days). Students in Denmark (6.8 days), Iceland (6.7 days), Finland, the Netherlands, Sweden (6.6 days each) and Estonia (6.5 days) were online every day of the week. No gender differences were observed.

\section{Internet activities}

Overall, $78 \%$ of the students had used the internet for social media activities regularly, i.e. on 4 or more days during the last 7 days (Tables 11a, 11b). Using social media was the predominant internet activity, and was reported by between $58 \%$ (Albania) and $94 \%$ (Finland) of the students. There were gender differences in the use of social media, with higher figures overall for girls than boys. In two thirds of the ESPAD countries, rates among girls were 10 or more percentage points higher than among boys. Exceptions were Albania (63\% for boys versus $54 \%$ for girls) and Monaco (87\% versus $80 \%$ ), where more boys than girls reported social media use.
Slightly less than half of the students were regularly (at least four times for each of these activities in the last 7 days) using the internet for information seeking/surfing (43\% on average) or streaming/downloading (48\%). The highest figures for information seeking/surfing were found in Monaco (63\%), Finland (61 \%) and Denmark (58 \%), and for streaming/downloading in Norway (80 \%), Finland (74 \%) and Cyprus (67\%). Lower rates (30\% or less) of information seeking/surfing were reported in Montenegro and Portugal, and for streaming/downloading in the Czech Republic. With few exceptions, in nearly all countries, more girls than boys used the internet for information seeking/surfing or streaming/downloading. Nearly every 10th student (9\%) regularly used the internet for buying/selling, ranging from $3 \%$ in Iceland and Liechtenstein to $19 \%$ in Hungary and the Netherlands. On average, $11 \%$ of the boys and $8 \%$ of the girls reported these activities.

\section{Online gaming and gambling}

More than one in five students (23\%) used the internet for online gaming regularly (at least four times in the last 7 days) (Table 11b). Nearly half of the students from Denmark played regularly online (45\%). Regular online gaming was not so common in Georgia (13\%), the former Yugoslav Republic of Macedonia and Moldova (16 \% each). Online gaming was much more common among boys (39\%) than girls (7\%). Among boys, the highest figures for the regular playing of online games were found in Denmark (64 \%), Sweden (58 \%), Estonia (55 \%), Norway (52 \%) and Finland (51\%), and the lowest in Georgia and Monaco (23\% each). The countries with the highest proportion of girls reporting regularly playing games online were Denmark (28\%) and Monaco (18\%).

Online money gambling was the least common of the internet activities (ESPAD average: $3 \%$ ), with the highest figures in Bulgaria (8\%), Albania, Cyprus and the former Yugoslav Republic of Macedonia (7 \% each). Like online gaming, online gambling for money is predominantly done by boys ( $6 \%$ compared with $1 \%$ of girls). The highest rates of boys reporting online gambling for money were found in Albania, Bulgaria, Croatia, Cyprus and the former Yugoslav Republic of Macedonia (11-13\%). 
Table 11a. Average number of days on the internet (mean number of days) and prevalence of internet activities on 4 or more days in the last 7 days (percentage)

\begin{tabular}{|c|c|c|c|c|c|c|c|c|c|c|c|c|}
\hline \multirow[t]{2}{*}{ Country } & \multirow[t]{2}{*}{$\begin{array}{l}\text { Days } \\
\text { online }\end{array}$} & \multirow[t]{2}{*}{$\begin{array}{l}\text { Social } \\
\text { media }\end{array}$} & \multirow{2}{*}{$\begin{array}{l}\text { Infor- } \\
\text { mation } \\
\text { seeking, } \\
\text { surfing }\end{array}$} & \multirow{2}{*}{$\begin{array}{l}\text { Streaming/ } \\
\text { download- } \\
\text { ing music, } \\
\text { films, etc. }\end{array}$} & \multicolumn{2}{|c|}{ Days online } & \multicolumn{2}{|c|}{ Social media } & \multicolumn{2}{|c|}{$\begin{array}{l}\text { Information } \\
\text { seeking, surfing }\end{array}$} & \multicolumn{2}{|c|}{$\begin{array}{c}\text { Streaming/ } \\
\text { downloading } \\
\text { music, films, etc. }\end{array}$} \\
\hline & & & & & Boys & Girls & Boys & Girls & Boys & Girls & Boys & Girls \\
\hline Albania & 4.1 & 58 & 38 & 46 & 4.4 & 3.8 & 63 & 54 & 32 & 43 & 46 & 46 \\
\hline Austria & 6.1 & 85 & 42 & 39 & 6.1 & 6.1 & 80 & 91 & 37 & 47 & 42 & 36 \\
\hline Belgium (Flanders) & & & & . & & & & . & . & . & . & . \\
\hline Bulgaria & 5.1 & 75 & 49 & 48 & 4.9 & 5.2 & 70 & 81 & 43 & 54 & 48 & 48 \\
\hline Croatia & 5.8 & 83 & 46 & 38 & 5.7 & 6.0 & 77 & 89 & 43 & 49 & 41 & 33 \\
\hline Cyprus & 6.2 & 77 & 36 & 67 & 5.9 & 6.4 & 66 & 86 & 34 & 39 & 59 & 75 \\
\hline Czech Republic & 6.2 & 83 & 42 & 28 & 6.1 & 6.3 & 77 & 88 & 42 & 42 & 29 & 27 \\
\hline Denmark & 6.8 & 85 & 58 & 50 & 6.8 & 6.9 & 81 & 89 & 53 & 62 & 53 & 48 \\
\hline Estonia & 6.5 & 85 & 53 & 42 & 6.5 & 6.5 & 80 & 90 & 48 & 58 & 42 & 43 \\
\hline Faroes & 6.1 & 89 & 31 & 32 & 6.3 & 6.0 & 85 & 94 & 32 & 31 & 31 & 33 \\
\hline Finland & 6.6 & 94 & 61 & 74 & 6.5 & 6.7 & 92 & 96 & 58 & 64 & 69 & 79 \\
\hline FYR Macedonia ${ }^{a}$ & 4.0 & 66 & 40 & 38 & 4.1 & 3.9 & 65 & 68 & 39 & 41 & 40 & 36 \\
\hline France & 6.2 & 79 & 40 & 35 & 6.2 & 6.3 & 74 & 85 & 40 & 39 & 36 & 34 \\
\hline Georgia & 3.8 & 64 & 36 & 48 & 3.9 & 3.7 & 60 & 67 & 31 & 42 & 47 & 49 \\
\hline Greece & 5.8 & 79 & 33 & 64 & 5.6 & 5.9 & 74 & 83 & 32 & 35 & 60 & 68 \\
\hline Hungary & 6.1 & 80 & 35 & 43 & 6.1 & 6.2 & 74 & 87 & 33 & 37 & 41 & 45 \\
\hline Iceland & 6.7 & 83 & 45 & 62 & 6.7 & 6.6 & 77 & 88 & 45 & 45 & 60 & 65 \\
\hline Ireland & 6.3 & 82 & 37 & 43 & 6.3 & 6.4 & 76 & 88 & 34 & 41 & 41 & 45 \\
\hline Italy & 5.7 & 80 & 44 & 40 & 5.6 & 5.9 & 74 & 88 & 41 & 47 & 36 & 44 \\
\hline Liechtenstein & 6.4 & 89 & 40 & 38 & 6.3 & 6.5 & 85 & 93 & 41 & 40 & 39 & 37 \\
\hline Lithuania & 5.7 & 71 & 38 & 52 & 5.6 & 5.8 & 60 & 82 & 34 & 42 & 49 & 56 \\
\hline Malta & 6.1 & 85 & 36 & 48 & 5.9 & 6.3 & 79 & 90 & 34 & 39 & 43 & 53 \\
\hline Moldova & 5.5 & 63 & 47 & 57 & 5.3 & 5.7 & 56 & 69 & 38 & 57 & 55 & 60 \\
\hline Monaco & 6.5 & 84 & 63 & 37 & 6.4 & 6.6 & 87 & 80 & 61 & 65 & 36 & 39 \\
\hline Montenegro & 4.9 & 65 & 30 & 35 & 4.8 & 4.9 & 59 & 72 & 25 & 35 & 32 & 39 \\
\hline Netherlands & 6.6 & 92 & 34 & 65 & 6.5 & 6.7 & 87 & 96 & 30 & 38 & 62 & 68 \\
\hline Norway & 5.9 & 88 & 56 & 80 & 5.8 & 6.0 & 84 & 94 & 54 & 58 & 75 & 86 \\
\hline Poland & 5.9 & 78 & 54 & 58 & 5.8 & 6.0 & 73 & 82 & 52 & 56 & 57 & 58 \\
\hline Portugal & 5.9 & 74 & 26 & 43 & 5.8 & 5.9 & 68 & 80 & 25 & 27 & 45 & 41 \\
\hline Romania & 4.4 & 67 & 33 & 33 & 4.2 & 4.6 & 60 & 74 & 27 & 39 & 32 & 34 \\
\hline Slovakia & 6.0 & 65 & 36 & 43 & 6.0 & 6.0 & 59 & 71 & 36 & 36 & 39 & 46 \\
\hline Slovenia & 6.3 & 78 & 41 & 63 & 6.1 & 6.4 & 69 & 86 & 37 & 44 & 57 & 68 \\
\hline Sweden & 6.6 & 85 & 53 & 36 & 6.5 & 6.7 & 79 & 91 & 48 & 59 & 36 & 36 \\
\hline Ukraine & 4.9 & 75 & 50 & 45 & 4.7 & 5.1 & 68 & 82 & 44 & 55 & 41 & 48 \\
\hline AVERAGE & 5.8 & 78 & 43 & 48 & 5.7 & 5.9 & 73 & 83 & 39 & 46 & 46 & 49 \\
\hline Latvia & 5.3 & 78 & 50 & 66 & 5.3 & 5.4 & 5 & 2 & 2 & 1 & 2 & 3 \\
\hline Spain & 5.9 & & & . & 5.8 & 6.0 & & & . & . & . & . \\
\hline United States & & & & & & & & & & & & \\
\hline
\end{tabular}

a Official name former Yugoslav Republic of Macedonia. 
Table 11b. Prevalence of internet activities on 4 or more days in the last 7 days by gender (percentage)

\begin{tabular}{|c|c|c|c|c|c|c|c|c|c|}
\hline \multirow{2}{*}{ Country } & \multirow{2}{*}{ Gaming } & \multirow{2}{*}{$\begin{array}{l}\text { Money } \\
\text { gambling }\end{array}$} & \multirow{2}{*}{ Buying/selling } & \multicolumn{2}{|c|}{ Gaming } & \multicolumn{2}{|c|}{ Money gambling } & \multicolumn{2}{|c|}{ Buying/selling } \\
\hline & & & & Boys & Girls & Boys & Girls & Boys & Girls \\
\hline Albania & 19 & 7 & 10 & 28 & 11 & 11 & 3 & 13 & 8 \\
\hline Austria & 21 & 1 & 7 & 37 & 5 & 2 & 0 & 8 & 5 \\
\hline Belgium (Flanders) & . & . & . & . & . & . & . & . & . \\
\hline Bulgaria & 25 & 8 & 16 & 41 & 10 & 13 & 4 & 18 & 14 \\
\hline Croatia & 23 & 6 & 9 & 39 & 6 & 11 & 2 & 11 & 6 \\
\hline Cyprus & 25 & 7 & 13 & 42 & 9 & 12 & 3 & 16 & 10 \\
\hline Czech Republic & 26 & 3 & 11 & 44 & 7 & 4 & 1 & 11 & 10 \\
\hline Denmark & 45 & 5 & 8 & 64 & 28 & 9 & 1 & 8 & 8 \\
\hline Estonia & 31 & 3 & 4 & 55 & 6 & 6 & 1 & 6 & 3 \\
\hline Faroes & 26 & 1 & 6 & 50 & 3 & 2 & 0 & 4 & 8 \\
\hline Finland & 27 & 2 & 5 & 51 & 5 & 3 & 0 & 7 & 3 \\
\hline FYR Macedonia $^{a}$ & 16 & 7 & 14 & 26 & 6 & 11 & 3 & 17 & 10 \\
\hline France & 23 & 1 & 6 & 41 & 6 & 1 & 0 & 7 & 6 \\
\hline Georgia & 13 & 6 & 10 & 23 & 2 & 10 & 1 & 13 & 6 \\
\hline Greece & 18 & 3 & 5 & 33 & 3 & 5 & 1 & 6 & 4 \\
\hline Hungary & 21 & 3 & 19 & 35 & 8 & 5 & 1 & 22 & 15 \\
\hline Iceland & 22 & 1 & 3 & 41 & 4 & 2 & 0 & 3 & 3 \\
\hline Ireland & 18 & 3 & 10 & 32 & 3 & 5 & 0 & 12 & 8 \\
\hline Italy & 22 & 3 & 9 & 33 & 10 & 5 & 1 & 11 & 8 \\
\hline Liechtenstein & 20 & 1 & 3 & 41 & 2 & 1 & 0 & 6 & 1 \\
\hline Lithuania & 30 & 5 & 11 & 46 & 13 & 9 & 1 & 13 & 9 \\
\hline Malta & 24 & 1 & 13 & 41 & 8 & 2 & 0 & 12 & 13 \\
\hline Moldova & 16 & 2 & 12 & 28 & 4 & 3 & 1 & 17 & 6 \\
\hline Monaco & 20 & 2 & 8 & 23 & 18 & 3 & 2 & 10 & 7 \\
\hline Montenegro & 18 & 5 & 9 & 31 & 6 & 8 & 2 & 11 & 7 \\
\hline Netherlands & 27 & 4 & 19 & 48 & 6 & 7 & 2 & 22 & 16 \\
\hline Norway & 30 & 2 & 14 & 52 & 5 & 4 & 1 & 16 & 12 \\
\hline Poland & 22 & 3 & 10 & 39 & 6 & 5 & 1 & 11 & 8 \\
\hline Portugal & 20 & 2 & 5 & 39 & 5 & 5 & 0 & 8 & 3 \\
\hline Romania & 21 & 4 & 9 & 36 & 7 & 6 & 2 & 12 & 6 \\
\hline Slovakia & 20 & 4 & 11 & 31 & 9 & 5 & 2 & 12 & 10 \\
\hline Slovenia & 18 & 3 & 9 & 33 & 4 & 5 & 1 & 10 & 7 \\
\hline Sweden & 32 & 5 & 10 & 58 & 7 & 7 & 2 & 13 & 7 \\
\hline Ukraine & 17 & 2 & 6 & 30 & 5 & 3 & 1 & 7 & 4 \\
\hline AVERAGE & 23 & 3 & 9 & 39 & 7 & 6 & 1 & 11 & 8 \\
\hline Latvia & 27 & 8 & 13 & 2 & 0 & 2 & 1 & 7 & 7 \\
\hline Spain & . & . & . & . & . & . & . & . & . \\
\hline United States & . & & . & . & . & & . & & . \\
\hline
\end{tabular}

a Official name former Yugoslav Republic of Macedonia.

\section{Gambling}

On average, $14 \%$ of the students reported gambling for money at least once and $7 \%$ had gambled frequently (2-4 times a month or more often; Table 12) in the last 12 months. The highest rates of gambling in the past year (30 \%) and frequent gambling (16\%) were found in Greece. About one in five students in Cyprus, Finland, Montenegro and Slovenia reported gambling in the past 12 months, and, in addition to Greece, more than every 10th student in Finland and Ireland gambled frequently. In all countries, considerably more boys than girls had gambled in the previous year (23\% versus $5 \%$ on average) or gambled frequently (12\% versus $2 \%$ ). About one third or more of the boys in Croatia, Cyprus, Finland, Greece, Montenegro and Slovenia reported gambling with money in the last 12 months. At least $20 \%$ of the boys reported having gambled frequently in Cyprus, Greece, Montenegro and Slovenia. In Greece, 12 \% of the girls reported gambling experience in the previous 12 months and $3 \%$ gambled frequently. Comparably high proportions for girls were also found in Slovenia (11\% gambling experience, $4 \%$ frequent gambling). 
Table 12. Gambling for money: prevalence in the last 12 months (percentage)

\begin{tabular}{|c|c|c|c|c|c|c|}
\hline \multirow{2}{*}{ Country } & \multirow{2}{*}{ At least once } & \multirow{2}{*}{ Frequently } & \multicolumn{2}{|c|}{ At least once } & \multicolumn{2}{|c|}{ Frequently } \\
\hline & & & Boys & Girls & Boys & Girls \\
\hline Albania & 8 & 3 & 15 & 2 & 10 & 1 \\
\hline Austria & 7 & 4 & 11 & 2 & 5 & 0 \\
\hline Belgium (Flanders) & . & . & . & . & . & . \\
\hline Bulgaria & 18 & 7 & 30 & 7 & 19 & 3 \\
\hline Croatia & 19 & 8 & 33 & 4 & 20 & 2 \\
\hline Cyprus & 23 & 9 & 39 & 8 & 26 & 3 \\
\hline Czech Republic & 9 & 5 & 15 & 3 & 7 & 1 \\
\hline Denmark & 16 & 8 & 29 & 4 & 16 & 0 \\
\hline Estonia & 12 & 6 & 20 & 4 & 10 & 2 \\
\hline Faroes & 11 & 7 & 20 & 2 & 8 & 0 \\
\hline Finland & 20 & 13 & 34 & 7 & 14 & 1 \\
\hline FYR Macedonia a & 14 & 6 & 23 & 5 & 14 & 2 \\
\hline France & 17 & 9 & 27 & 8 & 15 & 2 \\
\hline Georgia & 14 & 4 & 24 & 3 & 17 & 2 \\
\hline Greece & 30 & 16 & 49 & 12 & 27 & 3 \\
\hline Hungary & 16 & 6 & 26 & 6 & 17 & 3 \\
\hline Iceland & 7 & 4 & 12 & 2 & 4 & 1 \\
\hline Ireland & 16 & 11 & 26 & 6 & 9 & 1 \\
\hline Italy & 15 & 6 & 24 & 5 & 15 & 2 \\
\hline Liechtenstein & 9 & 4 & 17 & 2 & 9 & 1 \\
\hline Lithuania & 12 & 6 & 20 & 3 & 11 & 1 \\
\hline Malta & 7 & 4 & 12 & 3 & 5 & 1 \\
\hline Moldova & 5 & 3 & 9 & 2 & 4 & 1 \\
\hline Monaco & 14 & 7 & 23 & 6 & 12 & 2 \\
\hline Montenegro & 23 & 8 & 38 & 8 & 26 & 3 \\
\hline Netherlands & 14 & 9 & 23 & 5 & 9 & 1 \\
\hline Norway & 7 & 4 & 11 & 3 & 6 & 1 \\
\hline Poland & 10 & 5 & 17 & 4 & 9 & 3 \\
\hline Portugal & 8 & 4 & 14 & 4 & 8 & 1 \\
\hline Romania & 13 & 6 & 22 & 5 & 12 & 2 \\
\hline Slovakia & 14 & 7 & 24 & 5 & 12 & 2 \\
\hline Slovenia & 21 & 9 & 32 & 11 & 20 & 4 \\
\hline Sweden & 13 & 5 & 22 & 5 & 14 & 2 \\
\hline Ukraine & 7 & 4 & 12 & 3 & 6 & 1 \\
\hline AVERAGE & 14 & 7 & 23 & 5 & 12 & 2 \\
\hline Latvia & 16 & 8 & 23 & 9 & 12 & 4 \\
\hline Spain & 16 & 6 & 29 & 9 & 14 & 2 \\
\hline United States & & . & . & . & . & . \\
\hline
\end{tabular}

a Official name former Yugoslav Republic of Macedonia. 



\section{Trends 1995-2015}

This chapter presents changes in substance use for selected indicators from 1995 to 2015. The indicators covered include students' perceptions of substance use availability, early onset of substance use, substance use experience and patterns of substance use. Sample sizes and class participation rates for all countries are shown in Table 13. the Faroes, Finland, France, Greece, Hungary, Iceland, Ireland, Italy, Lithuania, Malta, the Netherlands, Norway, Poland, Portugal, Romania, Slovakia, Slovenia, Sweden and Ukraine (Figure 10). Trends for 15 key variables are shown in Table 14 and trends by gender are graphically depicted in Figures 11-25.

\section{Trends across 25 countries}

In this section, overall trends measured across countryspecific means of 25 countries are reported between 1995 and 2015. The 25 countries included are Bulgaria, Croatia, Cyprus, the Czech Republic, Denmark, Estonia,

\section{Figure 10. Countries included in the 25-country average (marked in blue)}

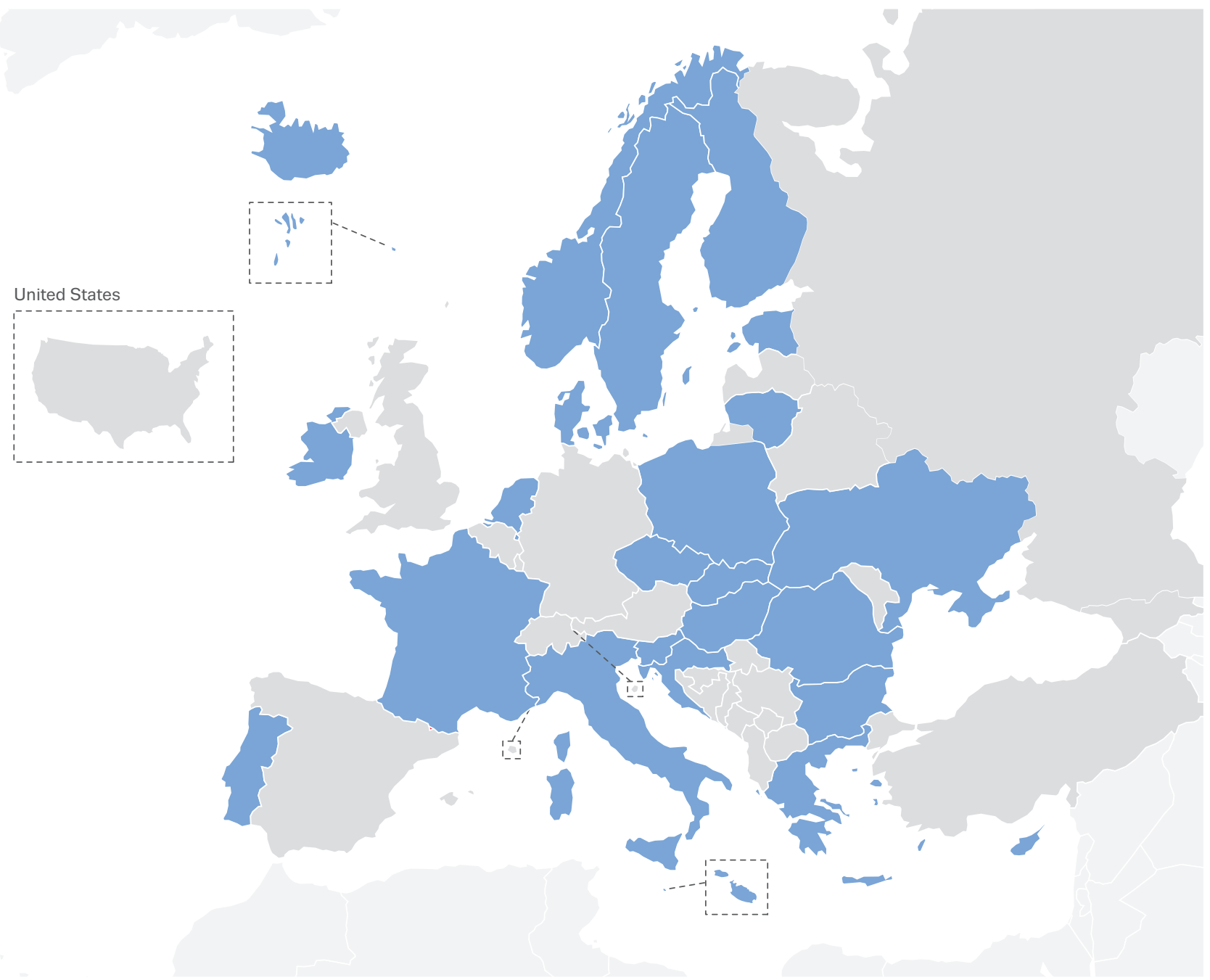


Table 13. Overview of ESPAD surveys conducted between 1995 and 2015 by country: sample size and participation rate

\begin{tabular}{|c|c|c|c|c|c|c|c|c|c|c|c|c|}
\hline \multirow{2}{*}{ Country } & \multicolumn{2}{|c|}{1995} & \multicolumn{2}{|c|}{1999} & \multicolumn{2}{|c|}{2003} & \multicolumn{2}{|c|}{2007} & \multicolumn{2}{|c|}{2011} & \multicolumn{2}{|c|}{2015} \\
\hline & $n$ & $\%^{a}$ & $n$ & $\%^{a}$ & $n$ & $\%^{a}$ & $n$ & $\%^{a}$ & $n$ & $\%$ & $n^{\text {a }}$ & $\%^{\mathrm{a}}$ \\
\hline Albania & & & . & . & 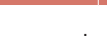 & & & . & 3189 & 100 & 2553 & 100 \\
\hline Austria & & & . & . & 2402 & 73 & 2571 & 63 & & & 3684 & $17^{b}$ \\
\hline Belgium (Flanders) & . & & . & . & $2320^{c}$ & 88 & $1889^{d}$ & $54^{e}$ & $1798^{f}$ & $58^{e}$ & $1771^{f}$ & $56^{e}$ \\
\hline $\begin{array}{l}\text { Bosnia and } \\
\text { Herzegovina (FBiH) }\end{array}$ & & & . & . & & & $2973 \mathrm{~g}$ & 100 & $3813^{d}$ & 99 & & 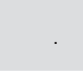 \\
\hline $\begin{array}{l}\text { Bosnia and } \\
\text { Herzegovina (RS) }\end{array}$ & & & & & & & $2609 \mathrm{~g}$ & 97 & 3132 & 98 & 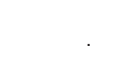 & \\
\hline Bulgaria & & & 5391 & 100 & 2740 & 100 & 2353 & 100 & 2217 & 100 & 2922 & 98 \\
\hline Croatia & 2815 & 100 & 3602 & 100 & 2884 & 99 & 3008 & 99 & 3002 & 90 & 2558 & 98 \\
\hline Cyprus & 632 & 100 & 2095 & 100 & 2152 & $98^{e}$ & 6340 & 100 & 4243 & 76 & 2098 & 85 \\
\hline Czech Republic & 2962 & 100 & 3579 & 99 & 3195 & 100 & 3901 & 100 & 3913 & 98 & 2738 & $96^{\mathrm{e}}$ \\
\hline Denmark & 2439 & 78 & 1790 & 56 & 2978 & 65 & 877 & 46 & 2181 & $42^{e}$ & 1670 & $26^{e}$ \\
\hline Estonia & 3118 & 94 & 3254 & 89 & 2463 & 80 & 2372 & 90 & 2460 & 95 & 2452 & 90 \\
\hline Faroes & 543 & 100 & 463 & 100 & 640 & 97 & 552 & 100 & 557 & 100 & 511 & 100 \\
\hline Finland & 2300 & 100 & 3286 & $99^{e}$ & 3543 & 97 & 4988 & 99 & 3744 & 81 & 4049 & 85 \\
\hline FYR Macedonia ${ }^{k}$ & & & 5199 & 100 & & & $2452 \mathrm{~g}$ & 97 & & & 2428 & 98 \\
\hline France & & & 2284 & 97 & 2199 & 86 & 2916 & 98 & 2572 & 95 & 2714 & 93 \\
\hline Germany ${ }^{h}$ & & & & & 5110 & 91 & 5011 & 90 & 2796 & 40 & & . \\
\hline Greece & . & . & 2259 & 94 & 1906 & 97 & 3060 & 88 & 5908 & 87 & 3202 & 95 \\
\hline Greenland & & & 421 & $76^{e}$ & 555 & n.a. & & & & & & \\
\hline Hungary & 2571 & 99 & 6421 & 92 & 2677 & 98 & 2817 & 94 & 3063 & 85 & 2735 & 93 \\
\hline Iceland & 3814 & 90 & 3524 & $99 e$ & 3348 & 98 & 3510 & 97 & 3333 & 95 & 2663 & 79 \\
\hline Ireland & 1849 & 81 & 2277 & 100 & 2407 & 91 & 2221 & 76 & 2207 & 72 & 1470 & $18^{b}$ \\
\hline Isle of Man & & & & . & 721 & $100^{e}$ & 740 & 100 & $i^{i}$ & & & . \\
\hline Italy & 1555 & 99 & 4106 & 100 & 4871 & 97 & 9981 & 99 & 4837 & 88 & 4059 & 85 \\
\hline Latvia & 2179 & 49 & 2284 & 90 & 2841 & 97 & 2275 & 93 & 2622 & 95 & 1119 & 42 \\
\hline Liechtenstein & . & & . & . & . & . & . & . & 366 & 100 & 316 & 100 \\
\hline Lithuania & 3196 & 100 & 5039 & 100 & 5036 & 100 & 2411 & 99 & 2476 & 99 & 2573 & 99 \\
\hline Malta & 2832 & 100 & 4321 & 100 & 3500 & 99 & 3668 & 99 & 3377 & 100 & 3326 & 98 \\
\hline Moldova & & & . & . & & & $3176^{g}$ & 99 & 2162 & 100 & 2586 & 100 \\
\hline Monaco & . & & . & . & . & & 393 & 100 & 401 & 100 & 397 & 100 \\
\hline Montenegro & & & . & . & . & & $5823^{g}$ & 100 & 3387 & 100 & 3844 & 100 \\
\hline Netherlands & & & 2615 & n.a. & 2095 & 97 & 2091 & 98 & $2044^{d}$ & $50^{e}$ & $1684^{d}$ & $43^{e}$ \\
\hline Norway & 3910 & 90 & 3918 & 86 & 3833 & 77 & 3482 & $58^{e}$ & 2938 & 28 & 2584 & 53 \\
\hline Poland & 8940 & 96 & 3330 & n.a. & 5964 & 98 & 2120 & 93 & 5933 & 94 & 11822 & 94 \\
\hline Portugal & 2033 & 100 & 3609 & 100 & 2946 & 98 & 3141 & 95 & 1965 & 90 & 3456 & 96 \\
\hline Romania & & & 2393 & 94 & 4371 & 100 & 2289 & 98 & 2770 & 100 & 3500 & 100 \\
\hline Russia (Moscow) & & & 2937 & 95 & 1925 & 92 & $3939^{i}$ & $96^{e}$ & 1757 & 77 & & \\
\hline Serbia & & & . & . & & & $6156^{g}$ & $94^{e}$ & 6084 & 97 & . & . \\
\hline Slovakia & 2376 & 99 & 2442 & 100 & 2276 & 98 & 2468 & 100 & 2009 & 100 & 2208 & 100 \\
\hline Slovenia & 3306 & 100 & 3184 & 100 & 2785 & 100 & 3085 & 100 & 3186 & 100 & 3484 & 99 \\
\hline Sweden & 3472 & 94 & 3445 & 89 & 3232 & 87 & 3179 & 87 & 2569 & 80 & 2551 & 83 \\
\hline Switzerland & & & . & . & 2613 & 86 & 2499 & 88 & . & . & . & . \\
\hline Ukraine & 7193 & 99 & 2994 & $97^{e}$ & 4173 & 98 & 2447 & 98 & 2210 & 99 & 2350 & 98 \\
\hline United Kingdom & 7722 & $46^{e}$ & 2641 & $74^{e}$ & 2068 & $55^{\mathrm{e}}$ & 2179 & 40 & 1712 & 5 & & 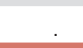 \\
\hline
\end{tabular}

a Class participation rate: proportion of selected classes participating in the survey.

b Estimated from the maximum number of classes that could participate.

c Flanders and Wallonia.

d Data collected in autumn.

e School participation rate (class participation rates not available).

f Data collected in previous autumn.

g Data collected in spring 2008. h Five federal states: Bavaria, Berlin, Brandenburg, Mecklenburg-Western Pomerania and Thuringia.

' Data collected but not delivered

j Russia.

k Official name former Yugoslav Republic of Macedonia.

Red typeface: countries included in the 25-country average. n.a. $=$ not available. 
Table 14. $\quad$ ESPAD average for selected indicators based on 25 countries: 1995-2015

\begin{tabular}{|c|c|c|c|c|c|c|}
\hline Measure & 1995 & 1999 & 2003 & 2007 & 2011 & 2015 \\
\hline Perceived availability of cannabis & 22 & 30 & 33 & 33 & 32 & 32 \\
\hline Early onset of daily cigarette use a & 10 & 9 & 10 & 7 & 7 & 4 \\
\hline Early onset of daily cannabis use a & 2 & 2 & 3 & 3 & 3 & 3 \\
\hline Lifetime use of cigarettes & 67 & 68 & 66 & 59 & 56 & 47 \\
\hline Current cigarette use ${ }^{b}$ & 32 & 36 & 33 & 29 & 29 & 22 \\
\hline Daily cigarette use ${ }^{b}$ & 20 & 24 & 23 & 18 & 18 & 13 \\
\hline Lifetime alcohol use & 89 & 90 & 90 & 88 & 86 & 81 \\
\hline Current alcohol use ${ }^{b}$ & 56 & 61 & 63 & 60 & 58 & 47 \\
\hline Heavy episodic drinking ${ }^{c}$ & 36 & 39 & 40 & 42 & 41 & 35 \\
\hline Lifetime illicit drug use & 11 & 17 & 20 & 18 & 19 & 18 \\
\hline Lifetime cannabis use & 11 & 16 & 19 & 17 & 18 & 17 \\
\hline Lifetime use of illicit drugs other than cannabis & 3 & 6 & 5 & 7 & 6 & 5 \\
\hline Current cannabis use ${ }^{b}$ & 4 & 6 & 8 & 7 & 7 & 7 \\
\hline Lifetime inhalant use & 8 & 9 & 9 & 9 & 9 & 8 \\
\hline $\begin{array}{l}\text { Lifetime use of tranquillisers or sedatives } \\
\text { without a doctor's prescription }\end{array}$ & 8 & 7 & 7 & 7 & 7 & 6 \\
\hline
\end{tabular}

a At age 13 or younger.

b Last 30 days.

${ }^{c}$ More than five drinks on one occasion at least once in the last 30 days.

\section{Availability of cannabis}

The average proportion of students who answered that they would find it easy (combined positive responses on 'very easy' and 'fairly easy') to obtain cannabis, if they wanted to, increased from 1995 to 2003 in both genders and levelled off thereafter (Figure 11). Rates among boys are slightly higher than among girls. Overall, the perceived availability of cannabis among boys increased from $23 \%$ to $33 \%$ and among girls from $21 \%$ to $30 \%$.

\section{Early onset of substance use}

\section{Daily smoking}

On average, between 1995 and 2003 rates of early onset of daily smoking (that is, at the age of 13 or younger) were rather stable at about $10 \%$, but rates dropped thereafter to $4 \%$ in 2015, indicating a strong decrease in early onset daily smoking over the last 10 years (Table 14). Genderspecific trends are almost parallel, with slightly lower rates in girls than boys (1-2 percentage points difference in recent surveys; Figure 12).

\section{Cannabis use}

Rates of cannabis use at the age of 13 years or younger increased slightly until 2003 among girls and until 2007 among boys and stabilised thereafter (Figure 13). Trends by gender are almost parallel, with girls' rates being slightly lower than boys' rates.

\section{Cigarette use}

On average, lifetime prevalence rates of smoking showed a stable trend between 1995 and 2003 and decreased thereafter (Table 14). Rates of lifetime smoking among boys and girls follow this general trend. However, the gender gap in lifetime smoking rates, still visible in 1995, closed in 2015 (Figure 14). Similar trends can be observed for current smoking and daily smoking (Table 14). Rates of current (last30-day) use decreased by 10 percentage points between 1995 and 2015 (Table 14; Figure 15); reductions in daily use amounted to 7 percentage points (Figure 16).

\section{Alcohol use}

The prevalence of lifetime as well as current (last-30-day) use of alcohol decreased between 2003 and 2015 (Table 14; Figures 17 and 18). No gender differences in trends can be observed, with the exception of constantly higher rates among boys. 
The prevalence of heavy episodic drinking, although showing the same level in 2015 as 20 years before, peaked in the middle of the 2000s and has decreased since then. However, as shown in Figure 19, rates of heavy episodic drinking generally increased among girls, resulting in a narrowing of the gender differences over time.

\section{Illicit drug use}

Generally, between 1995 and 2003, an increase can be seen in the prevalence of illicit drug use, most of which occurred between the first two surveys. Since then, the prevalence has remained largely unchanged. Trends in illicit drug use experience among boys and girls follow the general trend, with girls' rates being about 6 percentage points lower than boys' rates (Figure 20). Trends for lifetime cannabis use are similar to the trends for any illicit drug use, with rates being only slightly lower (Table 14 and Figure 21). Prevalence rates of lifetime cannabis use as well as current (last-30-day) use for both genders peaked in 2003 and stabilised thereafter (Figures 21 and 22).

Lifetime use of illicit drugs other than cannabis rose to a peak in 2007 (Table 14; Figure 23). Since 2007, the

Figure 11. Perceived availability of cannabis by gender; students responding cannabis 'fairly easy' or 'very easy' to obtain: 25-country trend 19952015 (percentage)

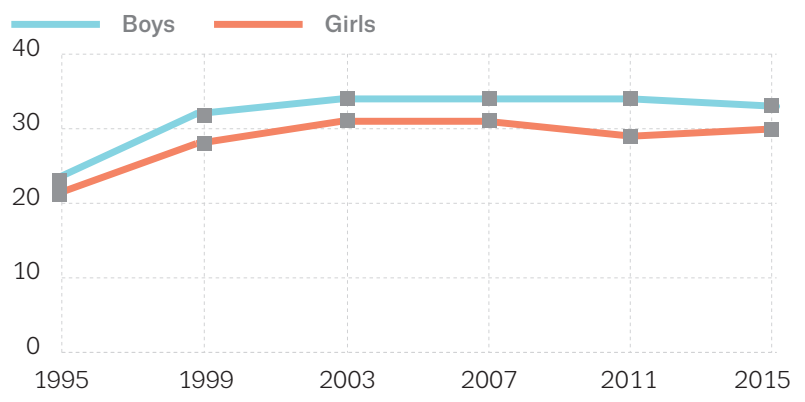

rates appear to have slightly decreased. This trend is also seen for boys and girls, with a consistent gender gap of 1-2 percentage points.

\section{Inhalant use}

The use of other psychoactive substances such as inhalants shows generally stable lifetime prevalence rates over the observed period. The gender-specific curves reveal a narrowing and, by the end, closure of the gender gap, with rates among boys slightly decreasing but rather unchanged rates among girls (Figure 24).

\section{Pharmaceutical use}

The lifetime prevalence rates for the use of tranquillisers or sedatives without a doctor's prescription show a slightly downward trend, with similar trends for boys and girls. Tranquillisers or sedatives are the only psychoactive substances that were taken more frequently by girls than boys (Figure 25)

Figure 12. Daily cigarette use at the age of 13 or younger by gender: 25-country trend 1995-2015 (percentage)

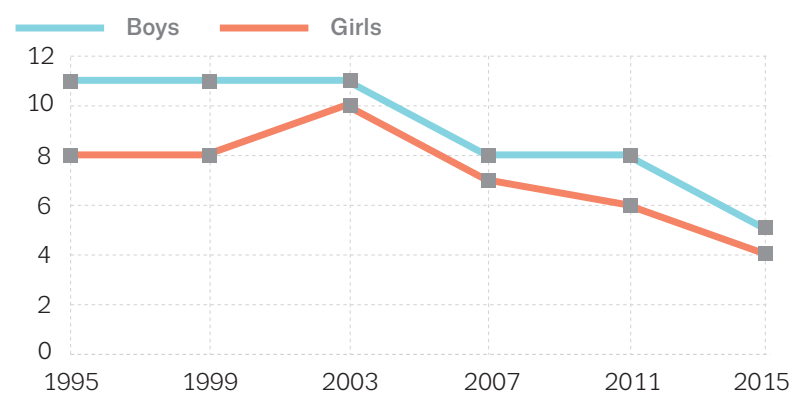


Figure 13. Cannabis use at the age of 13 or younger by gender: 25-country trend 1995-2015 (percentage)

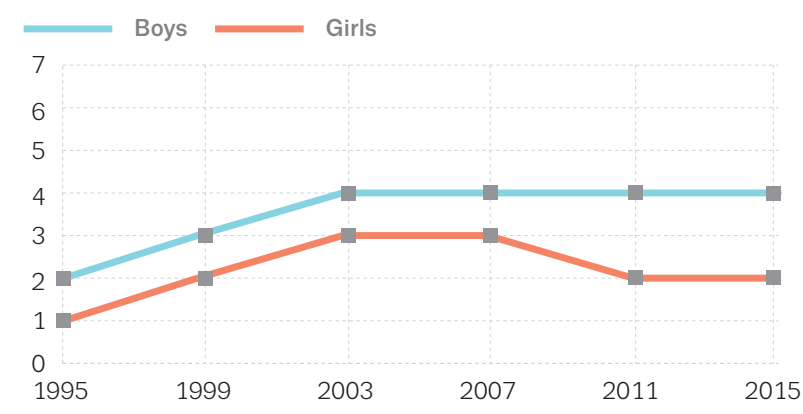

Figure 15. Cigarette use in the last 30 days by gender: 25-country trend 1995-2015 (percentage)

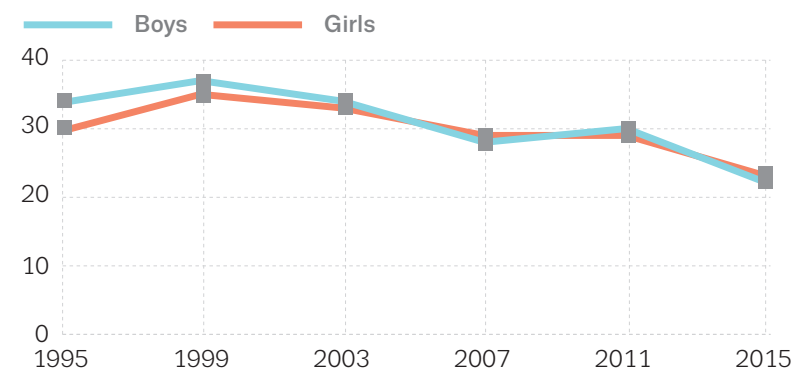

Figure 17. Lifetime alcohol use by gender: 25-country trend 1995-2015 (percentage)

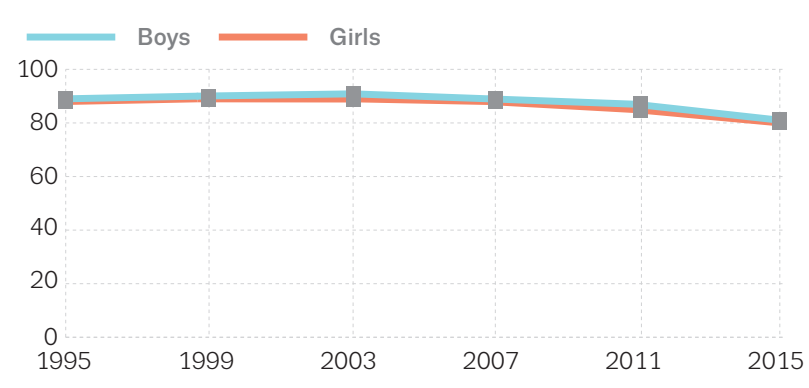

Figure 19. Heavy episodic drinking (five or more drinks on one occasion) during the last 30 days by gender: 25-country trend 1995-2015 (percentage)

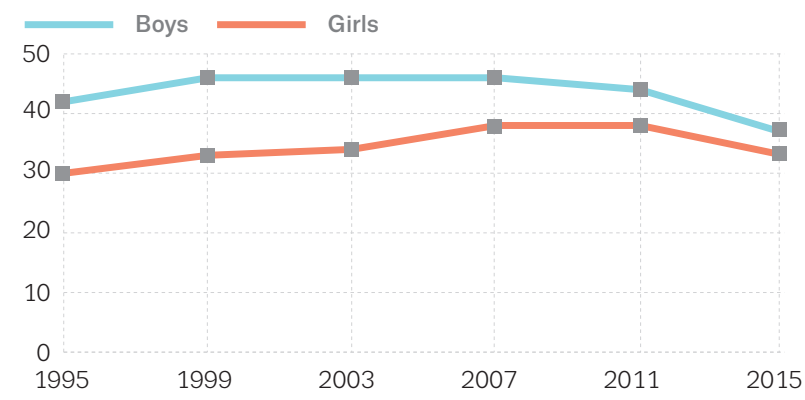

Figure 14. Lifetime use of cigarettes by gender: 25-country trend 1995-2015 (percentage)

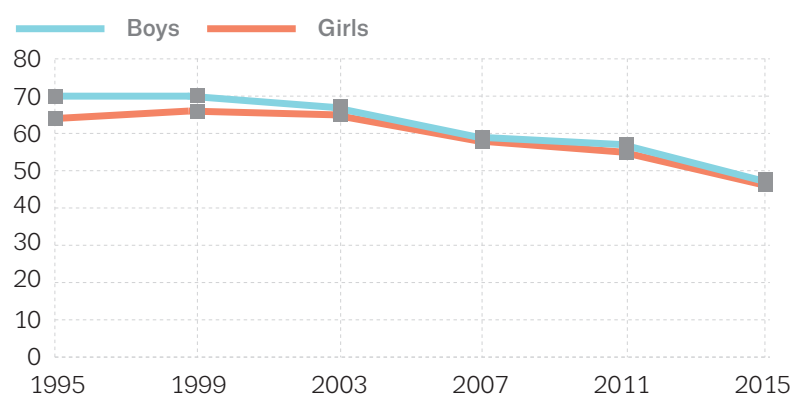

Figure 16. Daily cigarette use by gender: 25-country trend 1995-2015 (percentage)

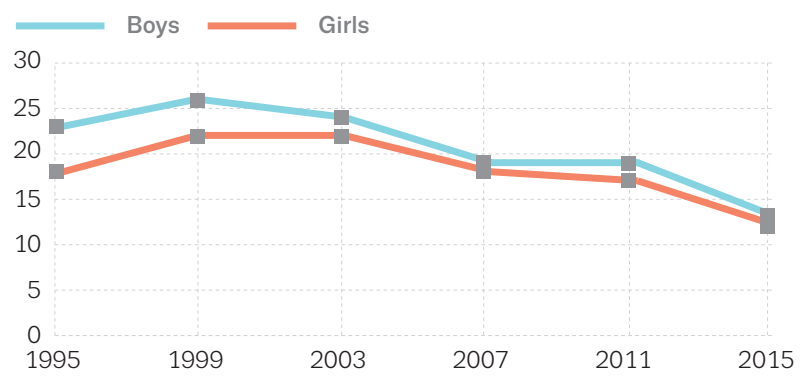

Figure 18. Alcohol use in the last 30 days by gender: 25-country trend 1995-2015 (percentage)

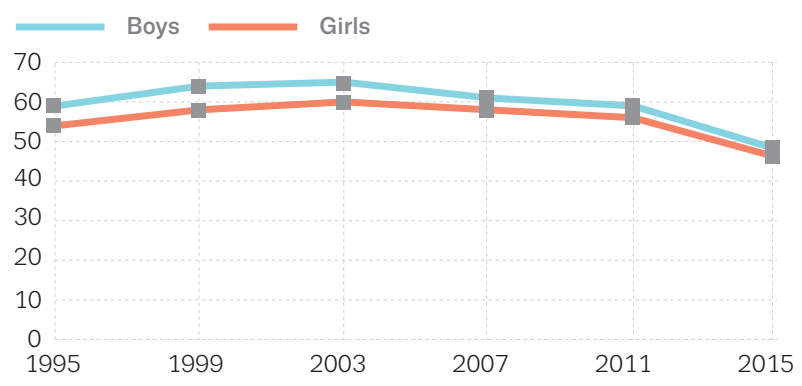

Figure 20. Lifetime use of illicit drugs by gender: 25-country trend 1995-2015 (percentage)

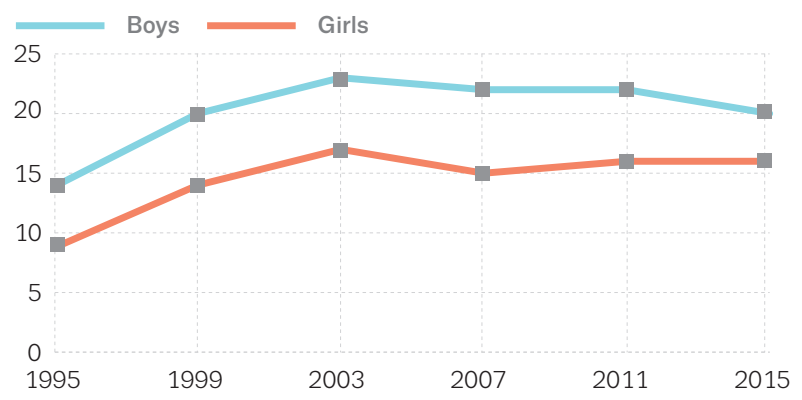


Figure 21. Lifetime use of cannabis by gender: 25-country trend 1995-2015 (percentage)

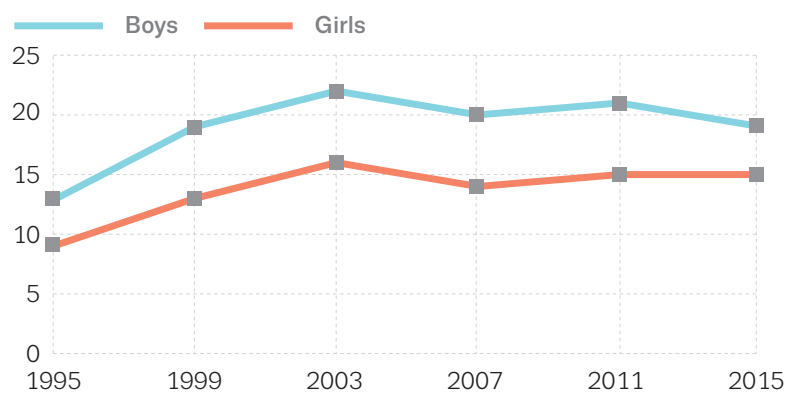

Figure 23. Lifetime use of illicit drugs other than cannabis by gender: 25-country trend 1995-2015 (percentage)

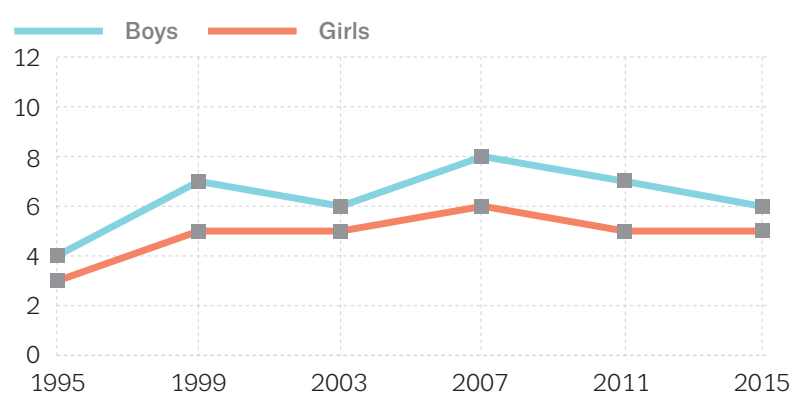

Figure 25. Lifetime use of tranquillisers or sedatives without a doctor's prescription by gender: 25-country trend 1995-2015 (percentage)

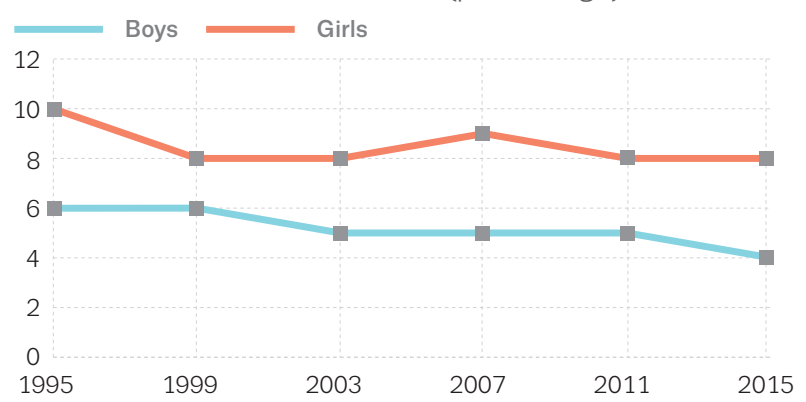

Figure 22. Cannabis use in the last 30 days by gender: 25-country trend 1995-2015 (percentage)

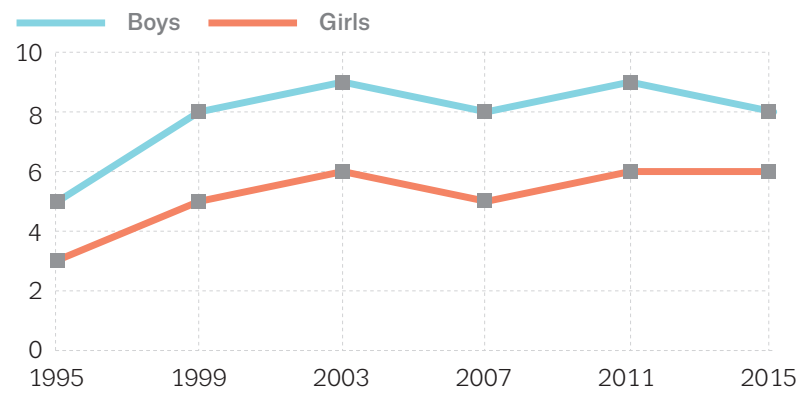

Figure 24. Lifetime use of inhalants by gender: 25-country trend 1995-2015 (percentage)

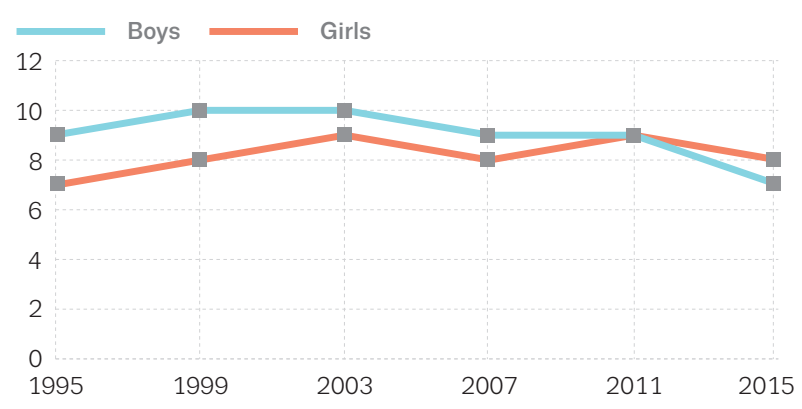




\section{Country-specific trends}

Individual country trends for five key variables of lifetime use of substances between 1995 and 2015 are shown in Figures 26-30. Trends are illustrated graphically, with decreases of 3 or more percentage points between successive surveys indicated in green, increases of 3 or more percentage points in red, and unchanged situations in yellow (less than \pm 3 percentage points). Temporal changes in countries with only two data points should be interpreted with caution.

\section{Cigarette use}

Between 1995 and 2015, the lifetime prevalence of cigarette use decreased in all countries except Lithuania, where there was no change. In the Czech Republic, Estonia, Hungary, Portugal, Slovakia, Slovenia and Ukraine, this decrease followed an initial increase until 2003. In Austria, Belgium (Flanders), Denmark, the Faroes, Finland, Iceland, Ireland, Norway, Portugal, Slovenia and Sweden, the reduction in prevalence between 2003 and 2015 amounts to 20 percentage points or more (Figure 26). Only three countries do not follow the overall trend, but show stable prevalence rates over the last three surveys (Montenegro, Poland and Romania).

\section{Alcohol use}

The prevalence of lifetime alcohol use showed reductions between 1995 and 2015 in most countries. In Finland, Iceland, Ireland, Norway and Sweden, substantial reductions of about 15 percentage points or more can be observed (Figure 27). Lifetime prevalence remained rather unchanged in Bulgaria, Cyprus, the Czech Republic, the Faroes, Hungary and Slovenia. The only country where alcohol use increased was Croatia, with prevalence rising by 10 percentage points.

\section{Cannabis use}

In most of the participating countries, the prevalence of lifetime cannabis use increased between 1995 and 2003/2007. Decreases in prevalence since then can be seen in the Czech Republic, Denmark, Finland, France, Iceland, Ireland, Slovenia and Ukraine. In contrast, increases in this period occurred in Bulgaria, Cyprus, Greece, Lithuania, Malta, Poland and Romania. Generally lower rates of lifetime cannabis use in 2015 compared to 1995 can be observed in Denmark, the Faroes, Ireland and Ukraine (Figure 28).

\section{Inhalant use}

The lifetime prevalence of inhalant use was quite stable in more than one third of the countries. A pronounced peak can be observed in 2011 for Croatia, Estonia, Latvia, Monaco and Slovenia, although rates have since returned to approximately the level observed in 2007 in most countries. Decreases since 2011 were observed in Belgium (Flanders), Croatia, the Faroes, France, Hungary, Malta, Monaco, Romania, Slovenia and Sweden (Figure 29).

\section{Pharmaceutical use}

The prevalence of lifetime use of tranquillisers or sedatives without a doctor's prescription was generally quite stable. Between 2011 and 2015, decreasing rates were found in Cyprus, Greece, Iceland, Italy, Lithuania and Monaco. In contrast, the Czech Republic, Montenegro and Slovakia showed an increase in lifetime use of tranquillisers and sedatives in the same time period (Figure 30). 
Figure 26. Lifetime use of cigarettes by country: 1995-2015 (percentage)
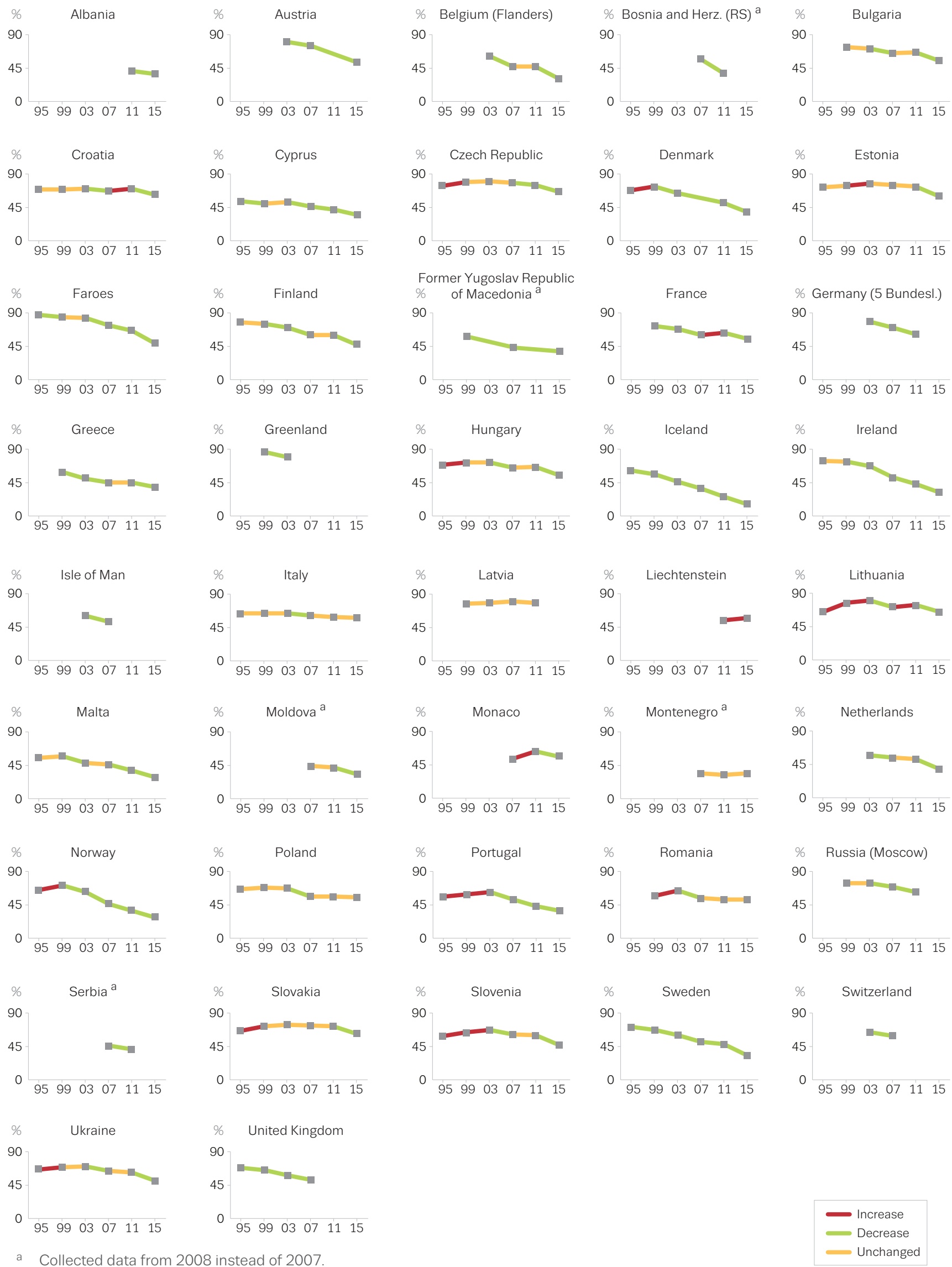
Figure 27. Lifetime alcohol use of alcohol by country: 1995-2015 (percentage)
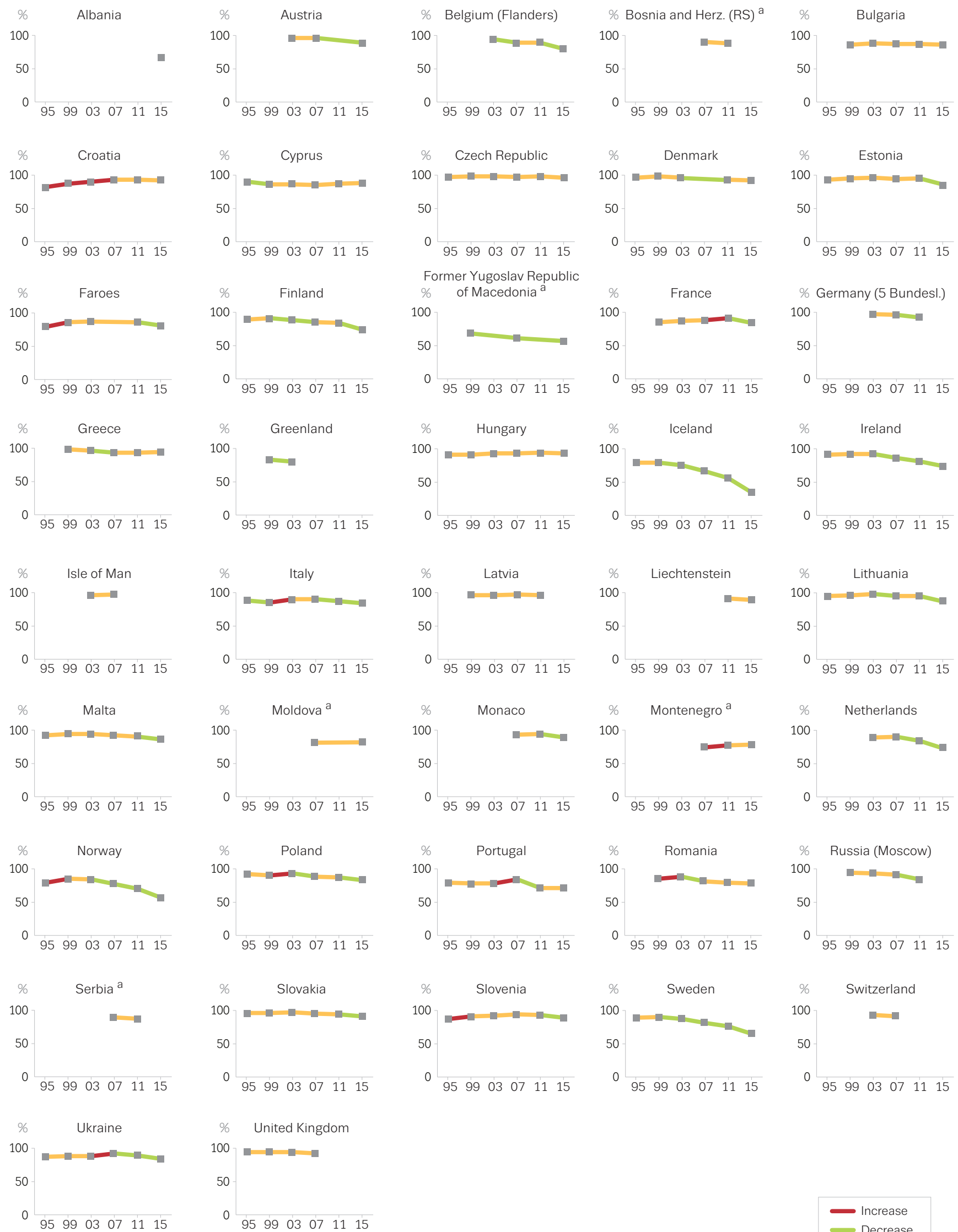

a Collected data from 2008 instead of 2007.

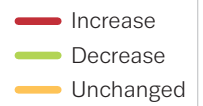


Figure 28. Lifetime use of cannabis by country: 1995-2015 (percentage)
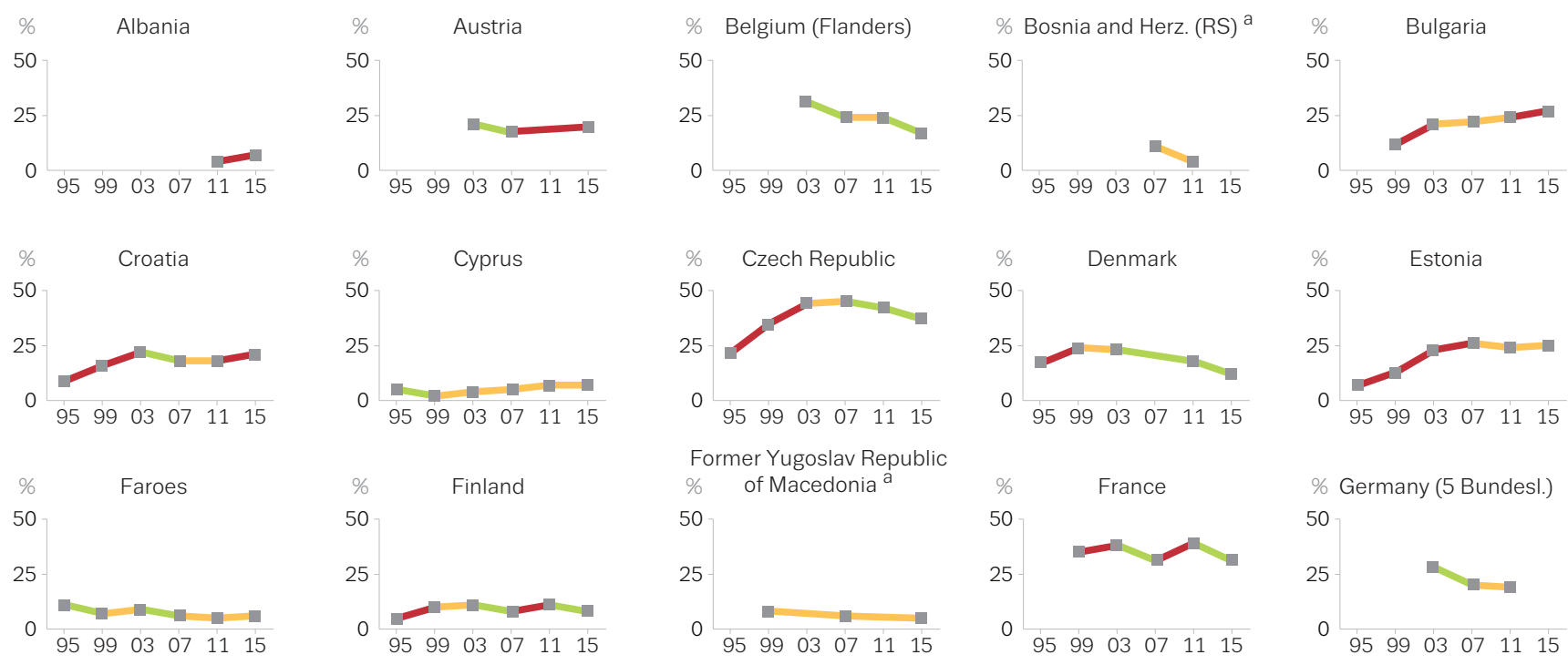

Former Yugoslav Republic
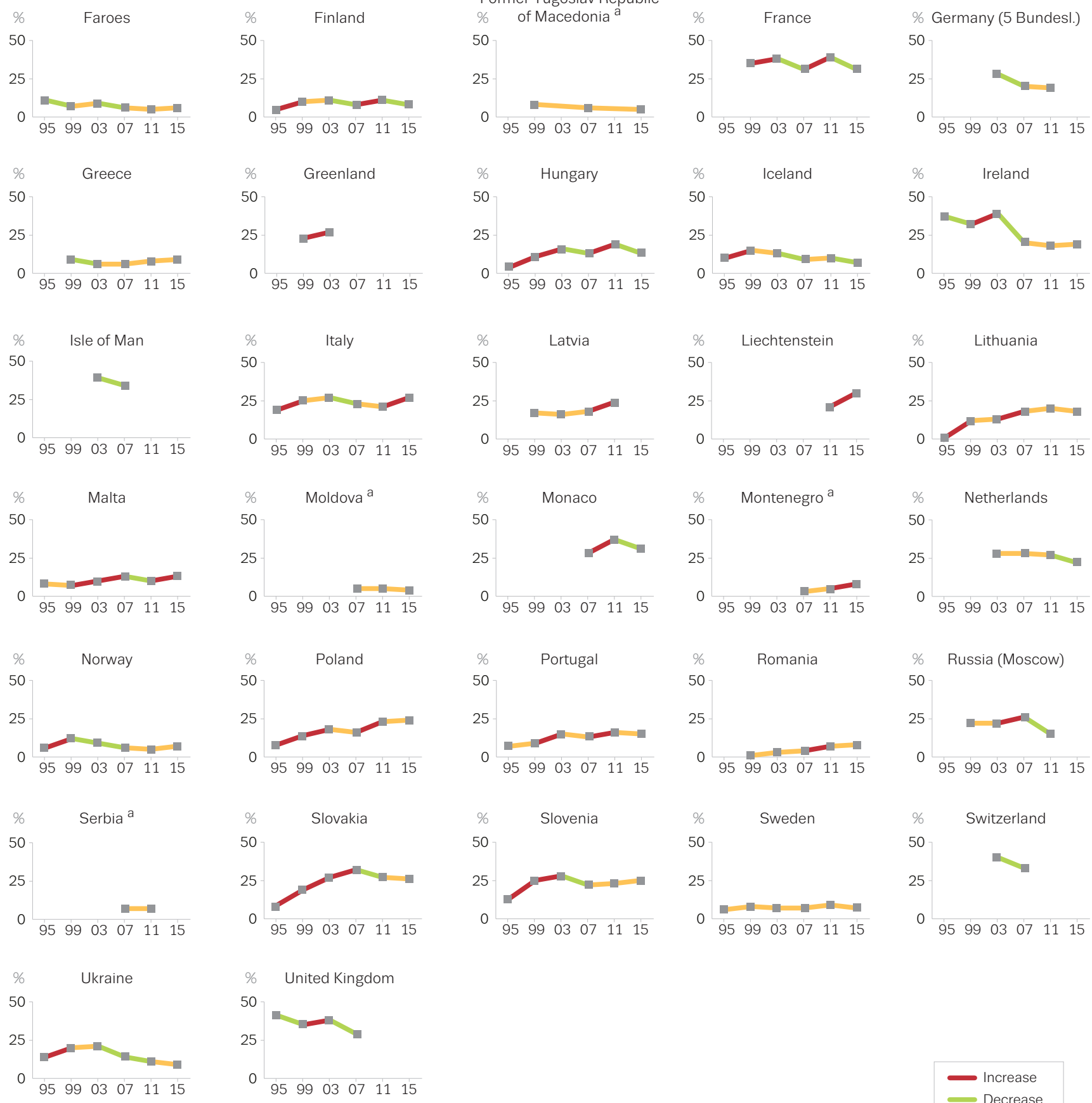

a Collected data from 2008 instead of 2007. 
Figure 29. Lifetime use of inhalants by country: 1995-2015 (percentage)
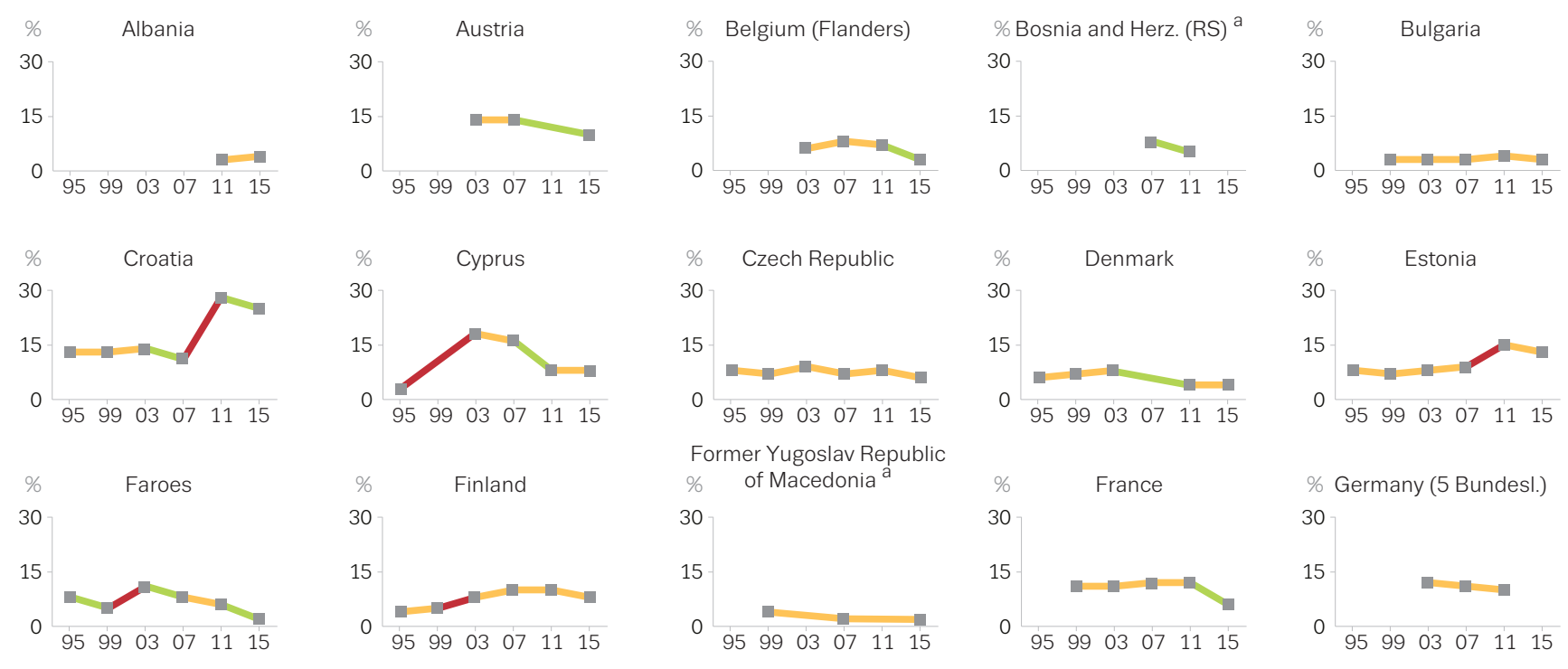

Former Yugoslav Republic
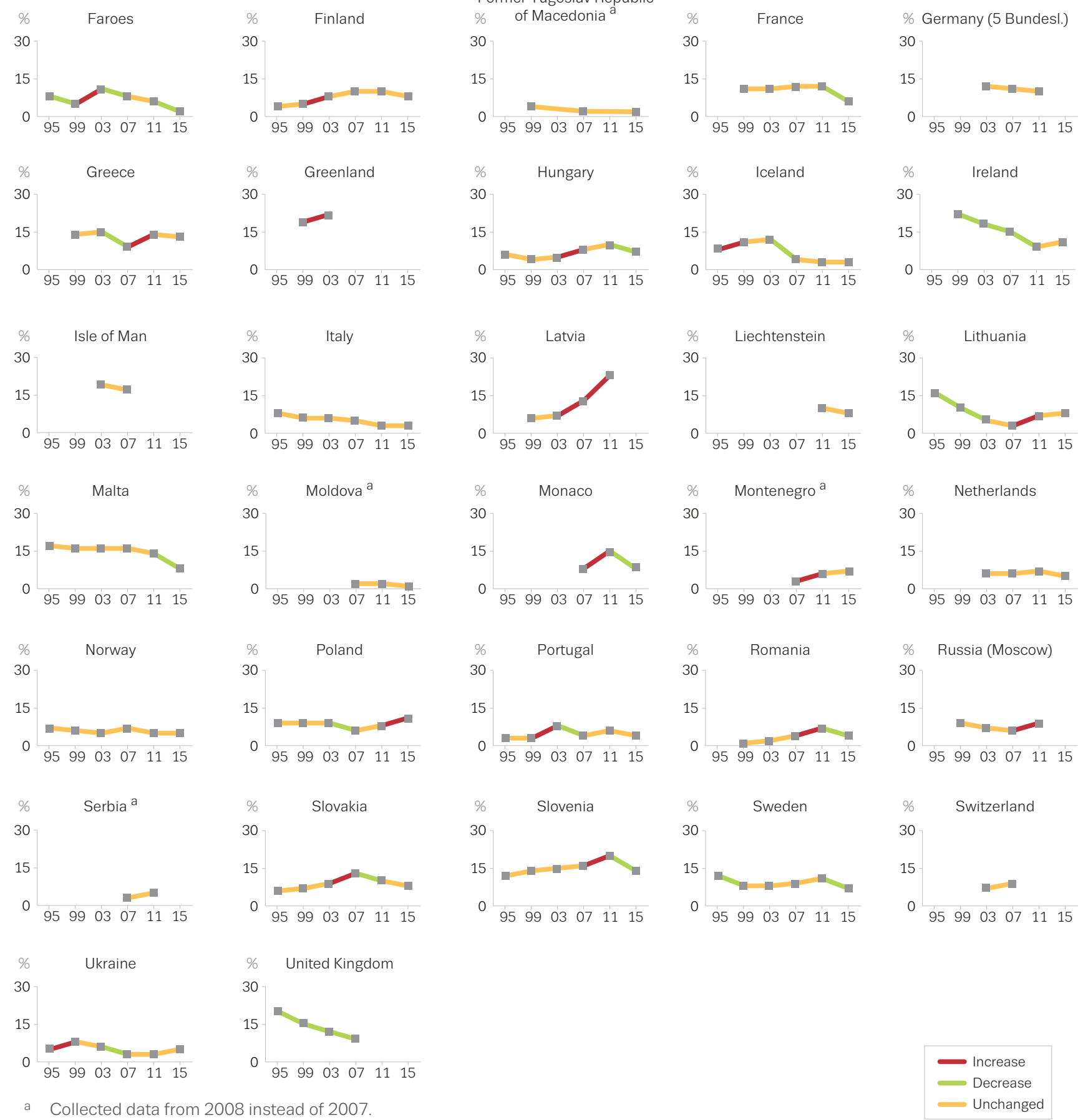
Figure 30. Lifetime use of tranquillisers or sedatives without a doctor's prescription by country: 1995-2015 (percentage)
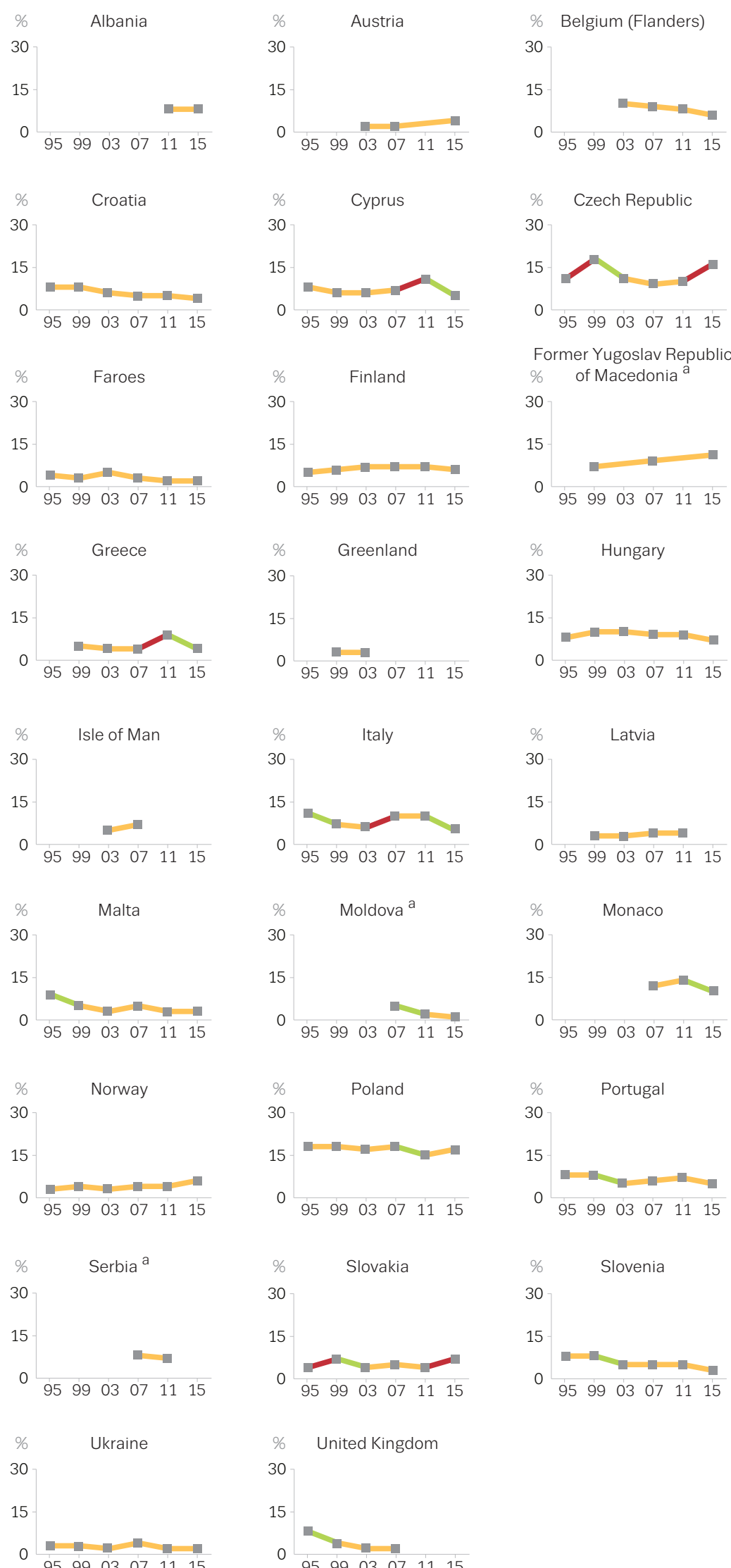

$\begin{array}{llllll}95 & 99 & 03 & 07 & 11 & 15\end{array}$
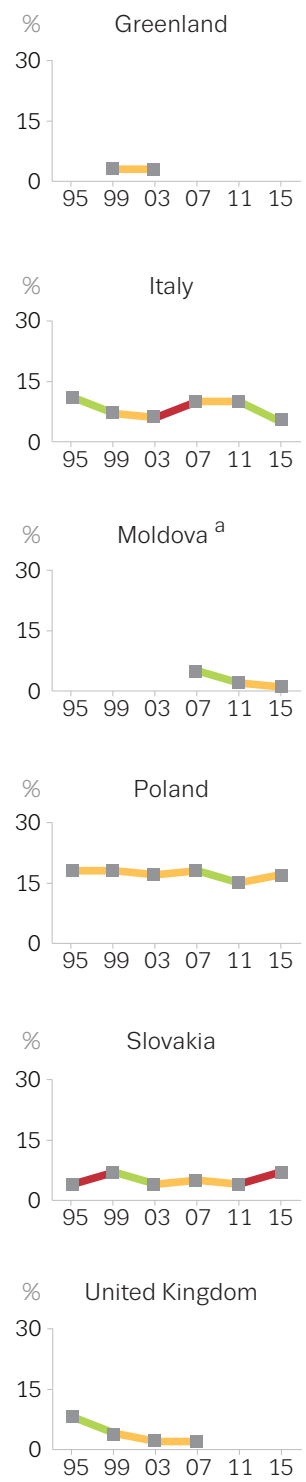

a Collected data from 2008 instead of 2007.

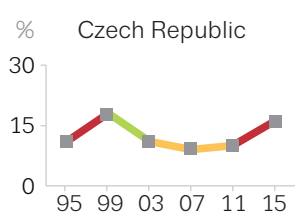

Former Yugoslav Republic
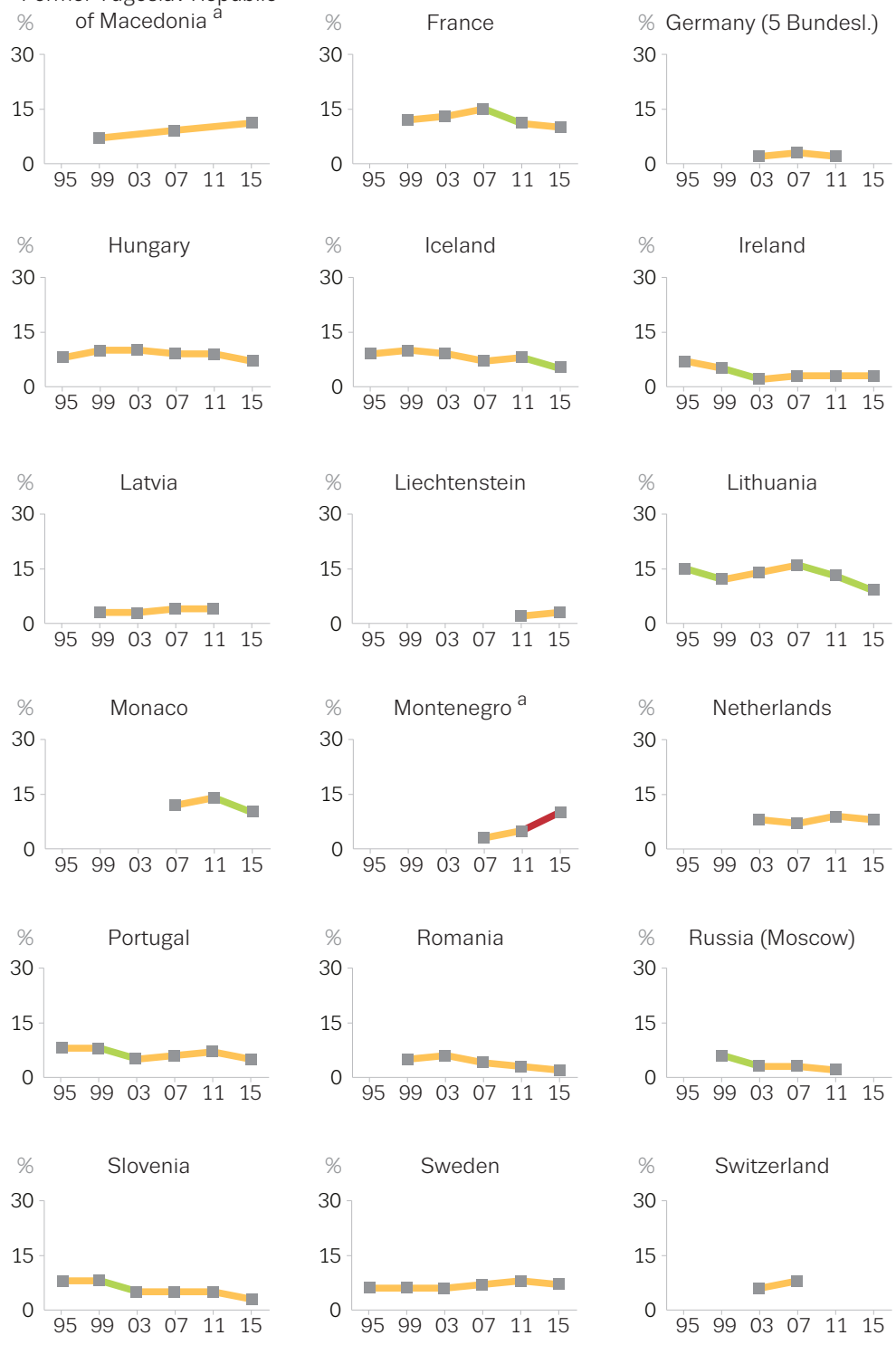



\section{Discussion \\ and conclusion}




\section{Discussion and conclusion}

According to the 'Global burden of disease, injuries and risk factors study' 2013 (Forouzanfar et al., 2015), tobacco and alcohol use are among the leading risk factors worldwide for premature death and morbidity, expressed in terms of disability-adjusted life years (DALYs). In Europe, of the 78 risk factors investigated, tobacco ranks second and alcohol fifth in terms of DALYs. Although not being a major risk factor, illicit drug use also contributes significantly (rank 22) to the global burden of years of life lost and years lived with disability. Substance-related harms to the users and to others and public health and safety concerns are the main reasons for the worldwide monitoring of such behaviours. Due to age restrictions on access to tobacco and alcohol, as well as the drug control measures covering illicit psychoactive substances, in most countries there is a particular emphasis on monitoring consumption among youths and adolescents. For instance, surveys on substance use among adolescents have a long tradition in Sweden (Swedish school surveys on substance use), England ('Smoking, drinking and drug use among young people in England'), Germany ('Drug affinity study') and the United States ('Monitoring the future' study) and were implemented as early as 1970 . With the initiation of the European School Survey Project on Alcohol and Other Drugs (ESPAD) in 1995, Europe created an instrument that enables comparisons between participating countries, due to a common methodology. After six waves of data collection over the past 20 years and the expansion of the European Union to now include 28 countries, the ESPAD survey also allows the analysis of temporal trends in over 40 countries, including 24 Member States of the European Union.

In the last few years, evidence has accumulated that behaviours such as internet use, gaming and gambling have the same potential to become addictive as psychoactive substances. However, while gambling has been included in the revised DSM-5 chapter 'Substance-related and addictive disorders', there is still no consensus for classifying excessive internet use and gaming as addictive behaviours (Regier et al., 2013). Independently of how these behaviours are treated by the international classification systems, extensive internet use, gaming or gambling in adolescents has long raised public concerns. This led the ESPAD researchers to extend the scope of the survey. In addition, new psychoactive substances, which are a public health and safety problem and have been monitored since the late 2000s, received special attention in the 2015 survey.

\section{Cigarette use}

In general, the results on cigarette smoking among European students can be interpreted as showing positive developments. Today, the majority of adolescents have never smoked (54\%) and less than one quarter (21\%) of the sample can be considered current smokers. With regard to national patterns, Italy stands out with the highest prevalence of current smoking (37\%), followed by Bulgaria and Croatia (both $33 \%)$, whereas Iceland has by far the lowest rate (6\%), with Moldova (9 \%) and Norway (10\%) ranking next lowest. Due to the relatively high addictive potential of nicotine, a particularly problematic pattern of use is early onset of smoking (Nutt et al., 2010). International studies suggest that the risk for dependence is higher when adolescents start smoking at an earlier age (Breslau and Peterson, 1996; Everett et al., 1999). Therefore, it is important to note that the proportion of adolescents who have started daily smoking at a very early age (before age 13) has largely decreased over the last 20 years. Most ESPAD countries follow this general pattern, with only a few exceptions showing stable rates of early onset of daily smoking over time (Cyprus, France, Italy and Romania).

Looking at the overall ESPAD trends for cigarette smoking, gender differences seem to narrow over time. In 1995, boys showed higher rates than girls with regard to all indicators. In 2015, these differences no longer existed or had become smaller. However, gender convergence is more marked in terms of prevalence of use, whereas problematic patterns of use (daily smoking, early onset) are still more prevalent among boys.

The trend data indicate an overall decrease in lifetime, last-30-day and daily cigarette use. Although the 'Health behaviour in school-aged children' (HBSC) study has a shorter observation time (2002-2010), trends on weekly tobacco use support the ESPAD results (Hublet et al., 2015). Tobacco use decreased in all observed European countries between 2002 and 2010, and this trend may be considered to be at least partially driven by policy measures that have been implemented in the majority of European countries in the context of the Framework Convention of Tobacco Control (FCTC) over the past two decades (Shibuya et al., 2003). The most important preventive guiding principles are information on the health hazards of tobacco and comprehensive multisectoral measures including price and tax measures, protection from exposure to environmental tobacco smoke, packaging and labelling, restriction of tobacco advertising, promotion and sponsorship, the implementation of cessation measures and limiting the access of underage persons to tobacco products. Increases in tobacco prices, which have 
made tobacco products less accessible to adolescents, are very likely to have played an important role (Agrawal et al., 2012). Although smoke-free legislation, as a measure to protect the population from exposure to second-hand smoke, does not target smoking behaviour per se, there is evidence that smoke-free legislation reduces tobacco use (Müller et al., 2010). In the global context, the total tax burden on cigarettes is highest in the European region, nevertheless, in most European countries other important measures, such as plain packaging and full restrictions on tobacco advertising, are still pending (World Health Organisation, 2012).

\section{Alcohol use}

Alcohol use among adolescents in Europe is still rather high. On average, four in five students reported lifetime alcohol experience and every second student reported alcohol use in the last 30 days. Nevertheless, countries vary to a large extent in the prevalence of lifetime and current use. The Nordic countries Finland, Iceland, Norway and Sweden are traditionally among the countries with the lowest rates of current alcohol use. However, low rates can also be found in Albania, the Faroes, the former Yugoslav Republic of Macedonia, Ireland and Ukraine and in the Baltic states Estonia and Lithuania. In countries with low consumption rates, the prevalence of heavy episodic drinking is also generally low. Conversely, high alcohol use prevalence generally coincides with high rates of heavy episodic drinking. Among the countries with the highest rates are Austria, Bulgaria, Croatia, Denmark, Hungary, Liechtenstein and Monaco.

Beverage preference is rather differently spread across the ESPAD countries. Countries where beer accounts for more than $50 \%$ of total alcohol consumption are Albania, Belgium (Flanders), the former Yugoslav Republic of Macedonia, Poland and Romania. In Croatia, Georgia, Moldova, Slovenia and Ukraine, wine accounts for at least $30 \%$ of all alcohol consumed. In approximately every second ESPAD country, spirits make up the largest share of total ethanol consumption. In a small number of countries, other beverages such as alcopops or cider account for more than $20 \%$ of total alcohol consumption. In Cyprus, Finland, Italy and Liechtenstein, alcopops account for one fifth or more, and in Denmark, Estonia, the Faroes, Ireland, Norway and Sweden, the share of cider is $20 \%$ or more.

Evidence for the existence of associations between beverage preferences, drinking patterns, alcohol-related consequences and the use of other substances is scarce. In a study among Swiss young men, beer preference was associated with risky drinking patterns and illicit drug use (Dey et al., 2014), and a study on youths in the United States revealed that a preference for hard liquor and beer was associated with riskier patterns of drinking and other health-risk behaviours (Siegel et al., 2011). However, it is difficult to draw firm conclusions from the limited evidence available. Improved surveillance of alcoholic beverage preference, particularly with regard to spirits, may help to elucidate the factors related to youth drinking and the negative consequences associated with beverage types.

Despite the still high rates of alcohol use and, in particular, of heavy use, temporal trends over the past two decades indicate a positive development, with an overall decrease in lifetime and 30-day use between 1995 and 2015 from $89 \%$ to $81 \%$ and from $56 \%$ to $47 \%$, respectively. Interestingly, both lifetime and 30-day prevalence have decreased markedly from a peak reached in 2003. Unfortunately, changes in heavy episodic drinking have been less pronounced and only observed among boys (42\% to $37 \%$ ), with overall rates declining by one percentage point (36 \% to $35 \%)$ over the past 20 years. The reported decline in weekly alcohol use among 15-year-olds in the HBSC study between 2002 and 2010 supports the present findings (de Looze et al., 2015). Although changes in alcohol use prevalence varied in magnitude, there are only a few countries with stable or increasing lifetime prevalence (Croatia, Cyprus, the Czech Republic, the Faroes, Hungary and Slovenia).

Factors that may have played some part in the general decrease observed in alcohol consumption include changes in norms on drinking and intoxication, competing responsibilities and attractions that demand or favour sobriety, structural changes, external influences and the range of societal or cultural responses to alcohol problems (Room et al., 2009). Others have argued that the observed change in adolescent drinking behaviour was due to changes in adult prevalence, shifts in teen culture or parental control (Ryan et al., 2010; Simons-Morton et al., 2009; van der Vorst et al., 2006). More recently, based on age, period and cohort analyses, results clearly indicate that younger cohorts reported abstinence more frequently and drank less than older cohorts (Härkönen and Mäkelä, 2011; Kraus et al., 2015; Meng et al., 2014; Pabst et al., 2010). In all western European countries, policies are in place to limit underage access to alcohol (Brand et al., 2007). In addition, stricter prevention policies are emerging in many countries (Anderson and Baumberg, 2006; Anderson et al., 2012). Some countries in the east of Europe deviate from the generally observed decline in adolescent alcohol use. These exceptions have been explained by rapid increases in wealth since 1990 and opportunities for adolescents to acquire and consume goods, including alcohol, that were previously unavailable or difficult to obtain (Zaborskis et al., 2006).

Our findings on trends in alcohol use suggest a closure of the gender gap in heavy alcohol use among adolescents in Europe and support earlier findings (Kuntsche et al., 2011; Simons- 
Morton et al., 2009). The gender convergence, however, is more visible for heavy episodic drinking than for more regular drinking behaviours, such as monthly alcohol use.

\section{Illicit drug use}

\section{Cannabis use}

Cannabis is by far the most commonly used illicit drug used in developed countries, with use more recently spreading to low- and middle-income countries (Hall and Degenhardt, 2007; United Nations Office on Drugs and Crime, 2014). The average lifetime prevalence of cannabis use among adolescents in ESPAD countries (16\%) was considerably lower than that recorded in comparable school surveys in the United States (31\%) or Spain (27\%). Nevertheless, rates of use varied substantially between ESPAD countries. Lifetime experience of cannabis in the Czech Republic (37\%) even exceeded the level observed in the United States. At the lowprevalence end, rates of under $10 \%$ could be found in five of the Nordic countries (the Faroes, Finland, Iceland, Norway and Sweden), in several Balkan states (including Albania, the former Yugoslav Republic of Macedonia, Moldova, Montenegro and Romania) and in Cyprus and Greece.

The reasons for the large differences in cannabis use between European countries are unclear. The frequently found strong relationship between cannabis availability and use has often been interpreted as evidence for the preventive effect of restrictive drug policies (Gervilla et al., 2011; Gillespie et al., 2009; Höfler et al., 1999; von Sydow et al., 2002). Moreover, a study among adolescents in 32 European countries, investigating the effects of perceptions about cannabis on the use of the drug, identified strong and persistent individual-level effects for perceived availability, perceived harm and the number of cannabis-using friends. The effects on cannabis use prevalence and frequency were more pronounced than country-level effects such as cannabis price and last-12-month cannabis use prevalence in the adult population (Piontek et al., 2013). It has generally been assumed that drug availability is inversely related to the level of drug law enforcement and the severity of the legal sanctions. However, when comparing changes in cannabis policy with subsequent changes in prevalence, only in a few countries did the prevalence of use follow the expected pattern of change, i.e. a decrease in prevalence following an increase in sanctions and vice versa (European Monitoring Centre for Drugs and Drug Addiction, 2011). In a recent paper on cannabis policy prepared within the 'Addiction and lifestyles in contemporary Europe reframing addictions project' (Alice Rap), the authors argued that the prohibition approach has largely failed and, drawing on global and European experience in regulating tobacco and alcohol, they called for legal regulatory cannabis policies that protect public health, wealth and well-being (Alice Rap, 2014). The high prevalence of perceived cannabis availability and cannabis use among adolescents in many European countries seems to support their view.

Trends in cannabis use indicate an increase in both lifetime and current use between 1995 and 2015, from $11 \%$ to $17 \%$ and from $4 \%$ to $7 \%$, respectively. However, prevalence peaked in 2003 and decreased slightly thereafter. The observed decrease in cannabis prevalence after 2003 is supported by the results of the HBSC study. Temporal trends in last-12-month cannabis use among 15-year-olds in Europe between 2002 and 2010 showed, with the exception of eastern Europe, a general decrease in all regions (Hublet et al., 2015). However, the pattern of change in ESPAD countries since 2003 is not uniform. In contrast to the general trend, lifetime cannabis use increased in Bulgaria, Cyprus, Greece, Lithuania, Malta, Poland and Romania. Thus, when discussing the reasons for the change in cannabis use, factors other than legal regulations may play a significant role. For instance, in addition to drug control measures, other factors such as norms of use, competing responsibilities and attractions that demand or favour drug use abstinence, as well as societal or cultural responses to drug problems, may impact on consumption, in an upward or downward direction. It has been argued that the increasing trend in cannabis use, particularly evident in eastern European countries, may be explained by factors related to post-communist transition (Hublet et al., 2015). Firstly, the relative isolation of the former Soviet Union countries led to a delay in the development of cannabisdistribution networks, with the subsequent growth igniting an upward trend; secondly, social and economic changes, along with increases in wealth and leisure opportunities, have driven substance use; and thirdly, because public health authorities and decision-makers were not prepared for the growth in illicit drug use, countermeasures were slow to be implemented (Elekes and Kovacs, 2002).

\section{New psychoactive substances}

New psychoactive substances (NPS) are narcotic or psychotropic drugs that are not controlled by the United Nations drug conventions, but may pose a public health threat comparable to that caused by substances listed in these conventions. On average, $4 \%$ of the students surveyed have tried NPS - substances that imitate the effects of illicit drugs - and $3 \%$ have used them in the past 12 months. On average, these substances seem to be more commonly used than amphetamine, ecstasy, cocaine or LSD, all of which have lower lifetime prevalence rates. Several countries could be identified that showed above-average last-12-month use of NPS. Students in Estonia and Poland (both $8 \%$ ) were most likely to have experiences with NPS, followed by Bulgaria and Croatia (6 \%) and Ireland and Italy 
(5\%). Rather low lifetime rates of NPS use were reported in Belgium (Flanders), Denmark, the Faroes, Finland, the former Yugoslav Republic of Macedonia, Moldova, the Netherlands, Norway and Portugal (1\%).

The 2015 ESPAD study is one of the first international epidemiological studies to assess NPS use. On an international scale, there is not much information available against which to compare the results. As an exception, the Flash Eurobarometer, a comprehensive EU-wide survey among young people aged 15 to 24 years, reported an overall lifetime prevalence of 8 \% (European Commission, 2016). The regional patterns in the Eurobarometer study were slightly different to those observed in the present study, with France, Ireland, Slovenia and Spain being the top four countries regarding the prevalence of use. Differences in NPS prevalence rates between ESPAD and the Flash Eurobarometer, although the same definition was used, may be due to differences in the sampling frame (schools versus general population) and age (15-16 years versus 15 24 years). NPS comprise a variety of substances ranging from synthetic cannabinoids simulating the effects on the brain of THC (the principal psychoactive substance in cannabis) to synthetic cathinones that mimic the effects of amphetamine, methamphetamine or ecstasy (Hohmann et al., 2014). These substances are variously marketed as 'research chemicals', 'plant food', 'bath salts' or other misleading product names, with false content descriptions, in efforts to avoid control measures. Identification of the substance in question is very difficult, for the consumer, law enforcement and, critically in the event of poisoning, medical staff.

In a recent document on the outcome of the UN General Assembly Special Session on Drugs (2016), NPS are mentioned in 10 paragraphs and dominate the section on emerging and persistent challenges and threats (https:// www.incb.org/documents/News/A_S-30_L.1.pdf). The UN promotes data collection and early warning systems (EWS) and prioritises the review of the most prevalent, persistent and harmful NPS. To this end, an international action group on NPS has been established, consisting of UN member states and international organisations, to coordinate and drive the international response to NPS. At European level, the EMCDDA is responsible for a well-established EWS. The European EWS on NPS is a multidisciplinary network of 30 national early warning mechanisms that collect, appraise and rapidly disseminate information on new drugs and products (http://www.emcdda.europa.eu/attachements. cfm/att_157279_EN_EWS \%20profiles.pdf). The challenge associated with NPS is demonstrated by the increasing number, type and availability of new substances. Within the European EWS, almost 100 new substances were reported for the first time in 2015. Overall, the total number of new substances monitored by the EWS since its inception amounts to over 560 .

\section{Internet use, gaming and gambling}

\section{Internet use}

With widespread access to the internet, online communication has become an integral part of life, especially for adolescents (Inchley et al., 2016; Valkenburg and Peter, 2011). Not only has interacting with peers expanded to the virtual world, but also the internet plays an important role in learning and entertainment. Therefore, questions on the amount and purpose of use were included in the current ESPAD questionnaire.

In 2015, students were using the internet on an average of 5.8 days per week. Fewer online days per week were reported in Albania, Bulgaria, the former Yugoslav Republic of Macedonia, Georgia, Italy, Lithuania, Moldova, Montenegro, Romania and Ukraine, mostly countries in the east of Europe. Differences between countries in time spent online may not necessarily reflect cultural differences but may be due to differences in access to the internet and devices with internet capability, for example smartphones or personal computers, although a wide coverage of internet access in most countries in Europe can be assumed. Comparable data on internet use based on representative studies, even if recently published, may not reflect current behaviour in internet use (Boniel-Nissim et al., 2015; Inchley et al., 2016). This may be because, in the last 5 or 6 years, devices with internet capability have become increasingly affordable for young people, and being on the internet every day or every hour is much more common. Official data can be found at internet service providers, television stations, polling institutes or public agencies, but the figures differ greatly and it is difficult to make between-country comparisons. For instance, data in the United Kingdom suggest that more than four in five adults used the internet anywhere on any device (Office of Communication, 2015), and in Germany 14- to 29-year-olds were using the internet for 187 minutes per day in 2015 (Engel and Breunig, 2015)

Apart from information on how often and for how much time adolescents are using the internet, their online activities are of particular interest. The ESPAD questionnaire focused on six general activities: using social media, information seeking/surfing, streaming/downloading, online gaming, online money gambling and buying/selling. The results suggest that the internet plays an important role for adolescents: in 2015, using the internet for social media, for example to have daily social media contact with friends, was the most common online activity; $78 \%$ of the students stated that they have used social media on 4 or more days in the last 7 days. Students reported that using online communication made it easier to talk to friends of both sexes, making the internet a powerful tool for helping adolescents to connect. Overall, girls used social media more 
often than boys did. A gender difference in social media use was also found in the HBSC study, with $35 \%$ of the girls and $32 \%$ of the boys reporting daily social media contact with friends (Boniel-Nissim et al., 2015). In a longitudinal survey in the United Kingdom focusing on adolescents and adults (16 years and older), nearly three quarters of internet users had a social media profile in 2014, compared with $22 \%$ in 2007. Furthermore, $81 \%$ reported using social media at least once a day, which equals an increase of 51 percentage points compared to 2007. As expected, 16- to 24-year-olds reported higher levels of social media use compared with older users (Office of Communication, 2015). This is also in line with recent results from Germany: $58 \%$ of the 14- to 29-year-olds used the internet every day for social media, with an average of 139 minutes (Engel and Breunig, 2015).

The next most common internet activities were streaming/ downloading and information seeking/surfing, with $48 \%$ and $43 \%$ of the students, respectively, reporting these internet activities on 4 or more days in the last 7 days. These activities reflect the use of the internet as a tool, for example to listen to music or to watch a video, but young people spend only some of their internet time on these activities. For instance, among 14- to 29-year olds in Germany, only 48 minutes from an estimated total online time of 187 minutes per day was spent on these activities (Engel and Breunig, 2015). However, it can be assumed that this time will expand in the next few years, especially for streaming and downloading. Recent figures indicate that over a quarter of internet users watch TV or films online at least once a week, compared to one in ten in 2007. At the same time, watching video clips online has doubled among the internet users during this time, from $21 \%$ to $39 \%$. YouTube, launched in 2005, is now cited by one third of internet users as an important source for information (Office of Communication, 2015). This trend may continue, with new online services like film or music streaming services becoming more and more available in the coming years.

Research has raised concern that internet use and online communication contributes to loneliness and isolation (Hampton et al., 2011). Other studies, however, stress the importance of the internet as a powerful tool for helping people to connect (Boniel-Nissim et al., 2015; Kuntsche et al., 2009; Valkenburg and Peter, 2011).

\section{Online gaming and gambling}

Over the last 10 years, mainly driven by the increasing popularity of smartphones and tablets, gaming has become more popular and increasingly mobile. Since 2005, gaming, both online and mobile, has doubled in terms of weekly use (Office of Communication, 2015). According to the present study more than one in five students (23\%) regularly (at least four times in the last 7 days) used the internet for online gaming. Online gaming was more prevalent among boys (39\%) than among girls (7\%). Countries varied substantially in online gaming and gambling activities. While nearly half of the students from Denmark played regularly online (45\%), gaming was not so common in Georgia (13\%), the former Yugoslav Republic of Macedonia and Moldova (16 \% each).

Online money gambling was the least common of the internet activities (ESPAD average: $3 \%$ ). Like online gaming, online gambling for money was predominantly reported by boys (6\%) rather than girls (1\%). The highest participation rates in online money gambling were found in Bulgaria (8\%), Albania, Cyprus and the former Yugoslav Republic of Macedonia (7\% each).

Data from the United Kingdom indicate an increase in the prevalence of gaming on any device between 2007 and 2014 from $31 \%$ to $44 \%$ (Office of Communication, 2015). The most active gamers were young people aged 16-24 years. Research on factors associated with gaming indicates that early onset, opposite-sex friends and minimal parental mediation increase the risk for gaming. A high level of game playing was related to bullying in boys and lower life satisfaction in girls (Brooks et al., 2016).

\section{Gambling}

Although generally prohibited by law, youth gambling has become a popular form of recreation. In the 2015 ESPAD study, $14 \%$ of the students reported gambling for money at least once in the last 12 months and $7 \%$ gambled frequently (2-4 times a month or more often). In all countries, considerably more boys than girls had gambling experience or gambled frequently.

With prevalence rates of problematic gambling between $2 \%$ and $13 \%$ worldwide (Volberg et al., 2010), adolescent gambling has become a major public health concern (Ariyabuddhiphongs, 2013; Blinn-Pike et al., 2010). Gambling involvement in youth may lead to adverse consequences such as strained relationships, delinquency and criminal behaviour (Derevensky et al., 2004), depressive symptoms (Bonnaire et al., 2009), comorbid mental disorders (Lorains et al., 2011), low self-esteem (Bergh and Kühlhorn, 1994), impaired relations with family and friends (Dickson-Swift et al., 2005), greater risk for suicide ideation and attempts and poor general health (Potenza, 2008).

Gambling, as a social activity and its social context, is still not very well studied. Research suggests that parents' levels of schooling, family structure and family socio-demographic characteristics are not related to adolescent gambling behaviours or problem gambling (Langhinrichsen-Rohling 
et al., 2004; Vitaro et al., 1998). Similar to findings on substance abuse, family structural characteristics seem to be less influential in the development of problem gambling than family relational characteristics (Velleman et al., 2005). In a recent study on the role of family and socioeconomic indicators of welfare state in the development of problem gambling in adolescent students, those receiving more parental caring and monitoring had a lower risk for involvement in problem gambling (Molinaro et al., 2014). Moreover, family support and parental supervision were identified as preventive factors (Hardoon et al., 2004; Magoon and Ingersoll, 2006). Supportive families seem to offer social resources that adolescents can turn to when getting into trouble, and good family relations imply that parents are aware of how and with whom their children spend their free time. Contrary to this, high levels of disciplinary parental ruling were related to higher levels of adolescent problem gambling (Molinaro et al., 2014).

Country variation in rates of adolescent problem gambling has been found to be related to country-level characteristics. Higher health expenditure was associated with lower levels of gambling problems, while country-specific family spending had no effect (Molinaro et al., 2014).

\section{Limitations}

Although the ESPAD survey is based on a common methodology, some limitations that may possibly weaken the validity of the estimates need to be discussed. (1) In Belgium (Flanders), data were collected half a year earlier than in the majority of countries (in autumn of the previous year), and in Georgia and the Netherlands, half a year later (in the autumn of the same year). In the former case, students were on average half a year younger, while in the latter case they were on average half a year older. With the exception of Georgia, the target population was, however, redefined to give an average age in line with the other participating countries that collected data in spring. With students being on average 16.4 years compared to the ESPAD average of 15.8 years, rates of substance use may be slightly overestimated in Georgia due to students having had more time to experience or continue substance use. (2) The school/class participation rates in Austria (17\%), Ireland (18\%) and Denmark (26\%) were exceptionally low compared with the ESPAD average of $87 \%$. In addition, school/class participation rates were also slightly below $50 \%$ in Latvia and the Netherlands. Low participation rates, however, may not necessarily lead to biased estimates, unless the behaviour in question is rather unequally distributed across schools and classes. A recent simulation study from Germany found that school non-participation in surveys assessing substance use among students is not as worrisome as expected (Thrul et al., 2016). Systematic exclusion of schools, based on the size of the city, school or class, on school environment or on schools' substance use policies, resulted in significant but rather small changes in prevalence estimates. (3) In some countries, sampling was only possible in particular regions of the country. In Belgium, only schools from Flanders (representing approximately $60 \%$ of the population) participated in the survey; in Cyprus, data collection was restricted to government-controlled areas, representing approximately $80 \%$ of the population; and in Moldova, the sample represents approximately $85 \%$ of the Moldovan population, with the Transnistria region not included. In these cases, estimates only represent the population of the region where the survey took place. (4) In the 2015 ESPAD survey, four countries (Austria, Latvia, Liechtenstein and the Netherlands) conducted data collection online, deviating from the usual paper-and-pencil mode of administration. While experience suggests a number of advantages of online data collection, such as interactivity, minimising mistakes of data entry and saving time and costs, the comparability of results from online and paper-and-pencil questionnaires is of concern. Research on differences when comparing online and paper-and-pencil responses on substance use behaviour suggests only small mode effects (Brener et al., 2004; Eaton et al., 2010; Lygidakis et al., 2010; Raghupathy and Hahn-Smith, 2013; Wyrick and Bond, 2011). This is corroborated by a methodological study carried out in Latvia (Trapencieris, 2013). A sample of nearly 2800 students aged 14-16 years in grades 8-10 was randomly selected to answer the ESPAD questionnaire, either in the schools' computer lab or via the traditional paper-and-pencil mode. In only three of thirty-two variables measuring substance use were prevalence statistically significant differences found. Although in the majority of studies small mode differences were reported, the differences in most studies indicate higher rates of substance use and other sensitive behaviours if paper-and-pencil questionnaires were used. Thus, comparisons between studies using online and paper-andpencil questionnaires should be interpreted with caution.

\section{Conclusion}

Overall, a general decreasing trend can be observed in cigarette use and alcohol use among adolescents. However, despite rather strict regulations on tobacco in most countries and on alcohol in some countries, adolescents still report relatively easy access to tobacco and alcohol. Moreover, trends over the past two decades indicate a closing of the gender gap in the use of tobacco and alcohol. The data suggest that cannabis remains an 'established' drug. Although prevalence peaked in 2003 and decreased slightly thereafter, the prevalence rates in lifetime and current cannabis use are higher in 2015 than in 1995. In many countries, prevalence rates for NPS suggest that these substances are more attractive than the 'old drugs' 
amphetamine, ecstasy, cocaine or LSD. Availability of NPS and adolescents' use of these substances need to be closely monitored.

With the popularity of smartphones and tablets, internet use has become more popular and increasingly mobile. The students were using the internet quite regularly and most commonly reported using it for social media, for instance to stay in contact with friends. Since the internet has become an integral part of life and is used on a daily basis, the development of patterns of addictive use among children and adolescents needs to be closely monitored and investigated in further studies. Associated with the increased internet use, online gaming has also become more popular, especially among boys. Moreover, youth gambling has become a popular form of recreation. Measures to prevent adolescents from developing problems associated with gambling, such as debts, psychological deficits and social disadvantages, are of high priority.

Substance or internet use should not always be considered individually: there seems to be a high association between the use of different drugs, including alcohol and tobacco, and risky behaviours such as gambling. These associations have frequently been discussed in the light of the gateway theory, assuming that progression from one drug to another increases with the frequency of use of the former drug (Kandel et al., 1992). Others have suggested a connection between different types of problem behaviour and that certain risk-imbued behaviour patterns are caused by identical underlying common factors (Jessor and Jessor, 1977; Morral et al., 2002)

It seems necessary to make particular efforts to prevent early substance use and gambling as well as excessive use of the internet and gaming in childhood and adolescence. As a basis for decisions or approaches to achieve this goal, ESPAD provides data on such behaviours over a period of up to 20 years. In the following years, ESPAD will not only monitor substance use behaviour but will also assess future developments in internet use as well as online gaming and gambling, and strive to increase its contribution to the protection of children and adolescents from the negative consequences of substance use and addictive behaviours. 


\section{Acknowledgements}

The planning and implementation of the ESPAD 2015 project has been a collaborative effort between the coordination and all the research teams in each participating country. The importance of the ESPAD researchers and their supporting research groups and institutions cannot be overestimated. Since the project cannot provide funding for the data collection in participating countries, it relies on the ability of each principal investigator and ESPAD contact person to raise that money.

Much of the coordination has been supported by the Swedish Ministry of Health and Social Affairs. Its grant has covered costs for holding international meetings, constructing the international 2015 database and producing this report. The European Monitoring Centre for Drugs and Drug Addiction (EMCDDA) in Lisbon has co-funded data collection in Georgia, Moldova and Ukraine through the ENP first technical cooperation project (ENPI/2013/325-486), and has covered costs for some of the ESPAD meetings and coordination. Furthermore, the EMCDDA has provided editing, design and ensure the production of this report and the updating and hosting of the ESPAD website. The persons at the EMCDDA involved with ESPAD are Paul Griffiths, João Matias, André Noor, Sandrine Sleiman, Rosemary Martin de Sousa and Julian Vicente.

The Pompidou Group at the Council of Europe has supported the project ever since the first project meeting in 1994. In particular, the support of the Pompidou Group has enabled some researchers from eastern and central parts of Europe to participate in meetings. Special thanks are due to Florence Mabileau and Jan Malinowski at the Pompidou Group for their much-appreciated assistance and support.

A Coordination Committee, consisting of Ludwig Kraus (Germany), Håkan Leifman (Sweden) and Julian Vicente (EMCDDA), coordinated the project in the transition period from 2015 to 2016. A Steering Committee, appointed by the
ESPAD researchers at project meetings, worked together with the Coordination Committee. All important decisions relating to the planning of ESPAD meetings and the 2015 study have been taken jointly with the Steering Committee. Together with the three members of the Coordination Committee, the Steering Committee consists of Sharon Arpa (Malta), Sabrina Molinaro (Italy), Karin Monshouwer (the Netherlands) and Marcis Trapencieris (Latvia).

The Swedish Council for Information on Alcohol and Other Drugs (CAN) was responsible for collecting country reports and datasets and for constructing the 2015 international database. CAN also produced result tables and texts for the full online version of the ESPAD Report 2015. The persons at CAN involved are Anna Englund, Ulf Guttormsson, Håkan Leifman, Jonas Raninen (statistical tests) and Johan Svensson.

Ludwig Kraus, Nicki-Nils Seitz and Daniela Piontek from the IFT Institut für Therapieforschung drafted the print version of the report, with financial support from the Swedish government.

In addition to the results of the ESPAD 2015 survey, the report also includes data from the 'Monitoring the future' project in the United States and from the Spanish national school survey, kindly provided by Lloyd Johnston (US) and Begoña Brime Beteta (Spain), respectively.

Each country was represented in the project by a principal investigator or an ESPAD contact person, who is a contributing author of this report (see title page). In addition, a number of other persons have carried out important work in the context of the 2015 ESPAD study. The main persons from the national research teams in the 35 countries participating in the 2015 data collection are listed on the following pages, followed by a list of important funding agencies and supportive organisations. 


\section{Collaborating persons}

Below are listed, for each of the 35 countries participating in the 2015 data collection, the most important persons involved, beginning with the principal investigator (PI).

\section{Albania}

Ervin Toçi (PI); Arjan Bregu; Genc Burazeri; Enver Roshi; Eduard Kakarriqi; Gentiana Qirjako

\section{Austria}

Julian Strizek (PI); Alfred Uhl; Andrea Kadlik

\section{Belgium (Flanders)}

Patrick Lambrecht (PI); Caroline Andries; Christiane Janssens; Brigitte Bronselaer; Peter Van Rossem; Martin Verstegen; Katleen De Bont; Lieve Van Gompel; Esra Hortens; Michel Vermeersch; Elisabeth Cuypers; Vicky Reynaerts; Isabelle Rojaz; Roxanne Vega Fernandez; Thais Distelmans; Sarah Leysen

\section{Bulgaria}

Anina Chileva (PI); Momtchil Vassilev; Plamen Dimitov; Sophia Kandilarova-Georgieva; Ralitsa Bardarova

\section{Croatia}

Iva Pejnović Franelić (PI); Martina Markelić; Ljiljana Muslić; Irena Rojnić Palavra; Sanja Musić Milanović; Ivana Pavić Šimetin; Mario Hemen; Dijana Mayer; Marina Kuzman

\section{Cyprus}

Kyriakos Veresies (PI); Andreas Pavlakis; Byron Gaist; D. Mappouras; S. loannou; N. Georgiades

\section{Czech Republic}

Ladislav Csémy (PI); Pavla Chomynová; Viktor Mravčík; Jiř̌ Nepala

\section{Denmark}

Mette Vinther Skriver (PI); Kim Moesgaard Iburg

\section{Estonia}

Sigrid Vorobjov (PI).

\section{Faroes}

Pál Weihe (PI); Ólavur Jøkladal

\section{Finland}

Kirsimarja Raitasalo (PI); Petri Huhtanen

\section{Former Yugoslav Republic of Macedonia}

Silvana Oncheva (PI); Elena Kosevska

\section{France}

Stanislas Spilka (PI); Carine Mutatayi; François Beck; Olivier LeNézet

\section{Georgia}

Lela Sturua (PI); Sophiko Alavidze; Lela Kvachantiradze; Levan Baramidze

\section{Greece}

Anna Kokkevi (PI); Anastasios Fotiou; Clive Richardson; Eleftheria Kanavou; Myrto Stavrou

\section{Hungary}

Zsuzsanna Elekes (PI); Tamás Domokos; Eszter Szilágyi; Zita

Szűcsné Kovács; Tamás Kosztolnyik

Iceland

Ársæll Már Arnarsson (PI); Thoroddur Bjarnason

\section{Ireland}

Luke Clancy (PI); Kate Babineau; Sheila Keogan; Hannah Murphy; Mark Morgan; Keishia Taylor; Ellen Whelan

\section{Italy}

Sabrina Molinaro (PI); Valeria Siciliano; Loredana Fortunato; Cristina Doveri; Stefanella Pardini; Rita Taccini; Chiara Sbrana; Lucia Fortunato; Silvia Gazzetti; Antonella Pardini; Gabriele Trivellini; Arianna Cutilli; Lorena Mezzasalma; Elisa Benedetti; Francesca Denoth; Rodolfo Cotichini; Marco Scalese; Luca Bastiani

\section{Latvia}

Mārcis Trapencieris (PI); Ansis Petersons; Sigita Snikere; Jelena Vrublevska; Ildze Abele; Silga Priekule; Eva Mezaraupe

\section{Liechtenstein}

Esther Kocsis (PI); Jennifer Rheinberger

\section{Lithuania}

Liudmila Rupšienè (CP); Tadas Tamošiūnas; Irena Šutinienè; Aelita Skarbalienè; Algimantas Šimaitis; Regina Saveljeva

\section{Malta}

Sharon Arpa (PI); Sandra Cortis; Stephen Spiteri; Carmen Dimech; Lawrence Bonello; Antoine Saliba; Christiana Bajada; Daniela Bugeja; Isabelle Anastasi; Ruth Stivala

\section{Moldova}

Mihai Ciocanu (PI); Igor Condrat; Oleg Barba; Valeriu Plesca

\section{Monaco}

Stanislas Spilka (PI); Julie Marty; Olivier Le-Nézet

\section{Montenegro}

Tatijana Đurišić (PI); Džona Džeksona bb; Boban Mugosa; Ljiljana Golubovic; Biljana Popovic

\section{Netherlands}

Karin Monshouwer (PI); Saskia van Dorsselaer; Marlous Tuithof; Jacqueline Verdurmen

\section{Norway}

Elin K Bye (PI); Astrid Skretting

\section{Poland}

Janusz Sierosławski (PI); Katarzyna Dąbrowska; Łukasz Wieczorek

\section{Portugal}

Fernanda Feijão (PI); Rui Lima; Nuno Rodrigues 


\section{Romania}

Silvia Florescu (PI); Sorin Oprea; Ruxanda Iliescu; Milica Georgescu; Catalina Chendea; Liliana Preoteasa; Constanta Mihaescu Pintia

\section{Slovakia}

Alojz Nociar (PI); Alena Kopányiová; Ján Luha; Jana Hamade; Mária Slovíková

\section{Slovenia}

Tanja Urdih Lazar (PI); Eva Stergar; Metoda Dodič Fikfak; Maja Zupe

\section{Sweden}

Håkan Leifman (PI); Anna Englund; Isabella Gripe; Ulf Guttormsson; Siri Thor

\section{Ukraine}

Olga Balakireva (PI); Tatyana Bondar; Dmitro Dmitruk; Lidia

Romanovska; luliia Pryimak

\section{Funding agencies and supportive organisations}

Below are listed, for each of the 35 countries participating in the 2015 data collection, the most important organisations and funding agencies involved.

\section{Albania}

Institute of Public Health; Ministry of Health; Ministry of Education and Sport

\section{Austria}

Bundesministerium für Gesundheit (BMG); Bundesministerium für Bildung und Frauen (BMBF)

\section{Belgium (Flanders)}

Department of Clinical and Lifespan Psychology (KLEP - VUB); Ministry of Welfare, Public Health and Family of the Government of Flanders; Research Council of the Free University of Brussels

\section{Bulgaria}

National Centre for Public Health and Analyses (NCPHA); National Centre for Drug Addictions (NCDA); Ministry of Education and Science (MoES)

\section{Croatia}

Croatian Institute of Public Health (CIPH); Ministry of Health; Ministry of Science, Education and Sports

\section{Cyprus}

Kenthea; Ministry of Education and Culture; CMCDDA; Cyprus Anti-drugs Council

\section{Czech Republic}

Czech National Monitoring Centre for Drugs and Addiction; National Institute of Mental Health; Office of the Government of the Czech Republic

\section{Denmark}

Department of Public Health, Aarhus University; Danish Health Authority

\section{Estonia}

National Institute for Health Development

\section{Faroes}

Ministry of Education, Research and Culture; Faroese Board of Public Health

\section{Finland}

National Institute for Health and Welfare (THL)

\section{Former Yugoslav Republic of Macedonia}

National Institute of Public Health and Centres for Public Health in Skopje; Tetovo; Kumanovo; Stip; Veles; Prilep; Bitola; Ohrid; Strumica and Kocani; Kontakt non-governmental organisation; Ministry of Health; Ministry of Education and Science

\section{France}

French Monitoring Centre on Drugs and Drug Addictions (OFDT); Ministry of Education; Ministry of Agriculture; French National Institute of Health and Medical Research (Inserm)

\section{Georgia}

National Centre for Disease Control and Public Health (NCDC); Ministry of Education and Science; European Monitoring Centre for Drugs and Drug Addiction (EMCDDA), EMCDDA-ENP technical cooperation project (ENPI/2013/325-486) funding

\section{Greece}

Greek Organisation Against Drugs (OKANA); OKANA/local authority drug prevention centres; Ministry of Education

\section{Hungary}

OTKA K111740 (Hungarian Scientific Research Fund); Emberi Erőforrások Minisztériuma (Ministry of Human Resources); Corvinus University of Budapest, Institute of Sociology and Social Policy; ECHO Survey Sociological Research Institute

\section{Iceland}

Icelandic Directorate of Health; University of Akureyri

\section{Ireland}

Department of Health; TobaccoFree Research Institute Ireland; Focas Research Institute; DIT Dublin; Seefin DM; Kerry

\section{Italy}

National Research Council (CNR), Unit of Epidemiology and Health Service Research of the Institute of Clinical Physiology

\section{Latvia}

Centre for Disease Prevention and Control

\section{Liechtenstein}

School Board

\section{Lithuania}

Lithuanian Ministry of Education and Science; Qualifications and Vocational Education and Training Development Centre; Klaipeda University 


\section{Malta}

Agenzija Sedqa (National Agency against Drug and Alcohol Abuse and Compulsive Gambling), Foundation for Social Welfare Services; Directorate for Educational Services (DES). Student Services Department, Education Psycho-Social Services; Anti-Substance Abuse Service within the Education Psycho-Social Services; Directorate for Education, Secretariat for Catholic Education, Archdioceses of Malta; ISA-Independent Schools Association and the participating independent schools

\section{Moldova}

Ministry of Education of Republic of Moldova; European Monitoring Centre for Drugs and Drug Addiction (EMCDDA), EMCDDA-ENP technical cooperation project (ENPI/2013/325-486) funding

\section{Monaco}

French Monitoring Centre on Drugs and Drug Addiction (OFDT); Monaco Statistics (Monegasque Institute of Statistics and Economic Studies — IMSEE); Department of Education, Youth and Sport of Monaco (DENJS)

\section{Montenegro}

Institute of Public Health of Montenegro; Ministry of Education of Montenegro; Ministry of Health of Montenegro

\section{Netherlands}

Dutch Ministry of Health, Welfare and Sport; Regional Health Services; Trimbos-instituut

\section{Norway}

Norwegian Institute for Alcohol and Drug Research (SIRUS)

\section{Poland}

National Bureau for Drug Prevention (KBPN); State Agency for the Prevention of Alcohol-Related Problems (PARPA); Institute of Psychiatry and Neurology (IPiN)

\section{Portugal}

General-Directorate for Intervention on Addictive Behaviours and Dependencies (SICAD), Ministry of Health; Direção-Geral de Estatísticas da Educação e Ciência and Direçao-Geral da Educação, Ministry of Education

\section{Romania}

National Anti-drug Agency; Ministry of National Education and Scientific Research; National School of Public Health, Management and Professional Development

\section{Slovakia}

Research Institute for Child Psychology and Pathopsychology; St. Elizabeth University of Health and Social Sciences; Public Health Authority of the Slovak Republic; Slovak Centre of Scientific and Technical Information; National Monitoring Centre for Drugs

\section{Slovenia}

University Medical Centre Ljubljana; Clinical Institute of Occupational, Traffic and Sports Medicine; Ministry of Education, Science and Sport

\section{Sweden}

Swedish Ministry of Health and Social Affairs; Swedish Council for Information on Alcohol and Other Drugs (CAN)

\section{Ukraine}

Ukrainian Institute for Social Research after Olexander Yaremenko (UISR); Institute for Economics and Forecasting National Academy of Science of Ukraine (IEP NASU); Social Monitoring Centre (SMC); Ministry of Education and Science of Ukraine; European Monitoring Centre for Drugs and Drug Addiction (EMCDDA), EMCDDA-ENP technical cooperation project (ENPI/2013/325-486) funding; United Nations Children's Fund (Unicef) in Ukraine 


\section{References}

Agrawal, A., Budney, A. and Lynskey, M. T. (2012), 'The co-occurring use and misuse of cannabis and tobacco: a review', Addiction, Vol. 107, No 7, pp. $1221-1233$.

Alice Rap (2014), Cannabis: from prohibition to regulation (policy papers series, policy brief 5). Available at: http://www.alicerap. eu/resources/documents/cat_view/1-alice-rap-project-documents/19-policy-paper-series.html

Anderson, P. and Baumberg, B. (2006), 'Alcohol in Europe: public health perspective: report summary', Drugs: Education, Prevention, and Policy, Vol. 13, No 6, pp. 483-488.

Anderson, P., Møller, L. and Galea, G. (2012), Alcohol in the European Union - Consumption, harm and policy approaches, World Health Organisation, Regional Office for Europe, Copenhagen.

Ariyabuddhiphongs, V. (2013), 'Adolescent gambling: a narrative review of behavior and its predictors', International Journal of Mental Health and Addiction, Vol. 11, No 1, pp. 97-109.

Beck, F., Legleye, S., Chomynova, P. and Miller, P. (2014), 'A quantitative exploration of attitudes out of line with the prevailing norms toward alcohol, tobacco, and cannabis use among European students', Substance Use and Misuse, Vol. 49, No 7, pp. 877-890.

Bergh, C. and Kühlhorn, E. (1994), 'Social, psychological and physical consequences of pathological gambling in Sweden', Journal of Gambling Studies, Vol. 10, No 3, pp. 275-285.

Bjarnason, T., Steriu, A. and Kokkevi, A. (2010), ' 'Cannabis supply and demand reduction: evidence from the ESPAD study of adolescents in 31 European countries', Drugs: Education, Prevention, and Policy, Vol. 17, No 2, pp. 123-134.

Blinn-Pike, L., Worthy, S. L. and Jonkman, J. N. (2010), 'Adolescent gambling: a review of an emerging field of research', Journal of Adolescent Health, Vol. 47, No 3, pp. 223-236.

Boniel-Nissim, M., Lenzi, M., Zsiros, E., de Matos, M. G., Gommans, R., Harel-Fisch, Y. et al. (2015), 'International trends in electronic media communication among 11- to 15-year-olds in 30 countries from 2002 to 2010: association with ease of communication with friends of the opposite sex', European Journal of Public Health, Vol. 25 (Suppl. 2), pp. 41-45.

Bonnaire, C., Bungener, C. and Varescon, I. (2009), 'Subtypes of French pathological gamblers: comparison of sensation seeking, alexithymia and depression scores', Journal of Gambling Studies, Vol. 25, No 4, pp. 455-471.

Brand, D. A., Saisana, M., Rynn, L. A., Pennoni, F. and Lowenfels, A. B. (2007), 'Comparative analysis of alcohol control policies in 30 countries', Public Library of Science Medicine, Vol. 4, No 4, e151.
Brener, N., Kann, L., Kinchen, S. A., Grunbaum, J. A., Whalen, L., Eaton, D., Hawkins, J. and Ross, J. G. (2004), 'Methodology of the youth risk behavior surveillance system', MMWR Recommendations and Reports, Vol. 53, No 12. Available at: http://www.cdc.gov/ mmwr/preview/mmwrhtml/rr5312a1.htm

Breslau, N. and Peterson, E. (1996), 'Smoking cessation in youth adults: age at initiation of cigarette smoking and other suspected influences', American Journal of Public Health, Vol. 86, No 2, pp. 214-220.

Brooks, F. M., Chester, K. L., Smeeton, N. C. and Spencer, N. H. (2016), 'Video gaming in adolescence: factors associated with leisure time use', Journal of Youth Studies, Vol. 19, No 1, pp. 36-54.

Brunborg, S. G., Bye, E. K. and Rossow, I. (2014), 'Collectivity of drinking behavior among adolescents: an analysis of the Norwegian ESPAD data 1995-2011', Nordic Studies on Alcohol and Drugs, Vol. 31, No 4, pp. 389-400.

Council of the European Union (2012), EU drugs strategy (20132020), OJ C 402, 29.12.2012, p. 1.

COWI Consortium (2012), Assessment of the added value of the EU strategy to support Member States in reducing alcohol-related harm, Milieu Ltd, Brussels, Belgium.

Culley, D. M., Skoupy, J., Rubin, J., Hoorens, S., Disley, E. and Rabinovich, L. (2012), Assessment of the implementation of the EU drugs strategy 2005-2012 and its action plans, RAND Corp, Cambridge.

de Looze, M., Raaijmakers, Q., Ter Bogt, T., Bendtsen, P., Farhat, T., Ferreira, M. et al. (2015), 'Decreases in adolescent weekly alcohol use in Europe and North America: evidence from 28 countries from 2002 to 2010', European Journal of Public Health, Vol. 25, Suppl. 2, pp. 69-72.

Derevensky, J., Gupta, R., Messerlian, C. and Gillespie, M. (2004), 'Youth gambling problems: a need for responsible social policy', in Derevensky, J. and Gupta, R. (eds), Gambling problems in youth: theoretical and applied perspectives, Kluwer Academic, New York, pp. 231-252.

Dey, M., Gmel, G., Studer, J., Dermota, P. and Mohler-Kuo, M. (2014), 'Beverage preferences and associated drinking patterns, consequences and other substance use behaviours', European Journal of Public Health, Vol. 24, No 3, pp. 496-501.

Dickson-Swift, V. A., James, E. L. and Kippen, S. (2005), 'The experience of living with a problem gambler: spouses and partners speak out', Journal of Gambling Studies, Vol. 13, pp. 1-22.

Eaton, D. K., Brener, N. D., Kann, L., Denniston, M. M., McManus, T., Kyle, T. M. et al. (2010), 'Comparison of paper-and-pencil versus web administration of the Youth Risk Behavior Survey (YRBS): risk behavior prevalence estimates', Evaluation Review, Vol. 34, No 2, pp. 137-153. 
Elekes, Z. and Kovacs, L. (2002), 'Old and new drug consumption habits in Hungary, Romania and Moldova', European Addiction Research, Vol. 8, No 4, pp. 166-169.

Engel, B. and Breunig, C. (2015), 'Massenkommunikation 2015: Mediennutzung im Intermediavergleich. Ergebnisse der ARD/ZDFLangzeitstudie' [Mass Communication 2015: Media sharing by intermedia comparison. Results of the ARD/ZDF long-term study], Media Perspektiven, Vols 7-8, pp. 310-322.

European Commission (2016), 'Young people and drugs', Flash Eurobarometer 401. Available at: https://data.europa.eu/euodp/en/ data/dataset/S2029_401

European Monitoring Centre for Drugs and Drug Addiction (EMCDDA) (2011), Annual report 2011: the state of the drugs problem in Europe (online version), European Monitoring Centre for Drugs and Drug Addiction, Lisbon. Available at http://www.emcdda. europa.eu/online/annual-report/2011/boxes/p45

Everett, S. A., Warren, C. W., Sharp, D., Kann, L., Husten, C. G. and Crosell, L. S. (1999), 'Initiation of cigarette smoking and subsequent smoking behaviour among U.S. high school students', Preventive Medicine, Vol. 29, No 5, pp. 327-333.

Forouzanfar, M. H., Alexander, L., Anderson, H. R., Bachman, V. F., Biryukov, S., Brauer, M. et al. (2015), 'Global, regional, and national comparative risk assessment of 79 behavioural, environmental and occupational, and metabolic risks or clusters of risks in 188 countries, 1990-2013: a systematic analysis for the Global Burden of Disease Study 2013', The Lancet, Vol. 386, No 10 010, pp. 2287 2323.

Fotiou, A., Kanavou, E., Richardson, C., Ploumpidis, D. and Kokkevi, A. (2014), 'Misuse of prescription opioid analgesics among adolescents in Greece: the importance of peer use and past prescriptions', Drugs: Education, Prevention, and Policy, Vol. 21, No 5, pp. 357-369.

Gervilla, E., Cajal, B. and Palmer, A. (2011), 'Quantification of the influence of friends and antisocial behaviour in adolescent consumption of cannabis using the ZINB model and data mining', Addictive Behaviors, Vol. 36, No 4, pp. 368-374.

Gillespie, N. A., Neale, M. C. and Kendler, K. S. (2009), 'Pathways to cannabis abuse: a multi-stage model from cannabis availability, cannabis initiation and progression to abuse', Addiction, Vol. 104, No 3 , pp. 430-438.

Gmel, G., Kuntsche, E., Wicki, M. and Labhart, F. (2010), 'Measuring alcohol-related consequences in school surveys: alcohol-attributable consequences or consequences with students' alcohol attribution', American Journal of Epidemiology, Vol. 171, No 1, pp. 93-104.

Hall, W. and Degenhardt, L. (2007), 'Prevalence and correlates of cannabis use in developed and developing countries', Current Opinion in Psychiatry, Vol. 20, No 4, pp. 393-397.

Hampton, K. N., Sessions, L. F. and Her, E. J. (2011), 'Core networks, social isolation, and new media: how internet and mobile phone use is related to network size and diversity', Information, Communication and Society, Vol. 14, No 1, pp. 130-155.
Hardoon, K. K., Gupta, R. and Derevensky, J. L. (2004), 'Psychosocial variables associated with adolescent gambling', Psychology of Addictive Behaviors, Vol. 18, No 2, pp. 170-179.

Härkönen, J. T. and Mäkelä, P. (2011), 'Age, period and cohort analysis of light and binge drinking in Finland, 1968-2008', Alcohol and Alcoholism, Vol. 46, No 3, pp. 349-356.

Hibell, B. and Bjarnason, T. (2008), Report from the ESPAD 07 questionnaire test (manuscript), Swedish Council for Information on Alcohol and other Drugs, Stockholm.

Hibell, B. and Guttormsson, U. (2013), A supplement to the 2011 ESPAD report: Additional data from Bosnia and Herzegovina (Federation of Bosnia and Herzegovina), Kosovo (under UNSCR 1244) and the Netherlands, Swedish Council for Information on Alcohol and Other Drugs, Stockholm.

Hibell, B., Andersson, B., Bjarnason, T., Kokkevi, A., Morgan, M. and Narusk, A. (1997), The 1995 ESPAD report: alcohol and other drug use among students in 26 European countries, Swedish Council for Information on Alcohol and Other Drugs, Stockholm.

Hibell, B., Andersson, B., Ahlström, S., Balakireva, O., Bjarnason, T., Kokkevi, A. and Morgan, M. (2000), The 1999 ESPAD report: alcohol and other drug use among students in 30 European countries, Swedish Council for Information on Alcohol and Other Drugs, Stockholm

Hibell, B., Andersson, B., Bjarnason, T., Ahlström, S., Balakireva, O., Kokkevi A. and Morgan, M. (2004), The ESPAD report 2003: alcohol and other drug use among students in 35 European countries, Swedish Council for Information on Alcohol and Other Drugs, Stockholm

Hibell, B., Guttormsson, U., Ahlström, S., Balakireva, O., Bjarnason, T., Kokkevi, A. and Kraus, L. (2009), The 2007 ESPAD report: substance use among students in 35 European countries, Swedish Council for Information on Alcohol and Other Drugs, Stockholm.

Hibell, B., Guttormsson, U., Ahlström, S., Balakireva, O., Bjarnason, T., Kokkevi, A. and Kraus, L. (2012), The 2011 ESPAD report: substance use among students in 36 European countries, Swedish Council for Information on Alcohol and Other Drugs, Stockholm, European Monitoring Centre for Drugs and Drug Addiction, Council of Europe, Cooperation Group to Combat Drug Abuse and Illicit Trafficking in Drugs (Pompidou Group).

Höfler, M., Lieb, R., Perkonigg, A., Schuster, P., Sonntag, H. and Wittchen, H.-U. (1999), 'Covariates of cannabis use progression in a representative population sample of adolescents: a prospective examination of vulnerability and risk factors', Addiction, Vol. 94, No 11, pp. 1679-1694

Hohmann, N., Mikus, G. and Czock, D. (2014), 'Effects and risks associated with novel psychoactive substances: mislabeling and sale as bath salts, spice, and research chemicals', Deutsches Ärzteblatt International, Vol. 111, No 9, pp. 139-147. 
Hublet, A., Bendtsen, P., de Looze, M. E., Fotiou, A., Donnelly, P., Vilhjalmsson, R. et al. (2015), 'Trends in the co-occurrence of tobacco and cannabis use in 15-year-olds from 2002 to 2010 in 28 countries of Europe and North America', European Journal of Public Health, Vol. 25, Suppl. 2, pp. 73-75.

Inchley, J., Currie, D., Young, T., Samdal, O., Torsheim, T., Augustson, L., Mathison, F., Aleman-Diaz, A., Molcho, M., Weber, M. and Barnekow, V. (2016), Growing up unequal: gender and socioeconomic differences in young people's health and well-being - Health behaviour in school-aged children (HBSC) study: International report from the 2013/2014 survey, World Health Organisation, Geneva.

Jessor, R. and Jessor, S. I. (1977), Problem behavior and psychosocial development: a longitudinal study of youth, Academic Press, New York.

Johnston, L., Driessen, F. and Kokkevi, A. (1994), Surveying student drug misuse: a six-country pilot study, Council of Europe, Strasbourg.

Johnston, L. D., O'Malley, P. M., Miech, R. A., Bachman, J. G. and Schulenberg, J. E. (2016), Monitoring the future: national survey results on drug use: 1975-2014 - Overview: key findings on adolescent drug use, Institute for Social Research, University of Michigan, Ann Arbor.

Kandel, D. B., Yamaguchi, K. and Chen, K. (1992), 'Stages of progression in drug involvement from adolescence to adulthood: further evidence for the gateway theory', Journal of Studies on Alcohol, Vol. 53, No 5, pp. 447-457.

Kokkevi, A., Richardson, C., Olszewski, D., Matias, J., Monshouwer, K. and Bjarnason, T. (2012), 'Multiple substance use and self-reported suicide attempts by adolescents in 16 European countries', European Child and Adolescent Psychiatry, Vol. 21, No 8, pp. 443450.

Kraus, L., Metzner, C. and Piontek, D. (2010), 'Alcopops, alcohol consumption and alcohol-related problems in a sample of German adolescents: is there an alcopop-specific effect?', Drug and Alcohol Dependence, Vol. 110, Nos 1-2, pp. 15-20.

Kraus, L., Tinghög, E. M., Lindell, A., Pabst, A., Piontek, D. and Room, R. (2015), 'Age, period and cohort effects on time trends in alcohol consumption in the Swedish adult population 1979-2011', Alcohol and Alcoholism, Vol. 50, № 3, pp. 319-327.

Kuntsche, E., Simons-Morton, B., Ter Bogt T., Queija, I. S., Tinoco, V. M., Gaspar de Matos, M. et al. (2009), 'Electronic media communication with friends from 2002 to 2006 and links to face-to-face contacts in adolescence: an HBSC study in 31 European and North American countries and regions', International Journal of Public Health, Vol. 54 (Suppl. 2), pp. 243-250.

Kuntsche, E., Kuntsche, S., Knibbe, R., Simons-Morton, B., Farhat, T., Hublet, A. et al. (2011), 'Cultural and gender convergence in adolescent drunkenness: evidence from 23 European and North American countries', Archives of Pediatrics and Adolescent Medicine, Vol. 165, No 2, pp. 152-158.
Langhinrichsen-Rohling, J., Rohde, P., Seeley, J. R. and Rohling, M. L. (2004), 'Individual, family, and peer correlates of adolescent gambling', Journal of Gambling Studies, Vol. 20, No 1, pp. 23-46.

Lorains, F. K., Cowlishaw, S. and Thomas, S. A. (2011), 'Prevalence of comorbid disorders in problem and pathological gambling: systematic review and meta-analysis of population surveys', Addiction, Vol. 106, No 3, pp. 490-498.

Lygidakis, C., Rigon, S., Cambiaso, S., Bottoli, E., Cuozzo, F., Bonetti, S. et al. (2010), 'A web-based versus paper questionnaire on alcohol and tobacco in adolescents', Telemedicine and e-Health, Vol. 16, No 9, pp. 925-930

Magoon, M. E. and Ingersoll, G. M. (2006), 'Parental modeling, attachment, and supervision as moderators of adolescent gambling', Journal of Gambling Studies, Vol. 22, No 1, pp. 1-22.

Mammone, A., Fabi, F., Colasante, E., Siciliano, V., Molinaro, S., Kraus, L. et al. (2014), 'New indicators to compare and evaluate harmful drug use among adolescents in 38 European countries', Nordic Studies on Alcohol and Drugs, Vol. 31, No 4, pp. 343-358.

Meng, Y., Holmes, J., Hill-McManus, D., Brennan, A. and Meier, P. S. (2014), 'Trend analysis and modelling of gender-specific age, period and birth cohort effects on alcohol abstention and consumption level for drinkers in Great Britain using the general lifestyle survey 1984-2009', Addiction, Vol. 109, No 2, pp. 206-215.

Molinaro, S., Siciliano, V., Curzio, O., Denoth, F., Salvadori, S. and Mariani, F. (2011), 'Illegal substance use among Italian high school students: trends over 11 years (1999-2009)', PLoS One, Vol. 6, No 6, e20482.

Molinaro, S., Canale, N., Vieno, A., Lenzi, M., Siciliano, V., Gori, M. et al. (2014), 'Country- and individual-level determinants of probable problematic gambling in adolescence: a multi-level cross-national comparison', Addiction, Vol. 109, No 12, pp. 2 089-2 097.

Molinaro, S., Siciliano, V., Curzio, O., Denoth, F. and Mariani, F. (2012), 'Concordance and consistency of answers to the self-delivered ESPAD questionnaire on use of psychoactive substances', International Journal of Methods in Psychiatric Research, Vol. 21, No 2, pp. 158-168.

Morral, A., McCaffrey, D. and Paddock, S. (2002), 'Reassessing the marijuana gateway effect', Addiction, Vol. 97, No 12, pp. $1493-$ 1504.

Müller, S., Kraus, L., Piontek, D. and Pabst, A. (2010), 'Changes in exposure to secondhand smoke and smoking behaviour in the general population after the introduction of new smoke-free laws in Germany', Sucht, Vol. 56, No 5, pp. 373-384.

Müller, S., Piontek, D., Pabst, A., Baumeister, S. E. and Kraus, L. (2010), 'Changes in alcohol consumption and beverage preference among adolescents after the introduction of the alcopops tax in Germany', Addiction, Vol. 105, No 7, pp. 1205-1213.

Nutt, D. J., King, L. A. and Phillips, L. D. (2010), 'Drug harms in the UK: a multicriteria decision analysis', The Lancet, Vol. 376, No 9752 , pp. 1558-1 565 . 
Office of Communication (2015), Adults' media use and attitudes Report 2015, London, UK: Ofcom.

Olszewski, D., Matias, J., Monshouwer, K. and Kokkevi, A. (2010), 'Polydrug use among 15- to 16-year olds: similarities and differences in Europe', Drugs: Education, Prevention, and Policy, Vol. 17, No 4, pp. 287-302.

Pabst, A., Kraus, L., Piontek, D. and Müller, S. (2010), 'Age, period, and cohort effects on time trends in alcohol consumption in the German adult population', Sucht, Vol. 56, No 5, pp. 349-359.

Piontek, D., Kraus, L., Bjarnason, T., Demetrovics, Z. and Ramstedt, M. (2013), 'Individual and country-level effects of cannabis-related perceptions on cannabis use. A multilevel study among adolescents in 32 European countries', Journal of Adolescent Health, Vol. 52, pp. 473-479.

Potenza, M. N. (2008), 'The neurobiology of pathological gambling and drug addiction: an overview and new findings', Philosophical Transactions of the Royal Society of London. Series B: Biological Sciences, Vol. 363, No 1507, pp. 3 181-3 189.

Raghupathy, S. and Hahn-Smith, S. (2013), 'The effect of survey mode on high school risk behaviour data: a comparison between web and paper-based surveys', Current Issues in Education, Vol. 16, No 2, pp. 1-11, http://cie.asu.edu/ojs/index.php/cieatasu/article/ viewFile/1172-499

Regier, D. A., Kuhl, E. A. and Kupfer, D. J. (2013), 'The DSM-5: classification and criteria changes', World Psychiatry, Vol. 12, No 2, pp. 92-98.

Room, R., Österberg, E., Ramstedt, M. and Rehm, J. (2009), 'Explaining change and stasis in alcohol consumption', Addiction Research and Theory, Vol. 17, No 6, pp. 562-576.

Ryan, S. M., Jorm, A. F. and Lubman, D. I. (2010), 'Parenting factors associated with reduced adolescent alcohol use: a systematic review of longitudinal studies', Australian and New Zealand Journal of Psychiatry, Vol. 44, No 9, pp. 774-783.

Shibuya, K., Ciecierski, C., Guindon, E. and Bettcher, D. W. (2003), 'WHO Framework Convention on Tobacco Control: development of an evidence-based global public health treaty', British Medical Journal, Vol. 327, No 7 407, p. 154.

Siegel, M. B., Naimi, T. S., Cremeens, J. L. and Nelson, D. E. (2011), 'Alcoholic beverage preferences and associated drinking patterns and risk behaviors among high school youth', American Journal of Preventive Medicine, Vol. 40, No 4, pp. 419-426.

Simons-Morton, B. G., Farhat, T., Ter Bogt, T. F., Hublet, A., Kuntsche, E., Gabhainn, N. S. et al. (2009), 'Gender-specific trends in alcohol use: cross-cultural comparisons from 1998 to 2006 in 24 countries and regions', International Journal of Public Health, Vol. 54 (Suppl. 2), pp. 199-208.

Spanish Observatory on Drugs and Drug Addiction (2016a), 2016 drug report - Alcohol, tobacco and illegal drugs in Spain, Ministry of Health, Social Services and Equality, Madrid.
Spanish Observatory on Drugs and Drug Addiction (2016b), 2016 statistical drug report - Alcohol, tobacco and illegal drugs in Spain, Ministry of Health, Social Services and Equality, Madrid.

Steppan, M., Kraus, L., Piontek, D. and Siciliano, V. (2013), 'Are cannabis prevalence estimates comparable across countries and regions? A cross-cultural validation using search engine query data', International Journal of Drug Policy, Vol. 24, No 1, pp. 23-29.

Thrul, J., Pabst, A. and Kraus, L. (2016), 'The impact of school nonresponse on substance use prevalence estimates: Germany as a case study', International Journal of Drug Policy, Vol. 27, pp. 164-172.

Trapencieris, M. (2013), Differences in prevalence rates: mode of questionnaire administration or inconsistent answers?, PowerPoint presentation at the ESPAD project meeting in Budapest, 1315 October.

UN General Assembly Special Session on Drugs (2016), 2016 outcome document - Our joint commitment to effectively addressing and countering the world drug problem, UN document A/S-30/L.1, 14 April 2016. Available at http://www.incb.org/documents/News/ A_S-30_L.1.pdf

United Nations Office on Drugs and Crime (UNODC) (2014), World drug report 2014 (United Nations publication, Sales No E.14. XI.7), United Nations Office on Drugs and Crime, Vienna. Available at http://www.unodc.org/documents/wdr2014/World_Drug_ Report_2014_web.pdf

Valkenburg, P. M. and Peter, J. (2011), 'Online communication among adolescents: an integrated model of its attraction, opportunities, and risks', Journal of Adolescent Health, Vol. 48, pp. 121-127.

van der Vorst, H., Engels, R. C. M. E., Meeus, W. and Dekovic, M. (2006), 'The impact of alcohol-specific rules, parental norms about early drinking and parental alcohol use on adolescents' drinking behavior', Journal of Child Psychology and Psychiatry, Vol. 47, No 12 , pp. $1299-1306$.

Velleman, R. D., Templeton, L. J. and Copello, A. G. (2005), 'The role of the family in preventing and intervening with substance use and misuse: a comprehensive review of family interventions, with a focus on young people', Drug and Alcohol Review, Vol. 24, No 2, pp. 93109.

Vitaro, F., Ferland, F., Jacques, C. and Ladouceur, R. (1998), 'Gambling, substance use, and impulsivity during adolescence', Psychology of Addiction Behavior, Vol. 12, pp. 185-194.

Volberg, R. A., Gupta, R., Griffiths, M. D., Olason, D. T. and Delfabbro, P. (2010), 'An international perspective on youth gambling prevalence studies', International Journal of Adolescent Medicine and Health, Vol. 22, No 1, pp. 3-38

von Sydow, K., Lieb, R., Pfister, H., Höfler, M. and Wittchen, H.-U. (2002), 'What predicts incident use of cannabis and progression to abuse and dependence? A 4-year prospective examination of risk factors in a community sample of adolescents and young adults', Drug and Alcohol Dependence, Vol. 68, pp. 49-64. 
Vorobjov, S., Saat, H. and Kull, M. (2014), 'Social skills and their relationship to drug use among 15-16-year-old students in Estonia: an analysis based on the ESPAD data', Nordic Studies on Alcohol and Drugs, Vol. 31, No 4, pp. 401-412.

World Health Organisation (2005), WHO Framework Convention on Tobacco Control (2003, updated reprint 2004, 2005), WHO Press, Geneva.

World Health Organisation (2012), 2012 global progress report on implementation of the WHO Framework Convention on Tobacco Control, WHO, Geneva.

World Health Organisation (2014), Global status report on alcohol and health 2014, WHO Press, Geneva.

Wyrick, D. L. and Bond, L. (2011), 'Reducing sensitive survey response bias in research on adolescents: a comparison of webbased and paper-and-pencil administration', American Journal of Health Promotion, Vol. 25, No 5, pp. 349-352.

Zaborskis, A., Sumskas, L., Maser, M. and Pudule, I. (2006), 'Trends in drinking habits among adolescents in the Baltic countries over the period of transition: HBSC survey results, 1993-2002', BMC Public Health, Vol. 6, No 67. 




\section{$\overline{\text { ESPAD }}$}

emcolda

\section{About this report}

This report presents the results from the sixth wave of data collection, conducted in 35 countries during the spring and autumn of 2015. It gives a comprehensive picture of the present situation among European young people as regards the use of tobacco, alcohol, cannabis and other substances, as well as an overview of trends in 1995-2015.

\section{About the EMCDDA}

The European Monitoring Centre for Drugs and Drug Addiction (EMCDDA) is the central source and confirmed authority on drug-related issues in Europe. For over 20 years, it has been collecting, analysing and disseminating scientifically sound information on drugs and drug addiction and their consequences, providing its audiences with an evidence-based picture of the drug phenomenon at the European level.

The EMCDDA's publications are a prime source of information for a wide range of audiences, including: policymakers and their advisors; professionals and researchers working in the drugs field; and, more broadly, the media and general public. Based in Lisbon, the EMCDDA is one of the decentralised agencies of the European Union.

\section{About ESPAD}

The European School Survey Project on Alcohol and Other Drugs (ESPAD) is a collaborative effort of independent research teams in more than 40 European countries, making it the largest cross-national research project on adolescent substance use in the world.

ESPAD was founded in 1993, on the initiative of the Swedish Council for Information on Alcohol and Other Drugs (CAN) and with the support of the Pompidou Group at the Council of Europe. In later years, ESPAD has also established increasingly close cooperation with the EMCDDA, and at present the agency plays an important role in the coordination of the ESPAD project.

Most of the European continent is now covered by ESPAD, meaning that it provides a reliable overview of trends in substance use among 15- to 16-year-old European students. Data are collected every 4 years.

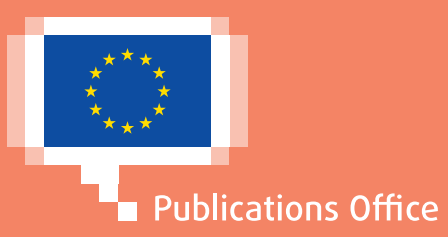

